\title{
c-Jun NH2-terminal kinase signaling controls cellular mechanisms of guided cortical interneuron migration
}

\author{
Skye Eleanor Smith \\ sehickling@mix.wvu.edu
}

Follow this and additional works at: https://researchrepository.wvu.edu/etd

Part of the Developmental Neuroscience Commons

\section{Recommended Citation}

Smith, Skye Eleanor, "c-Jun NH2-terminal kinase signaling controls cellular mechanisms of guided cortical interneuron migration" (2020). Graduate Theses, Dissertations, and Problem Reports. 7976.

https://researchrepository.wvu.edu/etd/7976

This Dissertation is protected by copyright and/or related rights. It has been brought to you by the The Research Repository @ WVU with permission from the rights-holder(s). You are free to use this Dissertation in any way that is permitted by the copyright and related rights legislation that applies to your use. For other uses you must obtain permission from the rights-holder(s) directly, unless additional rights are indicated by a Creative Commons license in the record and/ or on the work itself. This Dissertation has been accepted for inclusion in WVU Graduate Theses, Dissertations, and Problem Reports collection by an authorized administrator of The Research Repository @ WVU.

For more information, please contact researchrepository@mail.wvu.edu. 


\title{
C-Jun $\mathrm{NH}_{2}$-terminal kinase signaling controls cellular mechanisms of guided cortical interneuron migration
}

\author{
Skye Eleanor Smith \\ Dissertation submitted to the School of Medicine \\ at West Virginia University \\ In partial fulfillment of the requirements for the degree of \\ Doctor of Philosophy in \\ Biochemistry and Molecular Biology \\ Eric Tucker, Ph.D., Chair \\ Michael Schaller, Ph.D. \\ Peter Mathers, Ph.D. \\ Ariel Agmon, Ph.D. \\ Max Sokolov, Ph.D.
}

Biochemistry and Molecular Biology Graduate Program

Morgantown, WV

2020

Keywords: c-Jun $\mathrm{NH}_{2}$-terminal kinase, cortical interneurons, migration, live-imaging, development

Copyright 2020 Skye Eleanor Smith 


\section{Abstract \\ C-Jun $\mathrm{NH}_{2}$-terminal kinase signaling controls cellular mechanisms of guided cortical interneuron migration}

Skye Eleanor Smith

The cerebral cortex is an intricately organized brain structure responsible for high-level functions including sensory perception, movement, memory, language, and cognition. During corticogenesis, cortical excitatory neurons and inhibitory interneurons migrate from their respective progenitor zones into the developing cerebral cortex, deposit in the correct cortical layer, and establish connections with their appropriate synaptic partners. The balance between excitation and inhibition is critical for cortical circuitry development and function. Aberrant migration of inhibitory interneurons can alter the formation of cortical circuitry and lead to several neurodevelopmental disorders including epilepsy, autism spectrum disorder, and schizophrenia. Therefore, elucidating the mechanisms responsible for inhibitory interneuron migration will provide greater insight into the development of these diseases.

This dissertation explores the role of c-Jun $\mathrm{NH}_{2}$-terminal kinase (JNK) signaling pathway in the cellular mechanisms required for the guided migration of cortical interneurons. In Chapter 2, I used live-cell confocal microscopy to explore the mechanisms by which JNK activity coordinates two cell biological processes that are essential for the guided migration of cortical interneurons: nucleokinesis and leading process branching. I found that pharmacological inhibition and genetic ablation of JNK-signaling in cortical interneurons impairs the kinetics of nucleokinesis. Moreover, JNK signaling controls the subcellular localization of the centrosome and primary cilium, two organelles involved in nucleokinesis. To orient their direction of migration, cortical interneurons extend and retract leading process branches to respond to chemotactic guidance cues present in their environments. Both pharmacological inhibition and genetic removal of JNK disrupted the stability of leading process branches, resulting in decreased frequency of growth cone splits and the shortened duration of interstitial side branches. In Chapter 3, I explored the role of JNK signaling in nucleokinesis of interneurons migrating in different substrate and topographical environments and found that cortical interneurons have an intrinsic requirement for JNK signaling during nucleokinesis regardless of substrate environment. Moreover, I found that interneurons can use nanoscale features in their environment to orient their direction of migration. Additionally, cortical interneurons aligned on a nanopattern topography have a highly polarized subcellular localization of doublecortin, a substrate of JNK involved in microtubule stability. Together, these are the first studies examining the role of JNK signaling in the cellular mechanisms controlling cortical interneuron migration and provide novel insight into the roles of JNK in cortical inhibitory interneuron development. Future efforts should be aimed at unraveling the mechanism through which JNK controls interneuron migration by exploring JNK's role in cytoskeletal dynamics and chemotaxic attraction to gradient cues found in the cortex.

Understanding the molecular regulation of cortical development will provide novel insight into the etiology of cortical circuit disorders and may ultimately aid in the development of treatments for these neurodevelopmental diseases. 


\section{Acknowledgements}

First, I would like to thank my dissertation advisor, Dr. Eric Tucker, for his consistent support and guidance throughout this journey. Thank you for taking a young student who had no idea what a cortical interneuron was and training her to be a true scientist. You stood by my side and advocated for me when I did not have a voice. Thank you for working with me through all the ups, downs, and escape rooms along the way. Dr. Tucker, thank you for being my mentor.

I would like to thank my "Dream Team" of committee members, Drs. Schaller, Mathers, Agmon, and Sokolov for your time and support. I could not have asked for a better team to guide my dissertation project. From the long hours standing in front of a white board listening to my crazy proposal ideas, to handing me boxes of tissues when I thought I would never find my way, you were always there. Thank you for challenging my experimental design and finding the potential holes in my work. I am forever grateful for each of you.

To Catherine, I wrote this section at The Grind and choked back tears the entire time. Thank you, Cathy. Thank you for the friendship of a lifetime. Your unconditional love and support through every pot hole in the road is truly the reason why I made it. You are my scientific dreamer, my closest friend, roommate, now sister-in-law, and the purest happiness this world can give. You held my hand through the most challenging times of my life, and overenthusiastically celebrated every win. Thank you for never giving up on me. Thank you for teaching me that the universe can be kind, and that I belong in it.

To Deidre, who is always here for it, thank you for the friendship I never knew I needed. Thank you for looking past this tough outer shell and smiling at my grump anyway. From your absolute brilliance in every aspect of science (and life), to your fashion knowledge and equal love of anime and manga, you mean the world to me. Thank you for your contagious laugh. You helped me find mine again. Your drive to be the best you always inspired me to be a better me. Most of all, thank you for your kindness. Deidre, thank you for teaching me to enjoy the little things.

To Douglas, my love, thank you. Thank you for being my devil's advocate and pushing me to think outside of myself. Thank you for those quiet moments when I needed to just breathe. I love you with my whole heart.

To my lab mates, past and present, thank you for tolerating my snark, laughing at my ridiculous jokes, and being "work excited" with me every step of the way.

Thank you to my mom, Aunt Dorothy, the Smith tribe, Maddie, Dr. Ammer, Dr. Martin, my classmates, and my first research advisor Dr. Lane. I could not have done it without you all.

Words cannot describe how full my heart is because of each of you.

Thank you. 


\section{Table of Contents}

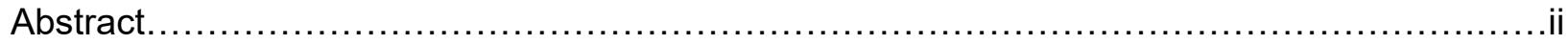

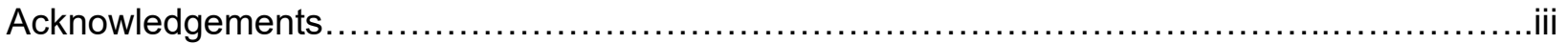

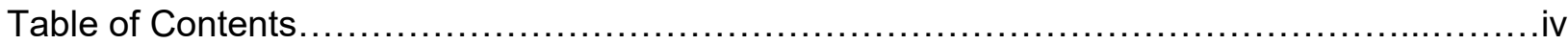

Chapter 1: Introduction and Literature Review.............................................

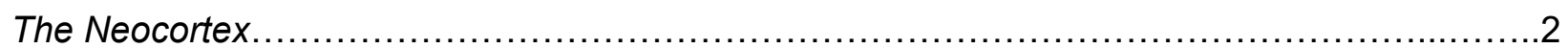

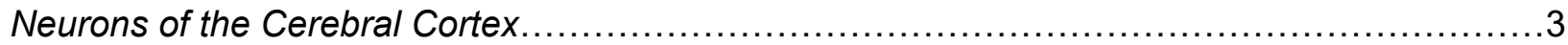

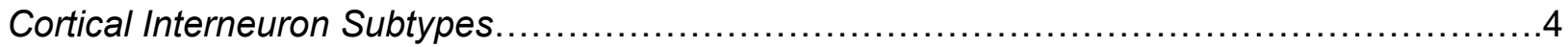

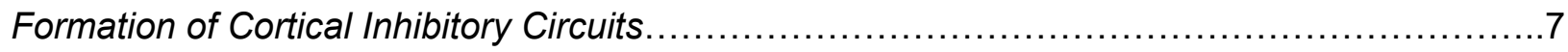

Interneuron Dysfunction and Neurodevelopmental Disorders ...............................

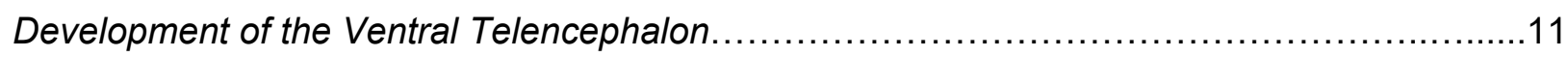

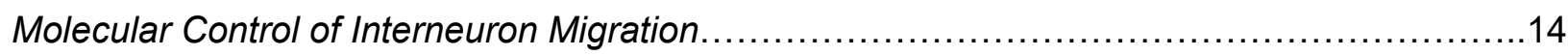

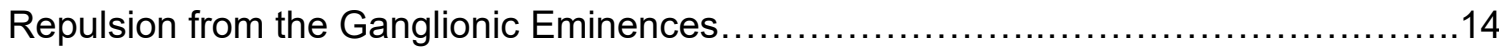

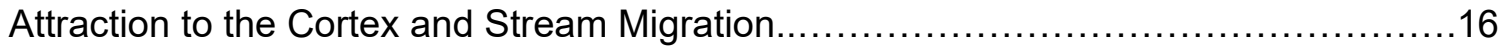

Cellular and Molecular Influences on Migratory Behavior..................................20

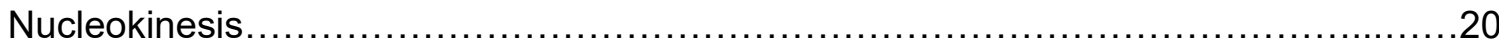

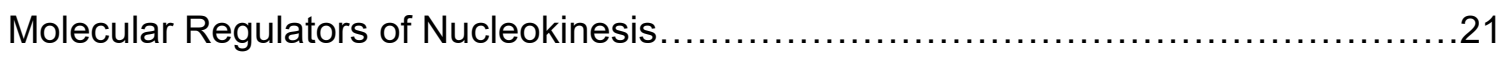

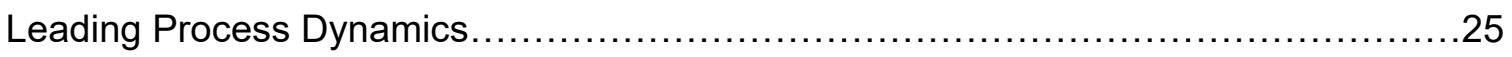

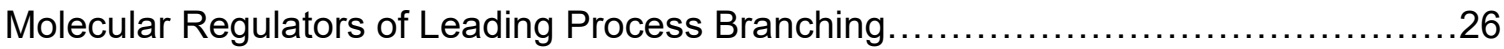

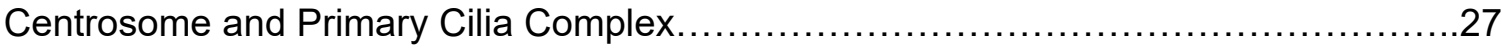

c-Jun NH2-terminal Kinase Signaling in Neuronal Migration..................................29

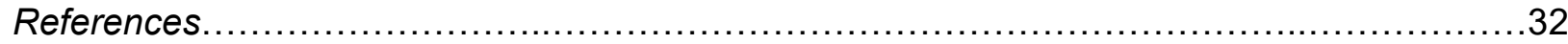

Chapter 2: JNK Signaling Regulates Cellular Mechanics of Cortical Interneuron Migration...........................................................................................46

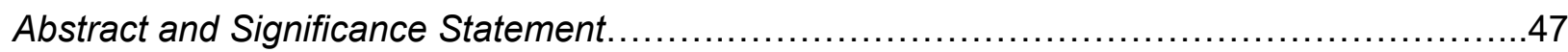

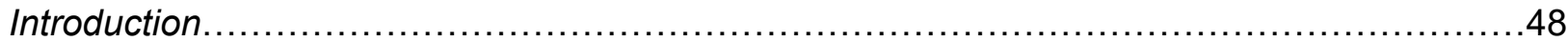

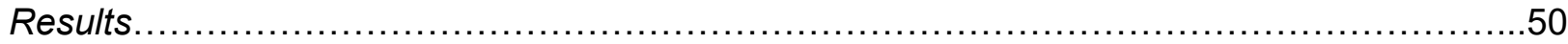

Pharmacological inhibition of JNK signaling disrupts MGE interneuron

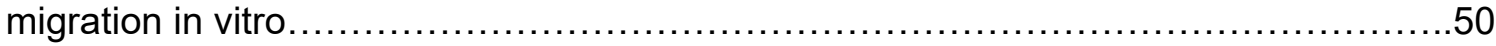

JNK signaling regulates branching dynamics of migrating MGE interneurons ............51 Acute loss of JNK signaling impairs nucleokinesis and cytoplasmic swelling dynamics of

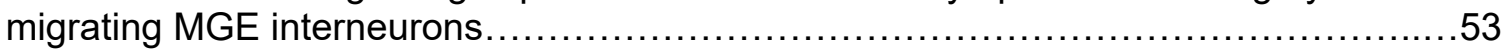

Complete genetic loss of JNK impairs nucleokinesis and leading process branching of

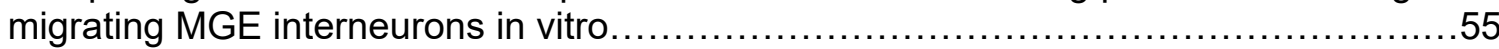

Subcellular localization and dynamic behavior of the centrosome and primary cilia in migrating MGE interneurons depend on intact JNK-signaling..... 
Discussion

Cytoskeletal regulation during leading process branching and nucleokinesis of migrating interneurons.

Position and function of the centrosome and primary cilium during cortical interneuron migration. 63

Cellular influences of JNK signaling during cortical interneuron migration................65

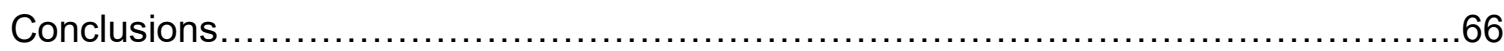

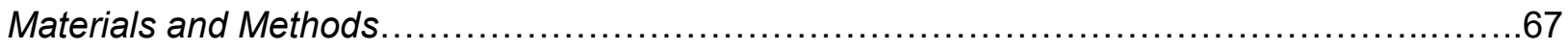

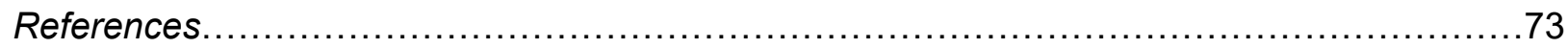

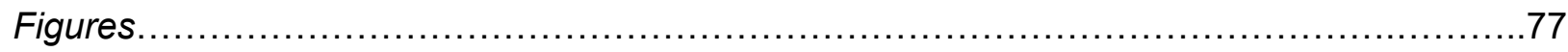

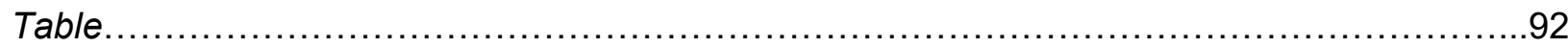

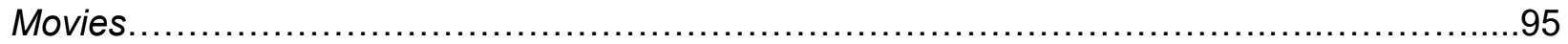

Chapter 3: Migrating cortical interneurons require JNK signaling and nanotopographical

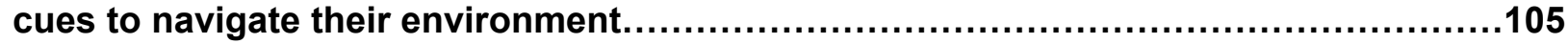

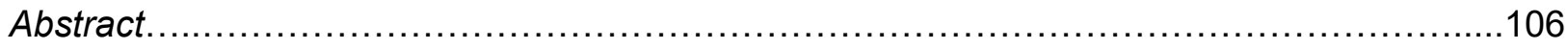

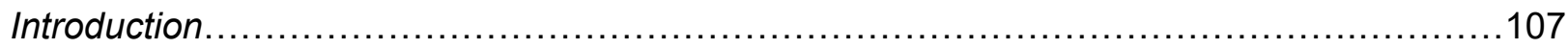

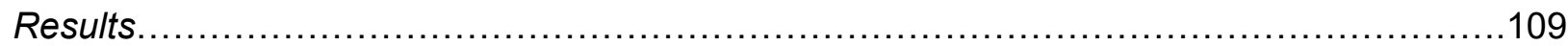

Cortical interneurons require JNK signaling for proper migration regardless of

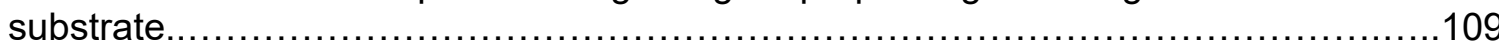

Nanopattern topography mimics control environment for migrating cortical interneurons

Interneurons migrating on flat substrate have disrupted nucleokinesis dynamics when compared to cells migrating on nanopatterns............................................113

Interneurons aligned to nanotopographical gratings have altered cytoskeletal

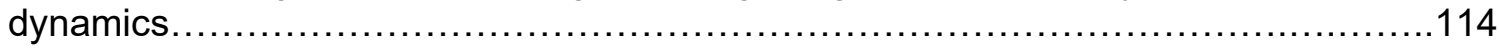

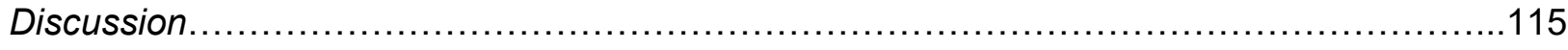

Control of cortical interneuron migration and nucleokinesis through the regulation of cellular adhesion molecules..........................................................117

Nanoscale topographical influences on cortical interneuron migratory behavior........119

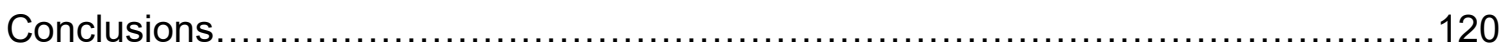

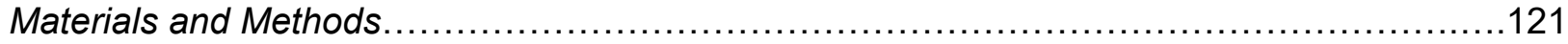

References.

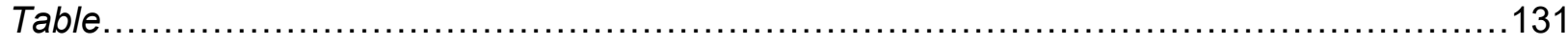

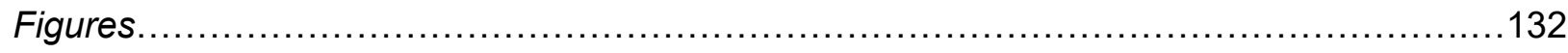

Chapter 4: Summary and Future Directions....................................................141

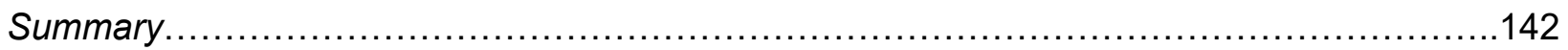

Discussion and Future Directions............................................................... 145

JNK signaling in Migrating Cortical Interneurons Across Embryonic Development......145

Control of Ciliary Position and Signaling .............................................147 
JNK Signaling in Cytoskeletal Dynamics........................................

JNK signaling in interneuron migration: instructive or permissive?...........................153

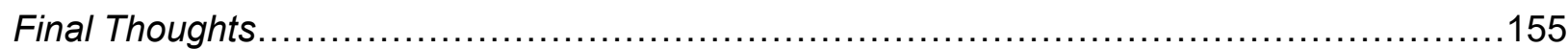

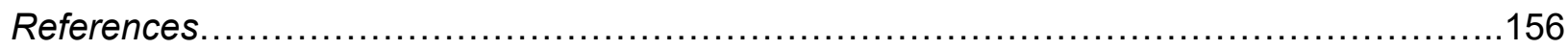

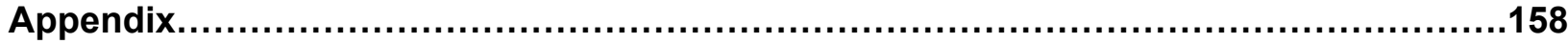


Chapter 1: Introduction and Literature Review 


\section{The Neocortex}

The cerebral cortex is the largest, most complex structure of the brain. More specifically, the cerebral cortex can be subdivided into the allocortex, with 3-4 cellular layers, and the neocortex, with 6 cellular layers. The neocortex is responsible for our ability to sense and respond to our environment through movement, vision, hearing, sensory perception, and decision making. It consists of two cerebral hemispheres and five lobes (frontal, parietal, occipital, temporal, and limbic), each responsible for higher orders of function. These lobes work in unison to perform sensory, motor, and association tasks. The sensory areas of the cortex receive and process information from the bodily senses such as vision, audition, pain, and touch. The motor areas are involved in the control of voluntary movements of the body. The association areas are involved in integrating information collected from other cortical areas, as well as performing specialized tasks including language and behavior. These functions are carried out through the interactions of glutamatergic excitatory projection neurons, $\mathrm{y}$-aminobutyric acid expressing (GABAergic) inhibitory interneurons, and glia (Chu and Anderson, 2015). The two populations of neurons act in a balance of excitation and inhibition to enable proper circuit function which is imperative for normal human (and animal) behavior and cognition (Rakic, 1972; Benes et al., 1991). Though excitatory neurons and inhibitory interneurons ultimately occupy the same cortical laminae, their developmental origins and modes of migration are distinct (Wichterle et al., 2001; Nadarajah and Parnavelas, 2002). Excitatory neurons are produced from progenitor pools in the ventricular zone of the cortex and migrate radially along radial glia scaffolding to their final laminar position, whereas inhibitory interneurons are born in the ventral telencephalon and migrate tangentially before turning and depositing into the cortical plate alongside their excitatory neuron counterparts. Disruptions to the final positioning or function of neurons within cortex during embryonic development can alter the formation of cortical circuitry leading to many neuropsychiatric and neurological disorders such as autism spectrum disorder, epilepsy, and 
schizophrenia (Kato and Dobyns, 2005; Rossignol, 2011). Therefore, understanding the developmental processes required for proper cortical circuit formation is critical for the development of new therapeutics to treat these diseases.

\section{Neurons of the Cerebral Cortex}

Glutamatergic excitatory neurons are broadly categorized into two groups: pyramidal and spiny stellate neurons. Pyramidal neurons, found in neocortical layers 2-6, represent the majority of the total population of neurons in the cortex, and are identified by their pyramid-shaped soma and apical dendrites directed towards the pial surface of the cortex (Kwan et al., 2012). These cells extend axons that may project to either intracortical regions or over long distances into subcortical regions. Infragranular pyramidal neurons, found in layers 5 and 6 , are the major source of output from the neocortex (Baker et al., 2018). These neurons are divided into two categories based on their axonal projections with intratelencephalic (IT) neurons sending projections to the telencephalon and extratelencephalic (ET) that project to both the telencephalon and beyond (Reiner et al., 2003; Saiki et al., 2018). ET cells can be further identified as pyramidal tract neurons with projections that descend to the brainstem and spinal cord, and can innervate many targets within and outside of the telencephalon (Hirai et al., 2012; Kita and Kita, 2012; Ueta et al., 2014). In contrast, spiny stellate neurons, with either short or no apical dendrites and axonal projections predominantly restricted to a single cortical column, are found in layer 4 of the cortex (Lübke et al., 2000; Schubert et al., 2003). Layer 4 spiny stellate neurons in the ferret primary visual cortex were found to initially appear as pyramidal in origin but later reshape their dendritic arbor by shortening their apical dendrite while growing basal dendrites, acquiring a stellate morphology (Rakic, 1972; Wichterle et al., 2001).

GABAergic inhibitory interneurons in the cortex, or cortical interneurons, represent less than $20 \%$ of the total population of neurons in the cortex, and are distributed throughout all layers of 
the cortical wall. Cortical interneurons serve a vital role in modulating cortical output by acting as a local inhibitory signal to balance the output of excitatory neurons (Cherubini and Conti, 2001; Krimer and Goldman-Rakic, 2001). Cortical interneurons are also a diverse population (Rudy et al., 2011). The distinct functions of cortical interneurons are performed by diverse subtypes that differ in axonal and dendritic morphology (Lund and Lewis, 1993), chemical markers (DeFelipe, 1993; Gonchar and Burkhalter, 1997), electrophysiological properties (Cauli et al., 1997; Kawaguchi and Kubota, 1997), and laminar location (Flames and Marín, 2005; Chu and Anderson, 2015). The majority of cortical interneurons can be categorized into three main subtypes: parvalbumin-expressing (PV), somatostatin-expressing (SOM), and the ionotropic serotonin receptor $5 \mathrm{HT} 3 \mathrm{a}-$-expressing $(5 \mathrm{HT} 3 \mathrm{aR})$ interneurons.

\section{Cortical Interneuron Subtypes}

Parvalbumin-expressing (PV) interneurons originating from the medial ganglionic eminence represent the largest class of the GABAergic cortical interneuron population (Rudy et al., 2011). Three major subclasses of PV are chandelier cells, basket cells, and translaminar interneurons, which all exhibit a characteristic fast-spiking firing pattern. Chandelier and basket cells are easily identified by their stereotypic morphology. Chandelier cells exhibit an axonal arborization that closely resembles a chandelier light fixture. These interneurons form synapses onto the axon initial segment of pyramidal cells (Somogyi et al., 1982) and are found at the border between layers 1 and 2, and in layer 6 (Taniguchi et al., 2013). PV expressing basket cells are thought to be the most abundant interneuron in the neocortex. The axons of basket cells target the proximal dendrites and soma of pyramidal cells and even other interneurons (Hu et al., 2014). Basket cells are found in layers 2-6 in the neocortex and across all cortical regions. The more recently discovered and considered relatively rare translaminar interneurons are found in layers 5 and 6 (Buchanan et al., 2012; Bortone et al., 2014). These basket cells extend axons that span the thickness of the cortex and target pyramidal neurons across cortical layers 
(Bortone et al., 2014). PV interneurons receive inputs from excitatory neurons from both the cortex and thalamus (Rudy et al., 2011). Optogenetic studies have provided further understanding of PV interneuron function in the cortex. Using optogenetic stimulation of PV interneurons in the primary visual cortex of awake mice lead to increased orientation tuning and direction selectivity of nearby neurons which resulted in improved orientation discrimination behavior (Lee et al., 2012; Ingram et al., 2019). The balance in activity of PV interneurons is necessary for the generation and maintenance of gamma oscillations which are important for information processing and are often disrupted in neurological and psychiatric diseases (Cardin et al., 2009; Sohal et al., 2009).

The second major class of cortical interneurons originating from the medial ganglionic eminence is characterized by the expression of the neuropeptide somatostatin (SOM) and can be subcategorized into Martinotti and non-Martinotti cells. Anatomically, the cell bodies of Martinotti cells are most abundantly found in layers $2 / 3$ and 5 but are also found to a lesser extent in layer 6 (Oliva et al., 2000). These interneurons extend an ascending axon into layer 1 which then spreads horizontally with spine-like boutons to make synaptic connections onto the distal dendritic tufts of pyramidal cells (Wang et al., 2004; Xu et al., 2006; Rudy et al., 2011; Kelsom and Lu, 2013). However, not all SOM-expressing interneurons are Martinotti cells. Three transgenic mouse lines expressing green fluorescent protein (GFP) under a GAD67 promoter in SOM interneurons, identified distinct subsets of SOM-expressing interneurons named GFPexpressing inhibitory neuron (GIN), X98, and X94 (Ma et al., 2006). Ma and colleagues discovered these additional SOM subtypes based on their laminar position, axonal distribution, molecular markers, and electrophysiological properties (Ma et al., 2006). While X98 and GIN interneurons both shared similar features with Martinotti cells, the most pronounced differences were found in the X94 cells. X98 and GIN interneurons are found in layers 5 and 2/3 respectively with layer 1 targets and a low-threshold spiking behavior, suggesting that these 
subtypes are mostly Martinotti cells. The non-Martinotti X94 cells are present in layers 4 and 5 with most axonal branches found locally residing within layer 4 inhibiting both PV-expressing interneurons (Xu et al., 2013), and spiny stellate cells (Ma et al., 2013). In each of these transgenic lines, GFP was expressed in some, but not all SOM neurons in the hippocampus and cortex. Morphological and electrophysiological analyses of the three lines revealed that the X94 line exhibit distinct subtypes of SOM-expressing interneurons, while the GIN line labeled a mixed population (Ma et al., 2006; Scheyltjens and Arckens, 2016). Optogenetic inhibition of SOM interneurons in layer 4 revealed a disinhibitory circuit mechanism in which SOM interneurons control information processing of layer 4 (Xu et al., 2013).

Finally, $5 \mathrm{HT} 3 \mathrm{aR}$ expressing interneurons are found mostly in layers 1-3 of the cortex and are separated into two subgroups: vasoactive intestinal peptide-expressing (VIP) and reelinexpressing interneurons. VIP interneurons originate from the caudal ganglionic eminence and are enriched in layers $2 / 3$. These cells have bipolar, bitufted, or multipolar morphology and axons that target proximal dendrites of other interneurons (Miyoshi et al., 2010; Rudy et al., 2011). VIP interneurons have been shown to mainly target other interneurons (Dávid et al., 2007), but similar to baskets cells, they have also been observed making synapses around the soma of pyramidal cell bodies (Kawaguchi and Kubota, 1996). Similarly, reelin-expressing interneurons are found in layer 1 and show glia-like processes targeting both pyramidal cells and other GABAergic interneurons (Rudy et al., 2011). The proper laminar allocation of excitatory projection neurons and inhibitory interneurons in the cerebral cortex is imperative for proper behavioral, motor, and sensory functioning (Lewis et al., 2004; Di Cristo, 2007; Bozzi et al., 2012). 


\section{Formation of Cortical Inhibitory Circuits}

Cortical interneurons are initially produced in excess then migrate into the cortex, settle into their laminar position, and are finally pruned to the correct number through apoptosis during the

first and second weeks of postnatal life in the mouse (Southwell et al., 2012; Priya et al., 2018). This pruning phase is activity dependent with increased cell death of low activity interneurons and decreased cell death of interneurons with high activity (Blanquie et al., 2017; Denaxa et al., 2018; Priya et al., 2018). However, VIP expressing interneurons are the exception, and are not pruned based on activity, but are instead hypothesized to be pruned under trophic control (Mardinly et al., 2016).

As the proper numbers of cortical interneurons are established, they begin to extend axons to form synaptic connections with excitatory neurons and other cortical interneurons (Galarreta and Hestrin, 1999; Tamás et al., 2000; Hu et al., 2011). The location of synapse formation is specific to interneuron subtype with PV interneurons targeting the soma and proximal dendrites or axon initial segments of excitatory neurons (Somogyi et al., 1982), SOM interneurons generally targeting the tuft dendrites of excitatory neurons (Wang et al., 2004; Rudy et al., 2011), and 5HT3aR interneurons targeting the proximal dendrites of other interneurons (Miyoshi et al., 2010; Rudy et al., 2011). While the output of interneurons is necessary to modulate cortical excitability, input from excitatory neurons to interneurons is equally important for circuit function and neuronal firing. Excitatory neurons reciprocally form synapses onto inhibitory interneurons, such as layer 2/3 pyramidal cells that form facilitating synapses with bitufted SOM interneurons, but can also form depressing synapses on multipolar PV interneurons (Reyes and Sakmann, 1999; Buchanan et al., 2012; Blackman et al., 2013). Similar target-specific short term plasticity is found with layer 5 pyramidal neurons, which form facilitating synapses on SOM interneurons and depressing on PV interneurons (Buchanan et al., 2012; Lu et al., 2014). However, postnatal maturation leads to functional changes in local excitatory connections where 
short term plasticity switches from depression to facilitation in brain regions such as the barrel cortex and visual cortex in rats and mice which may rely on experience-dependent mechanisms during postnatal development (Frick et al., 2007; Cheetham and Fox, 2010).

Chemical release of GABA and expression of GABA receptor, which are controlled by neuronal activity, are thought to control the maturation of inhibitory connections and fine tune synapse formation of both interneurons and excitatory neurons within the cortex (Liang et al., 1996; Rivera et al., 1999; Wang and Kriegstein, 2008; Le Magueresse and Monyer, 2013). Deans and colleagues discovered that connexin 36 , a gap junction protein, is important for the generation of synchronous and rhythmic activity in the mouse cortex, and genetic removal of connexin 36 resulted in loss of electrical coupling of interneurons suggesting that connexin 36 is a key component of electrical synapse formation and function in cortical interneurons (Deans et al., 2001). Neuronal cell adhesion molecules (NCAMs) have also been found to influence neurite outgrowth, axon branching, and synaptogenesis of cortical interneurons (Pillai-Nair et al., 2005; Hinkle et al., 2006; Brennaman and Maness, 2008). Overexpression of the extracellular domain of NCAM results in disrupted neurite arborization and reduced perisomatic synapses formed by PV interneurons in vivo (Di Cristo et al., 2007; Brennaman and Maness, 2008).

All in all, the temporal generation and control of oscillatory rhythms between excitation and inhibition are required for normal cortical function (Nelson and Valakh, 2015; Dehorter et al., 2017). Dysfunction in the formation, maturation, and synchronization of cortical interneuron circuitry are thought to underly many neurodevelopmental disorders in humans (Gillberg and Billstedt, 2000; Lewis et al., 2012; Le Magueresse and Monyer, 2013).

\section{Interneuron Dysfunction and Neurodevelopmental Disorders}

Inhibitory interneurons regulate the activity of the excitatory neurons to maintain the excitatoryinhibitory (E/I) balance of the cerebral cortex (Meyer et al., 2011). Several neurodevelopmental 
diseases such as schizophrenia, epilepsy, and autism spectrum disorder (ASD) have been associated with disrupted E/I balance of the cerebral cortex (Kato and Dobyns, 2005; Cho et al., 2006; Rossignol, 2011; Snijders et al., 2013; Meechan et al., 2015). Although the clinical symptoms of these diseases manifest during early childhood, adolescence and into adulthood, disruptions to the E/I balance may occur during embryonic development and corticogenesis. It is thought that disruptions to cortical interneuron development including generation, specification, migration, synapse formation, and ultimately function of cortical interneuron circuits may underly the etiologies of these debilitating diseases.

Schizophrenia is a neuropsychiatric disease affecting approximately $1.1 \%$ of the population that is characterized by positive, negative, and cognitive symptoms (Regier et al., 1993). While the development and use of antipsychotics and psychotherapy have eased the burden of the positive symptoms such as hallucinations or delusions and negative symptoms such as alogia or social isolation, the cognitive deficits such as reduced working memory and cognitive flexibility remain unaffected with current treatments (Lee and Park, 2005; Insel, 2010). Abnormal inhibitory neuron function in the prefrontal cortex of individuals with schizophrenia is thought to cause the observed cognitive symptoms of this disease. Patients with schizophrenia have deficits in cortical inhibition (Ongür et al., 2010; Yoon et al., 2010), particularly in PV interneurons (Akbarian et al., 1995; Hashimoto et al., 2003). Indeed, multiple studies have found a reduction of the GABA synthesizing enzyme glutamate decarboxylase-67 (GAD-67) in PV interneurons (Akbarian and Huang, 2006; Lewis et al., 2012), as well as a decrease in PV levels (Hashimoto et al., 2008; Mellios et al., 2009) in the prefrontal cortex of post mortem patients with schizophrenia, suggesting that the function of PV interneurons is affected in schizophrenia. A recent meta-analysis of post-mortem studies found that patients with schizophrenia had a significant reduction in the density of PV interneurons in the prefrontal cortex (Kaar et al., 2019). Disruptions to GAD-67 activity have been associated with bipolar disorder (Lundorf et al., 2005), 
suggesting that these two diseases may be genetically or functionally linked. Therefore, analyzing the genes involved in the development of cortical interneurons and interneuron subtypes will provide further insight into the underlying causes of schizophrenia, and facilitate future therapeutics to treat this disease.

Epilepsy is a brain disorder characterized by recurrent seizures caused by abnormal electrical discharge in the brain which often lead to loss of consciousness and severely affects the patient's quality of life (Spreafico et al., 1998; Singh and Trevick, 2016). While many epilepsies are caused by focal or widespread brain lesions, developmental epilepsies have been linked to cortical interneuron dysfunction (Noebels, 2003; Rossignol, 2011). Inhibitory GABA receptor expression and function were found to be disrupted in resected brain tissue from infants with intractable epilepsy (Jansen et al., 2008; Jansen et al., 2010). These inhibitory defects may be caused by mutations of genes critical for proper interneuron generation, migration, or function. Mutations in the alpha 1 subunit of the voltage-gated sodium channel $\mathrm{Na}_{\vee} 1.1$, aristaless-related homeobox transcription factor, cyclin-dependent kinase-like 5, various subunits in $\mathrm{GABA}_{\mathrm{A}}$ receptor, and the alpha 1 subunit of the voltage-dependent $\mathrm{P} / \mathrm{Q}$-type $\mathrm{Ca}^{2+}$ channel have each been discovered in patients with epilepsy (Rossignol, 2011). While there are currently many therapies for epilepsy including anti-epileptic medication, neurosurgical resection of seizure focus (Kneen and Appleton, 2006), and electrical neurostimulation (Lin and Wang, 2017), treatment-resistant seizures remain. One new and attractive treatment for epilepsy included transplanting medial ganglionic eminence stem cells (Hammad et al., 2015) or human pluripotent stem cell-derived GABAergic interneurons (Cunningham et al., 2014) into seizure foci of mice. These new methods have shown to ameliorate seizures, aggressiveness, and hyperactivity in mice (Cunningham et al., 2014) and could potentially treat intractable epilepsies in humans (Zhu et al., 2018). 
Autism spectrum disorder (ASD) is a highly heterogeneous disorder with many behavioral impairments arising on a spectrum of severity that appear in early childhood. Genetic studies have identified mutations in genes associated with ASD including SH3 and multiple ankyrinrepeat domain (SHANK), fragile X mental retardation 1 (FMR1), tuberous sclerosis 1 and 2

(TSC1 and TSC2), phosphatase and tensin homolog (PTEN), contactin associated protein-like 2 (CNTNAP2) and chromodomain helicase DNA binding protein 7 (CHD7), among others (Durand et al., 2007; Peñagarikano et al., 2011; Tsai and Sahin, 2011; Frazier et al., 2015; Gdalyahu et al., 2015; Yoo, 2015). Magnetic resonance spectroscopy revealed a reduction in GABA levels in the frontal, motor, and somatosensory and auditory cortices in patients with ASD (Harada et al., 2011; Puts et al., 2017). Post mortem analyses in patients with ASD showed a decrease in the number of PV interneurons in the prefrontal cortex (Hashemi et al., 2017; La Buissonnière-Ariza et al., 2018). Thus, understanding the role of cortical interneuron development in the pathophysiology of ASD and other neurodevelopmental diseases will aid in the creation of new therapies for these debilitating diseases.

\section{Development of the Ventral Telencephalon}

GABAergic cortical interneurons were initially thought to originate from the same progenitor cells as excitatory neurons within the pallium (Rakic, 1988). Anderson and colleagues later provided evidence that cortical inhibitory interneurons are in fact generated in the region of the telencephalon that generates the basal ganglia, the subpallium (Anderson et al., 1997). Comparison of post mortem human, non-human primate, and rodent brains revealed that cortical interneurons are produced by conserved progenitor zones within the subpallium (Ma et al., 2013). Cortical interneurons are produced in the ventral telencephalon in the medial and caudal ganglionic eminences (MGE and CGE) and the preoptic area (POA) (Butt et al., 2005; Yozu et al., 2005; Danglot et al., 2006; Gelman et al., 2011). While the lateral ganglionic eminence (LGE) is known to primarily generate GABAergic striatal projection neurons, there has 
been some evidence that the LGE may also generate small numbers of cortical interneurons (Anderson et al., 2001a). Each of these ganglionic eminences generate interneurons that reside in other pallial and subpallial regions such as the piriform cortex, hippocampus, olfactory bulb, striatum, and the pallidum (Xu et al., 2008; Potter et al., 2009). The ganglionic eminences are transient developmental structures, forming during embryonic days 9-11 (E9-11) in the mouse (about 5 weeks post conception in humans) from neuroepithelial swellings in the ventral telencephalon (Smart, 1976; Zecevic et al., 2011; Ansen-Wilson and Lipinski, 2017). These proliferative regions continually generate interneurons until about E17 in the mouse, which corresponds to about week 15 of human development (Otis and Brent, 1954).

Once postmitotic, cortical interneurons exit the ganglionic eminences then migrate from the subpallium into the neocortex (Anderson et al., 1997). As cortical interneurons enter the developing neocortex, they form two tangentially oriented streams located in the marginal zone $(\mathrm{MZ})$ and subventricular zone (SVZ) that are used to migrate to their final destinations in the cortex (Danglot et al., 2006; López-Bendito et al., 2008; Marín et al., 2010). This long-distance tangential migration from the subpallium begins after interneurons enter the neocortex at about E12.5 in the mouse. Once in the cortical rudiment, migrating cortical interneurons adhere to their two migratory streams until roughly E15.5 when they begin to reorient to a radial migration as they invade the cortical plate and settle into their specific cortical layers alongside excitatory neurons (Miyoshi and Fishell, 2011; Zecevic et al., 2011; Ma et al., 2013).

MGE-derived cortical interneurons contribute to $50-60 \%$ of all cortical interneurons (Gonchar and Burkhalter, 1997; Pleasure et al., 2000; Butt et al., 2005). These cells distribute throughout the cortical plate according to birthdate, with early-born cells preferentially populating the lower cortical layers 5 and 6 , and late-born cells mainly giving rise to upper layer $2 / 3$ fates (Valcanis and Tan, 2003). Transplantation (Valcanis and Tan, 2003) and birth-dating (Anderson et al., 2002) assays determined that MGE-derived cortical interneurons obey similar rules of cortical 
layering to that of pyramidal neurons, depositing in an inside-out manner within the cortical plate, despite having distinctly different modes of migration from excitatory neurons (Tan et al., 1998). The majority of PV and SOM-expressing cortical interneurons are produced in the MGE, with the dorsal MGE giving rise to SOM interneurons and the ventral MGE predominantly producing PV interneurons (Xu et al., 2004; Flames et al., 2007; Wonders et al., 2008).

The CGE contributes to about 20-30\% of cortical interneurons (Peyre et al., 2015). CGE neurogenesis begins about three days later than the initiation of MGE cells, occurring at about E12.5 in the mouse (Miyoshi et al., 2007; Miyoshi et al., 2010). Unlike to MGE-derived interneurons, CGE-derived cortical interneurons do not settle in an inside-out manner, but preferentially occupy superficial cortical layers regardless of their birthdate (Miyoshi et al., 2010). CGE-derived interneurons express 5HT3aR along with reelin, calretinin, or VIP (Pleasure et al., 2000; Butt et al., 2005; Miyoshi et al., 2010). Finally, the POA contributes to approximately $10 \%$ of the cortical interneuron population (Gelman et al., 2009). This region produces subtypes of cortical interneurons overlapping with those derived from other regions including PV, SOM, and reelin-expressing interneurons (Flandin et al., 2011; Gelman et al., 2011). These interneurons are often found in the superficial layers $2 / 3$ of the cortex, have a multipolar morphology, and have the intrinsic electrophysiological profile of adapting interneurons (Ascoli et al., 2008; Gelman et al., 2011). The fewest number of cortical interneurons arise from the POA. Genetic fate mapping and in utero transplantation experiments were used to trace the progeny POA progenitor cells characterized by the expression of the transcription factor $D b \times 1$ and determined that these interneurons primarily populate the deep cortical layers (Gelman et al., 2011).

While cortical interneurons are produced in each of these different regions of the developing telencephalon, each population must depart from their birthplace and migrate a long distance past the pallial/subpallial boundary into the cortical rudiment. To complete this task, cortical 
interneurons must integrate extracellular guidance molecules with their intracellular signaling pathways and machinery to physically move their entire cell bodies in the direction of migration.

\section{Molecular Control of Interneuron Migration}

Interneurons migrate long distances from their places of origin to reach the cortical plate and integrate into their final cortical circuit to establish the correct excitatory-inhibitory balance of the cortex. As cortical interneurons leave their birthplaces in the ventral forebrain, they organize into streams, migrate tangentially, then reorient into radial migration patterns to populate the cortical plate and integrate into circuits alongside their excitatory counterparts. During this tortuous journey, cortical interneurons encounter many guidance molecules that attract them to or repel them from areas of the developing forebrain to guide them into their final resting places within the cortical wall.

\section{Repulsion from the Ganglionic Eminences}

As cortical interneurons become post-mitotic and prepare to leave the ganglionic eminences to begin their lengthy journey into the cortical wall, they begin to up- and downregulate many receptors essential for their guided migration. Many of the mechanisms that were previously implicated in axon guidance hold true for cortical interneuron guidance.

One such family of molecules, ephrins, were shown to not only act as repulsive cues for growing axons, but also for migrating cortical interneurons (Drescher et al., 1995; Santiago and Erickson, 2002; Zimmer et al., 2008). Eph-receptor tyrosine kinases, specifically Eph-A and Eph-B receptors, are expressed on cortical interneurons (Zimmer et al., 2008; Talebian et al., 2017). Cells in the ventricular zone of the ganglionic eminences express the membrane-bound molecule ephrin-A5 which interacts with Eph-A4 receptors on cortical interneurons to drive them away from the ganglionic eminences (Zimmer et al., 2008). Ex vivo slice culture experiments revealed that ephrin-A5 was lost over time in culture (Zimmer et al., 2008). Consequentially, 
MGE interneurons in these slices began to ectopically migrate into the ventricular zone of the ganglionic eminences, a location usually avoided by migrating cortical interneurons. Addition of recombinant ephrin-A5 to these slices compensated for this effect, and cortical interneurons again avoided the ventricular zone of the ganglionic eminences. More recently ephrin-A2 was shown to be required for interneuron guidance into the cortex (Homman-Ludiye et al., 2017). Constitutive removal of ephrin-A2 in mice resulted in reduced migration of interneurons into the developing cortex during embryonic timepoints, reduced calbindin expression, and significant reductions of neurons in malformations along the cortex (Homman-Ludiye et al., 2017). Removal of ephrin-A2 led to perturbed social interactions and repetitive grooming which are behavioral phenotypes associated with ASD (Wurzman et al., 2015). Ephrin-B signaling has also been linked to regulation of cortical interneuron migration (Talebian et al., 2017). Conditional triple knockout of ephrin-B from cortical interneurons resulted in reduced interneurons in the developing and mature cortex and ultimately cortical hyperexcitability leading to audiogenic seizures. Conditional removal of ephrin-B from interneurons resulted in their aberrant accumulation in lateral regions of the developing cortex such as the amygdala. These studies suggest that ephrin signaling is a key regulator of cortical interneuron migration and may prevent cortical interneurons from entering inappropriate territories in the developing forebrain.

After cortical interneurons leave the ganglionic eminences, they specifically avoid the striatum as they are guided towards the pallial-subpallial boundary and into the cortex. MGE-derived interneurons express semaphorin family receptors (Neuropilin1 and 2) for the ligands Sema3A and Sema3F that act as chemorepulsive factors, guiding these cells away from the striatum and dorsally towards the cortical rudiment (Marín et al., 2001). The Nkx2.1 transcription factor controls the expression of these receptors and determines whether MGE-derived interneurons migrate towards the striatum or away from it and into the developing cerebral cortex (NóbregaPereira et al., 2008). Nkx2.1 is highly expressed in cortical interneuron progenitor zones, but as 
cortical interneurons leave these zones, they begin to downregulate Nkx2.1 expression. Overexpression of Nkx2.1 prevents cortical interneuron migration into the cortex and instead accumulation in the basal ganglia, whereas loss of Nkx2.1 drives cortical infiltration. Increased

Nkx2.1 expression suppresses Sema3A and Sema3F repulsion of interneurons while downregulation of Nkx2.1 increases the expression of the Neuropilin receptors. Thus, postmitotic downregulation of Nkx2.1 drives interneuron repulsion from the striatum and guides them towards the cortex (Nóbrega-Pereira et al., 2008).

Slit/Roundabout homolog 1 (Robo1) signaling is also highly involved in mediating cortical interneuron repulsion from the ganglionic eminences. Cortical interneurons express Robo1 which a receptor that binds to the ligands Slit1 and Slit2 (Bagri et al., 2002; Marillat et al., 2002). While Slit/Robo1 signaling was originally thought to push cortical interneurons away from the ventricular zone of the ganglionic eminences due to expression patterns in the ganglionic eminences, this is not the case. Genetic removal of Slit1/2 did not appear to disrupt the tangential migration of interneurons to the cortex (Marín et al., 2003). However, removal of Robo1 resulted in aberrant striatal invasion by cortical interneurons suggesting both Slitdependent and independent events controlling interneuron repulsion from the striatum (Andrews et al., 2006; Hernández-Miranda et al., 2011). Thus, Slit/Robo signaling is also required for steering migrating cortical interneurons around the striatum and into the developing cortex.

\section{Attraction to the Cortex and Stream Migration}

As cortical interneurons leave the ganglionic eminences and are repelled from the striatum, they are simultaneously attracted towards the corticostriatal boundary, into the cortical rudiment, and into their migratory streams. Cortical interneurons use two main migratory streams to enter and navigate the cortex, a marginal zone (MZ) and subventricular zone (SVZ) stream. During this 
journey, cortical interneurons are exposed to more attractant and repulsive cues that are integrated and deciphered into directions that drive stream migration.

Neuregulin-1 (Nrg-1) is a strong attractant for interneurons, driving their entry into the developing cortical wall (Yau et al., 2003; Flames et al., 2004; Bean et al., 2014). The function of $\mathrm{Nrg}-1$ is mediated by the receptor tyrosine kinase ErbB4, which is expressed on migrating cortical interneurons (Yau et al., 2003; Flames et al., 2004). Diffusible Nrg-1 is expressed in the developing cortex at high levels as cortical interneurons (expressing ErbB4) begin to enter. Nrg1 is also more highly expressed in lateral regions than medial regions at earlier time points (about E13.5) and gradually progresses medially as development continues in parallel with the medial advancement of cortical interneurons. Indeed, placing an aggregate of cells expressing Nrg-1 on ex vivo slice cultures revealed that cortical interneurons will redirect their migration towards the ectopic expression of Nrg-1 (Flames et al., 2004). Removal of Nrg-1/ErbB4 signaling with either a dominant negative construct, or genetic manipulation leads to decreased interneuron sensitivity to $\mathrm{Nrg}-1$, reduced numbers of interneurons entering the cortex, and disruptions to the laminar allocation of interneurons in the postnatal cortex (Flames et al., 2004; Bartolini et al., 2017). Overexpression of Nrg-1 in mice leads to schizophrenia-like behavioral phenotypes (Deakin et al., 2012; Yin et al., 2013; Luo et al., 2014), and post-mortem samples from brains of humans with schizophrenia show increased Nrg-1 and ErbB4 mRNA levels in the prefrontal cortex (Hashimoto et al., 2004; Chong et al., 2008; Joshi et al., 2014).

Chemokine signaling from C-x-c motif chemokine 12 (Cxcl12) is also involved in both interneuron entry into the cortex and stream migration (Tiveron et al., 2006; Stumm et al., 2007; Li et al., 2008; Lysko et al., 2011, 2014). Cxcl12 serves as a chemoattractant for cortical interneurons that express the cognate chemokine receptors Cxcr4 and Cxcr7 (Liapi et al., 2008; López-Bendito et al., 2008; Wang et al., 2011). Cxcl12 is highly expressed at the corticostriatal boundary and in the MZ and SVZ stream territories (López-Bendito et al., 2008), and ectopic 
expression of $\mathrm{Cxcl} 12$ in the cortex induces cortical interneurons to aggregate around the ectopic Cxcl12 (Li et al., 2008). Slice culture experiments revealed that pharmacological inhibition of Cxcr4 with AMD3100 (blocks Cxcl12 binding to Cxcr4) results in cortical interneuron departure from the SVZ stream and accumulation of interneurons in the cortical plate (Lysko et al., 2011). Genetic removal of Cxcr4, Cxcr7, or Cxcl12 leads to departure of cortical interneurons from MZ and SVZ streams and accumulation of interneurons in the cortical plate (Li et al., 2008; Abe et al., 2014). Loss of Cxcr4 function disrupts the laminar allocation of interneurons in the cortex (López-Bendito et al., 2008).

The signaling molecule sonic hedgehog (Shh) is involved in the induction of transcription factors required for proper embryo development, the formation of the ventral telencephalon, and patterning of the MGE (Chiang et al., 1996; Kohtz et al., 1998; Fuccillo et al., 2004; Xu et al., 2005). The identity of cortical interneurons is at least in part dependent on Shh signaling in the MGE, with high levels of Shh promoting the generation of somatostatin-expressing cortical interneurons (Xu et al., 2010). Shh signaling has been implicated in the guided migration of cortical interneurons (Baudoin et al., 2012). Genetic removal of proteins involved in Shh signaling, Kif3a and IFT88, led to increased density of interneurons migrating in streams, more tightly packed migratory streams, and failure to depart from tangential migration to enter the cortical plate. Treating live cortical slices with the Shh antagonist cyclopamine resulted in a similar phenotype, suggesting that Shh is involved in the formation and maintenance of cortical interneurons migratory streams.

There is evidence for the role of neurotransmitters including $y$-aminobutyric acid (GABA), glycine, glutamate, and dopamine in the guided migration of cortical interneurons (Poluch et al., 2001; López-Bendito et al., 2003; Cuzon et al., 2006; Crandall et al., 2007; Cuzon Carlson and Yeh, 2011; Inada et al., 2011; Avila et al., 2013). Pharmacological blockade of GABA receptors reduces the migratory speed and disrupts stream formation of cortical interneurons in vitro and 
in vivo (Cuzon Carlson and Yeh, 2011; Inada et al., 2011). Cortical interneurons have increased responsiveness to GABA as they leave the MGE and traverse through the corticostriatal boundary into the cortex (Cuzon et al., 2006; Cuzon Carlson and Yeh, 2011). Similar effects were found with inhibition of $\mathrm{GABA}_{\mathrm{B}}$ receptors (López-Bendito et al., 2003). Glycine receptor (GlyR) blockage in cortical slices led to significant alterations in cortical interneuron migration, with impaired corticostriatal boundary crossing and decreased speed of migration (Avila et al., 2013). Since GlyR activation leads to membrane depolarization and opening of voltage-gated calcium channels, it was suggested that glycine could be required for calcium oscillations in migrating cortical interneurons. Indeed, cortical slices treated with glycine show increased intracellular calcium in cortical interneurons, and inhibition of GlyR disrupted this effect along with disrupted migration, suggesting that glycine mediates calcium concentrations migrating cortical interneurons (Avila et al., 2013). Glutamate binding to AMPA receptor has also been suggested to control the migration of cortical interneurons by promoting slowed movement and radial direction (Poluch et al., 2001; Yozu et al., 2008). Finally, dopamine controls cortical interneuron migration by interacting with D1 and D2 receptors. Activation of the dopamine receptor revealed that $\mathrm{D} 1 \mathrm{R}$ promotes whereas $\mathrm{D} 2 \mathrm{R}$ represses interneuron migration from the MGE into the cortex (Crandall et al., 2007). These results were confirmed with genetic removal of D1R and D2R. Removal of D1R led to significant reduction of interneurons migrating in the SVZ, whereas removal of D2R promoted SVZ migration (Crandall et al., 2007).

Taken together, migrating cortical interneurons must interpret environmental cues into meaningful directions that are necessary for their guided migration. These directions must then be carefully followed for cortical interneurons to physically move in the selected direction of migration. 


\section{Cellular and Molecular Influences on Migratory Behavior}

\section{Nucleokinesis}

Migrating cortical interneurons must coordinate two cell biological processes that are essential for their guided migration: nucleokinesis and leading process branching. Nucleokinesis is a cyclical process whereby the cell bodies of migrating neurons translocate into a cytoplasmic swelling that forms in their leading process (Polleux et al., 2002; Ang et al., 2003; Nadarajah et al., 2003; Moya and Valdeolmillos, 2004; Bellion et al., 2005). As cortical interneurons engage in nucleokinesis, the cytoplasmic swelling is filled with the centrosome, primary cilium, Golgi apparatus, and mitochondria, along with other cellular machinery necessary to pull the cell body forward. During the "resting phase," when the nucleus is stationary, these cytoplasmic organelles that were originally positioned in the perinuclear area move into the leading process and form the swelling (Bellion et al., 2005). Through electron microscopy and immunohistochemistry, it was discovered that the centrosome and Golgi apparatus both undergo morphological changes during their translocation into the swelling. As the swelling forms, the centrosome will often split into two centromeres, and the Golgi apparatus will elongate into a linear conformation between them. The nucleus will then translocate forward to combine with the swelling, completing nucleokinesis (Bellion et al., 2005).

During nucleokinesis, cortical interneurons physically propel their nucleus in the forward direction of migration. Since the nucleus of cortical interneurons is encaged by microtubules that are tethered to the centrosome (Tanaka et al., 2004; Higginbotham and Gleeson, 2007), it was originally thought that the centrosome acts as a "pulling" force on the nucleus and preceded nuclear translocation. However, while it is still controversial whether nucleokinesis is dependent on the "pulling force" of the centrosome ahead of the nucleus, others have shown that chemical destabilization of microtubules with nocodazole does not completely abolish nucleokinesis of 
interneurons (Bellion et al., 2005; Schaar and McConnell, 2005; Martini and Valdeolmillos, 2010). Thus, nucleokinesis is not entirely dependent on centrosomal movement into the leading process.

While pulling on the nucleus by the centrosome may not be required for forward movement, actomyosin contraction at the rear of the cell body is indispensable (Bellion et al., 2005; Schaar and McConnell, 2005). Prior to nuclear translocation, myosin II transiently accumulates at the rear of the cell body, and the phosphorylation of myosin's regulatory light chain is required for nucleokinesis (Schaar and McConnell, 2005). Treating migrating interneurons with blebbistatin, a selective nonmuscular myosin II inhibitor, halts nuclear movement, showing that myosin contraction is required to move the nucleus forward (Bellion et al., 2005). Therefore, the combination of the microtubule-generated pulling forces and pushing forces from actomyosin contractility work in tandem to create this saltatory forward movement of the nucleus towards the centrosome in the swelling of the leading process.

\section{Molecular Regulators of Nucleokinesis}

Identifying key regulators of microtubule and actin cytoskeleton dynamics and how they control nucleokinesis is crucial for our understanding of cortical interneuron migration and development. Indeed, many studies have recently explored how regulators of nucleokinesis are linked to the control of cytoskeletal dynamics.

For instance, $\mathrm{p} 27^{\mathrm{kip} 1}$, which was first identified as a cell cycle inhibitor, is now known to also be a microtubule associated protein involved in cortical interneuron migration. p2 $7^{\text {kip } 1}$ coordinates both actomyosin contraction and microtubule organization to control leading process branching and nucleokinesis in migrating interneurons (Godin et al., 2012). Conditional deletion of p27kip1 from post-mitotic interneurons led to slower migratory speeds, and fewer numbers of cortical interneurons that had advanced into the cortex at E12.5 in ex vivo slice cultures. Using an in 
vitro co-culture assay to grow migratory cortical interneuron on a monolayer of dissociated cortical cells, Godin and colleagues found that conditional deletion of p27kip increased frequency of nucleokinesis, diminished distance of translocations, and decreased the duration of time that cytoplasmic swellings persisted (Godin et al., 2012). p27 kip1 colocalized with the GTPase RhoA, a known regulator of actin dynamics (Besson et al., 2004), and deletion of p2 $7^{\text {kip } 1}$ resulted in increased RhoA activity. This increase in RhoA activity led to higher levels of myosin II activity which promotes nuclear translocation of neurons (Schaar and McConnell, 2005; Solecki et al., 2009), and resulted in temporal dysregulation of actomyosin contractions and disrupted nucleokinesis (Godin et al., 2012).

The deglutamylation enzyme cytosolic carboxypeptidase 1 (CCP1) that removes glutamate side chains from microtubules was recently found to be expressed in migrating cortical interneurons and is involved in regulating nucleokinesis in mice (Silva et al., 2018). Mutations in the gene for CCP1 are associated with delayed cognitive development, suggesting that CCP1 is crucial for normal brain development (Firth et al., 2009). Conditional deletion of CCP1 from cortical interneurons led to reduced amplitude of nucleokinesis and pausing between nucleokinesis events, without affecting average migratory speed in E13.5 slices. Actin contraction at the rear of the cell body was increased in CCP1 knockout interneurons, which was due to an increase in myosin light chain kinase (MLCK) activity on MLC. Treating co-cultures with the MLCK inhibitor ML7 rescued the nucleokinesis defects in CCP1 knockout interneurons. Thus, the defects in migration were attributed to CCP1 control of actomyosin contraction by regulating the balance of myosin light chain kinase activity during migration (Silva et al., 2018).

Mutations to the Elongator complex proteins have been associated with neurological disorders such as familial dysautonomia and amyotrophic lateral sclerosis (Anderson et al., 2001b; Nguyen et al., 2010). More recently, the role of the enzymatic core subunit Elp3 was identified to fine-tune the actomyosin network by regulating the distribution and turnover of actin during 
cortical interneuron migration (Tielens et al., 2016). Conditional removal of Elp3 from cortical interneurons reduces the number of interneurons in the cortex across rostro-caudal axes and leads to decreased cells in the MZ and SVZ streams in vivo. Co-culture and slice culture assays revealed that Elp3 knockout interneurons migrate at significantly slower speeds, with reduced amplitudes of nucleokinesis, and less frequent nuclear translocation events. A construct that fluorescently labels actin was electroporated into cortical interneurons to determine the effect of Elp3 loss on actomyosin contraction. Loss of Elp3 impairs the subcellular distribution of actin and leads to decreased cofilin activity, a known actin-severing enzyme that interacts with Elp3 (Tielens et al., 2016). Blocking cofilin dephosphorylation with siRNAs in Elp3 knockout cortical interneurons rescued the nucleokinesis defects. Together, these experiments provide evidence for a role of Epl3 in controlling actomyosin dynamics through the activity of cofilin in migrating cortical interneurons.

X-linked lissencephaly and subcortical band heterotopia (or "double-cortex" syndrome) are human brain disorders caused by mutations in the gene for doublecortin (Dcx; Raymond et al., 1995; Gleeson et al., 1998; Matsumoto et al., 2001). Dcx is a microtubule associated protein that stabilizes microtubules in the leading process and around the perinuclear cage, and was first identified as a key regulator in the migration of neurons in the rat cortex (Francis et al., 1999; Gleeson et al., 1999; Tanaka et al., 2004; Schaar and McConnell, 2005; Ettinger et al., 2016). Knockdown of Dcx leads to subcortical band heterotopia and seizures due to a failure of radial migration in the rat cortex, which can be rescued in early postnatal life by re-expression of Dcx (Manent et al., 2009). While Dcx knockout mice do not exhibit the same radial organization abnormalities as in rat models, the migration of cortical interneurons is significantly affected (Kappeler et al., 2006). Knockout of Dcx results in less frequent nucleokinesis events and altered swelling dynamics when compared to control interneurons, suggesting a role of Dcx in the movement of the cell body during migration (Kappeler et al., 2006). Dcx knockout leads to 
decreased density and disrupted laminar distribution of cortical interneurons at postnatal day 0 (Friocourt et al., 2007). More recently, Dcx was shown to interact not only directly with microtubules, but indirectly with the actin network through the Rac1-specific guanine nucleotide exchange factor Asef2, stimulating lamellipodia formation to promote the migration of neural progenitor cells (Toriyama et al., 2012).

Lissencephaly, meaning "smooth brain," is a severe brain malformation caused by mutations in numerous genes, including Lis1, which lead to defective neuronal migration during embryonic development (Reiner et al., 1993; Reiner et al., 1995). Lis1 is a protein involved in microtubule dynamics that interacts with the motor protein dynein to regulate nucleokinesis and is required for normal neuronal migration (Cahana et al., 2001; McManus et al., 2004; Tanaka et al., 2004). Post mortem analyses from fetuses with microdeletion of chromosome 17p13.3 (encoding Lis1), also known as Miller-Dieker syndrome, showed reduced numbers of calretinin-expressing interneurons, suggesting a role for Lis1 in the migration of cortical interneurons (Pancoast et al., 2005). This hypothesis was confirmed with heterozygous removal of Lis 1 in mice (McManus et al., 2004). Removal of Lis1 resulted in deficits of cortical interneuron migration with delayed entry into the cortical rudiment and reduced medial progression in the cortex (McManus et al., 2004). Lis1 and Dcx coimmunoprecipitate and overexpression of one can rescue migration deficits with loss of the other, suggesting potential overlapping roles for Dcx and Lis1 in nuclear movement during neuronal migration (Caspi et al., 2000; Tanaka et al., 2004).

Disruptions in the neurotransmitter dopamine have been linked to neurodevelopmental disorders such as schizophrenia, epilepsy, and ASD (Benes et al., 2000; Robinson et al., 2001; Treiman, 2001; Casanova et al., 2003). D1R and D2R are expressed in migrating cortical interneurons and altering the physiological balance between their activation impairs interneuron migration (Crandall et al., 2007). Activation of D1R increased speed and promotes cortical interneuron tangential migration. More recently, it was discovered that disrupting D1R 
interaction with synaptic Ras-guanosine triphosphate-activating protein 1 (SynGAP1), which is essential for synaptic development (Clement et al., 2012; Aceti et al., 2015), leads to disrupted cortical interneuron migration (Su et al., 2019). Mouse brains injected with a peptide to block D1R-SynGAP1 resulted in decreased migratory distance of cortical interneurons from MGE explants in vitro, as well as reduced tangential progression of interneurons throughout the cortex in vivo. Disruption of the D1R-SynGAP1 complex led to decreased actin in the leading process and aberrant localization of dynein in the soma, suggesting that this complex regulates multiple aspects of the cytoskeleton involved in proper interneuron migration (Su et al., 2019).

\section{Leading Process Dynamics}

On the other end of the cell, the leading process is a highly dynamic structure that extends and retracts branches bearing dynamic growth cones to sense and respond to extracellular guidance cues (Lysko et al., 2011). The cytoskeletal structure of the leading process consists predominantly of microtubules, with actin localized more distally in the growth cones and at the rear of the cell body (Lysko et al., 2014). Posttranslational modifications of microtubules regulate the stability of microtubules involved in branching. For example, acetylation of tubulin is a stabilizer of microtubules, whereas tyrosination of tubulin acts as a microtubule destabilizer (Bulinski and Gundersen, 1991; Bulinski, 2007). Cortical interneuron leading process branching begins with the formation of a membrane protrusion formed by an F-actin meshwork containing cortactin and actin-related proteins $2 / 3$, then microtubules quickly invade to stabilize the protrusion and form a new branch (Spillane et al., 2011; Lysko et al., 2014). As a branch forms, it is tipped with a growth cone, which functions very similarly to the growth cones of developing axons by sensing chemo-attractant and repulsive cues to direct movement. However, branches in migrating interneurons tend to grow more linearly, maintaining the angle established from their branching point instead of making sharp turns like axons (Valiente and Martini, 2009). 
Many of the mechanisms associated with the control of nucleokinesis are also involved in leading process branch dynamics.

\section{Molecular Regulators of Leading Process Branching}

Microtubule polymerization is essential for neurite growth and migration properties of cortical interneurons (Godin et al., 2012). Cortical interneurons lacking the microtubule-associated protein $\mathrm{p} 27^{\mathrm{kip} 1}$ displayed a delayed tangential migration due to defects found in both nucleokinesis and leading process branching. Experiments with conditional knockout of p27kip1 from cortical interneurons determined that it controls leading process branching by promoting the polymerization of microtubules in extending neurites, which was not rescued by activating actomyosin contraction. Cortical interneurons lacking Dcx have increased frequency of growth cone splits resulting in a hyper-branched phenotype, however these branches do not extend as far as controls and are shorter-lived (Kappeler et al., 2006; Lysko et al., 2014). Overexpression of Dcx in migrating cortical interneurons reduces the frequency of growth cone splitting (Lysko et al., 2014). Cxcl12 binding to Cxcr4, which reduces leading process branching, is dependent on Dcx bundling of microtubules, suggesting that Cxcl12 control of interneuron migration in migratory streams depends on Dcx activity. Migrating cortical interneurons lacking the microtubule associated protein Lis1 have reduced acetylation of microtubules and reduced frequency of leading process splitting suggesting a role of Lis 1 in the formation and stability of newly formed branches (Gopal et al., 2010). Conditional knockout of Elp3 from cortical interneurons also significantly alters leading process branching dynamics (Tielens et al., 2016). Elp3 knockout cortical interneurons have decreased frequency of growth cone splits and neurite length in vitro due to dysregulated actin dynamics in the leading process. CCP1 knockout leads to subtle defects in leading process branching in vitro with increased duration of branches and no changes to growth cone split frequency or neurite length, again suggesting dual roles for 
CCP1 in regulating both nucleokinesis and leading process branching dynamics (Silva et al., 2018).

\section{Centrosome and Primary Cilia Complex}

During nucleokinesis, a cytoplasmic swelling emerges from the cell body containing multiple subcellular organelles including the centrosome and primary cilium which are involved in the directed migration of cortical interneurons (Bellion et al., 2005; Martini and Valdeolmillos, 2010; Yanagida et al., 2012). The centrosome is a central component of the neuronal cytoskeleton and acts as the microtubule organization center, linking the microtubules around the nucleus to those in the leading process (Tsai and Gleeson, 2005; Umeshima et al., 2007). It was suggested that the microtubule-driven pulling forces generated in the leading process act through the centrosome as a driving force in the forward movement of the nucleus (Tsai and Gleeson, 2005). This theory, however, remains controversial as some studies have suggested nuclear translocation occurs independent of microtubule-based centrosome positioning (Umeshima et al., 2007; Martini and Valdeolmillos, 2010).

Extending from the mother centriole of the centrosome, is the microtubule-based primary cilium, which is involved in the guided migration of cortical interneurons (Baudoin et al., 2012; Higginbotham et al., 2012; Park et al., 2019). The primary cilium docks to the cell membrane via transition fibers connected to the mother centriole, compartmentalizing this organelle from the cytosol (Baudoin et al., 2012). Furthermore, the primary cilium is thought to act as a cellular antenna, containing many receptors and signaling molecules required for proper neuronal migration (Métin and Pedraza, 2014; Sarkisian and Guadiana, 2015). Together, the subcellular positioning and function of the centrosome-primary cilium complex has been shown to be required for cortical interneuron migration and disruptions to its function may underly 
nucleokinesis and leading process branching defects (Baudoin et al., 2012; Higginbotham et al., 2012; Luccardini et al., 2013; Matsumoto et al., 2019).

Historically, the primary cilium has been associated with its role in Shh signaling and cell differentiation and patterning during embryogenesis (Bangs and Anderson, 2017). While the primary cilium controls Shh signaling, other signaling receptors and ciliary-specific proteins are also found in the primary cilium of cortical interneurons. Indeed, cortical interneurons lacking key ciliary-specific proteins involved in the formation of the primary cilium or Shh signaling exhibit defects in migration (Baudoin et al., 2012; Higginbotham et al., 2012). Conditional removal of the intraflagellar transport (IFT) protein IFT88, anterograde transport protein Kif3a, or ciliary-specific small GTP-ase Arl13b from cortical interneurons lead to altered migration (Baudoin et al., 2012; Higginbotham et al., 2012). Conditional knockout of IFT88 or Kif3a result in increased leading process branching and prevented cells from leaving migratory streams to infiltrate the cortical plate. The subcellular positioning of the centrosome-cilium complex was found to be mispositioned at the rear of the cell body with knockdown of Kif3a or IFT88 from migrating olfactory bulb interneurons, further suggesting a role in the positioning of cilia in directed migration (Matsumoto et al., 2019).

$\mathrm{N}$-cadherin is a membrane bound homophilic adhesion molecule expressed in cortical interneurons that is involved in the positioning of the centrosome-cilium complex (Luccardini et al., 2013; Luccardini et al., 2015). Conditional removal of n-cadherin from cortical interneurons results in slower migratory speed, increased pausing, and decreased directionality in vitro (Luccardini et al., 2013). Dominant-negative knockdown of n-cadherin led to rearward positioning of the centrosome, loss of synchrony between the nucleus and centrosome with the centrosome making more sporadic movements in vitro (Luccardini et al., 2013; Luccardini et al., 2015). This rearward positioning of the centrosome was attributed to the loss of myosin polarity when $\mathrm{n}$-cadherin is knocked down in interneurons. Since the positioning of the centrosome is 
dependent on the actomyosin cytoskeleton (Solecki et al., 2009), and myosin polarity is lost in n-cadherin knockdown interneurons, n-cadherin may promote nucleokinesis by guiding the centrosome to the leading process prior to nucleokinesis.

While many of the mechanisms influencing the guided migration of cortical interneurons have been elucidated, including the role of membrane-bound receptors, extracellular ligands, and cytoskeletal proteins, the roles that intracellular signaling pathways play in interneuron migration remain largely unknown.

\section{C-Jun $\mathrm{NH}_{2}$-terminal kinase Signaling in Neuronal Migration}

The c-Jun $\mathrm{NH}_{2}$-terminal kinase (JNK) intracellular signaling pathway is involved in a myriad of cellular behaviors including proliferation, apoptosis, migration, axon growth and others (Chang and Karin, 2001; Chang et al., 2003; Westerlund et al., 2011). JNK is a member and terminal kinase of the mitogen-activated protein kinase (MAPK) superfamily of kinases. JNK is activated by phosphorylation from two upstream kinases, MAPKK7 and MAPKK4. These two upstream MAPKKs are activates by several MAPKKKs in response to a variety of extracellular stimuli (Weston and Davis, 2007; Yamasaki et al., 2012). After activation, JNK phosphorylates downstream substrates in the cytoplasm and nucleus to control various aspects of cellular behavior, including cellular migration (Huang et al., 2003; Manning and Davis, 2003).

The JNK proteins are encoded by three genes named Jnk1 (Mapk8), Jnk2 (Mapk9), and Jnk3 (Mapk10) which are alternatively spliced to produce ten protein isoforms (Gupta et al., 1996). Jnk1 and Jnk2 are ubiquitously expressed throughout the body, whereas Jnk3 is found in the brain, heart, and testis (Kuan et al., 1999). The highest levels of Jnk1/2/3 mRNA are found in the neocortex (Carboni et al., 1998). Over the years the JNK signaling pathway has been targeted for genetic knockout studies to further probe for its potential developmental roles. While mouse models with constitutive removal of individual JNKs survive to adulthood, these animals 
still exhibit cellular and behavioral phenotypes (Yang et al., 1997; Dong et al., 2001; Westerlund et al., 2011). Removal of both JNK1 and JNK2 from mice leads to defective neural tube closure and is thus embryonic lethal (Kuan et al., 1999; Sabapathy et al., 1999), suggesting an obligate role for JNK signaling in brain development.

JNK signaling is highly involved in neuronal migration. Indeed, multiple studies have established a role for JNK signaling in the radial migration of cortical excitatory neurons (Mizuno et al., 2005; Westerlund et al., 2011). Radially migrating neurons overexpressing the JNK binding domain of JIP (JBD), a peptide inhibitor of JNK that prevents substrate binding, reach the cortical plate faster than control neurons (Mizuno et al., 2005; Westerlund et al., 2011). Pharmacological inhibition of JNK signaling in the cytoplasm also results in accelerated migration of cortical neurons, whereas JNK inhibition in the nucleus slowed migration. Excitatory neurons in Jnk1 knockout mice migrate faster than controls, and final cell positioning in the cortex becomes disorganized (Westerlund et al., 2011). While knockdown of JNK2 halted radial migration of excitatory neurons in the subventricular zone region of the embryonic cortex, knockdown of JNK3 had no effect on migration, suggesting that individual JNKs could be preferentially involved in neuronal migration (Zhang et al., 2016). Inhibition of JNK signaling also reduces leading process length of excitatory neurons in vitro (Kawauchi et al., 2003) and induces slower nuclear translocation without affecting the formation or shape of the cytoplasmic swelling in ex vivo slices (Nishimura et al., 2014).

Our lab was the first to establish the requirement for JNK signaling in the migration of cortical interneurons. Using pharmacological and genetic manipulations, we found that cortical interneurons require Jnk1 for timely entry of cortical interneurons into the cortical rudiment and for early migratory stream formation (Myers et al., 2014). Additionally, both pharmacological inhibition and genetic removal of all three JNK genes resulted in the premature departure of cortical interneurons from migratory streams, and disrupted positioning in the early postnatal 
cortex (Myers et al., 2020). However, the influence of JNK on the cellular mechanisms controlling the coordinated movement of cortical interneurons was unknown prior to this dissertation.

In summary, the proper arrival and laminar allocation of cortical interneurons in the developing cortical plate is crucial for the function of the mature cerebral cortex. After cortical interneurons are born in the ventral telencephalon, they migrate tangentially in two streams to enter the cortical rudiment. During this migration, cortical interneurons must integrate extracellular cues from their environment with intracellular signaling pathways and machinery to enter and navigate through the developing cortex. While much progress has been made in elucidating the extracellular guidance cues necessary for migration, the field is currently lacking insight in the intracellular mechanisms controlling and ultimately finetuning the guided migration of cortical interneurons. In this dissertation, the requirements for JNK function in nucleokinesis and leading process branching are explored through in vitro and ex vivo experiments with pharmacological inhibition of JNK signaling and the use of a conditional triple knockout mouse model. In Chapter 2, an MGE explant cortical cell co-culture assay was utilized to examine the role of JNK signaling in nucleokinesis, leading process branching, and the subcellular localization of the centrosome-ciliary complex. In Chapter 3, ex vivo slices, in vitro 3-dimensional matrices, and in vitro nanotopography were used to examine the requirement of JNK signaling for interneuron migration in different topographical and substrate environments. Prior to this work, the role of JNK signaling in the cellular mechanisms controlling the coordinated movement of cortical interneurons was unknown. This dissertation demonstrates the crucial need for JNK function in the coordinated movement and guidance of cortical interneurons throughout their environment. 


\section{REFERENCES}

Abe P, Mueller W, Schütz D, MacKay F, Thelen M, Zhang P, Stumm R (2014) CXCR7 prevents excessive CXCL12-mediated downregulation of CXCR4 in migrating cortical interneurons. Development 141:1857-1863.

Aceti M, Creson TK, Vaissiere T, Rojas C, Huang WC, Wang YX, Petralia RS, Page DT, Miller CA, Rumbaugh G (2015) Syngap1 haploinsufficiency damages a postnatal critical period of pyramidal cell structural maturation linked to cortical circuit assembly. Biol Psychiatry 77:805-815.

Akbarian S, Huang HS (2006) Molecular and cellular mechanisms of altered GAD1/GAD67 expression in schizophrenia and related disorders. Brain Res Rev 52:293-304.

Akbarian S, Kim JJ, Potkin SG, Hagman JO, Tafazzoli A, Bunney WE, Jones EG (1995) Gene expression for glutamic acid decarboxylase is reduced without loss of neurons in prefrontal cortex of schizophrenics. Arch Gen Psychiatry 52:258-266.

Anderson SA, Eisenstat DD, Shi L, Rubenstein JL (1997) Interneuron migration from basal forebrain to neocortex: dependence on DIx genes. Science 278:474-476.

Anderson SA, Marín O, Horn C, Jennings K, Rubenstein JL (2001a) Distinct cortical migrations from the medial and lateral ganglionic eminences. Development 128:353-363.

Anderson SA, Kaznowski CE, Horn C, Rubenstein JL, McConnell SK (2002) Distinct origins of neocortical projection neurons and interneurons in vivo. Cereb Cortex 12:702-709.

Anderson SL, Coli R, Daly IW, Kichula EA, Rork MJ, Volpi SA, Ekstein J, Rubin BY (2001b) Familial dysautonomia is caused by mutations of the IKAP gene. Am J Hum Genet 68:753-758.

Andrews W, Liapi A, Plachez C, Camurri L, Zhang J, Mori S, Murakami F, Parnavelas JG, Sundaresan V, Richards LJ (2006) Robo1 regulates the development of major axon tracts and interneuron migration in the forebrain. Development 133:2243-2252.

Ang ES, Haydar TF, Gluncic V, Rakic P (2003) Four-dimensional migratory coordinates of GABAergic interneurons in the developing mouse cortex. J Neurosci 23:5805-5815.

Ansen-Wilson LJ, Lipinski RJ (2017) Gene-environment interactions in cortical interneuron development and dysfunction: A review of preclinical studies. Neurotoxicology 58:120129.

Ascoli GA et al. (2008) Petilla terminology: nomenclature of features of GABAergic interneurons of the cerebral cortex. Nat Rev Neurosci 9:557-568.

Avila A, Vidal PM, Dear TN, Harvey RJ, Rigo JM, Nguyen L (2013) Glycine receptor a2 subunit activation promotes cortical interneuron migration. Cell Rep 4:738-750.

Bagri A, Marín O, Plump AS, Mak J, Pleasure SJ, Rubenstein JL, Tessier-Lavigne M (2002) Slit proteins prevent midline crossing and determine the dorsoventral position of major axonal pathways in the mammalian forebrain. Neuron 33:233-248.

Baker A, Kalmbach B, Morishima M, Kim J, Juavinett A, Li N, Dembrow N (2018) Specialized Subpopulations of Deep-Layer Pyramidal Neurons in the Neocortex: Bridging Cellular Properties to Functional Consequences. J Neurosci 38:5441-5455.

Bangs F, Anderson KV (2017) Primary Cilia and Mammalian Hedgehog Signaling. Cold Spring Harb Perspect Biol 9.

Bartolini G, Sánchez-Alcañiz JA, Osório C, Valiente M, García-Frigola C, Marín O (2017) Neuregulin 3 Mediates Cortical Plate Invasion and Laminar Allocation of GABAergic Interneurons. Cell Rep 18:1157-1170.

Baudoin JP, Viou L, Launay PS, Luccardini C, Espeso Gil S, Kiyasova V, Irinopoulou T, Alvarez C, Rio JP, Boudier T, Lechaire JP, Kessaris N, Spassky N, Métin C (2012) Tangentially migrating neurons assemble a primary cilium that promotes their reorientation to the cortical plate. Neuron 76:1108-1122. 
Bean JC, Lin TW, Sathyamurthy A, Liu F, Yin DM, Xiong WC, Mei L (2014) Genetic labeling reveals novel cellular targets of schizophrenia susceptibility gene: distribution of GABA and non-GABA ErbB4-positive cells in adult mouse brain. J Neurosci 34:13549-13566.

Bellion A, Baudoin JP, Alvarez C, Bornens M, Métin C (2005) Nucleokinesis in tangentially migrating neurons comprises two alternating phases: forward migration of the Golgi/centrosome associated with centrosome splitting and myosin contraction at the rear. J Neurosci 25:5691-5699.

Benes FM, Taylor JB, Cunningham MC (2000) Convergence and plasticity of monoaminergic systems in the medial prefrontal cortex during the postnatal period: implications for the development of psychopathology. Cereb Cortex 10:1014-1027.

Benes FM, McSparren J, Bird ED, SanGiovanni JP, Vincent SL (1991) Deficits in small interneurons in prefrontal and cingulate cortices of schizophrenic and schizoaffective patients. Arch Gen Psychiatry 48:996-1001.

Besson A, Gurian-West M, Schmidt A, Hall A, Roberts JM (2004) p27Kip1 modulates cell migration through the regulation of RhoA activation. Genes Dev 18:862-876.

Blackman AV, Abrahamsson T, Costa RP, Lalanne T, Sjöström PJ (2013) Target-cell-specific short-term plasticity in local circuits. Front Synaptic Neurosci 5:11.

Blanquie O, Yang JW, Kilb W, Sharopov S, Sinning A, Luhmann HJ (2017) Electrical activity controls area-specific expression of neuronal apoptosis in the mouse developing cerebral cortex. Elife 6 .

Bortone DS, Olsen SR, Scanziani M (2014) Translaminar inhibitory cells recruited by layer 6 corticothalamic neurons suppress visual cortex. Neuron 82:474-485.

Bozzi Y, Casarosa S, Caleo M (2012) Epilepsy as a neurodevelopmental disorder. Front Psychiatry 3:19.

Brennaman LH, Maness PF (2008) Developmental regulation of GABAergic interneuron branching and synaptic development in the prefrontal cortex by soluble neural cell adhesion molecule. Mol Cell Neurosci 37:781-793.

Buchanan KA, Blackman AV, Moreau AW, Elgar D, Costa RP, Lalanne T, Tudor Jones AA, Oyrer J, Sjöström PJ (2012) Target-specific expression of presynaptic NMDA receptors in neocortical microcircuits. Neuron 75:451-466.

Bulinski JC (2007) Microtubule modification: acetylation speeds anterograde traffic flow. Curr Biol 17:R18-20.

Bulinski JC, Gundersen GG (1991) Stabilization of post-translational modification of microtubules during cellular morphogenesis. Bioessays 13:285-293.

Butt SJ, Fuccillo M, Nery S, Noctor S, Kriegstein A, Corbin JG, Fishell G (2005) The temporal and spatial origins of cortical interneurons predict their physiological subtype. Neuron 48:591-604.

Cahana A, Escamez T, Nowakowski RS, Hayes NL, Giacobini M, von Holst A, Shmueli O, Sapir T, McConnell SK, Wurst W, Martinez S, Reiner O (2001) Targeted mutagenesis of Lis1 disrupts cortical development and LIS1 homodimerization. Proc Natl Acad Sci U S A 98:6429-6434.

Carboni L, Carletti R, Tacconi S, Corti C, Ferraguti F (1998) Differential expression of SAPK isoforms in the rat brain. An in situ hybridisation study in the adult rat brain and during post-natal development. Brain Res Mol Brain Res 60:57-68.

Cardin JA, Carlén M, Meletis K, Knoblich U, Zhang F, Deisseroth K, Tsai LH, Moore Cl (2009) Driving fast-spiking cells induces gamma rhythm and controls sensory responses. Nature 459:663-667.

Casanova MF, Buxhoeveden D, Gomez J (2003) Disruption in the inhibitory architecture of the cell minicolumn: implications for autism. Neuroscientist 9:496-507.

Caspi M, Atlas R, Kantor A, Sapir T, Reiner O (2000) Interaction between LIS1 and doublecortin, two lissencephaly gene products. Hum Mol Genet 9:2205-2213. 
Cauli B, Audinat E, Lambolez B, Angulo MC, Ropert N, Tsuzuki K, Hestrin S, Rossier J (1997) Molecular and physiological diversity of cortical nonpyramidal cells. J Neurosci 17:38943906.

Chang L, Karin M (2001) Mammalian MAP kinase signalling cascades. Nature 410:37-40.

Chang L, Jones Y, Ellisman MH, Goldstein LS, Karin M (2003) JNK1 is required for maintenance of neuronal microtubules and controls phosphorylation of microtubuleassociated proteins. Dev Cell 4:521-533.

Cheetham CE, Fox K (2010) Presynaptic development at L4 to I2/3 excitatory synapses follows different time courses in visual and somatosensory cortex. J Neurosci 30:12566-12571.

Cherubini E, Conti F (2001) Generating diversity at GABAergic synapses. Trends Neurosci 24:155-162.

Chiang C, Litingtung Y, Lee E, Young KE, Corden JL, Westphal H, Beachy PA (1996) Cyclopia and defective axial patterning in mice lacking Sonic hedgehog gene function. Nature 383:407-413.

Cho RY, Konecky RO, Carter CS (2006) Impairments in frontal cortical gamma synchrony and cognitive control in schizophrenia. Proc Natl Acad Sci U S A 103:19878-19883.

Chong VZ, Thompson M, Beltaifa S, Webster MJ, Law AJ, Weickert CS (2008) Elevated neuregulin-1 and ErbB4 protein in the prefrontal cortex of schizophrenic patients. Schizophr Res 100:270-280.

Chu J, Anderson SA (2015) Development of cortical interneurons. Neuropsychopharmacology 40:16-23.

Clement JP, Aceti M, Creson TK, Ozkan ED, Shi Y, Reish NJ, Almonte AG, Miller BH, Wiltgen BJ, Miller CA, Xu X, Rumbaugh G (2012) Pathogenic SYNGAP1 mutations impair cognitive development by disrupting maturation of dendritic spine synapses. Cell 151:709-723.

Crandall JE, McCarthy DM, Araki KY, Sims JR, Ren JQ, Bhide PG (2007) Dopamine receptor activation modulates GABA neuron migration from the basal forebrain to the cerebral cortex. J Neurosci 27:3813-3822.

Cunningham M, Cho JH, Leung A, Savvidis G, Ahn S, Moon M, Lee PK, Han JJ, Azimi N, Kim KS, Bolshakov VY, Chung S (2014) hPSC-derived maturing GABAergic interneurons ameliorate seizures and abnormal behavior in epileptic mice. Cell Stem Cell 15:559-573.

Cuzon Carlson VC, Yeh HH (2011) GABAA receptor subunit profiles of tangentially migrating neurons derived from the medial ganglionic eminence. Cereb Cortex 21:1792-1802.

Cuzon VC, Yeh PW, Cheng Q, Yeh HH (2006) Ambient GABA promotes cortical entry of tangentially migrating cells derived from the medial ganglionic eminence. Cereb Cortex 16:1377-1388.

Danglot L, Triller A, Marty S (2006) The development of hippocampal interneurons in rodents. Hippocampus 16:1032-1060.

Deakin IH, Nissen W, Law AJ, Lane T, Kanso R, Schwab MH, Nave KA, Lamsa KP, Paulsen O, Bannerman DM, Harrison PJ (2012) Transgenic overexpression of the type I isoform of neuregulin 1 affects working memory and hippocampal oscillations but not long-term potentiation. Cereb Cortex 22:1520-1529.

Deans MR, Gibson JR, Sellitto C, Connors BW, Paul DL (2001) Synchronous activity of inhibitory networks in neocortex requires electrical synapses containing connexin 36. Neuron 31:477-485.

DeFelipe J (1993) Neocortical neuronal diversity: chemical heterogeneity revealed by colocalization studies of classic neurotransmitters, neuropeptides, calcium-binding proteins, and cell surface molecules. Cereb Cortex 3:273-289.

Dehorter N, Marichal N, Marín O, Berninger B (2017) Tuning neural circuits by turning the interneuron knob. Curr Opin Neurobiol 42:144-151. 
Denaxa M, Neves G, Rabinowitz A, Kemlo S, Liodis P, Burrone J, Pachnis V (2018) Modulation of Apoptosis Controls Inhibitory Interneuron Number in the Cortex. Cell Rep 22:17101721.

Di Cristo G (2007) Development of cortical GABAergic circuits and its implications for neurodevelopmental disorders. Clin Genet 72:1-8.

Di Cristo G, Chattopadhyaya B, Kuhlman SJ, Fu Y, Bélanger MC, Wu CZ, Rutishauser U, Maffei L, Huang ZJ (2007) Activity-dependent PSA expression regulates inhibitory maturation and onset of critical period plasticity. Nat Neurosci 10:1569-1577.

Dong C, Davis RJ, Flavell RA (2001) Signaling by the JNK group of MAP kinases. C-jun Nterminal Kinase. J Clin Immunol 21:253-257.

Drescher U, Kremoser C, Handwerker C, Löschinger J, Noda M, Bonhoeffer F (1995) In vitro guidance of retinal ganglion cell axons by RAGS, a $25 \mathrm{kDa}$ tectal protein related to ligands for Eph receptor tyrosine kinases. Cell 82:359-370.

Durand CM et al. (2007) Mutations in the gene encoding the synaptic scaffolding protein SHANK3 are associated with autism spectrum disorders. Nat Genet 39:25-27.

Dávid C, Schleicher A, Zuschratter W, Staiger JF (2007) The innervation of parvalbumincontaining interneurons by VIP-immunopositive interneurons in the primary somatosensory cortex of the adult rat. Eur J Neurosci 25:2329-2340.

Ettinger A, van Haren J, Ribeiro SA, Wittmann T (2016) Doublecortin Is Excluded from Growing Microtubule Ends and Recognizes the GDP-Microtubule Lattice. Curr Biol 26:1549-1555.

Firth HV, Richards SM, Bevan AP, Clayton S, Corpas M, Rajan D, Van Vooren S, Moreau Y, Pettett RM, Carter NP (2009) DECIPHER: Database of Chromosomal Imbalance and Phenotype in Humans Using Ensembl Resources. Am J Hum Genet 84:524-533.

Flames N, Marín O (2005) Developmental mechanisms underlying the generation of cortical interneuron diversity. Neuron 46:377-381.

Flames N, Pla R, Gelman DM, Rubenstein JL, Puelles L, Marín O (2007) Delineation of multiple subpallial progenitor domains by the combinatorial expression of transcriptional codes. $\mathrm{J}$ Neurosci 27:9682-9695.

Flames N, Long JE, Garratt AN, Fischer TM, Gassmann M, Birchmeier C, Lai C, Rubenstein JL, Marín O (2004) Short- and long-range attraction of cortical GABAergic interneurons by neuregulin-1. Neuron 44:251-261.

Flandin P, Zhao Y, Vogt D, Jeong J, Long J, Potter G, Westphal H, Rubenstein JL (2011) Lhx6 and Lhx8 coordinately induce neuronal expression of Shh that controls the generation of interneuron progenitors. Neuron 70:939-950.

Francis F, Koulakoff A, Boucher D, Chafey P, Schaar B, Vinet MC, Friocourt G, McDonnell N, Reiner O, Kahn A, McConnell SK, Berwald-Netter Y, Denoulet P, Chelly J (1999) Doublecortin is a developmentally regulated, microtubule-associated protein expressed in migrating and differentiating neurons. Neuron 23:247-256.

Frazier TW, Embacher R, Tilot AK, Koenig K, Mester J, Eng C (2015) Molecular and phenotypic abnormalities in individuals with germline heterozygous PTEN mutations and autism. Mol Psychiatry 20:1132-1138.

Frick A, Feldmeyer D, Sakmann B (2007) Postnatal development of synaptic transmission in local networks of L5A pyramidal neurons in rat somatosensory cortex. J Physiol 585:103-116.

Friocourt G, Liu JS, Antypa M, Rakic S, Walsh CA, Parnavelas JG (2007) Both doublecortin and doublecortin-like kinase play a role in cortical interneuron migration. J Neurosci 27:38753883.

Fuccillo M, Rallu M, McMahon AP, Fishell G (2004) Temporal requirement for hedgehog signaling in ventral telencephalic patterning. Development 131:5031-5040.

Galarreta M, Hestrin S (1999) A network of fast-spiking cells in the neocortex connected by electrical synapses. Nature 402:72-75. 
Gdalyahu A, Lazaro M, Penagarikano O, Golshani P, Trachtenberg JT, Geschwind DH, Gescwind DH (2015) The Autism Related Protein Contactin-Associated Protein-Like 2 (CNTNAP2) Stabilizes New Spines: An In Vivo Mouse Study. PLoS One 10:e0125633.

Gelman D, Griveau A, Dehorter N, Teissier A, Varela C, Pla R, Pierani A, Marín O (2011) A wide diversity of cortical GABAergic interneurons derives from the embryonic preoptic area. J Neurosci 31:16570-16580.

Gelman DM, Martini FJ, Nóbrega-Pereira S, Pierani A, Kessaris N, Marín O (2009) The embryonic preoptic area is a novel source of cortical GABAergic interneurons. J Neurosci 29:9380-9389.

Gillberg C, Billstedt E (2000) Autism and Asperger syndrome: coexistence with other clinical disorders. Acta Psychiatr Scand 102:321-330.

Gleeson JG, Lin PT, Flanagan LA, Walsh CA (1999) Doublecortin is a microtubule-associated protein and is expressed widely by migrating neurons. Neuron 23:257-271.

Gleeson JG, Allen KM, Fox JW, Lamperti ED, Berkovic S, Scheffer I, Cooper EC, Dobyns WB, Minnerath SR, Ross ME, Walsh CA (1998) Doublecortin, a brain-specific gene mutated in human $\mathrm{X}$-linked lissencephaly and double cortex syndrome, encodes a putative signaling protein. Cell 92:63-72.

Godin JD, Thomas N, Laguesse S, Malinouskaya L, Close P, Malaise O, Purnelle A, Raineteau O, Campbell K, Fero M, Moonen G, Malgrange B, Chariot A, Metin C, Besson A, Nguyen $\mathrm{L}(2012) \mathrm{p} 27$ (Kip1) is a microtubule-associated protein that promotes microtubule polymerization during neuron migration. Dev Cell 23:729-744.

Gonchar Y, Burkhalter A (1997) Three distinct families of GABAergic neurons in rat visual cortex. Cereb Cortex 7:347-358.

Gopal PP, Simonet JC, Shapiro W, Golden JA (2010) Leading process branch instability in Lis1+/- nonradially migrating interneurons. Cereb Cortex 20:1497-1505.

Gupta S, Barrett T, Whitmarsh AJ, Cavanagh J, Sluss HK, Dérijard B, Davis RJ (1996) Selective interaction of JNK protein kinase isoforms with transcription factors. EMBO J 15:27602770.

Hammad M, Schmidt SL, Zhang X, Bray R, Frohlich F, Ghashghaei HT (2015) Transplantation of GABAergic Interneurons into the Neonatal Primary Visual Cortex Reduces Absence Seizures in Stargazer Mice. Cereb Cortex 25:2970-2979.

Harada M, Kubo H, Nose A, Nishitani H, Matsuda T (2011) Measurement of variation in the human cerebral GABA level by in vivo MEGA-editing proton MR spectroscopy using a clinical $3 \mathrm{~T}$ instrument and its dependence on brain region and the female menstrual cycle. Hum Brain Mapp 32:828-833.

Hashemi E, Ariza J, Rogers H, Noctor SC, Martínez-Cerdeño V (2017) The Number of Parvalbumin-Expressing Interneurons Is Decreased in the Prefrontal Cortex in Autism. Cereb Cortex 27:1931-1943.

Hashimoto R, Straub RE, Weickert CS, Hyde TM, Kleinman JE, Weinberger DR (2004) Expression analysis of neuregulin-1 in the dorsolateral prefrontal cortex in schizophrenia. Mol Psychiatry 9:299-307.

Hashimoto T, Bazmi HH, Mirnics K, Wu Q, Sampson AR, Lewis DA (2008) Conserved regional patterns of GABA-related transcript expression in the neocortex of subjects with schizophrenia. Am J Psychiatry 165:479-489.

Hashimoto T, Volk DW, Eggan SM, Mirnics K, Pierri JN, Sun Z, Sampson AR, Lewis DA (2003) Gene expression deficits in a subclass of GABA neurons in the prefrontal cortex of subjects with schizophrenia. J Neurosci 23:6315-6326.

Hernández-Miranda LR, Cariboni A, Faux C, Ruhrberg C, Cho JH, Cloutier JF, Eickholt BJ, Parnavelas JG, Andrews WD (2011) Robo1 regulates semaphorin signaling to guide the migration of cortical interneurons through the ventral forebrain. J Neurosci 31:61746187. 
Higginbotham H, Eom TY, Mariani LE, Bachleda A, Hirt J, Gukassyan V, Cusack CL, Lai C, Caspary T, Anton ES (2012) Arl13b in primary cilia regulates the migration and placement of interneurons in the developing cerebral cortex. Dev Cell 23:925-938.

Higginbotham HR, Gleeson JG (2007) The centrosome in neuronal development. Trends Neurosci 30:276-283.

Hinkle CL, Diestel S, Lieberman J, Maness PF (2006) Metalloprotease-induced ectodomain shedding of neural cell adhesion molecule (NCAM). J Neurobiol 66:1378-1395.

Hirai Y, Morishima M, Karube F, Kawaguchi Y (2012) Specialized cortical subnetworks differentially connect frontal cortex to parahippocampal areas. J Neurosci 32:1898-1913.

Homman-Ludiye J, Kwan WC, de Souza MJ, Rodger J, Bourne JA (2017) Ephrin-A2 regulates excitatory neuron differentiation and interneuron migration in the developing neocortex. Sci Rep 7:11813.

$\mathrm{Hu} \mathrm{H}$, Ma Y, Agmon A (2011) Submillisecond firing synchrony between different subtypes of cortical interneurons connected chemically but not electrically. J Neurosci 31:3351-3361.

Hu H, Gan J, Jonas P (2014) Interneurons. Fast-spiking, parvalbumin ${ }^{+}$GABAergic interneurons: from cellular design to microcircuit function. Science 345:1255263.

Huang C, Rajfur Z, Borchers C, Schaller MD, Jacobson K (2003) JNK phosphorylates paxillin and regulates cell migration. Nature 424:219-223.

Inada $\mathrm{H}$, Watanabe $\mathrm{M}$, Uchida $\mathrm{T}$, Ishibashi $\mathrm{H}$, Wake $\mathrm{H}$, Nemoto $\mathrm{T}$, Yanagawa $\mathrm{Y}$, Fukuda $\mathrm{A}$, Nabekura J (2011) GABA regulates the multidirectional tangential migration of GABAergic interneurons in living neonatal mice. PLoS One 6:e27048.

Ingram TGJ, King JL, Crowder NA (2019) Divisive Inhibition Prevails During Simultaneous Optogenetic Activation of All Interneuron Subtypes in Mouse Primary Visual Cortex. Front Neural Circuits 13:40.

Insel TR (2010) Rethinking schizophrenia. Nature 468:187-193.

Jansen LA, Peugh LD, Ojemann JG (2008) GABA(A) receptor properties in catastrophic infantile epilepsy. Epilepsy Res 81:188-197.

Jansen LA, Peugh LD, Roden WH, Ojemann JG (2010) Impaired maturation of cortical GABA(A) receptor expression in pediatric epilepsy. Epilepsia 51:1456-1467.

Joshi D, Fullerton JM, Weickert CS (2014) Elevated ErbB4 mRNA is related to interneuron deficit in prefrontal cortex in schizophrenia. J Psychiatr Res 53:125-132.

Kaar SJ, Angelescu I, Marques TR, Howes OD (2019) Pre-frontal parvalbumin interneurons in schizophrenia: a meta-analysis of post-mortem studies. J Neural Transm (Vienna) 126:1637-1651.

Kappeler C, Saillour Y, Baudoin JP, Tuy FP, Alvarez C, Houbron C, Gaspar P, Hamard G, Chelly J, Métin C, Francis F (2006) Branching and nucleokinesis defects in migrating interneurons derived from doublecortin knockout mice. Hum Mol Genet 15:1387-1400.

Kato M, Dobyns WB (2005) X-linked lissencephaly with abnormal genitalia as a tangential migration disorder causing intractable epilepsy: proposal for a new term, "interneuronopathy". J Child Neurol 20:392-397.

Kawaguchi Y, Kubota Y (1996) Physiological and morphological identification of somatostatinor vasoactive intestinal polypeptide-containing cells among GABAergic cell subtypes in rat frontal cortex. J Neurosci 16:2701-2715.

Kawaguchi Y, Kubota Y (1997) GABAergic cell subtypes and their synaptic connections in rat frontal cortex. Cereb Cortex 7:476-486.

Kawauchi T, Chihama K, Nabeshima Y, Hoshino M (2003) The in vivo roles of STEF/Tiam1, Rac1 and JNK in cortical neuronal migration. EMBO J 22:4190-4201.

Kelsom C, Lu W (2013) Development and specification of GABAergic cortical interneurons. Cell Biosci 3:19.

Kita T, Kita $\mathrm{H}$ (2012) The subthalamic nucleus is one of multiple innervation sites for long-range corticofugal axons: a single-axon tracing study in the rat. J Neurosci 32:5990-5999. 
Kneen R, Appleton RE (2006) Alternative approaches to conventional antiepileptic drugs in the management of paediatric epilepsy. Arch Dis Child 91:936-941.

Kohtz JD, Baker DP, Corte G, Fishell G (1998) Regionalization within the mammalian telencephalon is mediated by changes in responsiveness to Sonic Hedgehog. Development 125:5079-5089.

Krimer LS, Goldman-Rakic PS (2001) Prefrontal microcircuits: membrane properties and excitatory input of local, medium, and wide arbor interneurons. J Neurosci 21:37883796.

Kuan CY, Yang DD, Samanta Roy DR, Davis RJ, Rakic P, Flavell RA (1999) The Jnk1 and Jnk2 protein kinases are required for regional specific apoptosis during early brain development. Neuron 22:667-676.

Kwan KY, Sestan N, Anton ES (2012) Transcriptional co-regulation of neuronal migration and laminar identity in the neocortex. Development 139:1535-1546.

La Buissonnière-Ariza V, Wood JJ, Kendall PC, McBride NM, Cepeda SL, Small BJ, Lewin AB, Kerns C, Storch EA (2018) Presentation and Correlates of Hoarding Behaviors in Children with Autism Spectrum Disorders and Comorbid Anxiety or ObsessiveCompulsive Symptoms. J Autism Dev Disord 48:4167-4178.

Le Magueresse C, Monyer H (2013) GABAergic interneurons shape the functional maturation of the cortex. Neuron 77:388-405.

Lee J, Park S (2005) Working memory impairments in schizophrenia: a meta-analysis. J Abnorm Psychol 114:599-611.

Lee SH, Kwan AC, Zhang S, Phoumthipphavong V, Flannery JG, Masmanidis SC, Taniguchi H, Huang ZJ, Zhang F, Boyden ES, Deisseroth K, Dan Y (2012) Activation of specific interneurons improves V1 feature selectivity and visual perception. Nature 488:379-383.

Lewis DA, Cruz D, Eggan S, Erickson S (2004) Postnatal development of prefrontal inhibitory circuits and the pathophysiology of cognitive dysfunction in schizophrenia. Ann N Y Acad Sci 1021:64-76.

Lewis DA, Curley AA, Glausier JR, Volk DW (2012) Cortical parvalbumin interneurons and cognitive dysfunction in schizophrenia. Trends Neurosci 35:57-67.

Li G, Adesnik H, Li J, Long J, Nicoll RA, Rubenstein JL, Pleasure SJ (2008) Regional distribution of cortical interneurons and development of inhibitory tone are regulated by Cxcl12/Cxcr4 signaling. J Neurosci 28:1085-1098.

Liang F, Isackson PJ, Jones EG (1996) Stimulus-dependent, reciprocal up- and downregulation of glutamic acid decarboxylase and $\mathrm{Ca} 2+/$ calmodulin-dependent protein kinase II gene expression in rat cerebral cortex. Exp Brain Res 110:163-174.

Liapi A, Pritchett J, Jones O, Fujii N, Parnavelas JG, Nadarajah B (2008) Stromal-derived factor 1 signalling regulates radial and tangential migration in the developing cerebral cortex. Dev Neurosci 30:117-131.

Lin Y, Wang Y (2017) Neurostimulation as a promising epilepsy therapy. Epilepsia Open 2:371387.

Lu J, Tucciarone J, Lin Y, Huang ZJ (2014) Input-specific maturation of synaptic dynamics of parvalbumin interneurons in primary visual cortex. Proc Natl Acad Sci U S A 111:1689516900.

Luccardini C, Leclech C, Viou L, Rio JP, Métin C (2015) Cortical interneurons migrating on a pure substrate of $\mathrm{N}$-cadherin exhibit fast synchronous centrosomal and nuclear movements and reduced ciliogenesis. Front Cell Neurosci 9:286.

Luccardini C, Hennekinne L, Viou L, Yanagida M, Murakami F, Kessaris N, Ma X, Adelstein RS, Mège RM, Métin C (2013) N-cadherin sustains motility and polarity of future cortical interneurons during tangential migration. J Neurosci 33:18149-18160.

Lund JS, Lewis DA (1993) Local circuit neurons of developing and mature macaque prefrontal cortex: Golgi and immunocytochemical characteristics. J Comp Neurol 328:282-312. 
Lundorf MD, Buttenschøn HN, Foldager L, Blackwood DH, Muir WJ, Murray V, Pelosi AJ, Kruse TA, Ewald H, Mors $\mathrm{O}$ (2005) Mutational screening and association study of glutamate decarboxylase 1 as a candidate susceptibility gene for bipolar affective disorder and schizophrenia. Am J Med Genet B Neuropsychiatr Genet 135B:94-101.

Luo X, He W, Hu X, Yan R (2014) Reversible overexpression of bace1-cleaved neuregulin-1 Nterminal fragment induces schizophrenia-like phenotypes in mice. Biol Psychiatry 76:120-127.

Lysko DE, Putt M, Golden JA (2011) SDF1 regulates leading process branching and speed of migrating interneurons. J Neurosci 31:1739-1745.

Lysko DE, Putt M, Golden JA (2014) SDF1 reduces interneuron leading process branching through dual regulation of actin and microtubules. J Neurosci 34:4941-4962.

López-Bendito G, Luján R, Shigemoto R, Ganter P, Paulsen O, Molnár Z (2003) Blockade of $\mathrm{GABA}(\mathrm{B})$ receptors alters the tangential migration of cortical neurons. Cereb Cortex 13:932-942.

López-Bendito G, Sánchez-Alcañiz JA, Pla R, Borrell V, Picó E, Valdeolmillos M, Marín O (2008) Chemokine signaling controls intracortical migration and final distribution of GABAergic interneurons. J Neurosci 28:1613-1624.

Lübke J, Egger V, Sakmann B, Feldmeyer D (2000) Columnar organization of dendrites and axons of single and synaptically coupled excitatory spiny neurons in layer 4 of the rat barrel cortex. J Neurosci 20:5300-5311.

Ma T, Wang C, Wang L, Zhou X, Tian M, Zhang Q, Zhang Y, Li J, Liu Z, Cai Y, Liu F, You Y, Chen C, Campbell K, Song H, Ma L, Rubenstein JL, Yang Z (2013) Subcortical origins of human and monkey neocortical interneurons. Nat Neurosci 16:1588-1597.

Ma Y, Hu H, Berrebi AS, Mathers PH, Agmon A (2006) Distinct subtypes of somatostatincontaining neocortical interneurons revealed in transgenic mice. J Neurosci 26:50695082.

Manent JB, Wang Y, Chang Y, Paramasivam M, LoTurco JJ (2009) Dcx reexpression reduces subcortical band heterotopia and seizure threshold in an animal model of neuronal migration disorder. Nat Med 15:84-90.

Manning AM, Davis RJ (2003) Targeting JNK for therapeutic benefit: from junk to gold? Nat Rev Drug Discov 2:554-565.

Mardinly AR, Spiegel I, Patrizi A, Centofante E, Bazinet JE, Tzeng CP, Mandel-Brehm C, Harmin DA, Adesnik H, Fagiolini M, Greenberg ME (2016) Sensory experience regulates cortical inhibition by inducing IGF1 in VIP neurons. Nature 531:371-375.

Marillat V, Cases O, Nguyen-Ba-Charvet KT, Tessier-Lavigne M, Sotelo C, Chédotal A (2002) Spatiotemporal expression patterns of slit and robo genes in the rat brain. J Comp Neurol 442:130-155.

Martini FJ, Valdeolmillos M (2010) Actomyosin contraction at the cell rear drives nuclear translocation in migrating cortical interneurons. J Neurosci 30:8660-8670.

Marín O, Valiente M, Ge X, Tsai LH (2010) Guiding neuronal cell migrations. Cold Spring Harb Perspect Biol 2:a001834.

Marín O, Yaron A, Bagri A, Tessier-Lavigne M, Rubenstein JL (2001) Sorting of striatal and cortical interneurons regulated by semaphorin-neuropilin interactions. Science 293:872875.

Marín O, Plump AS, Flames N, Sánchez-Camacho C, Tessier-Lavigne M, Rubenstein JL (2003) Directional guidance of interneuron migration to the cerebral cortex relies on subcortical Slit1/2-independent repulsion and cortical attraction. Development 130:1889-1901.

Matsumoto M, Sawada M, García-González D, Herranz-Pérez V, Ogino T, Bang Nguyen H, Quynh Thai T, Narita K, Kumamoto N, Ugawa S, Saito Y, Takeda S, Kaneko N, Khodosevich K, Monyer H, García-Verdugo JM, Ohno N, Sawamoto K (2019) Dynamic 
Changes in Ultrastructure of the Primary Cilium in Migrating Neuroblasts in the Postnatal Brain. J Neurosci 39:9967-9988.

Matsumoto N, Leventer RJ, Kuc JA, Mewborn SK, Dudlicek LL, Ramocki MB, Pilz DT, Mills PL, Das S, Ross ME, Ledbetter DH, Dobyns WB (2001) Mutation analysis of the DCX gene and genotype/phenotype correlation in subcortical band heterotopia. Eur J Hum Genet 9:5-12.

McManus MF, Nasrallah IM, Pancoast MM, Wynshaw-Boris A, Golden JA (2004) Lis1 is necessary for normal non-radial migration of inhibitory interneurons. Am J Pathol 165:775-784.

Meechan DW, Rutz HL, Fralish MS, Maynard TM, Rothblat LA, LaMantia AS (2015) Cognitive ability is associated with altered medial frontal cortical circuits in the LgDel mouse model of 22q11.2DS. Cereb Cortex 25:1143-1151.

Mellios N, Huang HS, Baker SP, Galdzicka M, Ginns E, Akbarian S (2009) Molecular determinants of dysregulated GABAergic gene expression in the prefrontal cortex of subjects with schizophrenia. Biol Psychiatry 65:1006-1014.

Meyer HS, Schwarz D, Wimmer VC, Schmitt AC, Kerr JN, Sakmann B, Helmstaedter M (2011) Inhibitory interneurons in a cortical column form hot zones of inhibition in layers 2 and 5A. Proc Natl Acad Sci U S A 108:16807-16812.

Miyoshi G, Fishell G (2011) GABAergic interneuron lineages selectively sort into specific cortical layers during early postnatal development. Cereb Cortex 21:845-852.

Miyoshi G, Butt SJ, Takebayashi H, Fishell G (2007) Physiologically distinct temporal cohorts of cortical interneurons arise from telencephalic Olig2-expressing precursors. J Neurosci 27:7786-7798.

Miyoshi G, Hjerling-Leffler J, Karayannis T, Sousa VH, Butt SJ, Battiste J, Johnson JE, Machold RP, Fishell G (2010) Genetic fate mapping reveals that the caudal ganglionic eminence produces a large and diverse population of superficial cortical interneurons. J Neurosci 30:1582-1594.

Mizuno N, Kokubu H, Sato M, Nishimura A, Yamauchi J, Kurose H, Itoh H (2005) G proteincoupled receptor signaling through $\mathrm{Gq}$ and JNK negatively regulates neural progenitor cell migration. Proc Natl Acad Sci U S A 102:12365-12370.

Moya F, Valdeolmillos M (2004) Polarized increase of calcium and nucleokinesis in tangentially migrating neurons. Cereb Cortex 14:610-618.

Myers AK, Meechan DW, Adney DR, Tucker ES (2014) Cortical interneurons require Jnk1 to enter and navigate the developing cerebral cortex. J Neurosci 34:7787-7801.

Myers AK, Cunningham JG, Smith SE, Snow JP, Smoot CA, Tucker ES (2020) JNK signaling is required for proper tangential migration and laminar allocation of cortical interneurons. Development 147:Doi: 10.1242/dev.180646.

Métin C, Pedraza M (2014) Cilia: traffic directors along the road of cortical development. Neuroscientist 20:468-482.

Nadarajah B, Parnavelas JG (2002) Modes of neuronal migration in the developing cerebral cortex. Nat Rev Neurosci 3:423-432.

Nadarajah B, Alifragis P, Wong RO, Parnavelas JG (2003) Neuronal migration in the developing cerebral cortex: observations based on real-time imaging. Cereb Cortex 13:607-611.

Nelson SB, Valakh V (2015) Excitatory/Inhibitory Balance and Circuit Homeostasis in Autism Spectrum Disorders. Neuron 87:684-698.

Nguyen L, Humbert S, Saudou F, Chariot A (2010) Elongator - an emerging role in neurological disorders. Trends Mol Med 16:1-6.

Nishimura YV, Shikanai M, Hoshino M, Ohshima T, Nabeshima Y, Mizutani K, Nagata K, Nakajima K, Kawauchi T (2014) Cdk5 and its substrates, Dcx and p27kip1, regulate cytoplasmic dilation formation and nuclear elongation in migrating neurons.

Development 141:3540-3550. 
Noebels JL (2003) The biology of epilepsy genes. Annu Rev Neurosci 26:599-625.

Nóbrega-Pereira S, Kessaris N, Du T, Kimura S, Anderson SA, Marín O (2008) Postmitotic Nkx2-1 controls the migration of telencephalic interneurons by direct repression of guidance receptors. Neuron 59:733-745.

Oliva AA, Jiang M, Lam T, Smith KL, Swann JW (2000) Novel hippocampal interneuronal subtypes identified using transgenic mice that express green fluorescent protein in GABAergic interneurons. J Neurosci 20:3354-3368.

Ongür D, Prescot AP, McCarthy J, Cohen BM, Renshaw PF (2010) Elevated gammaaminobutyric acid levels in chronic schizophrenia. Biol Psychiatry 68:667-670.

Otis EM, Brent R (1954) Equivalent ages in mouse and human embryos. Anat Rec 120:33-63.

Pancoast M, Dobyns W, Golden JA (2005) Interneuron deficits in patients with the Miller-Dieker syndrome. Acta Neuropathol 109:400-404.

Park SM, Jang HJ, Lee JH (2019) Roles of Primary Cilia in the Developing Brain. Front Cell Neurosci 13:218.

Peyre E, Silva CG, Nguyen L (2015) Crosstalk between intracellular and extracellular signals regulating interneuron production, migration and integration into the cortex. Front Cell Neurosci 9:129.

Peñagarikano O, Abrahams BS, Herman El, Winden KD, Gdalyahu A, Dong H, Sonnenblick LI, Gruver R, Almajano J, Bragin A, Golshani P, Trachtenberg JT, Peles E, Geschwind DH (2011) Absence of CNTNAP2 leads to epilepsy, neuronal migration abnormalities, and core autism-related deficits. Cell 147:235-246.

Pillai-Nair N, Panicker AK, Rodriguiz RM, Gilmore KL, Demyanenko GP, Huang JZ, Wetsel WC, Maness PF (2005) Neural cell adhesion molecule-secreting transgenic mice display abnormalities in GABAergic interneurons and alterations in behavior. J Neurosci 25:4659-4671.

Pleasure SJ, Anderson S, Hevner R, Bagri A, Marin O, Lowenstein DH, Rubenstein JL (2000) Cell migration from the ganglionic eminences is required for the development of hippocampal GABAergic interneurons. Neuron 28:727-740.

Polleux F, Whitford KL, Dijkhuizen PA, Vitalis T, Ghosh A (2002) Control of cortical interneuron migration by neurotrophins and PI3-kinase signaling. Development 129:3147-3160.

Poluch S, Drian MJ, Durand M, Astier C, Benyamin Y, König N (2001) AMPA receptor activation leads to neurite retraction in tangentially migrating neurons in the intermediate zone of the embryonic rat neocortex. J Neurosci Res 63:35-44.

Potter GB, Petryniak MA, Shevchenko E, McKinsey GL, Ekker M, Rubenstein JL (2009) Generation of Cre-transgenic mice using DIx1/DIx2 enhancers and their characterization in GABAergic interneurons. Mol Cell Neurosci 40:167-186.

Priya R, Paredes MF, Karayannis T, Yusuf N, Liu X, Jaglin X, Graef I, Alvarez-Buylla A, Fishell G (2018) Activity Regulates Cell Death within Cortical Interneurons through a Calcineurin-Dependent Mechanism. Cell Rep 22:1695-1709.

Puts NAJ, Wodka EL, Harris AD, Crocetti D, Tommerdahl M, Mostofsky SH, Edden RAE (2017) Reduced GABA and altered somatosensory function in children with autism spectrum disorder. Autism Res 10:608-619.

Rakic $P$ (1972) Mode of cell migration to the superficial layers of fetal monkey neocortex. J Comp Neurol 145:61-83.

Rakic P (1988) Specification of cerebral cortical areas. Science 241:170-176.

Raymond AA, Fish DR, Sisodiya SM, Alsanjari N, Stevens JM, Shorvon SD (1995)

Abnormalities of gyration, heterotopias, tuberous sclerosis, focal cortical dysplasia, microdysgenesis, dysembryoplastic neuroepithelial tumour and dysgenesis of the archicortex in epilepsy. Clinical, EEG and neuroimaging features in 100 adult patients. Brain 118 ( Pt 3):629-660. 
Regier DA, Narrow WE, Rae DS, Manderscheid RW, Locke BZ, Goodwin FK (1993) The de facto US mental and addictive disorders service system. Epidemiologic catchment area prospective 1-year prevalence rates of disorders and services. Arch Gen Psychiatry 50:85-94.

Reiner A, Jiao Y, Del Mar N, Laverghetta AV, Lei WL (2003) Differential morphology of pyramidal tract-type and intratelencephalically projecting-type corticostriatal neurons and their intrastriatal terminals in rats. J Comp Neurol 457:420-440.

Reiner O, Carrozzo R, Shen Y, Wehnert M, Faustinella F, Dobyns WB, Caskey CT, Ledbetter $\mathrm{DH}$ (1993) Isolation of a Miller-Dieker lissencephaly gene containing $\mathrm{G}$ protein betasubunit-like repeats. Nature 364:717-721.

Reiner O, Albrecht U, Gordon M, Chianese KA, Wong C, Gal-Gerber O, Sapir T, Siracusa LD, Buchberg AM, Caskey CT (1995) Lissencephaly gene (LIS1) expression in the CNS suggests a role in neuronal migration. J Neurosci 15:3730-3738.

Reyes A, Sakmann B (1999) Developmental switch in the short-term modification of unitary EPSPs evoked in layer $2 / 3$ and layer 5 pyramidal neurons of rat neocortex. J Neurosci 19:3827-3835.

Rivera C, Voipio J, Payne JA, Ruusuvuori E, Lahtinen H, Lamsa K, Pirvola U, Saarma M, Kaila $\mathrm{K}$ (1999) The $\mathrm{K}+/ \mathrm{Cl}$ - co-transporter KCC2 renders GABA hyperpolarizing during neuronal maturation. Nature 397:251-255.

Robinson PD, Schutz CK, Macciardi F, White BN, Holden JJ (2001) Genetically determined low maternal serum dopamine beta-hydroxylase levels and the etiology of autism spectrum disorders. Am J Med Genet 100:30-36.

Rossignol E (2011) Genetics and function of neocortical GABAergic interneurons in neurodevelopmental disorders. Neural Plast 2011:649325.

Rudy B, Fishell G, Lee S, Hjerling-Leffler J (2011) Three groups of interneurons account for nearly $100 \%$ of neocortical GABAergic neurons. Dev Neurobiol 71:45-61.

Sabapathy K, Jochum W, Hochedlinger K, Chang L, Karin M, Wagner EF (1999) Defective neural tube morphogenesis and altered apoptosis in the absence of both JNK1 and JNK2. Mech Dev 89:115-124.

Saiki A, Sakai Y, Fukabori R, Soma S, Yoshida J, Kawabata M, Yawo H, Kobayashi K, Kimura M, Isomura Y (2018) In Vivo Spiking Dynamics of Intra- and Extratelencephalic Projection Neurons in Rat Motor Cortex. Cereb Cortex 28:1024-1038.

Santiago A, Erickson CA (2002) Ephrin-B ligands play a dual role in the control of neural crest cell migration. Development 129:3621-3632.

Sarkisian MR, Guadiana SM (2015) Influences of primary cilia on cortical morphogenesis and neuronal subtype maturation. Neuroscientist 21:136-151.

Schaar BT, McConnell SK (2005) Cytoskeletal coordination during neuronal migration. Proc Natl Acad Sci U S A 102:13652-13657.

Scheyltjens I, Arckens L (2016) The Current Status of Somatostatin-Interneurons in Inhibitory Control of Brain Function and Plasticity. Neural Plast 2016:8723623.

Schubert D, Kötter R, Zilles K, Luhmann HJ, Staiger JF (2003) Cell type-specific circuits of cortical layer IV spiny neurons. J Neurosci 23:2961-2970.

Silva CG, Peyre E, Adhikari MH, Tielens S, Tanco S, Van Damme P, Magno L, Krusy N, Agirman G, Magiera MM, Kessaris N, Malgrange B, Andrieux A, Janke C, Nguyen L (2018) Cell-Intrinsic Control of Interneuron Migration Drives Cortical Morphogenesis. Cell 172:1063-1078.e1019.

Singh A, Trevick S (2016) The Epidemiology of Global Epilepsy. Neurol Clin 34:837-847.

Smart IH (1976) A pilot study of cell production by the ganglionic eminences of the developing mouse brain. J Anat 121:71-84.

Snijders TM, Milivojevic B, Kemner C (2013) Atypical excitation-inhibition balance in autism captured by the gamma response to contextual modulation. Neuroimage Clin 3:65-72. 
Sohal VS, Zhang F, Yizhar O, Deisseroth K (2009) Parvalbumin neurons and gamma rhythms enhance cortical circuit performance. Nature 459:698-702.

Solecki DJ, Trivedi N, Govek EE, Kerekes RA, Gleason SS, Hatten ME (2009) Myosin II motors and F-actin dynamics drive the coordinated movement of the centrosome and soma during CNS glial-guided neuronal migration. Neuron 63:63-80.

Somogyi P, Freund TF, Cowey A (1982) The axo-axonic interneuron in the cerebral cortex of the rat, cat and monkey. Neuroscience 7:2577-2607.

Southwell DG, Paredes MF, Galvao RP, Jones DL, Froemke RC, Sebe JY, Alfaro-Cervello C, Tang Y, Garcia-Verdugo JM, Rubenstein JL, Baraban SC, Alvarez-Buylla A (2012) Intrinsically determined cell death of developing cortical interneurons. Nature 491:109113.

Spillane M, Ketschek A, Jones SL, Korobova F, Marsick B, Lanier L, Svitkina T, Gallo G (2011) The actin nucleating Arp2/3 complex contributes to the formation of axonal filopodia and branches through the regulation of actin patch precursors to filopodia. Dev Neurobiol 71:747-758.

Spreafico R, Battaglia G, Arcelli P, Andermann F, Dubeau F, Palmini A, Olivier A, Villemure JG, Tampieri D, Avanzini G, Avoli M (1998) Cortical dysplasia: an immunocytochemical study of three patients. Neurology 50:27-36.

Stumm R, Kolodziej A, Schulz S, Kohtz JD, Höllt V (2007) Patterns of SDF-1alpha and SDF1gamma mRNAs, migration pathways, and phenotypes of CXCR4-expressing neurons in the developing rat telencephalon. J Comp Neurol 502:382-399.

Su P, Lai TKY, Lee FHF, Abela AR, Fletcher PJ, Liu F (2019) Disruption of SynGAP-dopamine D1 receptor complexes alters actin and microtubule dynamics and impairs GABAergic interneuron migration. Sci Signal 12.

Talebian A, Britton R, Ammanuel S, Bepari A, Sprouse F, Birnbaum SG, Szabó G, Tamamaki N, Gibson J, Henkemeyer M (2017) Autonomous and non-autonomous roles for ephrin$B$ in interneuron migration. Dev Biol 431:179-193.

Tamás G, Buhl EH, Lörincz A, Somogyi P (2000) Proximally targeted GABAergic synapses and gap junctions synchronize cortical interneurons. Nat Neurosci 3:366-371.

Tan SS, Kalloniatis M, Sturm K, Tam PP, Reese BE, Faulkner-Jones B (1998) Separate progenitors for radial and tangential cell dispersion during development of the cerebral neocortex. Neuron 21:295-304.

Tanaka T, Serneo FF, Higgins C, Gambello MJ, Wynshaw-Boris A, Gleeson JG (2004) Lis1 and doublecortin function with dynein to mediate coupling of the nucleus to the centrosome in neuronal migration. J Cell Biol 165:709-721.

Taniguchi H, Lu J, Huang ZJ (2013) The spatial and temporal origin of chandelier cells in mouse neocortex. Science 339:70-74.

Tielens S, Huysseune S, Godin JD, Chariot A, Malgrange B, Nguyen L (2016) Elongator controls cortical interneuron migration by regulating actomyosin dynamics. Cell Res 26:1131-1148.

Tiveron MC, Rossel M, Moepps B, Zhang YL, Seidenfaden R, Favor J, König N, Cremer H (2006) Molecular interaction between projection neuron precursors and invading interneurons via stromal-derived factor 1 (CXCL12)/CXCR4 signaling in the cortical subventricular zone/intermediate zone. J Neurosci 26:13273-13278.

Toriyama M, Mizuno N, Fukami T, Iguchi T, Tago K, Itoh H (2012) Phosphorylation of doublecortin by protein kinase A orchestrates microtubule and actin dynamics to promote neuronal progenitor cell migration. J Biol Chem 287:12691-12702.

Treiman DM (2001) GABAergic mechanisms in epilepsy. Epilepsia 42 Suppl 3:8-12.

Tsai LH, Gleeson JG (2005) Nucleokinesis in neuronal migration. Neuron 46:383-388.

Tsai P, Sahin M (2011) Mechanisms of neurocognitive dysfunction and therapeutic considerations in tuberous sclerosis complex. Curr Opin Neurol 24:106-113. 
Ueta Y, Otsuka T, Morishima M, Ushimaru M, Kawaguchi Y (2014) Multiple layer 5 pyramidal cell subtypes relay cortical feedback from secondary to primary motor areas in rats. Cereb Cortex 24:2362-2376.

Umeshima H, Hirano T, Kengaku M (2007) Microtubule-based nuclear movement occurs independently of centrosome positioning in migrating neurons. Proc Natl Acad Sci U S A 104:16182-16187.

Valcanis $\mathrm{H}$, Tan SS (2003) Layer specification of transplanted interneurons in developing mouse neocortex. J Neurosci 23:5113-5122.

Valiente M, Martini FJ (2009) Migration of cortical interneurons relies on branched leading process dynamics. Cell Adh Migr 3:278-280.

Wang DD, Kriegstein AR (2008) GABA regulates excitatory synapse formation in the neocortex via NMDA receptor activation. J Neurosci 28:5547-5558.

Wang Y, Toledo-Rodriguez M, Gupta A, Wu C, Silberberg G, Luo J, Markram H (2004) Anatomical, physiological and molecular properties of Martinotti cells in the somatosensory cortex of the juvenile rat. J Physiol 561:65-90.

Wang Y, Li G, Stanco A, Long JE, Crawford D, Potter GB, Pleasure SJ, Behrens T, Rubenstein JL (2011) CXCR4 and CXCR7 have distinct functions in regulating interneuron migration. Neuron 69:61-76.

Westerlund N, Zdrojewska J, Padzik A, Komulainen E, Björkblom B, Rannikko E, Tararuk T, Garcia-Frigola C, Sandholm J, Nguyen L, Kallunki T, Courtney MJ, Coffey ET (2011) Phosphorylation of SCG10/stathmin-2 determines multipolar stage exit and neuronal migration rate. Nat Neurosci 14:305-313.

Weston CR, Davis RJ (2007) The JNK signal transduction pathway. Curr Opin Cell Biol 19:142149.

Wichterle H, Turnbull DH, Nery S, Fishell G, Alvarez-Buylla A (2001) In utero fate mapping reveals distinct migratory pathways and fates of neurons born in the mammalian basal forebrain. Development 128:3759-3771.

Wonders CP, Taylor L, Welagen J, Mbata IC, Xiang JZ, Anderson SA (2008) A spatial bias for the origins of interneuron subgroups within the medial ganglionic eminence. Dev Biol 314:127-136.

Wurzman R, Forcelli PA, Griffey CJ, Kromer LF (2015) Repetitive grooming and sensorimotor abnormalities in an ephrin-A knockout model for Autism Spectrum Disorders. Behav Brain Res 278:115-128.

Xu H, Jeong HY, Tremblay R, Rudy B (2013) Neocortical somatostatin-expressing GABAergic interneurons disinhibit the thalamorecipient layer 4. Neuron 77:155-167.

Xu Q, Wonders CP, Anderson SA (2005) Sonic hedgehog maintains the identity of cortical interneuron progenitors in the ventral telencephalon. Development 132:4987-4998.

Xu Q, Tam M, Anderson SA (2008) Fate mapping Nkx2.1-lineage cells in the mouse telencephalon. J Comp Neurol 506:16-29.

Xu Q, Cobos I, De La Cruz E, Rubenstein JL, Anderson SA (2004) Origins of cortical interneuron subtypes. J Neurosci 24:2612-2622.

Xu Q, Guo L, Moore H, Waclaw RR, Campbell K, Anderson SA (2010) Sonic hedgehog signaling confers ventral telencephalic progenitors with distinct cortical interneuron fates. Neuron 65:328-340.

Xu X, Roby KD, Callaway EM (2006) Mouse cortical inhibitory neuron type that coexpresses somatostatin and calretinin. J Comp Neurol 499:144-160.

Yamasaki T, Kawasaki H, Nishina H (2012) Diverse Roles of JNK and MKK Pathways in the Brain. J Signal Transduct 2012:459265.

Yanagida M, Miyoshi R, Toyokuni R, Zhu Y, Murakami F (2012) Dynamics of the leading process, nucleus, and Golgi apparatus of migrating cortical interneurons in living mouse embryos. Proc Natl Acad Sci U S A 109:16737-16742. 
Yang DD, Kuan CY, Whitmarsh AJ, Rincón M, Zheng TS, Davis RJ, Rakic P, Flavell RA (1997) Absence of excitotoxicity-induced apoptosis in the hippocampus of mice lacking the Jnk3 gene. Nature 389:865-870.

Yau HJ, Wang HF, Lai C, Liu FC (2003) Neural development of the neuregulin receptor ErbB4 in the cerebral cortex and the hippocampus: preferential expression by interneurons tangentially migrating from the ganglionic eminences. Cereb Cortex 13:252-264.

Yin DM, Chen YJ, Lu YS, Bean JC, Sathyamurthy A, Shen C, Liu X, Lin TW, Smith CA, Xiong WC, Mei L (2013) Reversal of behavioral deficits and synaptic dysfunction in mice overexpressing neuregulin 1. Neuron 78:644-657.

Yoo H (2015) Genetics of Autism Spectrum Disorder: Current Status and Possible Clinical Applications. Exp Neurobiol 24:257-272.

Yoon JH, Maddock RJ, Rokem A, Silver MA, Minzenberg MJ, Ragland JD, Carter CS (2010) GABA concentration is reduced in visual cortex in schizophrenia and correlates with orientation-specific surround suppression. J Neurosci 30:3777-3781.

Yozu M, Tabata H, Nakajima K (2005) The caudal migratory stream: a novel migratory stream of interneurons derived from the caudal ganglionic eminence in the developing mouse forebrain. J Neurosci 25:7268-7277.

Yozu M, Tabata H, Konig N, Nakajima K (2008) Migratory behavior of presumptive interneurons is affected by AMPA receptor activation in slice cultures of embryonic mouse neocortex. Dev Neurosci 30:105-116.

Zecevic N, Hu F, Jakovcevski I (2011) Interneurons in the developing human neocortex. Dev Neurobiol 71:18-33.

Zhang F, Yu J, Yang T, Xu D, Chi Z, Xia Y, Xu Z (2016) A Novel c-Jun N-terminal Kinase (JNK) Signaling Complex Involved in Neuronal Migration during Brain Development. J Biol Chem 291:11466-11475.

Zhu Q, Naegele JR, Chung S (2018) Cortical GABAergic Interneuron/Progenitor Transplantation as a Novel Therapy for Intractable Epilepsy. Front Cell Neurosci 12:167.

Zimmer G, Garcez P, Rudolph J, Niehage R, Weth F, Lent R, Bolz J (2008) Ephrin-A5 acts as a repulsive cue for migrating cortical interneurons. Eur $\mathrm{J}$ Neurosci 28:62-73. 


\section{Chapter 2: JNK signaling regulates cellular mechanics of cortical interneuron migration}

Skye E. Smith ${ }^{1,2,3}$, Nicholas K. Coker ${ }^{1}$, and Eric S. Tucker ${ }^{1,3}$

${ }^{1}$ Department of Neuroscience, ${ }^{2}$ Biochemistry and Molecular Biology Graduate Program,

${ }^{3}$ Rockefeller Neuroscience Institute, West Virginia University School of Medicine, Morgantown, WV 26506.

Correspondence: etucker@hsc.wvu.edu

Abbreviated title: Interneuron migratory dynamics require JNK

Key Words: GABAergic interneuron; development; forebrain; intracellular signaling; neuronal migration; live imaging

Published in eNeuro, July $31^{\text {st }}, 2020$

https://doi.org/10.1523/ENEURO.0132-20.2020 


\section{ABSTRACT}

Aberrant migration of inhibitory interneurons can alter the formation of cortical circuitry and lead to severe neurological disorders including epilepsy, autism, and schizophrenia. However, mechanisms involved in directing the migration of interneurons remain incompletely understood. Using a mouse model, we performed live-cell confocal microscopy to explore the mechanisms by which the c-Jun $\mathrm{NH}_{2}$-terminal kinase (JNK) pathway coordinates leading process branching and nucleokinesis, two cell biological processes that are essential for the guided migration of cortical interneurons. Pharmacological inhibition of JNK signaling disrupts the kinetics of leading process branching, rate and amplitude of nucleokinesis, and leads to the rearward mislocalization of the centrosome and primary cilium to the trailing process. Genetic loss of Jnk from interneurons also impairs leading process branching and nucleokinesis, suggesting that important mechanics of interneuron migration depend on the intrinsic activity of JNK. These findings highlight key roles for JNK signaling in leading process branching, nucleokinesis, and the trafficking of centrosomes and cilia during interneuron migration, and further implicates JNK signaling as an important mediator of cortical development.

\section{SIGIFICANCE STATEMENT}

Unlike their excitatory counterparts, inhibitory interneurons are generated in the ventral forebrain and migrate long distances to reach the cerebral cortex. Although many factors influencing the guided migration of cortical interneurons have been elucidated, the role of intracellular signaling pathways in interneuron migration have remained elusive. Here, we show with single cell resolution that the c-Jun $\mathrm{NH}_{2}$-terminal kinase (JNK) signaling pathway coordinates multiple cellular mechanisms that direct the migration of cortical interneurons, including leading process branching, nucleokinesis, and the subcellular positioning of the centrosome-cilia complex. Furthermore, we show that cortical interneuron migration depends on the intrinsic activity of JNK. These results provide new insight into the cellular and molecular mechanisms controlling cortical interneuron migration in normal and pathologic brain development. 


\section{INTRODUCTION}

During embryonic development, cortical interneurons are born in the medial and caudal ganglionic eminences (MGE and CGE) of the ventral forebrain and then migrate long distances to reach the place of their terminal differentiation in the overlying cerebral cortex (Wichterle et al., 1999; Nery et al., 2002; Xu et al., 2004; Miyoshi et al., 2010). While navigating their environments, cortical interneurons must integrate extracellular guidance cues with intracellular machinery in order to reach the cortex, travel in tangentially oriented migratory streams, and disembark from streams at the correct time and place to properly infiltrate the cortical plate. Two cellular mechanisms that enable interneurons to make these complex migratory decisions are leading process branching, where cortical interneurons dynamically remodel their leading processes to sense and respond to extracellular guidance cues, and nucleokinesis, where interneurons propel their cell bodies forward in the selected direction of migration (Polleux et al., 2002; Ang et al., 2003; Nadarajah et al., 2003; Moya and Valdeolmillos, 2004; Bellion et al., 2005). Moreover, proper positioning and signaling from two subcellular organelles, the centrosome and primary cilium, have been implicated in the guided migration of cortical interneurons (Higginbotham et al., 2012; Yanagida et al., 2012; Luccardini et al., 2013; Luccardini et al., 2015). Failure to coordinate these cellular and subcellular events can alter cortical interneuron migration and impair the development of cortical circuitry, which may underlie severe neurological disorders such as autism spectrum disorder, schizophrenia, and epilepsy (Kato and Dobyns, 2005; Hildebrandt et al., 2011; Meechan et al., 2012; Volk et al., 2015). While progress has been made on elucidating the complex molecular mechanisms underlying nucleokinesis and leading process branching (Tsai and Gleeson, 2005; Baudoin et al., 2012; Godin et al., 2012; Silva et al., 2018), the intracellular signaling pathways that regulate these cellular mechanisms remain largely unknown. 
The c-Jun $\mathrm{NH}_{2}$-terminal kinases (JNKs) are evolutionarily conserved members of the mitogenactivated protein kinase (MAPK) super-family (Davis, 2000; Chang and Karin, 2001). The JNK proteins are encoded by three genes, Jnk1 (Mapk8), Jnk2 (Mapk9), and Jnk3 (Mapk10). JNKs phosphorylate numerous substrates in response to extracellular stimuli to mediate physiological processes including cellular proliferation, apoptosis, differentiation, and migration (Davis, 2000).

JNK signaling has been implicated in multiple aspects of brain development, including neuronal migration in the cerebral cortex (Hirai et al., 2006; Wang et al., 2007; Westerlund et al., 2011; Yamasaki et al., 2011; Myers et al., 2014; Zhang et al., 2016; Myers et al., 2020). Indeed, our laboratory previously demonstrated that JNK function is required for the proper timing of interneuron entry into the cerebral cortex (Myers et al., 2014), as well as the tangential progression of interneurons in migratory streams (Myers et al., 2020). However, these previous studies did not assess the influence of JNK on the cellular mechanics of individual cortical interneurons during migration.

In the current study, we extend upon those findings by using a combination of pharmacological and genetic manipulations in an MGE explant cortical cell co-culture assay to demonstrate that interneurons require JNK-signaling to regulate leading process branching and nucleokinesis. JNK-inhibited MGE interneurons dramatically slow their migration while displaying more variable speeds, and exhibit decreased migratory displacement. Concomitantly, JNK-inhibited interneurons display significant defects in leading process branching with decreased growth cone splitting frequency and interstitial side branch duration, as well as disrupted nucleokinesis and swelling dynamics. Genetic ablation of Jnk from MGE interneurons results in leading process branching defects, which were similar to pharmacologic inhibition, and nucleokinesis defects, which were distinct. Nevertheless, migratory deficits resulting from interneuron-specific loss of JNK function indicates that interneurons have a cell-intrinsic requirement for JNK signaling during migration. In addition, we discovered a novel role for JNK signaling in the 
dynamic localization of the centrosome and primary cilium in migrating interneurons.

Surprisingly, the centrosomes and the primary cilia of JNK-inhibited interneurons aberrantly localized to the cell body or trailing process, regardless of whether the leading process contained a swelling. These findings implicate the JNK pathway as a key intracellular mediator of leading process branching, nucleokinesis, and organelle dynamics in migrating MGE interneurons.

\section{RESULTS}

\section{Pharmacological inhibition of JNK signaling disrupts MGE interneuron migration in vitro}

In order to determine the cellular mechanisms by which JNK signaling influences cortical interneuron migration, we examined the migratory dynamics of individual cortical interneurons grown from medial ganglionic eminence (MGE) explants in control or JNK-inhibited conditions. MGE explants from embryonic day 14.5 (E14.5) DIx5/6-Cre-IRES-EGFP (DIx5/6-CIE) positive embryos were cultured on top of a DIx5/6-CIE negative (wild type, WT) monolayer of dissociated cortical cells for 24 hours (Fig. 2.1A). We then treated cultures with SP600125, a pan inhibitor of JNK signaling (Bennett et al., 2001), or vehicle control and immediately performed live-cell imaging for 12 hours (Fig. 2.1A). We treated cultures with $20 \mu \mathrm{M}$ SP600125 since this concentration of inhibitor caused significant deficiencies in interneuron migration without altering cell viability in previous dosage series and live imaging experiments (Myers et al., 2014; Myers et al., 2020). At the beginning of the imaging period (Time 0), the field of view was placed at the distal edge of interneuron outgrowth (Fig. 2.1B-C).

Many control interneurons migrated into the field of view by 12 hours of imaging (Fig. 2.1B; Movie 2.1), but SP600125-treated cells failed to progress through the frame and appeared to move slower (Fig. 2.1C; Movie 2.2). To assess potential differences in their migratory dynamics, we tracked individual cells in order to evaluate how JNK inhibition affects interneuron migration 
on a single cell level (representative cell tracks in Fig. 2.1B, C). The migratory speeds of JNKinhibited interneurons were significantly slower than controls, including the maximum (values = mean \pm s.e.m.; control:132.28 $\pm 4.25 \mu \mathrm{m} /$ hour; SP600125: 78.02 $\pm 1.69 \mu \mathrm{m} / \mathrm{hour} ; \mathrm{p}=1.68 \times 10^{-10}$ ), mean (control: $54.62 \pm 2.54 \mu \mathrm{m} /$ hour; SP600125: $26.48 \pm 0.94 \mu \mathrm{m} /$ hour; $p=1.68 \times 10^{-9}$ ), and minimum (control: $6.64 \pm 0.91 \mu \mathrm{m} /$ hour; SP600125: $1.96 \pm 0.21 \mu \mathrm{m} /$ hour; $p=7.17 \times 10^{-5}$ ) migratory speeds (Fig. 2.1D). While JNK-inhibited interneurons migrated slower, speed variation, which is the ratio of track standard deviation to track mean speed was significantly increased in SP600125-treated conditions (control: $0.62 \pm 0.02 ;$ SP600125 0.76 $\pm-0.02 ; p=0.00019 ;$ Fig. $2.1 \mathrm{E}$ ). Due to the decrease in migratory speed, the migratory displacement of SP600125-treated interneurons was also significantly reduced compared to control interneurons (control: 156.93 $\pm 10.37 \mu \mathrm{m}$; SP600125: $75.76 \pm 4.04 \mu \mathrm{m} ; \mathrm{p}=4.73 \times 10^{-7} ; \mathrm{Fig} .2 .1 \mathrm{~F}$ ). Despite these changes in overall migratory dynamics, JNK-inhibited interneurons displayed no change in their migratory straightness (control: $0.71 \pm 0.03 ;$ SP600125: 0.68 $\pm 0.02 ; p=0.45 ;$ Fig. 2.1G). Collectively, these data demonstrate that JNK inhibition impairs the migratory speed and displacement of MGE interneurons in an MGE explant cortical cell co-culture assay, confirming previous results in ex vivo slice culture experiments (Myers et al., 2020).

\section{JNK signaling regulates branching dynamics of migrating MGE interneurons}

Migrating cortical interneurons repeatedly extend and retract leading process branches to sense extracellular guidance cues and establish a forward direction of movement (Polleux et al., 2002; Bellion et al., 2005; Yanagida et al., 2012). Leading process branching normally occurs through two mechanisms: growth cone splitting at the distal end of the leading process, and formation of interstitial side branches along the length of the leading process (Martini et al., 2009; Lysko et al., 2011). 
To determine if JNK inhibition effected leading process morphology, we first measured the length of leading processes over time from live-imaged $D / \times 5 / 6-C I E$ positive MGE interneurons. Maximum (control: 84.96 $\pm 4.45 \mu \mathrm{m}$; SP600125: 85.14 $\pm 4.02 \mu \mathrm{m} / \mathrm{hour} ; \mathrm{p}=0.977$ ), mean (control: 60.39 $\pm 2.88 \mu \mathrm{m} ; \mathrm{SP} 600125: 60.14 \pm 2.56 \mu \mathrm{m} ; \mathrm{p}=0.947$ ), or minimum lengths (control:

37.40 $\pm 2.47 \mu \mathrm{m} ; \mathrm{SP} 600125: 37.81 \pm 2.72 \mu \mathrm{m} ; \mathrm{p}=0.912$ ) of leading processes of SP600125-treated interneurons remained unchanged (Fig. 2.2C). However, when we analyzed the dynamic behavior of leading processes, significant differences were found between interneurons in control and SP600125-treated conditions (Fig. 2.2; Movies 2.3-4). In control conditions, migrating MGE interneurons show frequent initiation of new branches from growth cone splitting at the tip of their leading processes (Fig. 2.2A; Movie 2.3, Clip 1). In JNK-inhibited conditions, interneurons still underwent growth cone splitting, but the frequency appeared to be reduced (Fig. 2.2B; Movie 2.4, Clip1). When we measured the rate of growth cone splitting, JNK-inhibited interneurons had a statistically significant reduction compared to controls (control: $1.83 \pm 0.17$ splits/hour; SP600125 1.15 \pm 0.20 splits/hour; p=0.01; Fig. 2.2D). In addition to branching from their growth cones, MGE interneurons extend and retract interstitial side branches from their leading processes. To determine whether JNK inhibition impacted the frequency and duration of interstitial branching, we measured the rate in which new side branches formed and determined the amount of time each newly generated branch was retained. Both control and SP600125treated interneurons extended side branches at similar frequencies (control: $1.18 \pm 0.19$ branches/hour; SP600125:1.22 \pm 0.17 branches/hour; p=0.89; Fig. 2.2E-G; Movies 2.3-4, Clip 2). However, the duration of time in which de novo side branches persisted was significantly reduced in interneurons treated with JNK inhibitor (control: 28.77 $\pm 2.53 \mathrm{~min}$; SP600125: 21.19 \pm 1.76 min; $p=0.02$; Fig. $2.2 \mathrm{H}$ ).

Here, we found that initiation of branching from growth cone splitting was significantly reduced during JNK inhibition. Also, we found that JNK-inhibited interneurons formed side branches at 
similar rates to controls, but these branches were shorter-lived. Our data indicate that JNK influences branching dynamics of migratory MGE interneurons by regulating the rate of growth cone splitting, and by promoting the stability of newly formed side branches.

\section{Acute loss of JNK signaling impairs nucleokinesis and cytoplasmic swelling dynamics of migrating MGE interneurons}

Since pharmacological inhibition of JNK signaling disrupted the overall migratory properties and leading process branching dynamics of MGE interneurons, we further examined the role for JNK in nucleokinesis, an obligate cell biological process in neuronal migration (Bellion et al., 2005; Yanagida et al., 2012). To closely examine the movement of interneuron cell bodies during migration, we imaged cultures at higher spatial and temporal resolution and analyzed the effect of JNK inhibition on nucleokinesis (Fig. 2.3). Time-lapse recordings show that under control conditions, a single cycle of nucleokinesis starts with the extension of a cytoplasmic swelling into the leading process and ends with the translocation of the cell body into the swelling (Fig. 2.3A; Movie 2.5, Clip 1). Although JNK-inhibited interneurons still engaged in nucleokinesis, the distance of individual nucleokinesis events were disrupted (Fig. 2.3B; Fig. 2.3H; Movie 2.5, Clip 2). When we measured the mean distance that cell bodies translocated over time (Fig. 2.3C diagram), JNK-inhibited interneurons advanced significantly shorter distances compared to control cells (control: $14.87 \pm 0.32 \mu \mathrm{m}$; SP600125: $8.50 \pm 0.39 \mu \mathrm{m} ; \mathrm{p}=2.36 \times 10^{-10}$; Fig. $2.3 \mathrm{C}$ ). Thus, while cell bodies of JNK-inhibited interneurons still translocated forward into the leading process, the distance of their movement was reduced.

Since cortical interneurons appeared to have slower kinetics of nucleokinesis under JNK inhibition (Fig. 2.3B), we measured the rate of nucleokinesis in control and JNK-inhibited conditions. Upon treatment with SP600125, interneurons completed significantly fewer translocation events per hour (control: $2.50 \pm 0.06$ events/hour; SP600125: $1.73 \pm 0.06$ 
events/hour; $p=1.92 \times 10^{-8}$; Fig. 2.3D). Along with this, interneurons in JNK-inhibited cultures displayed longer pauses between the initiation of nucleokinesis events (control: $31.21 \pm 1.05 \mathrm{~min}$; SP600125: 40.71 $\pm 0.58 \mathrm{~min} ; \mathrm{p}=1.45 \times 10^{-7}$; Fig. 2.3E). Because nuclear translocation is preceded by swelling extension, we measured the average distance from the soma to the swelling before translocation (Fig. 2.3F diagram) and found that SP600125-treated interneurons did not extend cytoplasmic swellings as far as controls (control: 13.13 $\pm 0.38 \mu \mathrm{m} ;$ SP600125: 11.34 $\pm 0.30 \mu \mathrm{m}$; $p=0.002 ;$ Fig. 2.3F). Since JNK-inhibited interneurons paused for longer periods of time, we asked if this was strictly due to delayed nuclear propulsion towards the swelling, or if the dynamics of swelling extension were also affected. Interneurons treated with SP600125 displayed significantly longer lasting cytoplasmic swellings (control: 11.27 $\pm 0.99 \mathrm{~min}$; SP600125: 18.31 $\pm 1.33 \mathrm{~min} ; \mathrm{p}=0.0005$; Fig. $2.3 \mathrm{G}$ ), indicating that swelling duration is concomitantly increased with pause duration. Finally, the frequency and amplitude of nuclear translocations that exceed a minimum distance of 5 microns was notably reduced when individual control and JNK-inhibited cells were compared (Fig. 2.3H).

In order to determine whether JNK inhibition altered the migratory properties of interneurons that traveled at similar average speeds, we assessed a subset of control and SP600125-treated MGE interneurons migrating 35-40 $\mu \mathrm{m} / \mathrm{hr}$ (Extended Data Fig. 2.1-1A). When MGE interneurons traveled at the same average speed, the minimum speed, displacement, and straightness were unaffected by JNK inhibition (Fig. 2.1-1B-E). However, the maximum speed that MGE interneurons traveled in SP600125 treated conditions was significantly less than that of controls (Fig. 2.1-1B). This decrease in maximum speed under JNK inhibition likely contributed to the significant decrease in the speed variation of MGE interneurons (Fig. 2.1-1C). We next asked whether interneurons traveling at the same average speed had impairments to nucleokinesis under JNK inhibition. The average distance that JNK-inhibited MGE interneurons extended a swelling from the cell body as well as the average distance traveled during nucleokinesis were 
both significantly less than controls (Fig. 2.1-1F-G), with no changes in frequency or pausing (Fig. 2.1-1J-K). Moreover, JNK-inhibition led to a significant reduction in the distance of large nucleokinesis events (Fig. 2.1-1I). These data likely explain why we found a significant decrease in the maximum speed that MGE interneurons traveled under JNK inhibition. Additionally, when we analyzed leading process branching, MGE interneurons treated with SP600125 had a significant reduction in growth cone split frequency with no changes in side-branch frequency or duration (Fig. 2.1-1M-O).

Together, these data point to a role for JNK signaling in regulating the dynamics of nucleokinesis and leading process branching in migrating MGE interneurons, regardless of the average migratory speed that they travel.

\section{Complete genetic loss of JNK impairs nucleokinesis and leading process branching of migrating MGE interneurons in vitro}

In order to determine that migratory deficits seen with pharmacological inhibition of JNK signaling were specific to the loss of JNK function in cortical interneurons, and not due to JNK inhibition of the cortical feeder cells, we genetically ablated all three JNK genes from interneurons by using mice containing the $D / x 5 / 6-C I E$ transgene to conditionally remove Jnk1

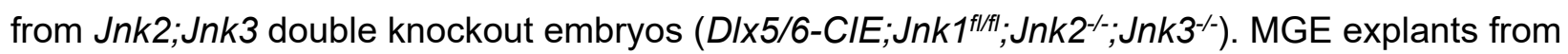
DIx5/6-CIE+ wild type (WT) or conditional triple knockout (cTKO) brains were cultured on a WT cortical feeder layer and imaged live (Fig. 2.4A). We tracked individual interneurons over time to assess the overall migratory properties of WT and cTKO interneurons (Fig. 2.4B,C). While there were no changes in migratory speed (Fig. 2.4D), cTKO interneurons exhibited greater variations in migratory speed compared to WT cells (WT: $0.54 \pm 0.01 ;$ cTKO: $0.59 \pm 0.02 ; p=0.02$; Figure 2.4E). We also found that $c T K O$ interneurons have shorter migratory displacements than WT interneurons (WT: 195.06 $\pm 6.80 \mu \mathrm{m} ; \mathrm{cTKO}$ : 165.99 $\pm 12.49 \mu \mathrm{m} ; \mathrm{p}=0.05 ;$ Fig. 2.4F). Additionally, 
the track straightness of $c T K O$ interneurons was decreased (WT: $0.77 \pm 0.02 ; c T K O: 0.71 \pm 0.02$; $p=0.03$; Figure 2.4G). The combination of increased speed variability and decreased migratory straightness explain why cTKO interneurons exhibited shorter migratory displacements. Together, these data indicate that cTKO interneurons migrating on WT cortical cells have subtle yet statistically significant deficits in their overall migratory dynamics, which closely match previous findings from ex vivo cTKO slice cultures (Myers et al., 2020).

To determine the genetic requirement for JNK signaling in branching, we analyzed leading process branching dynamics of cTKO and WT interneurons (Movies 2.6-7). cTKO interneurons displayed a significant reduction in the frequency of growth cone splitting compared to WT interneurons (WT: $1.92 \pm 0.18$ splits/hour; cTKO: 1.30 \pm 0.11 splits/hour; $p=0.04$; Fig. $2.4 \mathrm{H}$; Movie 2.6-7, Clip 1). In addition, genetic removal of JNK signaling from interneurons resulted in no change in side branch initiation (WT: $1.43 \pm 0.15$; cTKO:1.32 \pm 0.20 branches/hour; $p=0.66$; Fig. 4I), but significant decreases in the duration that side branches persisted (WT: $25.51 \pm 3.39 \mathrm{~min}$; cTKO:17.29 $\pm 1.71 \mathrm{~min} ; \mathrm{p}=0.05$; Fig. 2.4J; Movie 2.6-7, Clip 2). These data corroborate the findings from our pharmacological analyses and establish a cell intrinsic role for JNK signaling in controlling leading process branching dynamics.

Since we found alterations to overall migratory properties and branching dynamics, we next analyzed migrating cTKO interneurons for defects in nucleokinesis. Although cTKO interneurons engaged in nucleokinesis, the kinetics of nucleokinesis were significantly altered compared to WT interneurons (Fig. 2.5). The average distance cTKO cells traveled forward during nucleokinesis was significantly shorter compared to that of the WT cells (WT: $15.08 \pm 0.28 \mu \mathrm{m}$; cTKO: 14.16 $\pm 0.26 \mu \mathrm{m} ; \mathrm{p}=0.03$; Fig. 2.5A-C). However, unlike during acute pharmacological inhibition of JNK signaling, cTKO interneurons displayed increased rates of nucleokinesis (Fig 5A, B; Movie 2.8). Genetic ablation of JNK signaling in migrating MGE interneurons resulted in 
increased frequency of translocation events (WT: 2.76 \pm 0.05 events/hour; cTKO:

$3.22 \pm 0.11$ events/hour; $p=0.002$; Fig. $2.5 \mathrm{D}$ ). While both $\mathrm{WT}$ and $c T K O$ cells paused after the completion of a nucleokinesis event (after the cell body moves into the swelling), cTKO cells spent significantly less time pausing before they extended a new swelling (WT: $32.10 \pm 0.62 \mathrm{~min}$; cTKO 27.01 $1.02 \mathrm{~min} ; \mathrm{p}=0.0005$; Fig. 2.5E). When we measured the duration of time that cytoplasmic swellings persisted, the swellings in $C T K O$ interneurons were significantly shorterlived (WT: $10.47 \pm 0.62 \mathrm{~min} ;$ cTKO: $7.86 \pm 0.19 \mathrm{~min} ; \mathrm{p}=0.003$; Fig $2.5 \mathrm{~F})$. These data likely explain why we did not observe an overall change in migratory speeds between cTKO and WT interneurons. While $C T K O$ interneurons are not migrating as far during each translocation event they are initiating nucleokinesis at a faster rate, thus moving at similar speeds compared to controls.

Collectively, our data indicate that genetic removal of Jnk alters the migratory behavior of MGE interneurons, reinforcing our pharmacological findings. While the phenotypes observed with conditional removal of Jnk from migrating interneurons were not identical to pharmacological inhibition of JNK signaling, the results from our genetic experiments clearly indicate that interneurons have a cell intrinsic requirement for Jnk in leading process branching dynamics and nucleokinesis.

\section{Subcellular localization and dynamic behavior of the centrosome and primary cilia in migrating MGE interneurons depend on intact JNK-signaling}

The cytoplasmic swelling emerges from the cell body during nucleokinesis and contains multiple subcellular organelles involved in the forward movement of cortical interneurons (Bellion et al., 2005; Martini and Valdeolmillos, 2010; Yanagida et al., 2012). One organelle involved in nucleokinesis is the centrosome, which translocates from the cell body into the swelling during nucleokinesis. The centrosome is tethered to the nucleus through a perinuclear cage of 
microtubules and acts to generate a forward pulling force on the nucleus during nucleokinesis (Bellion et al., 2005; Umeshima et al., 2007). Disruptions in centrosome motility and positioning are thought to underly nucleokinesis defects seen in other studies of neuronal migration (Solecki et al., 2009; Luccardini et al., 2013; Luccardini et al., 2015; Silva et al., 2018). Since we found significant defects in nucleokinesis of MGE interneurons with both pharmacological and genetic loss of JNK function, we sought to determine if centrosome dynamics were also disrupted during JNK inhibition.

To visualize the centrosome and study the role of JNK signaling in centrosome dynamics in migrating MGE interneurons, we live-imaged $D / x 5 / 6-C I E+$ cells expressing a red-fluorescent centrosome marker, Cetn2-mCherry (Fig. 2.6A). In control cells, the centrosome moved correctly into the cytoplasmic swelling (Fig 2.6B; Movie 2.9, Clip 1), with centrioles occasionally splitting between the soma and swelling preceding nucleokinesis (Fig. 2.6B, frames 0:00-0:10 minutes), as reported elsewhere (Bellion et al., 2005; Umeshima et al., 2007). Upon JNKinhibition, the centrosome often maintained a position near the soma regardless of the presence of a swelling (Fig. 2.6C; Movie 2.9, Clip 2-3). Moreover, in many JNK-inhibited cells, the centrosome moved backwards into the trailing process, even when the cell body translocated forward (Fig. 2.6C; Movie 2.9, Clip 2-3). When we tracked the positioning of the centrosome over time, the centrosome of JNK-inhibited cells spent significantly more time in the trailing process and less time in the leading process ( $P=0.0001$; Fig. 2.6D). Additionally, when a swelling was formed in front of the soma, the centrosome of JNK-inhibited cells spent significantly less time inside of the swelling than controls (control: $66.64 \pm 5.99 \%$; SP600125: $16.08 \pm 5.52 \%$ of time; $P=0.0001 ;$ Fig. $2.6 E)$. When we measured the average maximal distance that the centrosome was displaced from the somal front, the centrosome of JNK-inhibited interneurons maintained a significantly closer position to the leading pole of the soma compared to controls (control: $9.93 \pm 0.99 \mu \mathrm{m}$; SP600125: $6.73 \pm 0.88 \mu \mathrm{m} ; \mathrm{p}=0.03$; Fig. $2.6 \mathrm{~F}$ ). This was not 
surprising since the soma-to-swelling distance in JNK-inhibited interneurons was decreased (Fig. 2.3E). However, when we compared the average maximal rearward distance between the centrosome and somal front, the centrosome of JNK-inhibited interneurons was significantly further behind that of controls (control: $9.40 \pm 0.77 \mu \mathrm{m}$; SP600125: $19.75 \pm 1.94 \mu \mathrm{m} ; \mathrm{p}=1.48 \times 10^{-5}$; Fig. 2.6F).

Since we found defects in centrosome dynamics, we wanted to determine whether primary cilia, which normally extend from the mother centriole and house receptors important for the guided migration of cortical interneurons (Baudoin et al., 2012; Higginbotham et al., 2012), were also perturbed in interneurons following JNK-inhibition. In order to study the localization of cilia in migrating interneurons, we performed live-cell confocal imaging on D/x5/6-CIE+ MGE cells expressing Arl13b-tdTomato, a red-fluorescent cilia marker.

Almost identical to that of our centrosome analyses, we found significant alterations in the dynamic positioning of primary cilia in migrating MGE interneurons (Fig. 2.7). In control cells, the primary cilium moved into the cytoplasmic swelling before nuclear translocation (Fig. 2.7A; Movie 2.10, Clip 1). However, upon JNK inhibition, the cilium was frequently positioned in the soma and often moved into the trailing process as the cell body translocated forward (Fig. 2.7B; Movie 2.10, Clip 2-3). Overall, the cilium spent significantly more time in the cell soma and behind the cell in the trailing process, and significantly less time in the leading process of JNKinhibited cells ( $P=0.0001$; Fig. $2.7 \mathrm{C})$. Additionally, the primary cilia in JNK-inhibited interneurons failed to spend as much time in formed cytoplasmic swellings as controls (control: $73.73 \pm 7.81 \%$ of time; SP600125: $33.85 \pm 8.20 \%$ of time; $P=0.0001$; Fig. $2.7 D)$. When we measured the maximal distance behind the somal front, the cilia of JNK-inhibited interneurons were also positioned further behind the cell body than controls, matching our centrosome findings (control: 9.71 $\pm 1.16 \mu \mathrm{m}$; SP600125: 16.09 $\pm-2.10 \mu \mathrm{m} ; \mathrm{p}=0.02$; Fig. 2.7E). Despite being mispositioned during JNK inhibition, the length of Arl13b-tdTomato labeled primary cilia remained unchanged 
over time (control: $2.75 \pm 0.12 \mu \mathrm{m}$; SP600125: 2.65 $\pm 0.12 \mu \mathrm{m} ; \mathrm{p}=0.56$; Fig. $2.7 \mathrm{~F}$ ), suggesting that the formation and maintenance of primary cilia were not interrupted. Taken together, our data indicate that JNK signaling plays a critical role in the dynamic movement and positioning of the centrosome and primary cilium in migrating interneurons.

\section{DISCUSSION}

In the present study, we demonstrated that migrating MGE interneurons rely on the JNK signaling pathway to properly undergo leading process branching and nucleokinesis. Pharmacological inhibition of JNK signaling in an in vitro assay resulted in reduced migratory speed and displacement with an increase in speed variation of migrating interneurons. Concomitant with these alterations in migratory properties, JNK-inhibited interneurons displayed decreased initiation of branches arising from growth cone tips, decreased persistence of interstitial side branches, as well as shorter, less frequent nucleokinesis events. Even when comparing interneurons that traveled at the same average speed, we found pronounced decreases in large nucleokinesis events, maximum migratory speeds, and growth cone branching of JNK-inhibited interneurons. Importantly, we extended our pharmacological findings by using a conditional triple knockout (cTKO) mouse line to completely remove Jnk from MGE interneurons and not the cortical feeder cells on which they were grown. cTKO interneurons migrating on wild-type feeder cells had decreased migratory displacement without reductions in overall migratory speed, apparently resulting from migratory trajectories that had more variable speeds and reduced track straightness compared to controls. cTKO interneurons displayed decreased growth cone branching and interstitial side branch duration, as well as shorter, more frequent nucleokinesis events. Therefore, our results indicate that MGE interneurons have a cell-intrinsic requirement for JNK in the coordination of leading process branching and nucleokinesis. Finally, we found a novel role of JNK signaling in regulating the dynamic positioning of two organelles involved in nucleokinesis: the centrosome and primary cilium. 
Centrosomes and primary cilia failed to properly translocate into a leading process swelling and spent significantly more time mislocalized to the trailing process of JNK-inhibited interneurons. In summary, we find that loss of JNK signaling impairs cellular and subcellular kinetics of MGE interneuron migration.

\section{Cytoskeletal regulation during leading process branching and nucleokinesis of migrating} interneurons

Leading process branching and nucleokinesis_the two main features of guided interneuron migration-rely on the coordination of actomyosin and microtubule-based cytoskeletal networks. Leading process branches initially form through membrane protrusions containing a F-actin meshwork, which are then stabilized by microtubules to allow for the emergence of the nascent branch (Martini et al., 2009; Spillane et al., 2011; Lysko et al., 2014; Peyre et al., 2015). Nucleokinesis is thought to be mediated through the combination of the forward pulling forces from microtubules at the front of the cell and pushing forces from actomyosin contraction at the rear (Bellion et al., 2005; Martini et al., 2009; Martini and Valdeolmillos, 2010). While mechanisms underlying these processes are still under investigation, molecular mediators of microtubule and actin dynamics in migrating interneurons have begun to emerge. Interestingly, disruptions to these cytoskeletal regulators result in migratory deficits that are reminiscent of those seen following the loss of JNK function.

For instance, p27 ${ }^{\mathrm{kip} 1}$, a microtubule associated protein, coordinates both actomyosin contraction and microtubule organization to control leading process branching and nucleokinesis in migrating interneurons (Godin et al., 2012). Conditional deletion of p27 kip1 from post-mitotic interneurons resulted in slower migratory speed, increased frequency of nucleokinesis, and shorter distance of translocations. Similarly, cTKO interneurons had shorter translocation distances and increased rates of nucleokinesis. In addition, p27 kip1 knockout interneurons 
displayed shorter-lived side branches, similar to our findings with both pharmacological and genetic loss of JNK. JNK signaling was reported to regulate $\mathrm{p} 27^{\mathrm{kip} 1}$ phosphorylation during cancer cell migration (Kim et al., 2012), suggesting a possible link between JNK signaling and this molecular mediator of cellular migration.

Another important regulator of nucleokinesis and leading process branching is the microtubule associated protein Doublecortin (Dcx; Kappeler et al., 2006; Friocourt et al., 2007), which is a downstream target of JNK signaling in neurons (Gdalyahu et al., 2004; Jin et al., 2010). Cortical interneurons lacking Dcx show a decreased duration of interstitial side branches, and significantly shorter nuclear translocation distances with no overall changes in migratory speed (Kappeler et al., 2006), similar to what we found in cTKO interneurons. Thus, it is possible that JNK signaling fine-tunes leading process branching and nucleokinesis in cortical interneurons by phosphorylating Dcx.

Recently, the role of the Elongator complex, specifically the enzymatic core Elp3, was found to control both leading process branching and nucleokinesis through the regulation of actomyosin activity (Tielens et al., 2016). MGE interneurons devoid of Elp3 displayed nucleokinesis and leading process branching defects strikingly similar to our pharmacological results, including decreased migratory speed, translocation frequency, nucleokinesis amplitude, and frequency of growth cone splitting (Tielens et al., 2016). Moreover, the Elongator complex was found to potentiate JNK activity during cellular stress in HeLa and HEK293 cells (Holmberg et al., 2002; Kojic and Wainwright, 2016). This suggests that the Elongator complex may potentiate the activity of JNK to phosphorylate effector proteins required for proper migration of interneurons.

Despite the possible connections, it is currently unknown whether JNK signaling is linked to the function of cytoskeletal regulators in migrating cortical interneurons. Future studies will be 
required to unravel the exact molecular mechanisms underlying how JNK coordinates leading process branching and nucleokinesis during cortical interneuron migration.

\section{Position and function of the centrosome and primary cilium during cortical interneuron migration}

During the migration cycle of cortical interneurons, a cytoplasmic swelling containing two interconnected organelles, the centrosome and primary cilium, extends ahead of the soma into the leading process (Bellion et al., 2005; Tsai and Gleeson, 2005). Disruptions to the movement, positioning, or function of these organelles have been found in neurons with migratory deficits (Baudoin et al., 2012; Higginbotham et al., 2012; Luccardini et al., 2013; Guo et al., 2015; Nakamuta et al., 2017; Matsumoto et al., 2019), suggesting centrosomes and cilia play essential roles in neuronal migration.

Migratory olfactory bulb interneurons require DOCK7, a member of the DOCK180 family of atypical Rac/Cdc42 guanine nucleotide exchange factors, for migration (Nakamuta et al., 2017). Knockdown of DOCK7 led to unstable movement of the centrosome from the swelling back into the cell body (Nakamuta et al., 2017), which was attributed to slower migration of olfactory bulb interneurons devoid of DOCK7. We observed similar migratory deficits and disrupted centrosome positioning in MGE interneurons treated with JNK inhibitor. Interestingly, knockdown of DOCK7 was previously shown to reduce JNK phosphorylation during Schwann cell development and migration (Yamauchi et al., 2008; Yamauchi et al., 2011).

Furthermore, inactivation of the cell adhesion molecule N-cadherin from MGE interneurons leads to mislocalization of the centrosome to the rear of the cell body (Luccardini et al., 2013). JNK-inhibition not only impeded the forward progression of centrosomes into the swelling, but also led to their unobstructed movement into the trailing process. Interestingly, JNK-inhibition has been reported to decrease $\mathrm{N}$-cadherin levels and cellular migration of myofibroblasts (De 
Wever et al., 2004), which suggests a potential role for JNK signaling in the regulation of Ncadherin during migration. While mechanisms that control the positioning of the centrosome in migrating neurons remain to be explored, JNK signaling may help synchronize the activity of cell adhesion molecules, cytoskeletal proteins, and cytoplasmic machinery that are critically involved in centrosome motility.

Finally, disruptions to ciliary proteins including Arl13b, Kif3a, and IFT88 or to the sonic hedgehog (Shh) signal transduction pathway all result in cortical interneuron migratory deficits (Baudoin et al., 2012; Higginbotham et al., 2012; Guo et al., 2017). Conditional deletion of Arl13b disrupts the formation of the primary cilium from the centrosome and the localization/transport of key receptors known to be critical for interneuron migration, including C$\mathrm{X}-\mathrm{C}$ motif chemokine receptor 4 (Cxcr4), neuregulin-1 receptor (ErbB4), and the Serotonin Receptor 6 (5-Htr6) (Riccio et al., 2009; Wang et al., 2011; Higginbotham et al., 2012). Dominant negative knockdown of Kif3a, a molecular motor required for cilium-specific Shh signal transduction, results in rearward movement of the centrosome of migrating olfactory bulb interneurons (Matsumoto et al., 2019), suggesting that functional primary cilia are necessary for the proper localization of the centrosome-cilium complex. Interestingly, the protein kinase A (PKA) signaling pathway appears to the regulate nucleokinesis through the centrosome-cilia complex of migratory olfactory bulb interneurons, since removal of cyclic AMP production from the primary cilium or delocalization of PKA from the centrosome resulted in disrupted nucleokinesis and centrosome movement (Stoufflet et al., 2019). Thus, cortical interneurons may require the function of signal transduction machinery inside the primary cilium for the centrosome-cilium complex to localize correctly, and to sense and respond to environmental guidance cues that promote directed migration of interneurons. Additionally, cortical interneurons lacking Arl13b exhibited leading process branching defects, suggesting that the primary cilium may have cytoskeletal functions along with its role in transducing guidance 
signals (Higginbotham et al., 2012). While JNK signaling does not appear to be necessary for the formation or stabilization of the primary cilium, it does control the dynamic subcellular position of the centrosome-ciliary complex during MGE interneuron migration. Future studies are needed to determine whether loss of JNK signaling impairs the localization of centrosome and cilia by disrupting ciliary signaling, and whether mislocalized cilia can compromise the guided migration of cortical interneurons in vivo.

\section{Cellular influences of JNK signaling during cortical interneuron migration}

In previously published work from ex vivo slice cultures, pharmacological inhibition of JNK signaling led to slowed migration and shorter migratory displacement, while genetic loss of Jnk from interneurons did not change migratory speed, but led to shorter displacement distances

(Myers et al., 2020). Here, we confirmed the requirement for JNK in interneuron migration using an in vitro co-culture assay and extended these observations to include a detailed assessment of the individual cellular and subcellular mechanics of leading process branching and nucleokinesis. Loss of JNK function disrupted leading process branching and nucleokinesis of MGE interneurons and led to significant alterations of their migratory properties. The requirement of $\mathrm{JNK}$ in interneuron migration could be multifactorial, however, and regulate interneuron migration through intrinsic mechanisms, extrinsic mechanisms, or both. Since SP600125 treatment inhibits JNK function in all cells of the MGE explant cortical cell co-culture assay, we cannot exclude the possibility that JNK inhibition disrupts cell-cell interactions between interneurons and the cortical feeder cells on which they are grown. To determine whether migrating MGE interneurons have a cell-autonomous requirement for JNK signaling, we genetically removed Jnk from interneurons and cultured them on WT cortical cells. Although we found migratory deficits in cTKO interneurons that were indicative of an intrinsic function for JNK, the deficits we uncovered were distinct from pharmacological experiments, suggesting that there may be additive effects when JNK is simultaneously removed from both populations of 
cells. Both pharmacological inhibition and genetic removal of Jnk resulted in consistent leading process branching phenotypes with decreased growth cone splitting and short-lived interstitial side branches. When we analyzed nucleokinesis, however, the kinetics of movement were opposite: JNK-inhibited cells completed nucleokinesis at slower rates, whereas CTKO cells completed at faster rates. These data imply that cortical interneuron migration is dependent on both intrinsic and extrinsic requirements for JNK signaling. Indeed, regulation of leading process branching in cortical interneurons may be dominated by an intrinsic function of JNK signaling, since the exclusive genetic loss of JNK from interneurons matches the combined pharmacological loss of JNK from both interneurons and cortical cells. Meanwhile, JNK signaling may influence nucleokinesis through both cell-intrinsic and extrinsic mechanisms, which could explain departures in the rates of nucleokinesis between JNK-inhibited and cTKO interneurons. While the exact mechanisms that cortical interneurons use to navigate their environment remain to be fully elucidated, we have found that JNK signaling exerts fine-tune control over cell biological processes required for proper interneuron migration.

\section{Conclusions}

Using a combination of pharmacological and genetic approaches, we found a novel requirement for JNK signaling in MGE interneuron leading process branching and nucleokinesis. Our findings are also the first to implicate the JNK signaling pathway as a key intracellular regulator of the dynamic positioning of multiple subcellular organelles involved in interneuron migration. The exact molecular mechanisms controlling JNK signaling in interneuron migration remain to be determined. Therefore, identifying the upstream activators and downstream targets of JNK signaling will provide further insight into the role of JNK signaling in cortical development and disease. 


\section{MATERIALS AND METHODS}

\section{Animals}

Animals were housed and cared for by the Office of Laboratory Animal Resources at West Virginia University. Timed-pregnant dams (day of vaginal plug = embryonic day 0.5 ) were euthanized by rapid cervical dislocation at embryonic day 14.5 (E14.5) and mouse embryos were immediately harvested for tissue culture. CF-1 (Charles River; Wilmington, MA, US) or C57BL/6J dams (Stock \# 000664; The Jackson Laboratory; Bar Harbour, ME, USA) were crossed to hemizygous DIx5/6-Cre-IRES-EGFP (DIx5/6-CIE; Stenman et al., 2003) males maintained on a C57BL/6J background to achieve timed pregnancies at E14.5. To generate

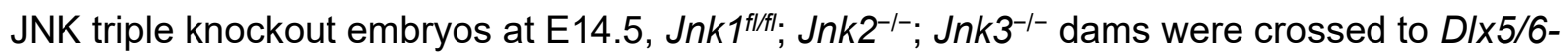
CIE; Jnk1 $1^{f l++}$ J Jnk2 ${ }^{-/-} ; \mathrm{Jnk} 3^{+/-}$males maintained on a C57BL/6J background. All animal procedures were performed in accordance to protocols approved by the Institutional Animal Care and Use Committee at West Virginia University.

\section{MGE explant cortical cell co-culture}

8-well chamber coverslip slides (Thermo Fisher 155411) were coated with a solution of poly-Llysine (Sigma P5899) and laminin (Sigma L2020) diluted in sterile water (Polleux and Ghosh, 2002), incubated overnight at $37^{\circ} \mathrm{C}$ with $5 \% \mathrm{CO}_{2}$, and rinsed with sterile water prior to cell plating. E14.5 DIx5/6-CIE+ and DIx5/6-CIE- embryos were sorted by GFP fluorescence and dissected in ice-cold complete Hank's Balanced Salt Solution (cHBSS; Tucker et al., 2006). Cortices were dissected from the negative brains and pooled together for dissociation (Polleux and Ghosh, 2002). After dissociation, $250 \mu \mathrm{L}$ of cell suspension diluted to $1680 \mathrm{cells} / \mu \mathrm{L}$ was added to each well and allowed to settle for 2 hours. MGE explants were dissected from GFP+ brains and plated on top of cortical cells. Cultures were grown for 24 hours before treatments and live imaging. Two E14.5 timed-pregnant dams were used for each genetic experiment. 
DIx5/6-CIE+ and DIx5/6-CIE- embryos were obtained from a DIx5/6-Cre-IRES-EGFP x C57BL/6J cross, while cTKO embryos were obtained by crossing a DIx5/6-CIE; Jnk $1^{f / l+}$;

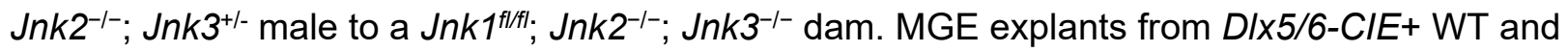
cTKO embryos were dissected and plated into separate wells containing a monolayer of D/x5/6CIE- WT cortical cells. Cultures were grown 24 hours prior to live imaging.

\section{Electroporations}

Intact ventral forebrains were microdissected from $D / x 5 / 6-C I E+$ embryos and placed on thin slices of 3\% low-melting point agarose (Fisher BP165-25) in cHBSS. Agar slices containing ventral forebrain tissue were placed onto a positive genepaddles electrode $(5 \times 7 \mathrm{~mm}$; Harvard Apparatus Inc \#45-0123; Holliston, MA, USA) from a BTX ECM 830 squarewave electroporation system under a stereo microscope. Endotoxin-free plasmid DNA (1-3 mg/ml) for Cetn2-mCherry and Arl13b-tdTomato (gift from Dr. Eva Anton) was injected into the MGE with a picospritzer

(6ms/spritz; General Valve Picospritzer II), a negative genepaddles electrode (5x7mm; Harvard Apparatus Inc \#45-0123) containing a droplet of cHBSS was lowered to the tissue, and electroporated (5 x 60mV/5ms pulse length/200ms interval pulses). Electroporated MGE explants were then dissected, plated as above, and grown for 48 hours before imaging.

\section{Live Imaging Experiments}

Cultures were treated with pre-warmed $37^{\circ} \mathrm{C}$ serum-free media containing a $1: 1000$ dilution of DMSO for vehicle control or $20 \mu \mathrm{M}$ SP600125 pan-JNK inhibitor (Enzo Life Sciences BMLEl305-0010; Farmingdale, NY, USA) and immediately transferred to a Zeiss 710 Confocal Microscope with stable environmental controls maintained at $37^{\circ} \mathrm{C}$ with $5 \%$ humidified $\mathrm{CO}_{2}$. Multi-position time-lapse z-series were acquired at 10-minute intervals over a 12-hour period with a 20X Plan-Apo objective (Zeiss; Oberkochen, Germany) for overall migration analysis, nucleokinesis distance, and swelling distance measurements. For measurements requiring 
higher temporal and spatial resolution, such as swelling duration, branch dynamics, and visualization of subcellular structures in electroporated cells, cultures were imaged using multiposition time-lapse z-series at 2-2.5 minute intervals over a 4-10 hour period with a 40X Capochromat 1.2W M27 objective (Zeiss; Oberkochen, Germany).

\section{Live Imaging Analyses}

4D live imaging movies were analyzed using Imaris 9.5.1 (Bitplane; Zürich, Switzerland) software. Movies collected at 20X were evaluated in the first $12 \mathrm{~h}$ of each recording. Individual interneurons were manually tracked by placing a "spot" in the center of the cell body in each frame of the movie for a minimum of $4 \mathrm{~h}$. Tracks were discontinued if a cell remained stationary for 60 contiguous minutes, or if the tracked cell could no longer be unambiguously identified. All tracks from each movie were averaged together for dynamic analyses, which included migratory speed, distance, displacement, and track straightness. Displacement was normalized to the minimum track length of $4 \mathrm{~h}$ to account for differences in the total times of tracked cells. For pharmacology data, a minimum of 10 cells were tracked from $n=11$ movies $(127$ cells/condition) obtained over 4 experimental days. Genetic data were acquired from a minimum of 10 cells measured from $n=13$ control movies ( 5 WT embryos, 130 cells) and $n=12$ conditional triple knockout (cTKO) movies (5 cTKO embryos, 120 cTKO cells), each obtained over 4 experimental days.

The distance of each nucleokinesis event was measured from the front of the cell body before and after translocation. For swelling analyses, a swelling was defined as a cytoplasmic dilation in the leading process. Swelling distance was measured from the front of the cell body to the most distal portion of the swelling. For pharmacological data, 50 cells were measured from $n=10$ movies obtained over 4 experimental days in each condition. For genetic data, nucleokinesis distance measurements included 50 cells sampled from $n=10$ movies obtained over 4 
experimental days (5 cTKO embryos, 5 WT embryos). Pharmacological swelling duration data were obtained from 43 control cells measured from $n=10$ control movies, and 53 treated cells from n=6 SP600125 movies collected over 4 experimental days. Genetic swelling duration was obtained from 37 WT cells from n=6 WT movies with 5 WT embryos, and 38 cTKO cells from $\mathrm{n}=6 \mathrm{cTKO}$ movies obtained over 4 experimental days with $4 \mathrm{cTKO}$ embryos.

For branching analyses, a growth cone split was defined as a bifurcation emerging from the tip of the leading process. An interstitial side branch was defined as a branch arising from the leading process that did not originate from the growth cone. Interneurons had to remain in frame and distinguishable from surrounding cells for a minimum of 3 hours to be included in branching analyses. Interstitial side branches had to form de novo, persist for a minimum of 10 minutes, and the branch could not become the new leading process. In pharmacological experiments, frequency data for interstitial side branch formation were obtained by measuring $n=19$ control cells from 8 movies and n=19 SP 600125 cells from 10 movies recorded over 5 experimental days. Data for interstitial side branch duration were obtained from $n=52$ branches from 14 control cells and $n=52$ branches from 18 SP 600125 cells measured from 10 movies/condition collected over 5 experimental days. Data for growth cone splitting were obtained from $n=19$ control cells from 8 movies and n=19 SP600125 cells from 10 movies collected over 5 experimental days. In genetic experiments, data for interstitial side branch frequency were obtained by measuring $n=11$ cells from 6 movies/condition collected over 4 experimental days. Data for side branch duration were obtained from $n=34$ branches in 10 WT cells and $n=28$ branches in 10 cTKO cells recorded from 6 movies/condition collected over 4 experimental days. The frequency of growth cone splitting in genetic experiments were obtained from $n=11$ cells in 6 movies/genotype collected over 4 experimental days.

For electroporation experiments, centrosome and ciliary localization and distance from the front of the cell body were manually tracked and recorded using Imaris software. For centrosome 
measurements, $n=20$ cells were analyzed from 11 movies in each condition obtained over 5 experimental days. For primary cilia measurements, $n=20$ cells were analyzed from 15 movies in each condition obtained over 6 experimental days. Two-way Anova followed by Fisher's LSD post-hoc analyses were performed to determine statistical differences for organelle localization (Prism Version 8 using GraphPad Software; San Diego, CA, USA). Statistical significances were determined by $x^{2}$ test for the presence of organelles to a formed swelling over time (Prism Version 8 using GraphPad Software; San Diego, CA, USA). Two-tailed unpaired Student's $t$ tests were used to determine statistical differences between groups for distance measurements. Length of primary cilia were measured in Imaris based on Arl13b-tdTomato expression. Any cilia that extended outside of the Z-stack were excluded from analyses. Data represent the average ciliary length measured over time per cell. A total of $n=17$ control and $n=15$ SP600125 cells collected over 13 movies and 6 experimental days were analyzed. Statistical differences between ciliary length measurements were determined by two-tailed unpaired Student's $t$ tests. Confocal micrographs were uniformly adjusted for levels, brightness, and contrast in Imaris for movie preparation, and Adobe Photoshop for figure images.

\section{Statistics}

Data were analyzed and graphs were produced using Prism Version 8 (GraphPad Software) or estimation coding software (Ho et al., 2019). For estimation statistics, data are presented as Gardner-Altman estimation plots. A total of 5000 bootstrap samples were taken, and the $95 \%$ confidence interval is bias-corrected. For graphs not containing estimation statistics, data are presented in scatter plots with solid lines corresponding to the mean \pm standard error of the mean as indicated in figures and results text. Statistical details can be found in Table 2.1. 
Author contributions: Conceptualization: S.E.S. and E.S.T.; Methodology: S.E.S. and E.S.T.; Formal analysis: S.E.S., and N.K.C.; Investigation: S.E.S.; Writing: S.E.S., and E.S.T.; Visualization: S.E.S.; Supervision: E.S.T.; Funding Acquisition: E.S.T.

Acknowledgements: We would like to thank Dr. Amanda Ammer and Dr. Karen Martin for their excellent microscopy support. Live-imaging experiments were performed in the West Virginia University (WVU) Imaging Facilities, which were supported by the WVU Cancer Institute, the WVU Health Science Center Office of Research and Graduate Education, and NIH grants P20RR016440, P30GM103488, P20GM121322, U54GM104942, P30GM103503, and P20GM103434.

Conflicts of Interest: No competing interests declared.

Funding: This work was supported by the National Institutes of Health grant R01NS082262 to EST. 


\section{REFERENCES}

Ang ES, Haydar TF, Gluncic V, Rakic P (2003) Four-dimensional migratory coordinates of GABAergic interneurons in the developing mouse cortex. J Neurosci 23:5805-5815.

Baudoin JP, Viou L, Launay PS, Luccardini C, Espeso Gil S, Kiyasova V, Irinopoulou T, Alvarez C, Rio JP, Boudier T, Lechaire JP, Kessaris N, Spassky N, Métin C (2012) Tangentially migrating neurons assemble a primary cilium that promotes their reorientation to the cortical plate. Neuron 76:1108-1122.

Bellion A, Baudoin JP, Alvarez C, Bornens M, Métin C (2005) Nucleokinesis in tangentially migrating neurons comprises two alternating phases: forward migration of the Golgi/centrosome associated with centrosome splitting and myosin contraction at the rear. J Neurosci 25:5691-5699.

Bennett BL, Sasaki DT, Murray BW, O'Leary EC, Sakata ST, Xu W, Leisten JC, Motiwala A, Pierce S, Satoh Y, Bhagwat SS, Manning AM, Anderson DW (2001) SP600125, an anthrapyrazolone inhibitor of Jun N-terminal kinase. Proc Natl Acad Sci U S A 98:1368113686.

Chang L, Karin M (2001) Mammalian MAP kinase signalling cascades. Nature 410:37-40.

Davis RJ (2000) Signal transduction by the JNK group of MAP kinases. Cell 103:239-252.

De Wever O, Westbroek W, Verloes A, Bloemen N, Bracke M, Gespach C, Bruyneel E, Mareel $\mathrm{M}(2004)$ Critical role of $\mathrm{N}$-cadherin in myofibroblast invasion and migration in vitro stimulated by colon-cancer-cell-derived TGF-beta or wounding. J Cell Sci 117:46914703.

Friocourt G, Liu JS, Antypa M, Rakic S, Walsh CA, Parnavelas JG (2007) Both doublecortin and doublecortin-like kinase play a role in cortical interneuron migration. J Neurosci 27:38753883.

Gdalyahu A, Ghosh I, Levy T, Sapir T, Sapoznik S, Fishler Y, Azoulai D, Reiner O (2004) DCX, a new mediator of the JNK pathway. EMBO J 23:823-832.

Godin JD, Thomas N, Laguesse S, Malinouskaya L, Close P, Malaise O, Purnelle A, Raineteau O, Campbell K, Fero M, Moonen G, Malgrange B, Chariot A, Metin C, Besson A, Nguyen $\mathrm{L}(2012) \mathrm{p} 27$ (Kip1) is a microtubule-associated protein that promotes microtubule polymerization during neuron migration. Dev Cell 23:729-744.

Guo J, Higginbotham H, Li J, Nichols J, Hirt J, Ghukasyan V, Anton ES (2015) Developmental disruptions underlying brain abnormalities in ciliopathies. Nat Commun 6:7857.

Guo J, Otis JM, Higginbotham H, Monckton C, Cheng J, Asokan A, Mykytyn K, Caspary T, Stuber GD, Anton ES (2017) Primary Cilia Signaling Shapes the Development of Interneuronal Connectivity. Dev Cell 42:286-300.e284.

Higginbotham H, Eom TY, Mariani LE, Bachleda A, Hirt J, Gukassyan V, Cusack CL, Lai C, Caspary T, Anton ES (2012) Arl13b in primary cilia regulates the migration and placement of interneurons in the developing cerebral cortex. Dev Cell 23:925-938.

Hildebrandt F, Benzing T, Katsanis N (2011) Ciliopathies. N Engl J Med 364:1533-1543.

Hirai S, Cui DF, Miyata T, Ogawa M, Kiyonari H, Suda Y, Aizawa S, Banba Y, Ohno S (2006) The c-Jun $\mathrm{N}$-terminal kinase activator dual leucine zipper kinase regulates axon growth and neuronal migration in the developing cerebral cortex. J Neurosci 26:11992-12002.

Ho J, Tumkaya T, Aryal S, Choi H, Claridge-Chang A (2019) Moving beyond P values: data analysis with estimation graphics. Nat Methods 16:565-566.

Holmberg C, Katz S, Lerdrup M, Herdegen T, Jäättelä M, Aronheim A, Kallunki T (2002) A novel specific role for I kappa B kinase complex-associated protein in cytosolic stress signaling. J Biol Chem 277:31918-31928.

Jin J, Suzuki H, Hirai S, Mikoshiba K, Ohshima T (2010) JNK phosphorylates Ser332 of doublecortin and regulates its function in neurite extension and neuronal migration. Dev Neurobiol 70:929-942. 
Kappeler C, Saillour Y, Baudoin JP, Tuy FP, Alvarez C, Houbron C, Gaspar P, Hamard G, Chelly J, Métin C, Francis F (2006) Branching and nucleokinesis defects in migrating interneurons derived from doublecortin knockout mice. Hum Mol Genet 15:1387-1400.

Kato M, Dobyns WB (2005) X-linked lissencephaly with abnormal genitalia as a tangential migration disorder causing intractable epilepsy: proposal for a new term, "interneuronopathy". J Child Neurol 20:392-397.

Kim H, Jung O, Kang M, Lee MS, Jeong D, Ryu J, Ko Y, Choi YJ, Lee JW (2012) JNK signaling activity regulates cell-cell adhesions via TM4SF5-mediated p27(Kip1) phosphorylation. Cancer Lett 314:198-205.

Kojic M, Wainwright B (2016) The Many Faces of Elongator in Neurodevelopment and Disease. Front Mol Neurosci 9:115.

Luccardini C, Leclech C, Viou L, Rio JP, Métin C (2015) Cortical interneurons migrating on a pure substrate of $\mathrm{N}$-cadherin exhibit fast synchronous centrosomal and nuclear movements and reduced ciliogenesis. Front Cell Neurosci 9:286.

Luccardini C, Hennekinne L, Viou L, Yanagida M, Murakami F, Kessaris N, Ma X, Adelstein RS, Mège RM, Métin C (2013) N-cadherin sustains motility and polarity of future cortical interneurons during tangential migration. J Neurosci 33:18149-18160.

Lysko DE, Putt M, Golden JA (2011) SDF1 regulates leading process branching and speed of migrating interneurons. J Neurosci 31:1739-1745.

Lysko DE, Putt M, Golden JA (2014) SDF1 reduces interneuron leading process branching through dual regulation of actin and microtubules. J Neurosci 34:4941-4962.

Martini FJ, Valdeolmillos M (2010) Actomyosin contraction at the cell rear drives nuclear translocation in migrating cortical interneurons. J Neurosci 30:8660-8670.

Martini FJ, Valiente M, López Bendito G, Szabó G, Moya F, Valdeolmillos M, Marín O (2009) Biased selection of leading process branches mediates chemotaxis during tangential neuronal migration. Development 136:41-50.

Matsumoto M, Sawada M, García-González D, Herranz-Pérez V, Ogino T, Bang Nguyen H, Quynh Thai T, Narita K, Kumamoto N, Ugawa S, Saito Y, Takeda S, Kaneko N, Khodosevich K, Monyer H, García-Verdugo JM, Ohno N, Sawamoto K (2019) Dynamic Changes in Ultrastructure of the Primary Cilium in Migrating Neuroblasts in the Postnatal Brain. J Neurosci 39:9967-9988.

Meechan DW, Tucker ES, Maynard TM, LaMantia AS (2012) Cxcr4 regulation of interneuron migration is disrupted in 22q11.2 deletion syndrome. Proc Natl Acad Sci U S A 109:18601-18606.

Miyoshi G, Hjerling-Leffler J, Karayannis T, Sousa VH, Butt SJ, Battiste J, Johnson JE, Machold RP, Fishell G (2010) Genetic fate mapping reveals that the caudal ganglionic eminence produces a large and diverse population of superficial cortical interneurons. J Neurosci 30:1582-1594.

Moya F, Valdeolmillos M (2004) Polarized increase of calcium and nucleokinesis in tangentially migrating neurons. Cereb Cortex 14:610-618.

Myers AK, Meechan DW, Adney DR, Tucker ES (2014) Cortical interneurons require Jnk1 to enter and navigate the developing cerebral cortex. J Neurosci 34:7787-7801.

Myers AK, Cunningham JG, Smith SE, Snow JP, Smoot CA, Tucker ES (2020) JNK signaling is required for proper tangential migration and laminar allocation of cortical interneurons. Development 147:Doi: 10.1242/dev.180646.

Nadarajah B, Alifragis P, Wong RO, Parnavelas JG (2003) Neuronal migration in the developing cerebral cortex: observations based on real-time imaging. Cereb Cortex 13:607-611.

Nakamuta S, Yang YT, Wang CL, Gallo NB, Yu JR, Tai Y, Van Aelst L (2017) Dual role for DOCK7 in tangential migration of interneuron precursors in the postnatal forebrain. $J$ Cell Biol 216:4313-4330. 
Nery S, Fishell G, Corbin JG (2002) The caudal ganglionic eminence is a source of distinct cortical and subcortical cell populations. Nat Neurosci 5:1279-1287.

Peyre E, Silva CG, Nguyen L (2015) Crosstalk between intracellular and extracellular signals regulating interneuron production, migration and integration into the cortex. Front Cell Neurosci 9:129.

Polleux F, Ghosh A (2002) The slice overlay assay: a versatile tool to study the influence of extracellular signals on neuronal development. Sci STKE 2002:pl9.

Polleux F, Whitford KL, Dijkhuizen PA, Vitalis T, Ghosh A (2002) Control of cortical interneuron migration by neurotrophins and PI3-kinase signaling. Development 129:3147-3160.

Riccio O, Potter G, Walzer C, Vallet P, Szabó G, Vutskits L, Kiss JZ, Dayer AG (2009) Excess of serotonin affects embryonic interneuron migration through activation of the serotonin receptor 6. Mol Psychiatry 14:280-290.

Silva CG, Peyre E, Adhikari MH, Tielens S, Tanco S, Van Damme P, Magno L, Krusy N, Agirman G, Magiera MM, Kessaris N, Malgrange B, Andrieux A, Janke C, Nguyen L (2018) Cell-Intrinsic Control of Interneuron Migration Drives Cortical Morphogenesis. Cell 172:1063-1078.e1019.

Solecki DJ, Trivedi N, Govek EE, Kerekes RA, Gleason SS, Hatten ME (2009) Myosin II motors and $\mathrm{F}$-actin dynamics drive the coordinated movement of the centrosome and soma during CNS glial-guided neuronal migration. Neuron 63:63-80.

Spillane M, Ketschek A, Jones SL, Korobova F, Marsick B, Lanier L, Svitkina T, Gallo G (2011) The actin nucleating Arp2/3 complex contributes to the formation of axonal filopodia and branches through the regulation of actin patch precursors to filopodia. Dev Neurobiol 71:747-758.

Stenman J, Toresson H, Campbell K (2003) Identification of two distinct progenitor populations in the lateral ganglionic eminence: implications for striatal and olfactory bulb neurogenesis. J Neurosci 23:167-174.

Stoufflet J, Chaulet M, Doulazmi M, Fouquet C, Dubacq C, Métin C, Trembleau A, Vincent P, Caillé I (2019) Primary cilium cAMP regulates cyclic saltatory neuronal migration at the centrosome. bioRvix.

Tielens S, Huysseune S, Godin JD, Chariot A, Malgrange B, Nguyen L (2016) Elongator controls cortical interneuron migration by regulating actomyosin dynamics. Cell Res 26:1131-1148.

Tsai LH, Gleeson JG (2005) Nucleokinesis in neuronal migration. Neuron 46:383-388.

Tucker ES, Polleux F, LaMantia AS (2006) Position and time specify the migration of a pioneering population of olfactory bulb interneurons. Dev Biol 297:387-401.

Umeshima H, Hirano T, Kengaku M (2007) Microtubule-based nuclear movement occurs independently of centrosome positioning in migrating neurons. Proc Natl Acad Sci U S A 104:16182-16187.

Volk DW, Chitrapu A, Edelson JR, Lewis DA (2015) Chemokine receptors and cortical interneuron dysfunction in schizophrenia. Schizophr Res 167:12-17.

Wang X, Nadarajah B, Robinson AC, McColl BW, Jin JW, Dajas-Bailador F, Boot-Handford RP, Tournier C (2007) Targeted deletion of the mitogen-activated protein kinase kinase 4 gene in the nervous system causes severe brain developmental defects and premature death. Mol Cell Biol 27:7935-7946.

Wang Y, Li G, Stanco A, Long JE, Crawford D, Potter GB, Pleasure SJ, Behrens T, Rubenstein JL (2011) CXCR4 and CXCR7 have distinct functions in regulating interneuron migration. Neuron 69:61-76.

Westerlund N, Zdrojewska J, Padzik A, Komulainen E, Björkblom B, Rannikko E, Tararuk T, Garcia-Frigola C, Sandholm J, Nguyen L, Kallunki T, Courtney MJ, Coffey ET (2011) Phosphorylation of SCG10/stathmin-2 determines multipolar stage exit and neuronal migration rate. Nat Neurosci 14:305-313. 
Wichterle H, Garcia-Verdugo JM, Herrera DG, Alvarez-Buylla A (1999) Young neurons from medial ganglionic eminence disperse in adult and embryonic brain. Nat Neurosci 2:461466.

Xu Q, Cobos I, De La Cruz E, Rubenstein JL, Anderson SA (2004) Origins of cortical interneuron subtypes. J Neurosci 24:2612-2622.

Yamasaki T, Kawasaki H, Arakawa S, Shimizu K, Shimizu S, Reiner O, Okano H, Nishina S, Azuma N, Penninger JM, Katada T, Nishina H (2011) Stress-activated protein kinase MKK7 regulates axon elongation in the developing cerebral cortex. J Neurosci 31:1687216883.

Yamauchi J, Miyamoto Y, Chan JR, Tanoue A (2008) ErbB2 directly activates the exchange factor Dock7 to promote Schwann cell migration. J Cell Biol 181:351-365.

Yamauchi J, Miyamoto Y, Hamasaki H, Sanbe A, Kusakawa S, Nakamura A, Tsumura H, Maeda M, Nemoto N, Kawahara K, Torii T, Tanoue A (2011) The atypical Guaninenucleotide exchange factor, dock7, negatively regulates schwann cell differentiation and myelination. J Neurosci 31:12579-12592.

Yanagida M, Miyoshi R, Toyokuni R, Zhu Y, Murakami F (2012) Dynamics of the leading process, nucleus, and Golgi apparatus of migrating cortical interneurons in living mouse embryos. Proc Natl Acad Sci U S A 109:16737-16742.

Zhang F, Yu J, Yang T, Xu D, Chi Z, Xia Y, Xu Z (2016) A Novel c-Jun N-terminal Kinase (JNK) Signaling Complex Involved in Neuronal Migration during Brain Development. J Biol Chem 291:11466-11475. 


\section{FIGURES}
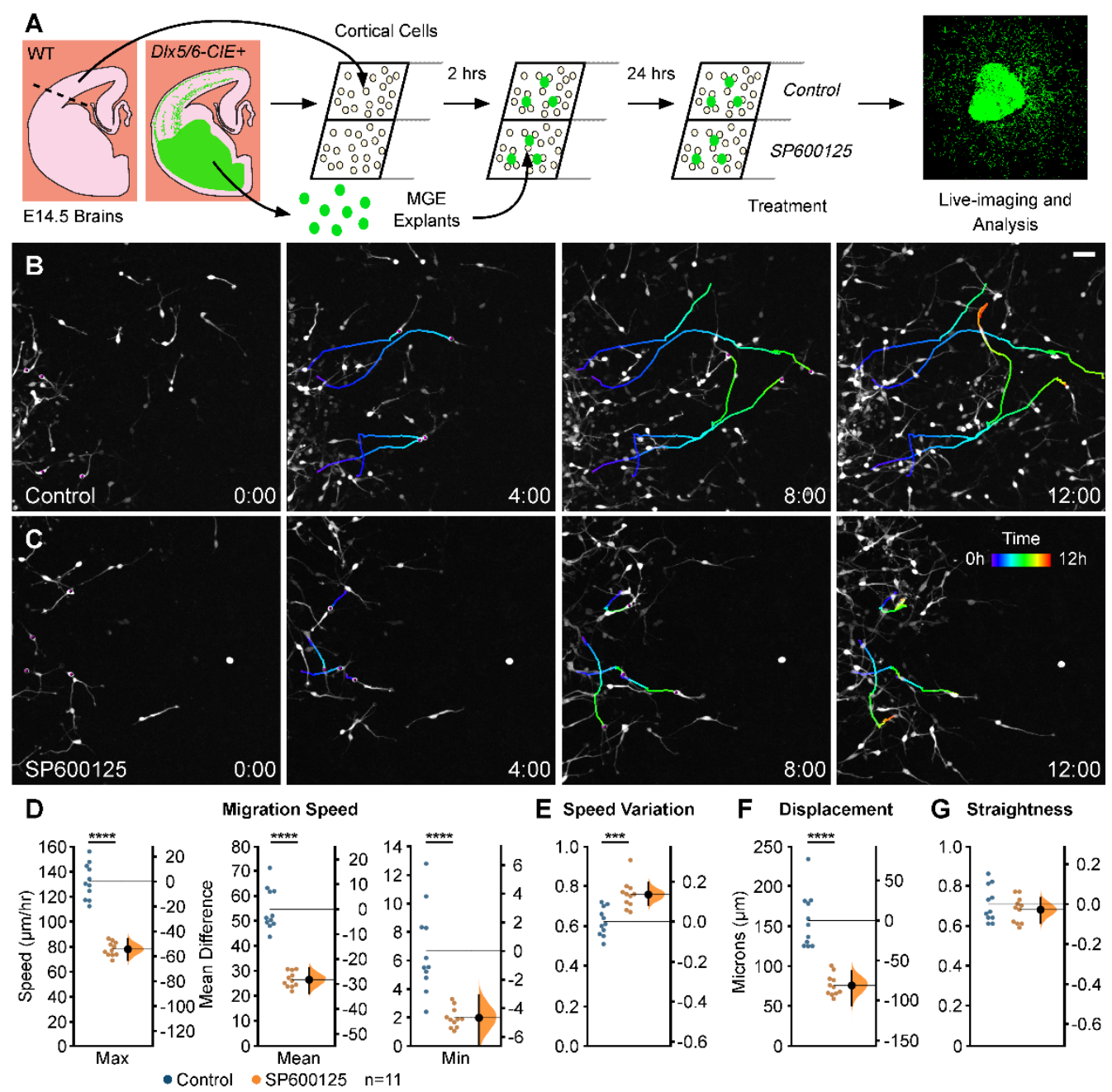

E Speed Variation
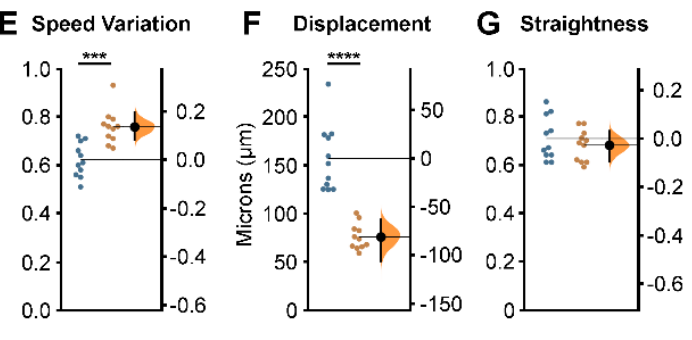

Figure 2.1. JNK signaling regulates the dynamic migratory properties of MGE

interneurons. A. Schematic diagram of MGE explant cortical cell co-culture assay with pharmacological inhibition of JNK signaling. B-C. Individual cell tracks (pseudo-colored by time) from four interneurons in control (B) or 20 $\mu \mathrm{M}$ SP600125 (C) treated cultures imaged live for 12 hours. D-G. Quantification of interneuron migratory properties revealed significant disruptions in migration speed $(D)$, speed variation $(E)$, and displacement $(F)$, but not straightness $(G)$ during JNK inhibition. For each condition, a minimum of 10 cells were tracked from $n=11$ movies (127 cells/condition) obtained over 4 experimental days. Data are presented as Gardner-Altman estimation plots. The values of both groups are plotted on the left axes with the mean difference 
between groups plotted on the right axes as a bootstrap resampling distribution. The mean difference is depicted as a large black dot with the $95 \%$ confidence interval indicated by the ends of the vertical error bar. ${ }^{* * *} p<0.0001,{ }^{* * *} p<0.001$, Student's $t$-test. Time in hours. Scale bar: $50 \mu \mathrm{m}$. In addition, a subset of MGE interneurons in control and JNK inhibited conditions were analyzed to determine whether JNK signaling influenced migratory properties of cells traveling at the same average speed (Extended Data Figure 1-1). 

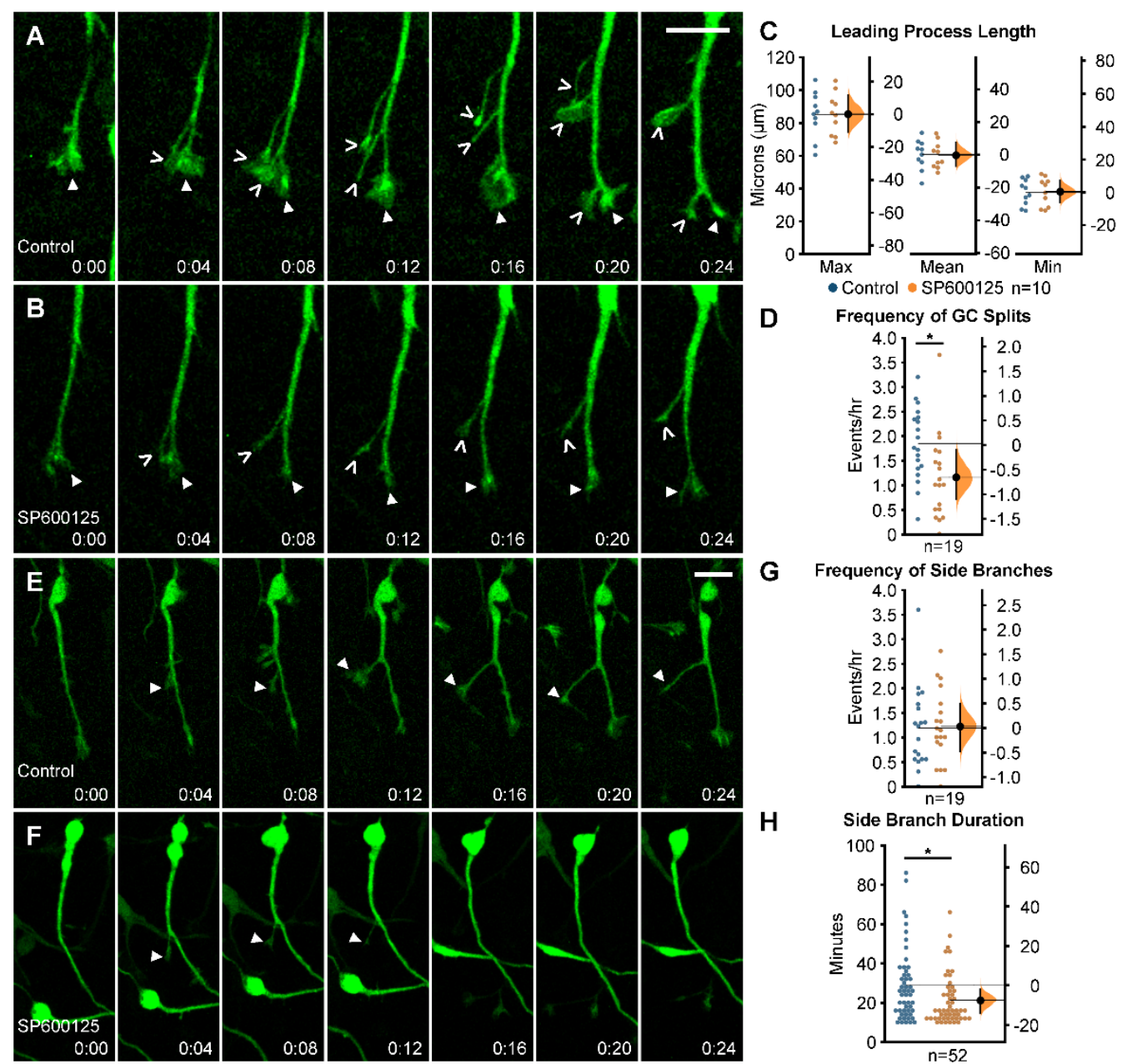

G Frequency of Side Branches

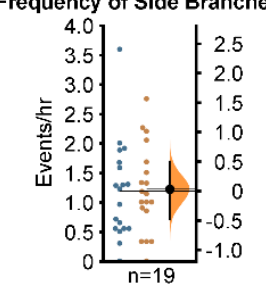

$\mathrm{H}$

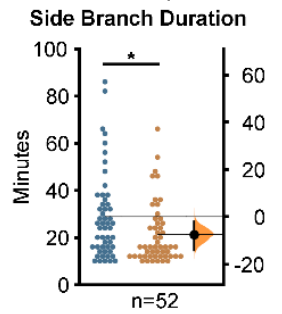

Figure 2.2. Migrating MGE interneurons require intact JNK signaling for proper leading process branching. A-B. Time series depicting growth cone (GC) splitting from control (A) or JNK-inhibited (B) MGE interneurons. Closed arrowhead = GC , open arrowhead = new GC branch. C. Quantification of leading process length. $n=10$ cells were measured from 8 movies/condition obtained over 4 experimental days. D. Quantification of GC splitting frequency. $\mathrm{n}=19$ control cells from 8 movies and $\mathrm{n}=19$ SP600125 cells from 10 movies were measured. EF. Interstitial side branching from control $(E)$ or JNK-inhibited $(F)$ interneurons. Closed arrowhead $=$ new side branch. G. Quantification of interstitial side branch frequency of control and SP600125 treated interneurons. $n=19$ control cells from 8 movies; $n=19$ SP600125 cells from 10 movies. H. Quantification of interstitial side branch duration in control and JNK-inhibited 
conditions. $n=52$ branches from 14 control cells and 18 SP600125 cells were measured from 10 movies/condition. All branching data were from movies obtained over 5 experimental days. Data are presented as Gardner-Altman estimation plots. ${ }^{*} p<0.05$, Student's $t$-test. Time in minutes. Scale bar: $15 \mu \mathrm{m}$. 

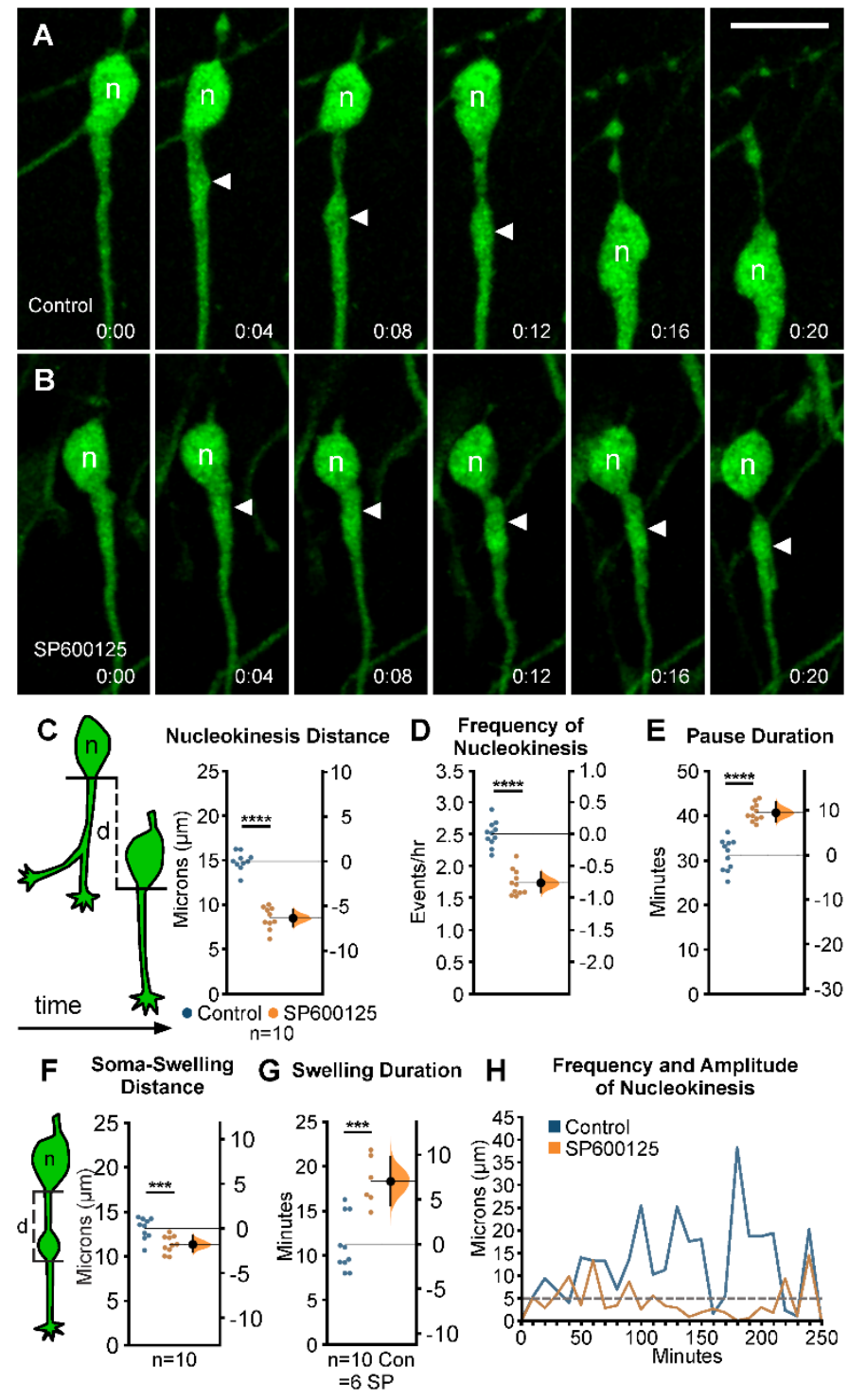

Figure 2.3. Pharmacological inhibition of JNK signaling impairs nucleokinesis in migrating MGE interneurons. A-B. Time series of a control (A) and SP600125-treated (B) interneuron undergoing a single cycle of nucleokinesis. Closed arrowhead $=$ leading process swelling, $n=$ nucleus. C-E. Cortical interneurons treated with JNK inhibitor have significantly shorter somal translocation distances (C), decreased frequency of nucleokinesis (D), and increased pause duration (E) compared to controls. C. Cartoon showing how the distance (d) that an interneuron cell body translocates over time was measured. In each condition, 50 cells were measured from $n=10$ movies obtained over 4 experimental days. F. Cartoon showing how 
the distance (d) that a swelling extends from a cell body was measured. JNK-inhibited cells display significantly decreased distance of swelling extension. G. Swelling duration is significantly increased in JNK-inhibited interneurons. 43 control cells were measured from $n=10$ control movies and 53 treated cells were measured from n=6 SP600125 (SP) movies, each obtained over 4 experimental days. $\mathrm{H}$. Histogram showing nuclear translocation over time for a single cell in each condition. Distance traveled between two points is plotted and every movement above $5 \mu \mathrm{m}$ (grey dashed line) is considered to be a nucleokinesis event. Data in C$\mathrm{G}$ are presented as Gardner-Altman estimation plots. ${ }^{* * *} \mathrm{p}<0.0001,{ }^{* * *} \mathrm{p}<0.001,{ }^{* *} \mathrm{p}<0.01$, Student's $t$-test. Time in minutes. Scale bar: $15 \mu \mathrm{m}$. 

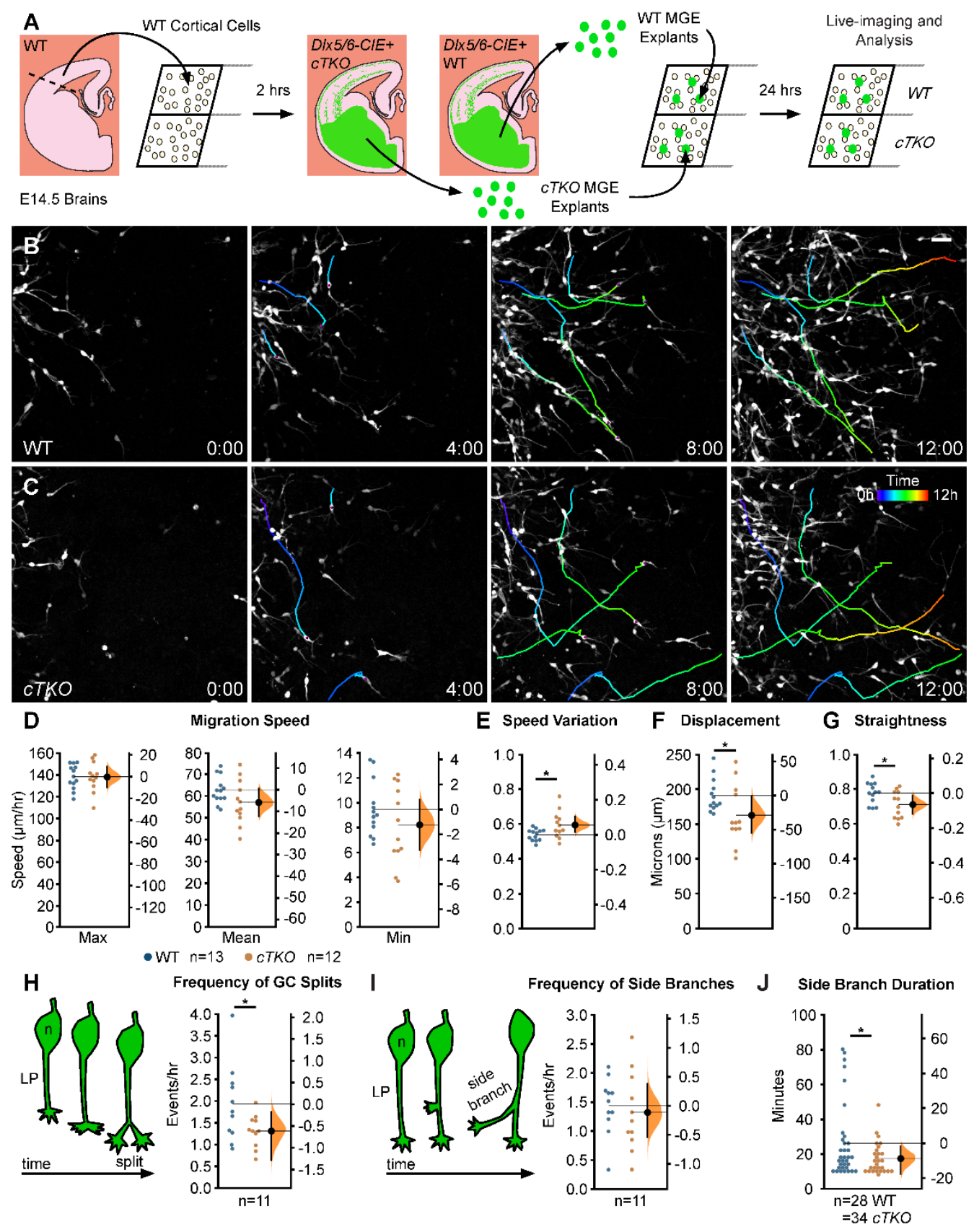

Figure 2.4. Genetic removal of JNK signaling impairs migratory properties and leading process dynamics of MGE interneurons. A. Diagram of MGE explant assay with $D / x 5 / 6-C / E+$ wild-type (WT) or JNK conditional triple knockout (cTKO) explants cultured on WT cortical feeder-cells. B-C. Four individual cell tracks (pseudo-colored by time) from WT or cTKO interneurons imaged live for 12 hours. D-G. Quantification of migratory properties reveals no 
alterations in migratory speed (D), but significant disruptions to speed variation (E), displacement $(F)$, and straightness $(G)$ between control and cTKO interneurons. 120 WT cells were measured from $n=13$ control movies and 130 cTKO cells were measured from $n=12 c T K O$ movies, each obtained over 4 experimental days. H-I. cTKO interneurons have significantly decreased growth cone split frequency $(\mathrm{H})$ without changes in interstitial side branch frequency (I). $n=11$ cells measured from 6 movies/condition collected over 4 experimental days. J. Side branches from cTKO interneurons are significantly shorter-lived than controls. $n=34$ branches were measured from 10 WT cells and $n=28$ branches were measured from 10 cTKO cells recorded from 6 movies/condition obtained over 4 experimental days. Data are presented as Gardner-Altman estimation plots. ${ }^{*} \mathrm{p}<0.05$, Student's $t$-test. Time in hours. Scale bar: $50 \mu \mathrm{m}$. 


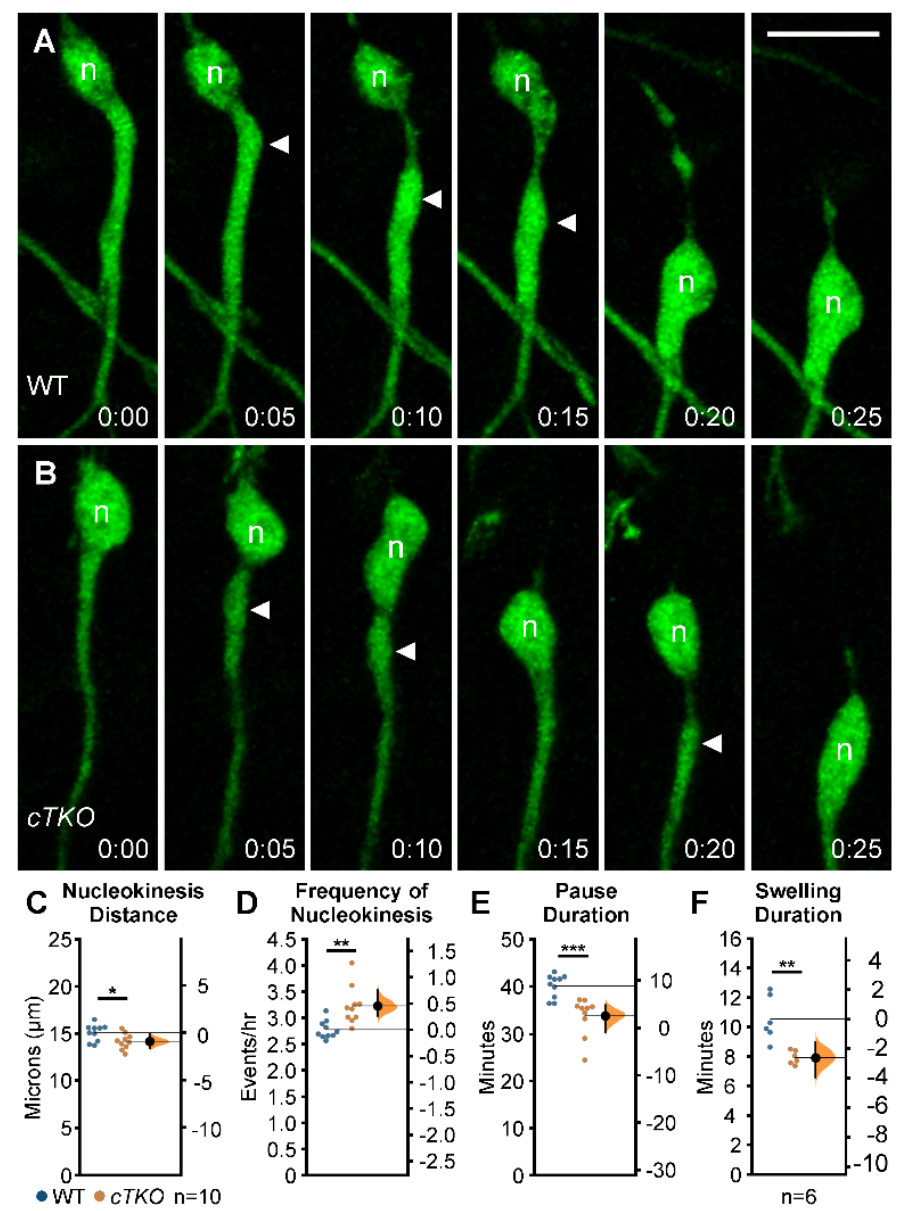

Figure 2.5. Genetic removal of Jnk disrupts nucleokinesis in migrating MGE

interneurons. A. WT cortical interneuron undergoing a single nucleokinesis event. B. cTKO cortical interneuron completing two nucleokinesis events over the same interval of time. Closed arrowhead $=$ leading process swelling, $\mathrm{n}=$ nucleus. $\mathrm{C}-\mathrm{E}$. cTKO interneurons have significantly decreased translocation distance (C), increased translocation frequency (D), and decreased pause duration (E) compared to WT interneurons. In each condition, 50 cells were measured from $n=10$ movies obtained over 4 experimental days. F. cTKO interneurons have decreased swelling duration compared to WT interneurons. 37 WT cells were measured from $n=6$ WT movies and $38 c T K O$ cells were measured from $n=6$ cTKO movies, each obtained over 4 experimental days. Data are presented as Gardner-Altman estimation plots. ${ }^{* * *} p<0.001$, ${ }^{* *} p<0.01,{ }^{*} p<0.05$, Student's $t$-test. Time in minutes. Scale bar: $15 \mu \mathrm{m}$. 

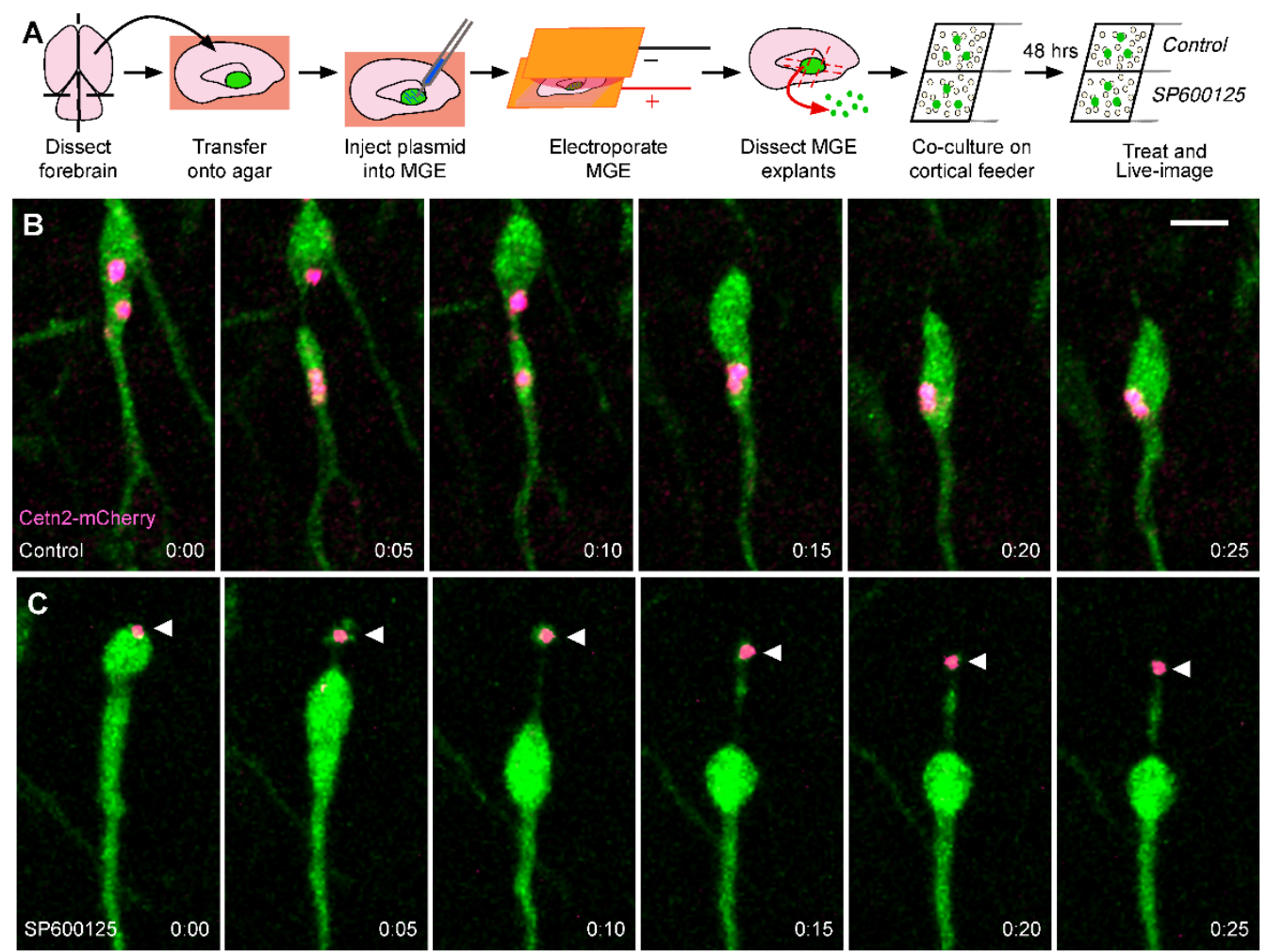

D

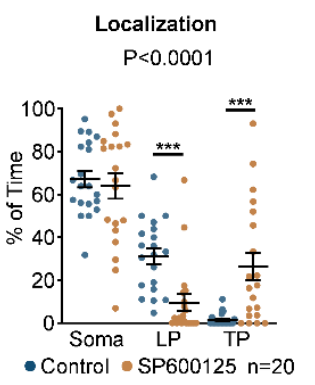

E Present in Formed Swelling

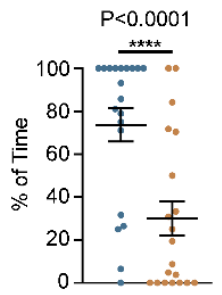

$\mathbf{F}$

Maximum Distance

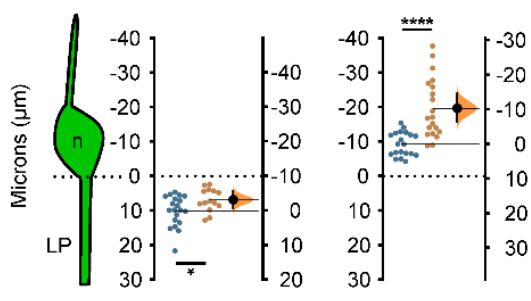

Figure 2.6. Centrosomes are mislocalized in MGE interneurons during JNK inhibition. A.

Diagram depicting ex vivo electroporation of MGE tissue and subsequent culture of MGE explants on cortical feeder cells. B. An interneuron expressing a fluorescently tagged centrosome protein (Centrin2; Cetn2-mCherry) shows translocation of the centrosome into the cytoplasmic swelling prior to nucleokinesis in control conditions. C. A Cetn2-mCherry expressing interneuron treated with SP600125 shows aberrant rearward movement of the centrosome into the trailing process. Arrowhead $=$ Cetn2-mCherry. D. Scatter plot of centrosome distribution over time (Centrosome: Two-way ANOVA: $F_{(2,114)}=13.82 ; \mathrm{P}<0.0001$; $\mathrm{P}<0.0001$ ). Error bars represent mean \pm standard error of the mean (s.e.m.), post-hoc by Fisher's 
LSD ${ }^{* * *} p<0.001,{ }^{* *} p<0.01,{ }^{*} p<0.05$. E. Scatter plot depicting centrosome occupancy of a formed swelling over time $\left(\mathrm{X}^{2}\right.$ test; $\left.{ }^{* * *} \mathrm{P}<0.0001\right)$. Error bars represent mean \pm s.e.m. F. Average maximum distance the centrosome traveled from the soma front (Student's $t$-test; ${ }^{* * *} p<0.0001$, $\left.{ }^{* * *} p<0.001,{ }^{* *} p<0.01,{ }^{*} p<0.05\right)$. In each condition, $n=20$ cells were measured from 11 movies obtained over 5 experimental days. Data in $\mathrm{F}$ are presented as Gardner-Altman estimation plots. Time in minutes. Scale bar: $7.5 \mu \mathrm{m}$. 

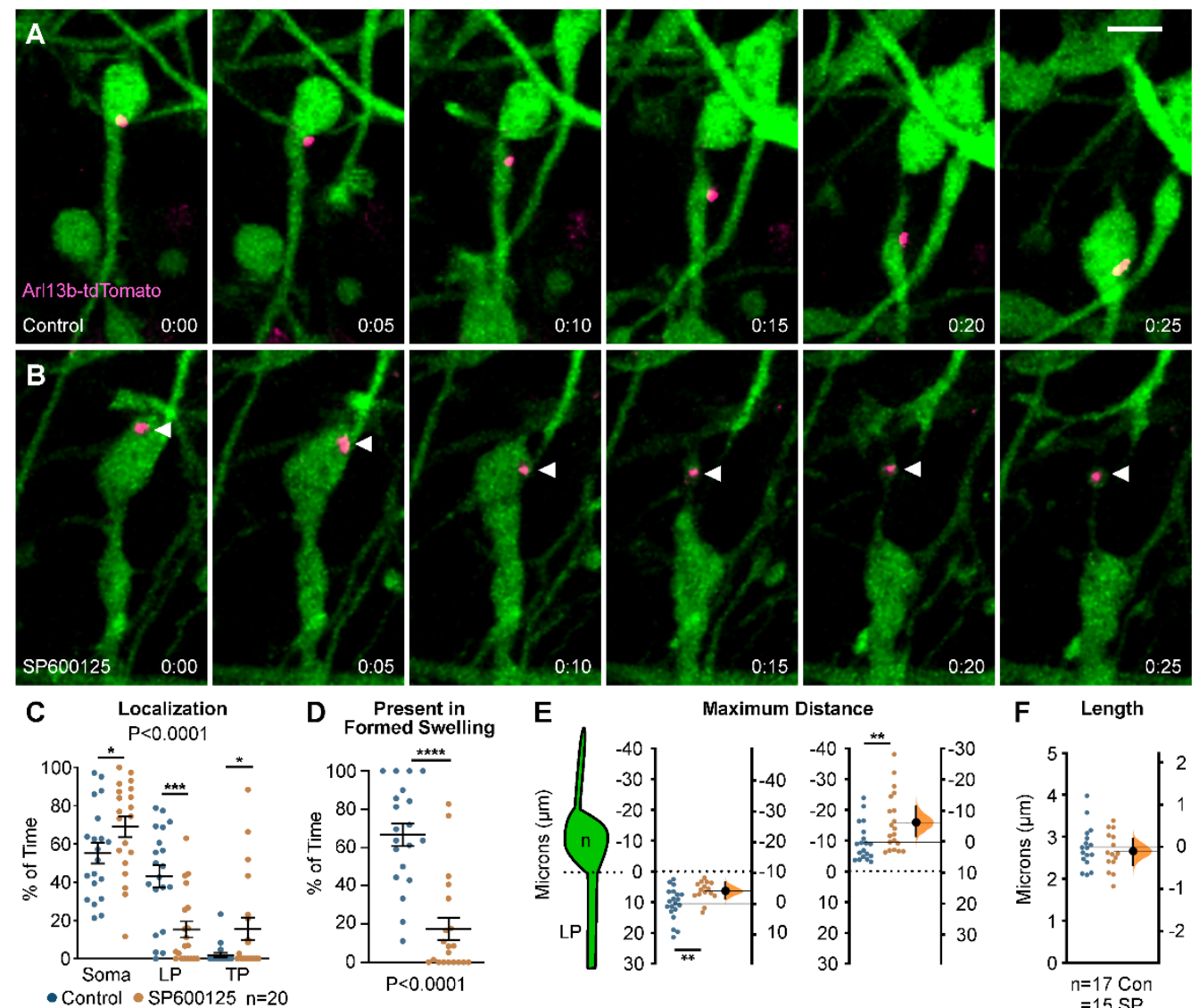

E

Maximum Distance

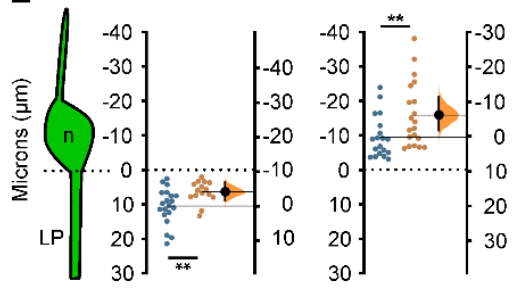

F Length

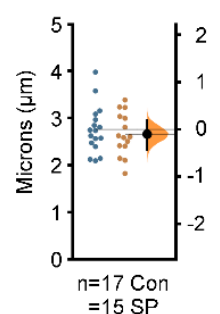

Figure 2.7. Primary cilium localization in MGE interneurons is disrupted during JNK

inhibition. A. An interneuron expressing a fluorescently tagged primary ciliary marker (Arl13btdTomato) shows translocation of the primary cilium into the cytoplasmic swelling prior to nucleokinesis in control conditions. B. An interneuron expressing Arl13b-tdTomato shows aberrant rearward movement of the primary cilium into the trailing process when treated with SP600125. Arrowhead $=$ Arl13b-tdTomato. C. Scatter plot of primary cilium distribution over time (Two-way ANOVA: $\left.F_{(2,114)}=12.13 ; \mathrm{P}<0.0001\right)$. Error bars represent mean \pm s.e.m., post-hoc by Fisher's LSD ${ }^{* * *} p<0.001,{ }^{* *} p<0.01,{ }^{*} p<0.05$. D. Scatter plot depicting primary cilium occupancy of a formed swelling over time $\left(X^{2}\right.$ test; $\left.{ }^{* * *} P<0.0001\right)$. E. Average maximum distance the primary cilium traveled from the soma front (Student's $t$-test; ${ }^{* *} p<0.01$ ). In each condition, $\mathrm{n}=20$ cells were measured from 15 movies obtained over 6 experimental days. $\mathrm{F}$. Average ciliary length measured over time. In each condition, $n=17$ control and $n=15$ SP600125 
(SP) cells were measured over 13 movies and 6 experimental days. Data in $\mathrm{E}$ and $\mathrm{F}$ are presented as Gardner-Altman estimation plots. Student's $t$-test; ${ }^{* * * *} p<0.0001,{ }^{* * *} p<0.001$, ${ }^{* *} p<0.01,{ }^{*} p<0.05$. Time in minutes. Scale bar: $7.5 \mu \mathrm{m}$. 

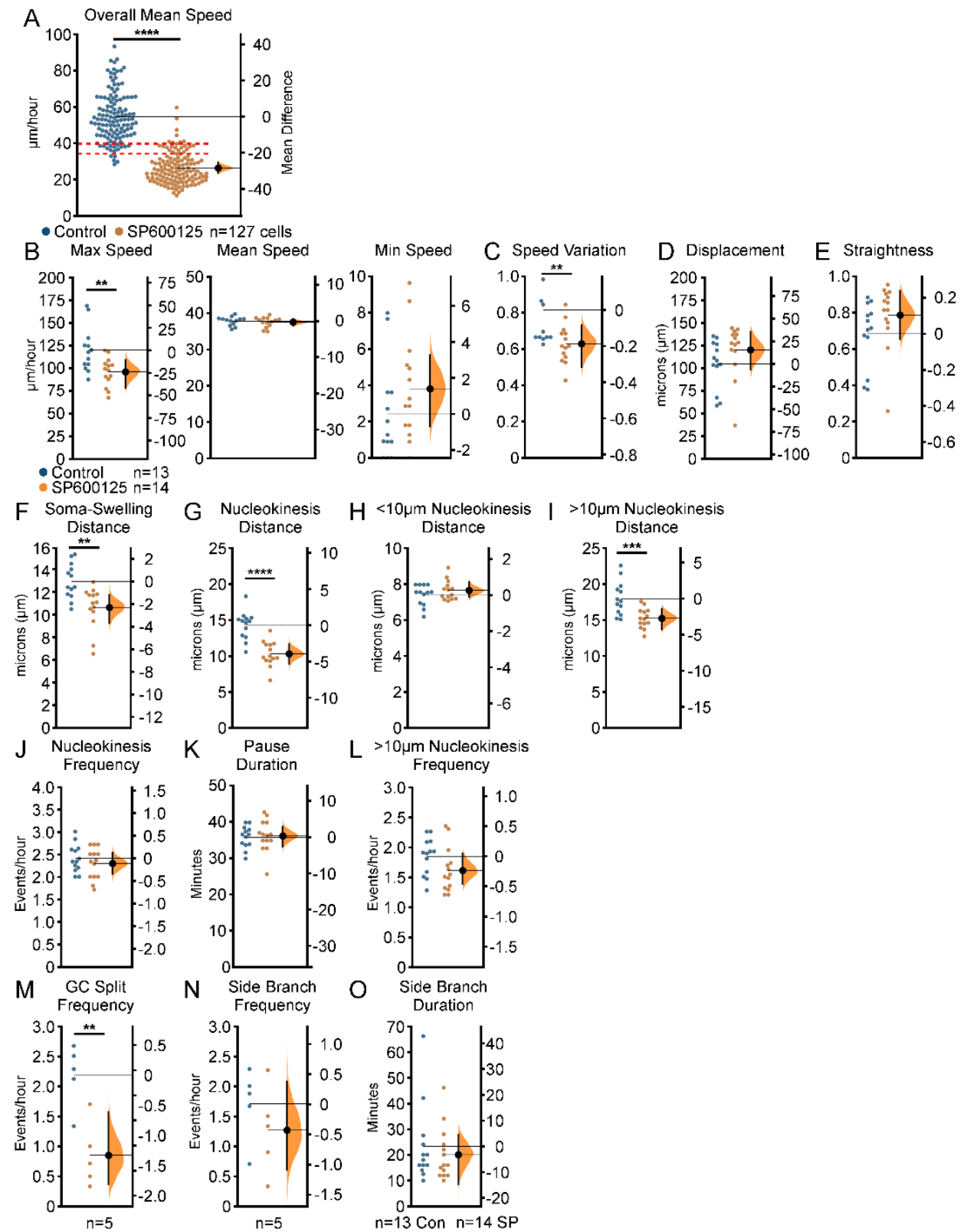

Extended Data Figure 2.1-1. JNK inhibition results in migratory deficits of cortical interneurons regardless of average migratory speed. A. Average migratory speed of individual interneurons in control and JNK inhibited conditions. Red dashed lines highlight cells migrating at the same average speed $(35-40 \mu \mathrm{m} / \mathrm{hr})$. Data are individual data points with 5000 bootstrap sampling distribution with the mean difference between control and SP600125-treated conditions on the right $y$-axis. In each condition, $n=127$ cells from 11 movies obtained over 4 
experimental days. Quantification of migratory properties in interneurons migrating at 35-40 $\mu \mathrm{m} / \mathrm{hr}$ revealed significant disruptions in maximum migration speed (B), and speed variation (C), but not displacement (D) or straightness $(E)$ during JNK inhibition. A total of $n=13$ control cells and $n=14$ SP600125-treated cells collected from 6-7 movies over 4 experimental days were within the 35-40 $\mu \mathrm{m} / \mathrm{hr}$ average speed. F-L. Quantification of nucleokinesis dynamics in control and JNK-inhibition interneurons traveling at the same average migratory speed. Cortical interneurons treated with $20 \mu \mathrm{M}$ SP600125 have significantly shorter average swelling distances $(F)$, smaller average translocation distances $(G)$, no change in short translocation distances $(H)$, and a significant reduction in large translocation distances (I) compared to controls. SP600125 had no effect on average nucleokinesis frequency $(\mathrm{J})$, pause duration $(\mathrm{K})$, or large translocation distance frequency (L) when compared to controls. M-O. Quantification of leading process branching dynamics in control and JNK-inhibited interneurons traveling at the same average migratory speed. Interneurons treated with SP600125 have significantly reduced growth cone split frequencies $(M)$, with no disruptions in side branch frequency $(N)$ or duration $(O)$. In each condition, $n=5$ cells were analyzed from 5 movies collected over 4 experimental days with $n=13$ control and n=14 SP600125 (SP) side branches. Data are presented as Gardner-Altman estimation plots. (Student's $t$-test; ${ }^{* * *} p<0.0001,{ }^{* * *} p<0.001,{ }^{* *} p<0.01,{ }^{*} p<0.05$ ). 
Table 1. Summary of Statistical Analyses. All statistical measurements performed in the study, organized by figure panel. The type of measurement, data structure, type of test, group comparison, and statistical values are included for each analysis. Estimation statistics are provided, where applicable. SP $=$ SP600125.

\begin{tabular}{|c|c|c|c|c|c|c|c|}
\hline & & & & & & Estimat & on Statistics \\
\hline Figure & Measurement & $\begin{array}{l}\text { Data } \\
\text { Structure }\end{array}$ & $\begin{array}{c}\text { Type of } \\
\text { Test }\end{array}$ & Comparison & $\begin{array}{l}\text { Statistical } \\
\text { Value }\end{array}$ & $\begin{array}{l}\text { Two-Sided } \\
\text { Permutation } \\
t \text { test Value }\end{array}$ & $\begin{array}{c}\text { Mean Difference } \\
\text { With } 95 \% \\
\text { Confidence } \\
\text { Interval }\end{array}$ \\
\hline Fig. 1D & $\begin{array}{c}\text { Maximum migration } \\
\text { speed }\end{array}$ & Normal & $\begin{array}{c}\text { Unpaired } \\
t \text { test }\end{array}$ & $\begin{array}{l}\text { Control vs } \\
\text { SP }\end{array}$ & $\begin{array}{c}p=1.68 E-10 ; \\
t_{(20)}=11.86\end{array}$ & 0.0 & $-54.2[-63.1,-46.0]$ \\
\hline Fig. 1D & $\begin{array}{c}\text { Mean migration } \\
\text { speed }\end{array}$ & Normal & $\begin{array}{c}\text { Unpaired } \\
t \text { test }\end{array}$ & $\begin{array}{c}\text { Control vs } \\
\text { SP }\end{array}$ & $\begin{array}{c}p=1.68 E-09 ; \\
t_{(20)}=10.38\end{array}$ & 0.0 & $-28.1[-33.8,-23.6]$ \\
\hline Fig. 1D & $\begin{array}{c}\text { Minimum migration } \\
\text { speed }\end{array}$ & Normal & $\begin{array}{c}\text { Unpaired } \\
t \text { test }\end{array}$ & $\begin{array}{c}\text { Control vs } \\
\text { SP }\end{array}$ & $\begin{array}{c}\mathrm{p}=0.0000717 \\
\mathrm{t}_{(20)}=4.98\end{array}$ & 0.0 & $-4.68[-6.76,-3.08]$ \\
\hline Fig. 1E & Speed variation & Normal & $\begin{array}{c}\text { Unpaired } \\
t \text { test }\end{array}$ & $\begin{array}{l}\text { Control vs } \\
\text { SP }\end{array}$ & $\begin{array}{c}\mathrm{p}=0.000188 \\
\mathrm{t}_{(20)}=-4.56\end{array}$ & 0.0002 & $\begin{array}{c}0.136[0.0827 \\
0.196]\end{array}$ \\
\hline Fig. $1 \mathrm{~F}$ & Displacement & Normal & $\begin{array}{c}\text { Unpaired } \\
t \text { test }\end{array}$ & $\begin{array}{c}\text { Control vs } \\
\text { SP }\end{array}$ & $\begin{array}{c}p=4.73 E-07 \\
t_{(20)}=7.29\end{array}$ & 0.0 & $\begin{array}{c}-81.2[-1.06 e+02 \\
-63.6]\end{array}$ \\
\hline Fig. $1 \mathrm{G}$ & Straightness & Normal & $\begin{array}{c}\text { Unpaired } \\
t \text { test }\end{array}$ & $\begin{array}{c}\text { Control vs } \\
\text { SP }\end{array}$ & $\begin{array}{c}p=0.451 \\
t_{(20)}=0.769\end{array}$ & 0.389 & $\begin{array}{c}-0.0282[-0.0955 \\
0.03]\end{array}$ \\
\hline Fig. 2C & $\begin{array}{l}\text { Maximum leading } \\
\text { process length }\end{array}$ & Normal & $\begin{array}{c}\text { Unpaired } \\
t \text { test }\end{array}$ & $\begin{array}{c}\text { Control vs } \\
\text { SP }\end{array}$ & $\begin{array}{c}p=0.977 ; \\
t_{(18)}=-0.0294\end{array}$ & 0.975 & $0.177[-10.7,11.7]$ \\
\hline Fig. 2C & $\begin{array}{l}\text { Mean leading } \\
\text { process length }\end{array}$ & Normal & $\begin{array}{c}\text { Unpaired } \\
t \text { test }\end{array}$ & $\begin{array}{c}\text { Control vs } \\
\text { SP }\end{array}$ & $\begin{array}{c}p=0.947 \\
t_{(18)}=0.0668\end{array}$ & 0.947 & $\begin{array}{c}-0.257[-6.85 \\
7.48]\end{array}$ \\
\hline Fig. 2C & $\begin{array}{l}\text { Minimum leading } \\
\text { process length }\end{array}$ & Normal & $\begin{array}{c}\text { Unpaired } \\
t \text { test }\end{array}$ & $\begin{array}{c}\text { Control vs } \\
\text { SP }\end{array}$ & $\begin{array}{c}p=0.911 ; \\
t_{(18)}=-0.112\end{array}$ & 0.917 & $0.413[-6.12,7.32]$ \\
\hline Fig. 2D & $\begin{array}{c}\text { Frequency of } \\
\text { growth cone splits }\end{array}$ & Normal & $\begin{array}{c}\text { Unpaired } \\
t \text { test }\end{array}$ & $\begin{array}{c}\text { Control vs } \\
\text { SP }\end{array}$ & $\begin{array}{l}\mathrm{p}=0.0169 \\
\mathrm{t}_{(34)}=2.51\end{array}$ & 0.0146 & $\begin{array}{c}-0.681[-1.13,- \\
0.121]\end{array}$ \\
\hline Fig. $2 \mathrm{G}$ & $\begin{array}{l}\text { Frequency of side } \\
\text { branches }\end{array}$ & Normal & $\begin{array}{c}\text { Unpaired } \\
t \text { test }\end{array}$ & $\begin{array}{c}\text { Control vs } \\
\text { SP }\end{array}$ & $\begin{array}{l}\mathrm{p}=0.900 \\
\mathrm{t}_{(34)}=0.126\end{array}$ & 0.897 & $\begin{array}{c}0.0347[-0.479 \\
0.499]\end{array}$ \\
\hline Fig. $2 \mathrm{H}$ & $\begin{array}{c}\text { Side branch } \\
\text { duration }\end{array}$ & Normal & $\begin{array}{c}\text { Unpaired } \\
t \text { test }\end{array}$ & $\begin{array}{c}\text { Control vs } \\
\text { SP }\end{array}$ & $\begin{array}{l}p=0.016 \\
t_{(102)}=2.46\end{array}$ & 0.0124 & $-7.58[-14.2,-2.12]$ \\
\hline Fig. 3C & $\begin{array}{c}\text { Nucleokinesis } \\
\text { distance }\end{array}$ & Normal & $\begin{array}{c}\text { Unpaired } \\
t \text { test }\end{array}$ & $\begin{array}{l}\text { Control vs } \\
\text { SP }\end{array}$ & $\begin{array}{c}p=2.36 E-10 ; \\
t_{(18)}=12.58\end{array}$ & 0.0 & $-6.36[-7.3,-5.42]$ \\
\hline Fig. 3D & $\begin{array}{c}\text { Nucleokinesis } \\
\text { frequency }\end{array}$ & Normal & $\begin{array}{c}\text { Unpaired } \\
t \text { test }\end{array}$ & $\begin{array}{c}\text { Control vs } \\
\text { SP }\end{array}$ & $\begin{array}{c}\mathrm{p}=1.92 \mathrm{E}-08 \\
\mathrm{t}_{(18)}=8.96\end{array}$ & 0.0 & $\begin{array}{c}-0.765[-0.912,- \\
0.598] \\
\end{array}$ \\
\hline Fig. $3 \mathrm{E}$ & Pause duration & Normal & $\begin{array}{c}\text { Unpaired } \\
t \text { test }\end{array}$ & $\begin{array}{c}\text { Control vs } \\
\text { SP }\end{array}$ & $\begin{array}{c}p=1.45 E-07 ; \\
t_{(18)}=-7.89\end{array}$ & 0.0 & $9.5[7.44,11.8]$ \\
\hline Fig. $3 F$ & $\begin{array}{l}\text { Soma-swelling } \\
\text { distance }\end{array}$ & Normal & $\begin{array}{c}\text { Unpaired } \\
t \text { test }\end{array}$ & $\begin{array}{c}\text { Control vs } \\
\text { SP }\end{array}$ & $\begin{array}{c}\mathrm{p}=0.001698 \\
\mathrm{t}_{(18)}=3.68\end{array}$ & 0.0022 & $\begin{array}{c}-1.79[-2.64,- \\
0.824]\end{array}$ \\
\hline Fig. 3G & Swelling duration & Normal & $\begin{array}{c}\text { Unpaired } \\
t \text { test }\end{array}$ & $\begin{array}{c}\text { Control vs } \\
\text { SP }\end{array}$ & $\begin{array}{l}p=0.00047 \\
t_{(14)}=-4.53\end{array}$ & 0.0014 & $7.04[4.33,9.76]$ \\
\hline Fig. 4D & $\begin{array}{c}\text { Maximum migration } \\
\text { speed }\end{array}$ & Normal & $\begin{array}{c}\text { Unpaired } \\
t \text { test }\end{array}$ & WT vs cTKO & $\begin{array}{c}\mathrm{p}=0.981 \\
\mathrm{t}_{(23)}=0.0236\end{array}$ & 0.982 & $-0.117[-9.81,9.2]$ \\
\hline Fig. 4D & $\begin{array}{c}\text { Mean migration } \\
\text { speed }\end{array}$ & Normal & $\begin{array}{c}\text { Unpaired } \\
t \text { test }\end{array}$ & WT vs cTKO & $\begin{array}{l}\mathrm{p}=0.105 \\
\mathrm{t}_{(23)}=1.69\end{array}$ & 0.11 & $-5.59[-12.0,0.867]$ \\
\hline Fig. 4D & $\begin{array}{c}\text { Minimum migration } \\
\text { speed }\end{array}$ & Normal & $\begin{array}{c}\text { Unpaired } \\
t \text { test }\end{array}$ & WT vs cTKO & $\begin{array}{l}\mathrm{p}=0.260 \\
\mathrm{t}_{(23)}=1.16\end{array}$ & 0.256 & $-1.24[-3.27,0.771]$ \\
\hline Fig. 4E & Speed variation & Normal & $\begin{array}{c}\text { Unpaired } \\
t \text { test }\end{array}$ & WT vs cTKO & $\begin{array}{l}p=0.022 \\
t_{(23)}=-2.46\end{array}$ & 0.0208 & $\begin{array}{c}0.057[0.0166 \\
0.107]\end{array}$ \\
\hline Fig. $4 \mathrm{~F}$ & Displacement & Normal & $\begin{array}{c}\text { Unpaired } \\
t \text { test }\end{array}$ & WT vs cTKO & $\begin{array}{l}\mathrm{p}=0.048 \\
\mathrm{t}_{(23)}=2.09\end{array}$ & 0.0492 & $\begin{array}{c}-29.1[-54.8,- \\
0.875]\end{array}$ \\
\hline Fig. $4 G$ & Straightness & Normal & $\begin{array}{c}\text { Unpaired } \\
t \text { test }\end{array}$ & WT vs cTKO & $\begin{array}{l}\mathrm{p}=0.027 \\
\mathrm{t}_{(23)}=2.37\end{array}$ & 0.0284 & $\begin{array}{c}-0.0651[-0.118 \\
-0.0133]\end{array}$ \\
\hline Fig. $4 \mathrm{H}$ & $\begin{array}{c}\text { Frequency of } \\
\text { growth cone splits }\end{array}$ & Normal & $\begin{array}{c}\text { Unpaired } \\
t \text { test }\end{array}$ & WT vs cTKO & $\begin{array}{l}\mathrm{p}=0.0454 \\
\mathrm{t}_{(20)}=2.13\end{array}$ & 0.0318 & $\begin{array}{c}-0.618[-1.29,- \\
0.183]\end{array}$ \\
\hline
\end{tabular}




\begin{tabular}{|c|c|c|c|c|c|c|c|}
\hline Fig. $4 \mid$ & $\begin{array}{c}\text { Frequency of side } \\
\text { branches }\end{array}$ & Normal & $\begin{array}{c}\text { Unpaired } \\
t \text { test }\end{array}$ & WT vs $c T K O$ & $\begin{array}{c}p=0.658 \\
t_{(20)}=0.448\end{array}$ & 0.654 & $\begin{array}{c}-0.113[-0.542, \\
0.385]\end{array}$ \\
\hline Fig. $4 \mathrm{~J}$ & $\begin{array}{l}\text { Side branch } \\
\text { duration }\end{array}$ & Normal & $\begin{array}{c}\text { Unpaired } \\
t \text { test }\end{array}$ & WT vs cTKO & $\begin{array}{l}\mathrm{p}=0.046 \\
\mathrm{t}_{(60)}=2.04\end{array}$ & 0.044 & $-8.83[-17.7,-1.83]$ \\
\hline Fig. $5 \mathrm{C}$ & $\begin{array}{c}\text { Nucleokinesis } \\
\text { distance }\end{array}$ & Normal & $\begin{array}{c}\text { Unpaired } \\
t \text { test }\end{array}$ & WT vs cTKO & $\begin{array}{l}\mathrm{p}=0.028 \\
\mathrm{t}_{(18)}=2.39\end{array}$ & 0.0298 & $-0.92[-1.61,-0.17]$ \\
\hline Fig. 5D & $\begin{array}{l}\text { Nucleokinesis } \\
\text { frequency }\end{array}$ & Normal & $\begin{array}{c}\text { Unpaired } \\
t \text { test }\end{array}$ & WT vs $c T K O$ & $\begin{array}{c}p=0.00203 \\
t_{(18)}=-3.60\end{array}$ & 0.0012 & $\begin{array}{c}0.458[0.262 \\
0.752]\end{array}$ \\
\hline Fig. $5 \mathrm{E}$ & Pause duration & Normal & $\begin{array}{c}\text { Unpaired } \\
t \text { test }\end{array}$ & WT vs cTKO & $\begin{array}{c}p=0.000464 ; \\
t_{(18)}=4.27\end{array}$ & 0.0002 & $-5.09[-7.84,-3.27]$ \\
\hline Fig. $5 \mathrm{~F}$ & Swelling duration & Normal & $\begin{array}{c}\text { Unpaired } \\
t \text { test }\end{array}$ & WT vs $c T K O$ & $\begin{array}{c}p=0.00257 \\
t_{(10)}=3.99\end{array}$ & 0.0012 & $-2.61[-3.94,-1.54]$ \\
\hline Fig. 6D & $\begin{array}{l}\text { Centrosome } \\
\text { localization }\end{array}$ & Normal & $\begin{array}{c}\text { Two-way } \\
\text { anova } \\
\text { (Post } \\
\text { hoc } \\
\text { Fisher's } \\
\text { exact) } \\
\end{array}$ & $\begin{array}{c}\text { Control vs } \\
\text { SP }\end{array}$ & $\begin{array}{c}P<0.0001 ; \\
F_{(2,114)}=13.82\end{array}$ & NA & 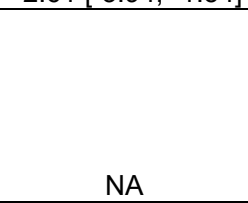 \\
\hline Fig. $6 \mathrm{E}$ & $\begin{array}{c}\text { Centrosome } \\
\text { presence in swelling }\end{array}$ & Normal & $\begin{array}{c}\text { chi } \\
\text { square }\end{array}$ & $\begin{array}{l}\text { Control vs } \\
\text { SP }\end{array}$ & $\begin{array}{c}\mathrm{P}<0.0001 \\
\mathrm{X}^{2}(331.1,1) \\
=18.20\end{array}$ & NA & NA \\
\hline Fig. $6 \mathrm{~F}$ & $\begin{array}{l}\text { Centrosome } \\
\text { maximum distance } \\
\text { forward }\end{array}$ & Normal & $\begin{array}{l}\text { Unpaired } \\
t \text { test }\end{array}$ & $\begin{array}{l}\text { Control vs } \\
\text { SP }\end{array}$ & $\begin{array}{l}\mathrm{p}=0.028 \\
\mathrm{t}_{(38)}=2.30\end{array}$ & 0.0256 & $-3.2[-5.82,-0.79]$ \\
\hline Fig. $6 \mathrm{~F}$ & $\begin{array}{c}\text { Centrosome } \\
\text { maximum distance } \\
\text { behind }\end{array}$ & Normal & $\begin{array}{c}\text { Unpaired } \\
t \text { test }\end{array}$ & $\begin{array}{l}\text { Control vs } \\
\text { SP }\end{array}$ & $\begin{array}{c}p=0.000015 \\
t_{(38)}=4.97\end{array}$ & 0 & $-10.3[-14.6,-6.49]$ \\
\hline Fig. $7 \mathrm{C}$ & Cilia localization & Normal & $\begin{array}{c}\text { Two-way } \\
\text { anova } \\
\text { (Post } \\
\text { hoc } \\
\text { Fisher's } \\
\text { exact) } \\
\end{array}$ & $\begin{array}{c}\text { Control vs } \\
\text { SP }\end{array}$ & $\begin{array}{c}P<0.0001 ; \\
F_{(2,114)}=12.13\end{array}$ & NA & NA \\
\hline Fig. 7D & $\begin{array}{l}\text { Cilia presence in } \\
\text { swelling }\end{array}$ & Normal & $\begin{array}{c}\text { chi } \\
\text { square }\end{array}$ & $\begin{array}{l}\text { Control vs } \\
\text { SP }\end{array}$ & $\begin{array}{c}P<0.0001 \\
X^{2}(314.2 \\
1)=17.72\end{array}$ & NA & NA \\
\hline Fig. 7E & $\begin{array}{l}\text { Cilia maximum } \\
\text { distance forward }\end{array}$ & Normal & $\begin{array}{c}\text { Unpaired } \\
t \text { test }\end{array}$ & $\begin{array}{c}\text { Control vs } \\
\text { SP }\end{array}$ & $\begin{array}{l}\mathrm{p}=0.0094 \\
\mathrm{t}_{(38)}=2.76\end{array}$ & 0.0094 & $-4.16[-7.0,-1.61]$ \\
\hline Fig. 7E & $\begin{array}{c}\text { Cilia maximum } \\
\text { distance behind }\end{array}$ & Normal & $\begin{array}{c}\text { Unpaired } \\
t \text { test }\end{array}$ & $\begin{array}{c}\text { Control vs } \\
\text { SP }\end{array}$ & $\begin{array}{l}\mathrm{p}=0.017 \\
\mathrm{t}_{(38)}=2.51\end{array}$ & 0.0152 & $-6.38[-11.6,-1.97]$ \\
\hline Fig. $7 F$ & Cilia Length & Normal & $\begin{array}{l}\text { Unpaired } \\
\text { t test }\end{array}$ & $\begin{array}{c}\text { Control vs } \\
\text { SP }\end{array}$ & $\begin{array}{l}p=0.558 \\
t_{(30)}=0.592\end{array}$ & 0.575 & $\begin{array}{c}-0.0983[-0.439 \\
0.195]\end{array}$ \\
\hline Fig, 1- & $\begin{array}{l}\text { Mean migration } \\
\text { speed all cells }\end{array}$ & Normal & $\begin{array}{l}\text { Unpaired } \\
\text { t test }\end{array}$ & $\begin{array}{c}\text { Control vs } \\
\text { SP }\end{array}$ & $\begin{array}{l}p=4.65 E-53 ; \\
t_{(252)}=19.74\end{array}$ & 0.0 & $-28.4[-31.1,-25.5]$ \\
\hline $\begin{array}{l}\text { Fig, 1- } \\
1 \mathrm{~B}\end{array}$ & $\begin{array}{c}\text { Maximum migration } \\
\text { speed }\end{array}$ & Normal & $\begin{array}{l}\text { Unpaired } \\
\text { t test }\end{array}$ & $\begin{array}{c}\text { Control vs } \\
\text { SP }\end{array}$ & $\begin{array}{l}p=0.0053 \\
t_{(25)}=3.05\end{array}$ & 0.0042 & $-24.0[-41.8,-10.6]$ \\
\hline $\begin{array}{l}\text { Fig, 1- } \\
1 \mathrm{~B}\end{array}$ & $\begin{array}{c}\text { Mean migration } \\
\text { speed }\end{array}$ & Normal & $\begin{array}{l}\text { Unpaired } \\
\text { t test }\end{array}$ & $\begin{array}{l}\text { Control vs } \\
\text { SP }\end{array}$ & $\begin{array}{l}p=0.559 \\
t_{(25)}=0.592\end{array}$ & 0.545 & $\begin{array}{c}-0.299[-1.28 \\
0.636]\end{array}$ \\
\hline $\begin{array}{l}\text { Fig, 1- } \\
\text { 1B }\end{array}$ & $\begin{array}{c}\text { Minimum migration } \\
\text { speed }\end{array}$ & Normal & $\begin{array}{l}\text { Unpaired } \\
\text { t test }\end{array}$ & $\begin{array}{c}\text { Control vs } \\
\text { SP }\end{array}$ & $\begin{array}{l}p=0.209 \\
t_{(25)}=-1.29\end{array}$ & 0.210 & $1.39[-0.708,3.25]$ \\
\hline $\begin{array}{l}\text { Fig, 1- } \\
1 \mathrm{C}\end{array}$ & Speed variation & Normal & $\begin{array}{l}\text { Unpaired } \\
\text { t test }\end{array}$ & $\begin{array}{c}\text { Control vs } \\
\text { SP }\end{array}$ & $\begin{array}{l}p=0.0038 \\
t_{(25)}=3.19\end{array}$ & 0.0028 & $\begin{array}{c}-0.187[-0.317 \\
-0.0848]\end{array}$ \\
\hline $\begin{array}{l}\text { Fig, 1- } \\
\text { 1D }\end{array}$ & Displacement & Normal & $\begin{array}{l}\text { Unpaired } \\
\text { t test }\end{array}$ & $\begin{array}{c}\text { Control vs } \\
\text { SP }\end{array}$ & $\begin{array}{l}p=0.158 \\
t_{(25)}=-1.45\end{array}$ & 0.172 & $15.6[-5.9,35.7]$ \\
\hline $\begin{array}{l}\text { Fig, 1- } \\
1 \mathrm{E}\end{array}$ & Straightness & Normal & $\begin{array}{c}\text { Unpaired } \\
\text { t test }\end{array}$ & $\begin{array}{l}\text { Control vs } \\
\text { SP }\end{array}$ & $\begin{array}{c}p=0.146 \\
t_{(25)}=-1.49\end{array}$ & 0.162 & $\begin{array}{c}0.104[-0.0304, \\
0.238]\end{array}$ \\
\hline $\begin{array}{l}\text { Fig, 1- } \\
\text { 1F }\end{array}$ & $\begin{array}{c}\text { Soma-Swelling } \\
\text { Distance }\end{array}$ & Normal & $\begin{array}{c}\text { Unpaired } \\
\text { t test }\end{array}$ & $\begin{array}{c}\text { Control vs } \\
\text { SP }\end{array}$ & $\begin{array}{l}p=0.0017 \\
t_{(25)}=3.51\end{array}$ & 0.0008 & $-2.3[-3.7,-1.19]$ \\
\hline $\begin{array}{l}\text { Fig, 1- } \\
1 G\end{array}$ & $\begin{array}{c}\text { Average } \\
\text { Nucleokinesis } \\
\text { Distance }\end{array}$ & Normal & $\begin{array}{l}\text { Unpaired } \\
\text { t test }\end{array}$ & $\begin{array}{l}\text { Control vs } \\
\text { SP }\end{array}$ & $\begin{array}{c}p=8.26 E-06 \\
t_{(25)}=5.58\end{array}$ & 0.0 & $-3.94[-5.36,-2.6]$ \\
\hline $\begin{array}{l}\text { Fig, } 1- \\
1 \mathrm{H}\end{array}$ & $\begin{array}{c}<10 \mu \mathrm{m} \\
\text { Nucleokinesis } \\
\text { Distance }\end{array}$ & Normal & $\begin{array}{l}\text { Unpaired } \\
\text { t test }\end{array}$ & $\begin{array}{l}\text { Control vs } \\
\text { SP }\end{array}$ & $\begin{array}{l}\mathrm{p}=0.239 \\
\mathrm{t}_{(25)}=-1.20\end{array}$ & 0.236 & $\begin{array}{c}0.259[-0.113 \\
0.719]\end{array}$ \\
\hline$\underset{1 \mid}{\text { Fig, } 1-}$ & $\begin{array}{c}>10 \mu \mathrm{m} \\
\text { Nucleokinesis } \\
\text { Distance }\end{array}$ & Normal & $\begin{array}{l}\text { Unpaired } \\
\text { t test }\end{array}$ & $\begin{array}{l}\text { Control vs } \\
\text { SP }\end{array}$ & $\begin{array}{c}p=0.00094 \\
t_{(25)}=3.75\end{array}$ & 0.0004 & $-2.73[-4.26,-1.43]$ \\
\hline
\end{tabular}




\begin{tabular}{|c|c|c|c|c|c|c|c|}
\hline $\begin{array}{l}\text { Fig, 1- } \\
1 \mathrm{~J}\end{array}$ & $\begin{array}{l}\text { Nucleokinesis } \\
\text { Frequency }\end{array}$ & Normal & $\begin{array}{c}\text { Unpaired } \\
\text { t test }\end{array}$ & $\begin{array}{c}\text { Control vs } \\
\text { SP }\end{array}$ & $\begin{array}{c}\mathrm{p}=0.382 \\
\mathrm{t}_{(25)}=0.890\end{array}$ & 0.381 & $\begin{array}{c}-0.111[-0.345 \\
0.123]\end{array}$ \\
\hline $\begin{array}{l}\text { Fig, 1- } \\
1 \mathrm{~K}\end{array}$ & Pause Duration & Normal & $\begin{array}{c}\text { Unpaired } \\
\text { t test }\end{array}$ & $\begin{array}{c}\text { Control vs } \\
\text { SP }\end{array}$ & $\begin{array}{c}p=0.805 \\
t_{(25)}=-0.250\end{array}$ & 0.805 & $0.363[-2.62,2.85]$ \\
\hline $\begin{array}{l}\text { Fig, } 1- \\
1 \mathrm{~L}\end{array}$ & $\begin{array}{c}>10 \mu m \\
\text { Nucleokinesis } \\
\text { Frequency }\end{array}$ & Normal & $\begin{array}{l}\text { Unpaired } \\
\text { t test }\end{array}$ & $\begin{array}{c}\text { Control vs } \\
\text { SP }\end{array}$ & $\begin{array}{l}\mathrm{p}=0.087 \\
\mathrm{t}_{(25)}=1.78\end{array}$ & 0.098 & $\begin{array}{c}-0.233[-0.458 \\
0.0489]\end{array}$ \\
\hline $\begin{array}{l}\text { Fig, 1- } \\
1 \mathrm{M}\end{array}$ & $\begin{array}{c}\text { Frequency of } \\
\text { growth cone splits }\end{array}$ & Normal & $\begin{array}{c}\text { Unpaired } \\
\text { t test }\end{array}$ & $\begin{array}{c}\text { Control vs } \\
\text { SP }\end{array}$ & $\begin{array}{c}p=0.00398 ; \\
t_{(8)}=3.99\end{array}$ & 0.0096 & $\begin{array}{c}-1.33[-1.81,- \\
0.612]\end{array}$ \\
\hline $\begin{array}{l}\text { Fig, 1- } \\
1 \mathrm{~N}\end{array}$ & $\begin{array}{c}\text { Frequency of side } \\
\text { branches }\end{array}$ & Normal & $\begin{array}{c}\text { Unpaired } \\
\text { t test }\end{array}$ & $\begin{array}{c}\text { Control vs } \\
\text { SP }\end{array}$ & $\begin{array}{l}p=0.324 \\
t_{(8)}=1.05\end{array}$ & 0.329 & $-0.44[-1.1,0.369]$ \\
\hline $\begin{array}{l}\text { Fig, 1- } \\
10\end{array}$ & $\begin{array}{c}\text { Side branch } \\
\text { duration }\end{array}$ & Normal & $\begin{array}{c}\text { Unpaired } \\
\text { t test }\end{array}$ & $\begin{array}{c}\text { Control vs } \\
\text { SP }\end{array}$ & $\begin{array}{l}p=0.529 \\
t_{(25)}=0.639\end{array}$ & 0.556 & $-3.16[-14.8,4.59]$ \\
\hline
\end{tabular}




\section{MOVIES}

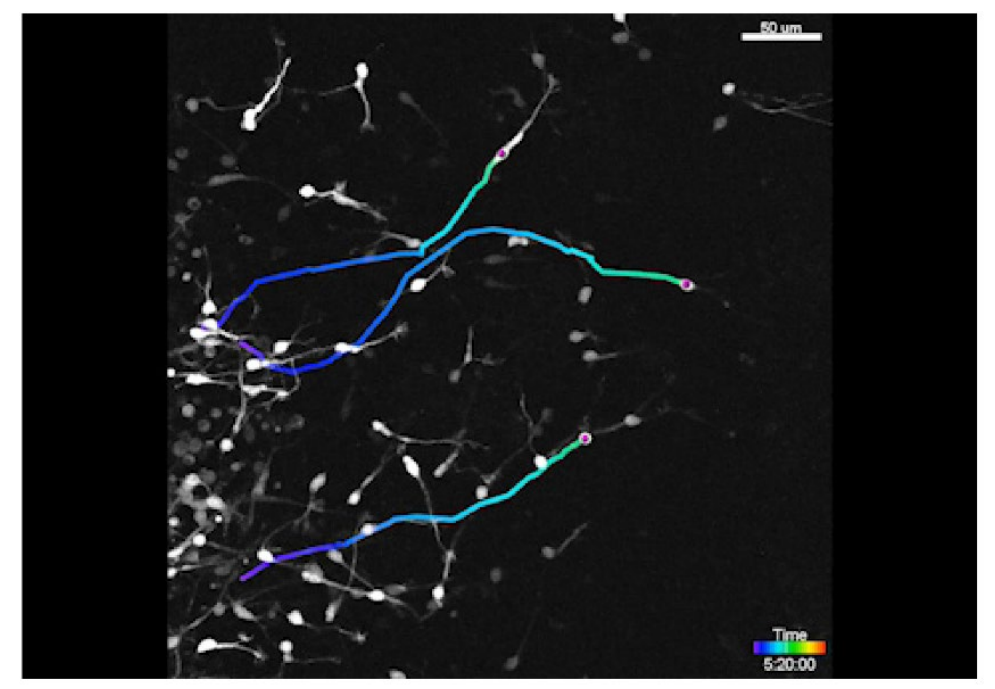

Movie 2.1. Live imaging of MGE interneurons under control conditions. Movie Clip 1. E14.5

DIx5/6-CIE MGE explant cortical cell co-culture imaged live for 12 hours in control conditions. Interneurons robustly migrate from the margin of the MGE explant to fill the field of view. Movie Clip 2. Three MGE interneurons tracked for the duration of the recording. 


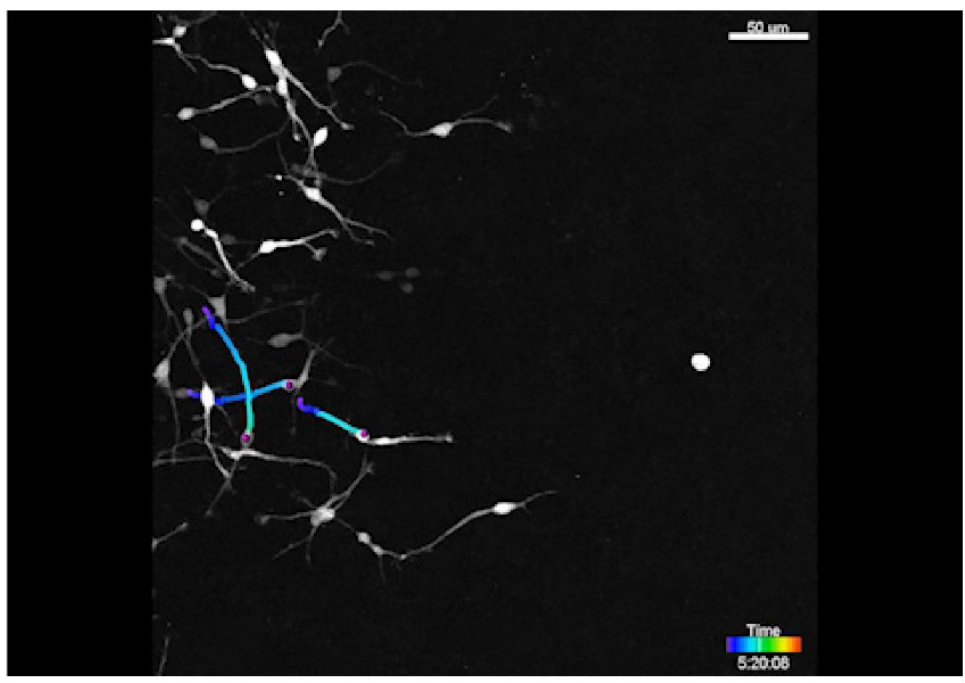

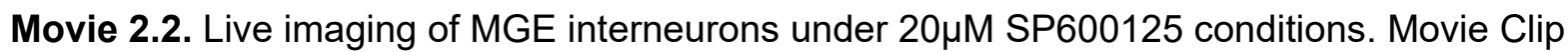
1. E14.5 DIx5/6-CIE MGE explant cortical cell co-culture imaged for 12 hours in SP600125 conditions. Interneurons slowly migrate from the margin of the explant, sparsely populating the field of view. Movie Clip 2. Three MGE interneurons tracked for the duration of the recording. 


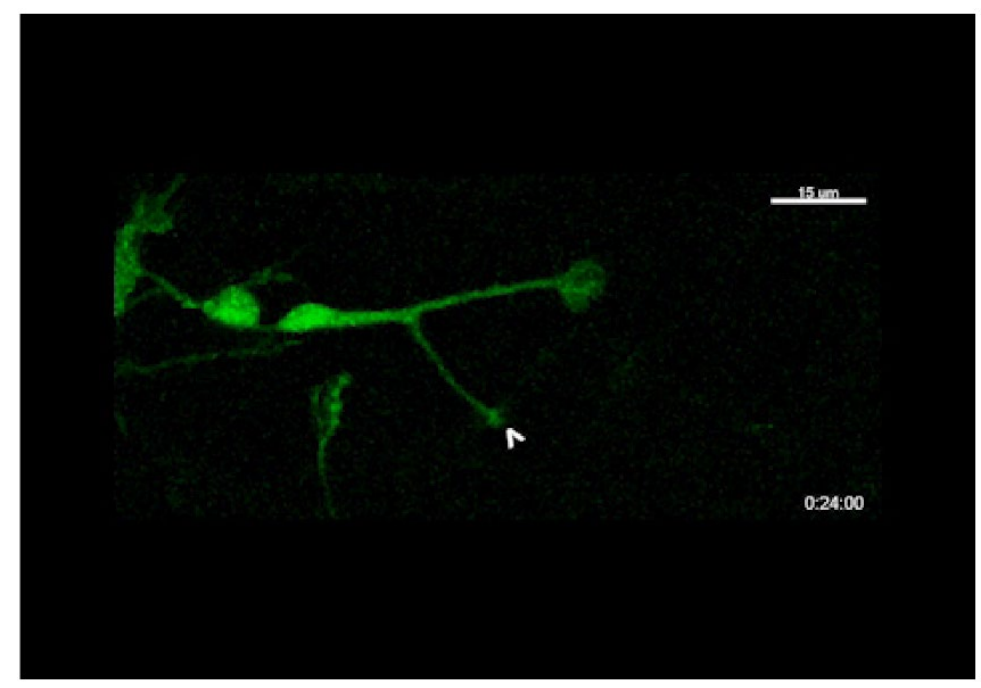

Movie 2.3. Leading process branching dynamics of MGE interneurons under control conditions. Movie Clip 1. Interneuron undergoing growth cone splitting over the course of an hour in control conditions. First growth cone split is marked with an open arrowhead. Movie Clip2. MGE interneuron extending an interstitial side branch (open arrowhead) over the course of an hour. Only side branches persisting for 10 min were measured (see methods). 


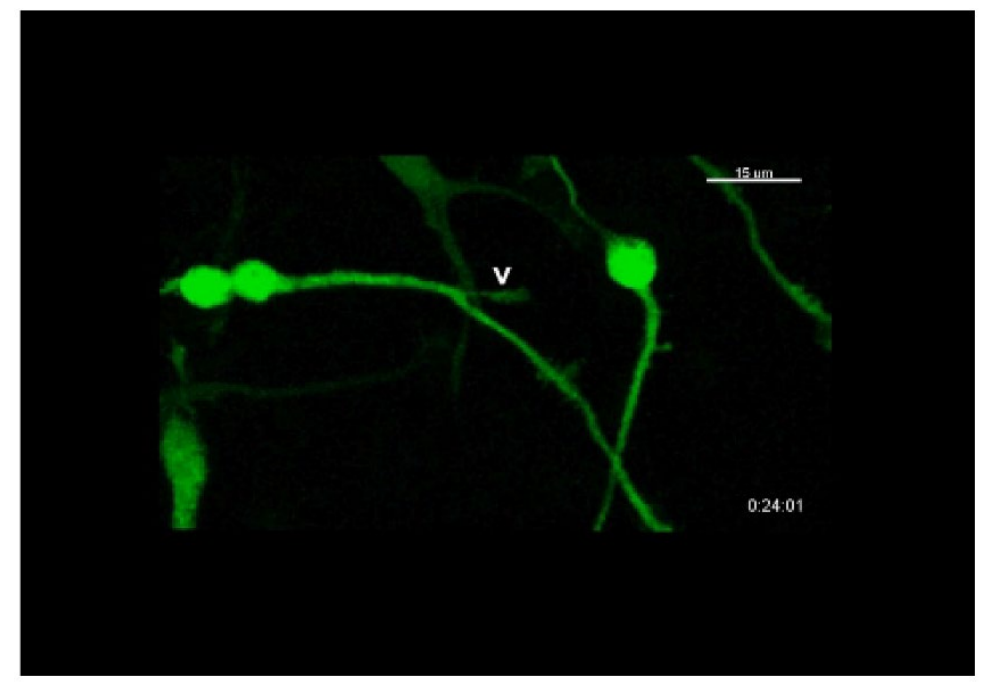

Movie 2.4. Leading process branching dynamics of MGE interneurons under $20 \mu M$ SP600125 conditions. Movie Clip 1. SP600125-treated interneuron undergoing one growth cone splitting event (marked by open arrowhead) over the course of an hour. Movie Clip 2. SP600125-treated interneuron extending a short-lived interstitial side branch (open arrowhead) over the course of an hour. 


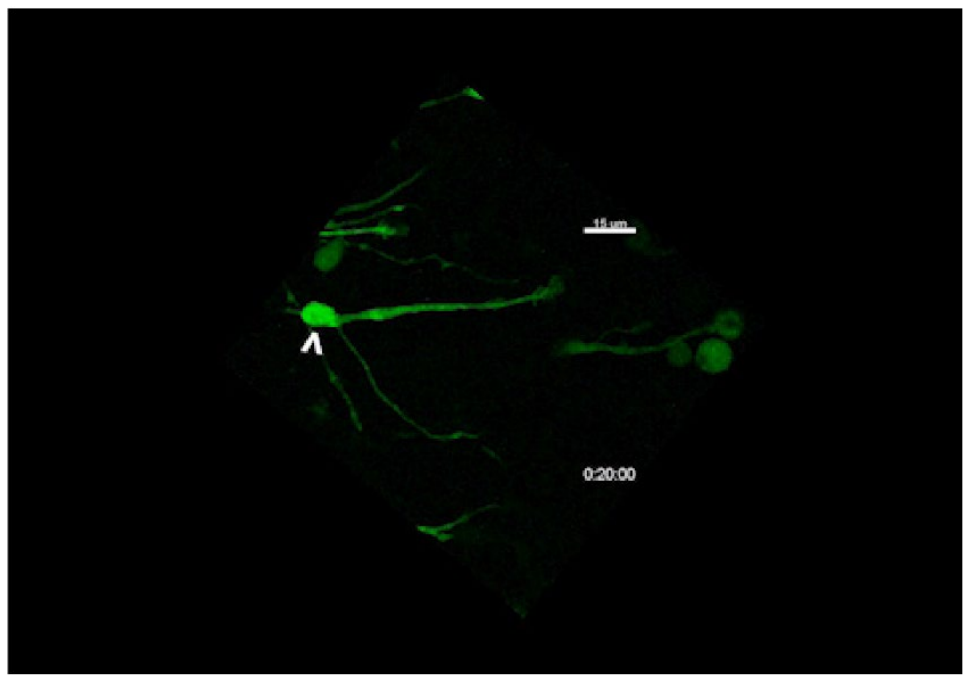

Movie 2.5. Nucleokinesis of MGE interneurons in control and JNK-inhibited conditions.

Movie Clip 1. Interneuron undergoing multiple nucleokinesis events in control conditions. Movie Clip 2. SP600125-treated interneuron engaging in nucleokinesis at a slower rate than control. Open arrowheads mark translocating cell body in both clips. 


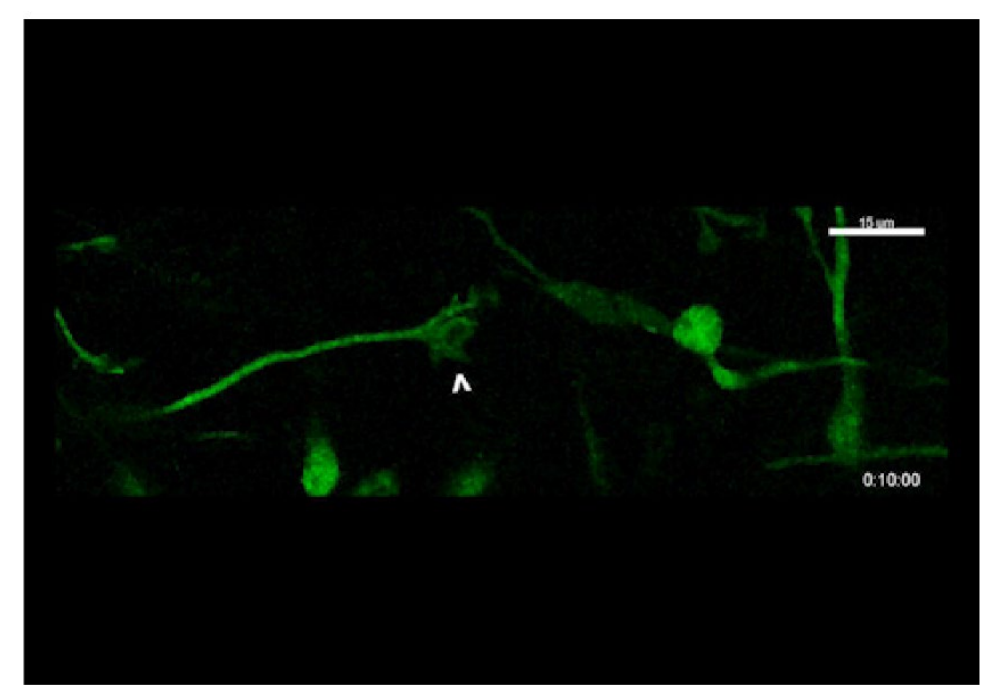

Movie 2.6. Leading process branching dynamics of WT MGE interneurons. Movie Clip 1.

WT interneuron undergoing multiple growth cone splitting events (open arrowhead) over the course of an hour. Movie Clip 2. WT interneuron extending an interstitial side branch (open arrowhead) over the course of an hour. 


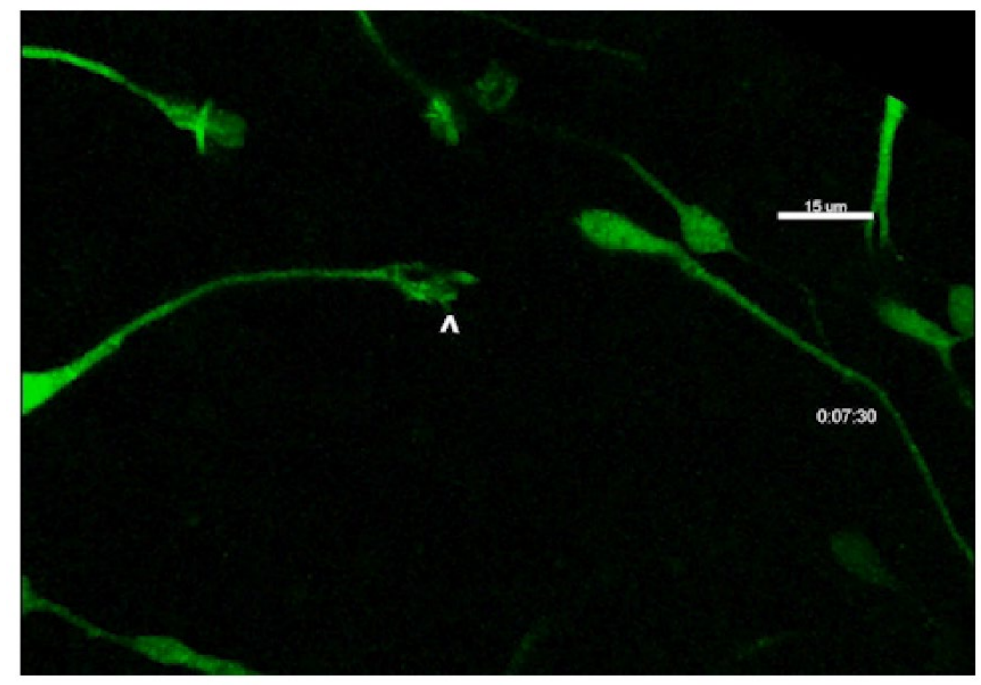

Movie 2.7. Leading process branching dynamics of conditional triple knockout (cTKO) MGE interneurons. Movie Clip 1. cTKO interneuron undergoing fewer growth cone splits (open arrowhead) over the course of an hour compared to control. Movie Clip 2. cTKO interneuron extending a short-lived interstitial side branch (open arrowhead) over the course of an hour. 


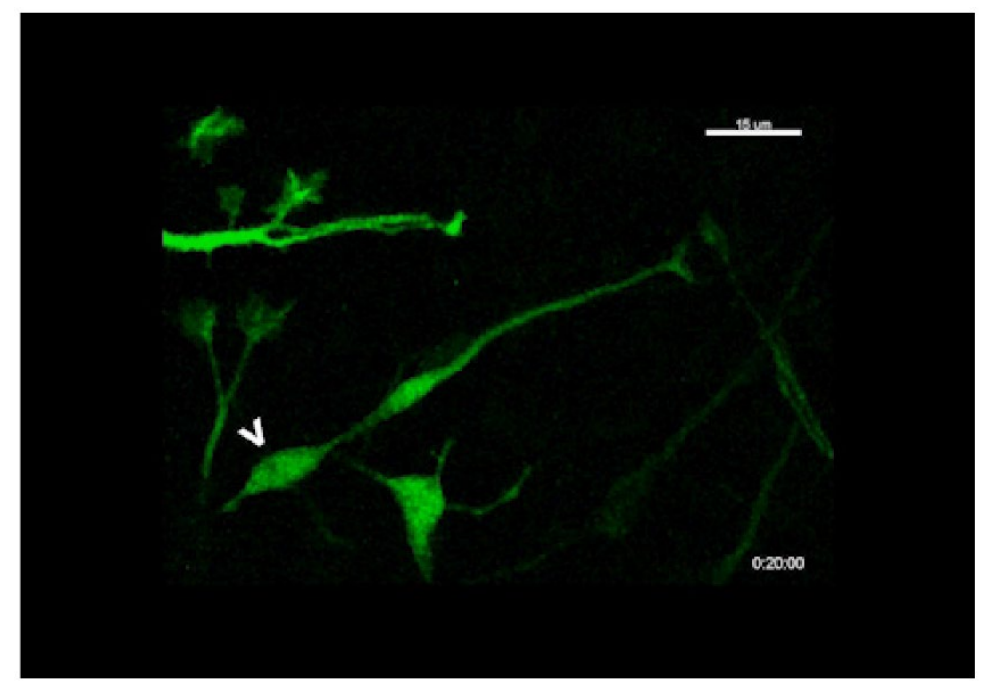

Movie 2.8. Nucleokinesis in WT and cTKO MGE interneurons. Movie Clip 1. WT interneuron undergoing nucleokinesis. Movie Clip 2. cTKO interneuron engaging in nucleokinesis at a higher rate than control. Open arrowheads mark translocating cell body in both clips. 


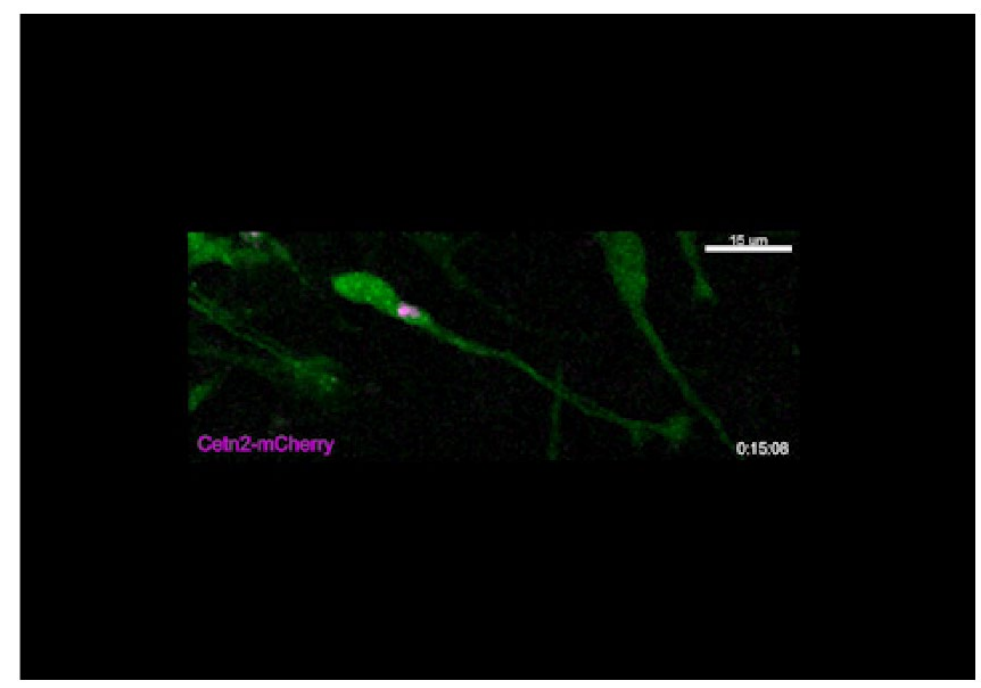

Movie 2.9. Centrosome dynamics in MGE interneurons under control and SP600125-treated conditions. Movie Clip 1. Control interneuron electroporated with centrosomal marker Cetn2mCherry. The centrosome moves from the cell body into the cytoplasmic swelling under control conditions. Movie Clip 2. SP600125-treated interneuron electroporated with Cetn2-mCherry. The centrosome moves from the cell body into the trailing process under SP600125 conditions. Movie Clip 3. A second SP600125-treated interneuron electroporated with Cetn2-mCherry. The centrosome separates into 2 centrioles and moves from the cell body into the trailing process and back under SP600125 conditions. Open arrowheads mark Cetn2-mCherry expressing interneurons in all clips. 


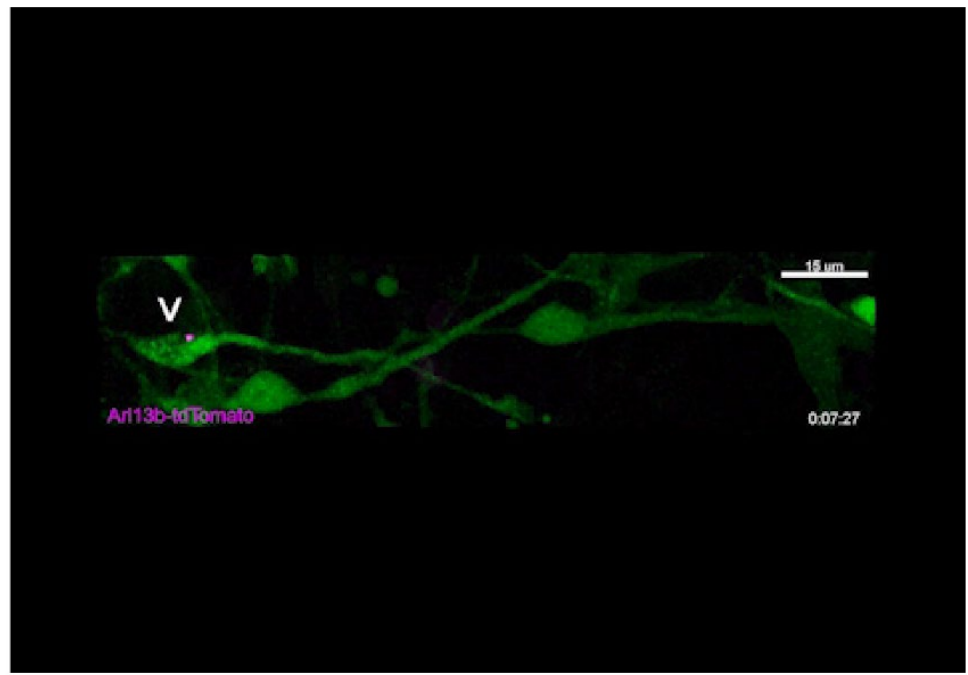

Movie 2.10. Dynamics of primary cilia in MGE interneurons under control and SP600125treated conditions. Movie Clip 1. Interneuron electroporated with primary ciliary marker Arl13btdTomato. The cilium moves from the cell body into the cytoplasmic swelling under control conditions. Movie Clip 2. Interneuron electroporated with Arl13b-tdTomato in SP600125treated conditions. The cilium moves from the cell body into the trailing process under SP600125 conditions. Movie Clip 3. A second interneuron expressing Arl13b-tdTomato under SP600125-treated conditions. The primary cilium moves from the cell body into the trailing process and returns to the cell body without ever entering the swelling. Open arrowheads mark Arl13btdTomato expressing interneurons in all clips. 


\section{Chapter 3: Migrating cortical interneurons require JNK signaling and nanotopographical cues to navigate their environment}

Skye Smith ${ }^{1,2,3}$, Kai Wang ${ }^{5}$, Abigail Myers ${ }^{1,3,4,{ }^{*}}$, Yong Yang ${ }^{5}$, and Eric Tucker ${ }^{1,3}$

${ }^{1}$ Department of Neuroscience, ${ }^{2}$ Biochemistry and Molecular Biology Graduate Program, ${ }^{3}$ Neuroscience Graduate Program, ${ }^{4}$ Rockefeller Neuroscience Institute, West Virginia University School of Medicine, Morgantown, WV 26506. ${ }^{5}$ Department of Biomedical Engineering, West Virginia University Benjamin M. Statler College of Engineering and Mineral Resources, Morgantown, WV 26506.

*Present address: Department of Pathology, Brigham and Women's Hospital, Harvard Medical School, Boston, MA 02115, USA.

Correspondence: etucker@hsc.wvu.edu

Running title: JNK controls nucleokinesis of interneurons

Key Words: GABAergic interneuron; development; topography; nanopattern; neuronal migration; live imaging 


\section{ABSTRACT}

During embryonic development, cortical interneurons travel tangentially in two migratory streams to reach the cerebral cortex and then turn radially to exit migratory streams and invade the cortical plate. Migrating cortical interneurons must constantly integrate both extracellular signals from the environment with intracellular machinery to maintain directed migration. Many of the intracellular mechanisms governing the timing of migratory stream exit and cortical plate invasion are poorly understood yet are of fundamental importance to cortical development. Our lab previously found that disruption of the c-Jun $\mathrm{NH}_{2}$-terminal kinase (JNK) signaling pathway results in a delayed entry of cortical interneurons into the cortex, as well as a premature departure from migratory streams. Here, we aimed to uncover the mechanisms by which JNK activity coordinates the cellular processes essential for the migration of cortical interneurons. In this study, we used multiple ex vivo and in vitro assays to establish that cortical interneurons require JNK signaling for migration. Interneurons treated with JNK inhibitor exhibit major deficiencies in migratory properties including nucleokinesis distance, rate of nucleokinesis events, and pause duration. Additionally, we developed a novel tool to explore the role of nanotopographical cues on cortical interneuron migration using an in vitro nanopattern substrate. Interneurons grown on nanopatterns have significantly faster migratory speeds and translocate further distances than cells on flat substrates, while maintaining a straighter migratory trajectory. Interneurons grown on nanopatterns also display a different subcellular distribution of Doublecortin, a microtubule associated protein involved in the guided migration of cortical interneurons. Our results highlight the importance of JNK signaling in migration of cortical interneurons regardless of their migratory environment and suggest that cortical interneurons are able to decipher topographical cues presented on a nanoscale level in order to orient their direction of migration. 


\section{INTRODUCTION}

Neuronal migration is a highly regulated process that is critical for the development of the cerebral cortex. Cortical interneurons born in the medial and caudal ganglionic eminences of the ventral forebrain must migrate through a complex three-dimensional environment before reaching the cerebral cortex (Anderson et al., 1997; Lavdas et al., 1999; Wichterle et al., 2001). During this migration, cortical interneurons migrate from the ventral telencephalon into the cortex, then assemble into tangential migratory streams, and finally infiltrate the cortical plate to establish proper cortical circuitry (Wichterle et al., 1999; Nery et al., 2002; Xu et al., 2004; Miyoshi et al., 2010). Thus, cortical interneurons are exposed to different chemical, topographic, and mechanical cues that they must detect and respond to in order to enter and navigate the cortex.

During migration, cortical interneurons undergo a two-stroke cyclical process of movement, termed nucleokinesis, to physically move their cell bodies in the direction of migration. During nucleokinesis, interneurons push forward a cytoplasmic swelling into their leading process, translocate their cell bodies into the swelling, then repeat the cycle (Morris et al., 1998; Moya and Valdeolmillos, 2004; Bellion et al., 2005). Failure to coordinate the cellular events involved in nucleokinesis can disrupt interneuron migration and impair the development of cortical circuitry which is thought to underlie autism spectrum disorder, schizophrenia, and epilepsy (Kato and Dobyns, 2005; Hildebrandt et al., 2011; Meechan et al., 2012; Volk et al., 2015). While progress has been made on elucidating the complex cell-extrinsic and -intrinsic cues that control nucleokinesis (Tsai and Gleeson, 2005; Baudoin et al., 2012; Godin et al., 2012; Silva et al., 2018; Su et al., 2019), the role that many of the intracellular signaling pathways play in this process remain largely unknown. 
The c-Jun $\mathrm{NH}_{2}$-terminal kinases (JNKs) are evolutionarily conserved members of the mitogenactivated protein kinase (MAPK) super-family and are encoded by three genes Jnk1 (Mapk8), Jnk2 (Mapk9), and Jnk3 (Mapk10) (Davis, 2000; Chang and Karin, 2001). The JNK proteins signal by phosphorylating different substrates in response to extracellular stimuli to enable normal physiological processes including cell proliferation, apoptosis, differentiation, and migration (Davis, 2000). JNK signaling has been implicated in multiple aspects of brain development including migration of cortical neurons (Hirai et al., 2006; Wang et al., 2007; Westerlund et al., 2011; Yamasaki et al., 2011; Zhang et al., 2016) and in cognitive disorders in humans (Kunde et al., 2013; McGuire et al., 2017). Previously, we discovered that JNK signaling controls cortical interneuron entry into the cerebral cortex as well as the formation and maintenance of tangential migratory streams during embryonic development (Myers et al., 2014; Myers et al., 2020). Additionally, using a cortical cell co-culture assay, we discovered a key role for JNK signaling in regulating nucleokinesis and leading process dynamics of individual migrating MGE interneurons (Smith et al., 2020). However, the role of JNK signaling in migratory dynamics of individual interneurons grown in different substrates and the involvement of topographical cues in the guided migration of cortical interneurons remain unknown.

In the current study, we use multiple substrates to assess the role of JNK signaling in nucleokinesis dynamics of migrating cortical interneurons. Pharmacological inhibition of JNK signaling in ex vivo slice cultures and in vitro 3-dimensional Matrigel matrixes confirm our previous findings in our in vitro co-culture assay. JNK inhibition results in significantly altered nucleokinesis dynamics in migrating cortical interneurons. Additionally, we describe a novel tool to explore cortical interneuron migration using nanopattern topography to control speed and direction of migration. Interestingly, interneurons migrating on nanopatterns have altered subcellular distribution of doublecortin, a microtubule associated protein involved in the 
migration of cortical interneurons. Together, our findings suggest a role for JNK signaling in the guided migration of cortical interneurons regardless of substrate or topographical environment.

\section{RESULTS}

Cortical interneurons require JNK signaling for proper migration regardless of substrate

In the current study, we examined the role of c-Jun $\mathrm{NH}_{2}$-terminal kinase (JNK) signaling in the migratory dynamics of individual interneurons grown in different substrate and topographical environments. To assess the role of JNK signaling in the migration of cortical interneurons on different substrates, we compared the migration of MGE cells in control and JNK-inhibited conditions in ex vivo slices, on dissociated cortical cells (Smith et al., 2020), and in a 3D Matrigel matrix.

We first cultured live sections from embryonic day 14.5 (E14.5) DIx5/6-Cre-IRES-EGFP (D/x5/6$\mathrm{CIE+}$ ) mouse brains in either control or JNK-inhibited conditions for $12 \mathrm{~h}$ (Fig. 3.1A). The panJNK inhibitor SP600125 (Bennett et al., 2001) was used to pharmacologically inhibit JNK signaling at a concentration previously shown to delay interneuron entry into the cerebral cortex and disrupt tangential migration, but not cell viability (Myers et al., 2014; Myers et al., 2020). We

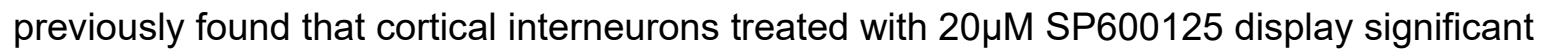
disruptions to their migratory properties including decreased migratory speeds, track displacement and track straightness (Myers et al., 2014; Myers et al., 2020), however, the cellular bases for these disruptions were not investigated. To begin this assessment, we measured the effect of JNK inhibition on nucleokinesis, an obligate cell biological mechanism of neuronal migration (Fig. 3.1B-F). Time-lapse recordings show that under control conditions, a single cycle of nucleokinesis starts with the extension of a cytoplasmic swelling into the leading process and ends with the translocation of the cell body into the swelling (Fig. 3.1B). Although JNK-inhibited interneurons were able to complete nucleokinesis, the distance and kinetics of 
individual nucleokinesis events were disrupted (Fig. 3.1C). When we measured the mean distance of nucleokinesis over time, JNK-inhibited cortical interneurons translocated significantly shorter distances compared to controls (Control: 16.48 \pm 0.46 ; SP600125: 10.83 $\pm 0.88 \mu \mathrm{m}$; $p=0.0047$; Fig. 3.1D). Since nucleokinesis is known to be cyclical, with the cell translocating its cell body into the leading process, and pausing before repeating the process, we measured the rates of nucleokinesis and pause duration in control and JNK-inhibited conditions. JNK-inhibited cortical interneurons completed significantly fewer translocation events per hour (Control: $2.82 \pm 0.17$; SP600125:1.51 \pm 0.08 events/hr; $p=0.0022$; Fig 3.1E) and displayed longer pauses between the initiation of nucleokinesis events (Control: $27.85 \pm 1.72$; SP600125 42.79 \pm 2.17 minutes; $p=0.0057$; Fig. 3.1F).

To assess the effect of JNK-inhibition on nucleokinesis of cortical interneurons in a 3D matrix, we developed an in vitro explant assay in which explants of E14.5 D/x5/6-CIE+ medial ganglionic eminence (MGE) tissue were grown in 3D Matrigel (Fig 3.2). After 1 day of growth, control medium or medium containing $20 \mu \mathrm{M}$ SP600125 was added to each well, and interneurons were imaged live for $12 \mathrm{~h}$ (Fig. 3.2A). At the beginning of imaging (Time 0), the field of view was placed at the distal edge of interneuron outgrowth (Fig. 3.2B,D). While many control interneurons appeared to migrate into the field of view by 12 hours of imaging (Fig. 3.2C), SP600125-treated cells failed to progress as far, appearing to move at slower rates (Fig. 3.1E). Indeed, we found that inhibiting JNK signaling in interneurons migrating in a 3D Matrigel impairs their migratory properties (Myers et al., 2020). Additionally, interneurons grown in Matrigel exhibited similar nucleokinesis cycles as in slices, with a swelling preceding nuclear translocation (Fig. 3.2F-G). However, SP600125-treated interneurons again displayed disrupted nucleokinesis compared to controls (Fig. 3.2F-G). The average distance that SP600125-treated cells traveled forward during nucleokinesis was significantly shorter compared to that of the control cells (Control: 11.18 \pm 0.71 ; SP600125: 8.36 $\pm 0.14 \mu \mathrm{m} ; \mathrm{p}=0.005$; Fig. 3.2H). Additionally, 
JNK-inhibited cells took longer to complete nucleokinesis events (Control: 2.26 \pm 0.20 ;

SP600125: 1.49 \pm 0.047 events/hr; p=0.006; Fig. 3.2I), with longer pause durations (Control:

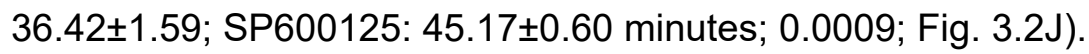

MGE interneurons co-cultured on dissociated cortical cells required JNK signaling for nucleokinesis (Smith et al., 2020). Co-cultured interneurons treated with SP600125 displayed short nuclear translocation distances, less frequent translocation events, and long pauses between translocations (Smith et al., 2020). The results found in ex vivo slices, 3D Matrigel, and co-cultures appear to phenocopy each other (Table 3.1). Interestingly, cortical interneurons appear to have a cell-intrinsic requirement for JNK in nucleokinesis, evident by our 3D Matrigel results with interneurons migrating in the absence of other cortical cells. Together, these data suggest that migrating cortical interneurons require JNK signaling to regulate nucleokinesis dynamics regardless of the environment in which they are grown.

\section{Nanopattern topography mimics control environment for migrating cortical interneurons}

Here we have shown that JNK signaling controls interneuron migration through nucleokinesis in multiple environments. However, these studies do not address the potential influence of topographical cues during cortical interneuron migration that could shape their migratory trajectories. Indeed, previous studies exploring guided cell migration determined that cancer cells align to and travel faster in the direction of nanotopographical grooves, suggesting that the physical architecture of the extracellular environment can influence guided cell migration (Nam et al., 2016; Ray et al., 2017). Therefore, we developed an in vitro assay using nanopatterned polystyrene (PS) to examine the role of topographical architecture on cortical interneuron migration.

Flat and nanopatterned polydimethylsiloxane (PDMS) or PS substrates were prepared as in (see methods; Wang et al., 2016). A nanopattern mask was produced on a thin film of 
polymethylmethacrylate (PMMA) spin-coated on a silicon substrate. The PMMA mask was used cast the nanopatterned or flat substrate from PDMS or PS to create a sheet of nanopatterned surface with $500 \mathrm{~nm}$ width and $500 \mathrm{~nm}$ height grooves (Fig. 3.3A). Once the substrates were constructed, the sheet was then secured to the bottom of 8-well coverglass slides using oxygen plasma treatment and weight (Fig. 3.3B). A representative image of both flat and nanopatterned substrates is shown (Fig. 3.3C). To initially assess the effect of nanopatterned substrate on the morphology and migration of cortical interneurons, we cultured E14.5 D/x5/6-CIE+ MGE explants on flat or nanopatterned substrates for $24 \mathrm{~h}$ then examined their outgrowth (Fig. 3.3D). From here, we determined the optimal oxygen plasma treatment exposure, coating method, and substrate material to utilize for experiments (Supplemental Fig. 3.1A-F). We determined that the best coating method was a thin layer of Matrigel on PS that allowed for MGE interneurons to adhere to the flat and nanopatterned substrates without disrupting the grooves of the nanopattern gratings (Supplemental Fig. 3.1F).

Using this method, we cultured E14.5 D/x5/6-CIE+ explants on flat or nanopatterned substrates for $24 \mathrm{~h}$, then live-imaged cultures and analyzed the migratory properties of individual MGE interneurons on flat and nanopattern substrates over time to assess the role of topographical environment on interneuron migration (Fig. 3.4). The individual trajectories of interneurons cultured on flat substrates appeared to be more random, without directionality compared to interneurons tracked on nanopatterns (Fig. 3.4A-B). Indeed, tracks from individual cells on nanopatterns were much longer and straighter than cells migrating on flat substrate (Representative tracks Fig. 3.4C-D). Interneurons on nanopatterned substrate had significantly faster average migratory speeds when compared to migration on flat substrates (Flat: 40.73 $\pm 6.61 \mathrm{um} / \mathrm{hr}$; Nanopattern: 56.59 $\pm 4.21 \mathrm{um} / \mathrm{hr} ; \mathrm{p}=0.05$; Fig. 3.4E). While the mean speeds of interneurons cultured on nanopatterns was greater than on flat substrate, the speed variation remained unchanged (Flat: 0.93 \pm 0.06 ; Nanopattern: 0.88 $\pm 0.05 ; p=0.062 ;$ Fig. 3.4F). Likely due 
to the decrease in migratory speed, the displacement of interneurons cultured on nanopatterns was significantly greater than that of flat substrates (Flat: 48.16 \pm 7.01 ; Nanopattern: 91.26 \pm 12.11 um/2 hours; $p=0.018$; Fig. 3.4G). Additionally, interneurons cultured on nanopatterns maintained a significantly straighter migratory trajectory when compared to

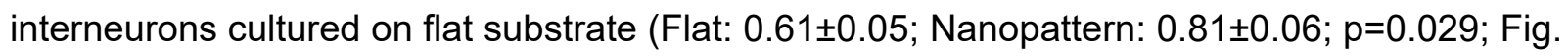
$3.4 \mathrm{H})$.

Collectively, these data suggest that the migratory behavior of MGE interneurons can be controlled by nanopattern gratings and increases their migratory speed and the overall displacement and straightness of their migratory trajectories. Surprisingly, the migratory deficits seen on the flat substrate mimicked the effects we previously found during JNK-inhibition.

\section{Interneurons migrating on flat substrate have disrupted nucleokinesis dynamics when compared to cells migrating on nanopatterns}

Since there were significant differences in the migratory properties of interneurons migrating on flat and nanopattern substrates, we aimed to further examine the effect of topographical environment on nucleokinesis dynamics.

Time-lapse recordings revealed that cells migrating on flat substrate initiate nucleokinesis with the extension of a cytoplasmic swelling into the leading process and end with the translocation of the cell body into the swelling (Fig. 3.5A). However, interneurons migrating on nanopatterns appeared to translocate greater distances over the same period of time (Fig. 3.5B). When we quantified the average distance that cell bodies advanced over time, interneurons migrating on nanopatterns translocated significantly further than cells on flat substrate (Flat: $13.00 \pm 0.85$; Nanopattern: 19.24 $\pm 1.13 ; p=0.001$; Fig. 3.5C). However, interneurons migrating on nanopatterns completed nucleokinesis at similar rates (Flat: $2.88 \pm 0.16$ events/hr; Nanopattern: 2.53 $\pm 0.23 ; p=0.24 ;$ Fig. 5D) when compared to interneurons migrating on flat substrate. Along 
with this, cells on nanopatterns paused for similar durations between nucleokinesis events (Flat: 30.21 \pm 2.08 ; Nanopattern: $34.71 \pm 2.39$ minutes; $p=0.19$; Fig. $3.5 E$ ) compared to cells on flat substrate.

Together, these data suggest that the cortical interneurons are capable of deciphering nanotopographic cues to regulate the straightness of their migratory trajectory and distance of nucleokinesis. This likely contributes to the increase in migratory speed and displacement seen when interneurons are grown on a nanopatterned substrate.

\section{Interneurons aligned to nanotopographical gratings have altered cytoskeletal dynamics}

It was recently discovered that cortical interneurons contained more stable microtubules along their leading processes when migrating on 10 4 m square micropatterns (Leclech et al., 2019). However, the effect of nanoscale topographical cues on cytoskeletal dynamics has not been examined. Since interneurons migrating on nanopatterned and flat substrate have significantly difference migratory properties and nucleokinesis dynamics, we sought to assess the effects of these substrates on cytoskeletal dynamics. Loss of the microtubule binding protein doublecortin (Dcx) impairs migration by disrupting nucleokinesis of migrating cortical interneurons (Kappeler et al., 2006). Dcx is thought to accumulate where the need for microtubule assembly is high, such as in axonal growth cones (Gdalyahu et al., 2004) and in the leading processes of migratory cortical interneurons (Lysko et al., 2014). To gain insight into the structural organization of the leading process of interneurons migrating on nanopatterns, we next examined the organization of the microtubule network through Dcx (Fig. 3.6).

Interneurons on both flat and nanopattern substrates expressed Dcx (Fig. 3.6A-B). Closer examination of individual interneurons revealed striking differences in the intensity and distribution of Dcx between conditions. Cortical interneurons migrating on flat substrates showed uniform amounts of Dcx along the leading process and in the growth cones (Fig. 3.6C). 
Interneurons aligned to the gratings of the nanopattern appeared to not only have more intense Dcx labeling, but also a change in the distribution of Dcx highly specific to the most distal portion of the leading process and growth cones (Fig. 3.6D). Interestingly, cells with leading processes perpendicular to nanopattern gratings showed Dcx more uniformly along the entire leading process, despite being cultured on the nanopattern substrate (Fig. 3.6E).

Together, these data suggest a role for Dcx in the alignment and migration of cortical interneurons on nanopattern substrate. The change in the subcellular localization of Dcx along the leading process of interneurons aligned versus not aligned to nanopatterns suggest that Dcx may play a key role in the migration of cortical interneurons by regulating cell alignment and microtubule stability inside of leading processes.

\section{DISCUSSION}

In the current study, we assessed the role of c-Jun $\mathrm{NH}_{2}$-terminal kinase (JNK) signaling in the migration of cortical interneurons in multiple environments. We established that cortical interneurons require JNK signaling for proper migration and nucleokinesis kinetics regardless of cellular environment. We have previously shown that cortical interneurons treated with a pan JNK inhibitor, SP600125, have significantly decreased migratory displacement, overall migratory speed, and reduced track straightness compared to controls in ex vivo slices, and in vitro co-culture and 3D Matrigel assays (Myers et al., 2020; Smith et al., 2020). Additionally, we recently discovered that JNK-inhibited interneurons in the co-culture assay had disrupted nucleokinesis including decreased translocation distances, less frequent nucleokinesis events, and longer pauses between events (Smith et al., 2020). Here, we found that JNK signaling is equally important in regulating nucleokinesis in the ex vivo slices and in 3D Matrigel matrixes. When we treated slices with SP600125, cortical interneurons had significantly smaller translocation distances, less frequency events, and longer pauses between events. 
Concomitantly, interneurons grown in 3D Matrigel treated with JNK-inhibitor also had significantly smaller translocation distances, decreased rates of nucleokinesis, and longer pause durations. These results suggest that JNK signaling is required to regulate the kinetics of nucleokinesis underlying cortical interneuron migration, irrespective of the cellular environment in which they migrate.

We next set out to determine if nanotopographical cues can control the migratory behavior of interneurons. Interneurons migrating on a flat topography migrated at significantly slower mean speeds than cells traveling on a nanopattern. While the speed variability remained unchanged, the track displacement length was significantly shorter in the flat environment compared to the nanopattern, likely due to the decreased straightness of trajectories on the flat substrate. We next assessed nucleokinesis dynamics of interneurons grown on flat or nanopattern topography. Interneurons migrating on a flat substrate had significantly smaller nucleokinesis distances compared to cells on the nanopattern. Interestingly, the $32.4 \%$ decrease in average nucleokinesis distance was almost identical to the decrease in distance (34.3\%) we found with pharmacological inhibition of JNK in ex vivo slices. However, cells grown in a flat environment completed nucleokinesis at similar rates and paused for similar durations between events compared to cells on nanopatterns. Overall, we have shown that fundamental events required for proper migratory behavior and nucleokinesis of interneurons are influenced by the nanoscale topography of their environment, which was previously unknown.

Finally, we asked whether nanotopographical cues influence cytoskeletal dynamics in cortical interneurons by regulating doublecortin (Dcx). Interneurons migrating on flat substrate or with unaligned leading processes on nanopatterns had uniform Dcx labeling in the leading process and in the growth cone. However, there was a substantial change in subcellular distribution of Dcx in the leading processes of cells aligned to nanopatterns, where Dcx was predominantly localized to the most distal portion of the leading process. These data suggest that the 
regulation Dcx in the leading process may assist in the alignment of interneurons to the nanopattern gratings and aid in directed migration. Alternately, alignment to nanopatterns may preferentially alter the subcellular distribution of Dcx, which may promote directed migration along the legth of nanopatterned gratings. Additional studies will be needed to unravel cause and effect, but our data point towards a central role for the cytoskeleton in mediating migratory decisions that cortical interneurons make in response to nanotopographic cues.

\section{Control of cortical interneuron migration and nucleokinesis through the regulation of cellular adhesion molecules}

Here, we have shown evidence that JNK signaling controls interneuron migration regardless of substrate environment. Cortical interneurons migrating in the presence of other cortical cells have greater disruptions to nucleokinesis under JNK inhibition than in the absence of other cells (3D Matrigel assay). However, there was a greater effect of JNK inhibition on nucleokinesis dynamics in ex vivo slices and co-cultures than on nucleokinesis dynamics of interneurons in the absence of all other cortical cells (3D Matrigel assay). This may be due to the regulation of cell-cell adhesion proteins required for nuclear translocation. During migration, neurons form and disassemble adhesive contacts with their substrates to control forward movement (Solecki, 2012; Luccardini et al., 2013). Therefore, JNK signaling may be regulating the expression of cell surface proteins required for adherence to other cortical cells to enable physical translocation of the cell body during interneuron migration.

For instance, the homophillic cell-cell adhesion protein $\mathrm{N}$-cadherin has been heavily implicated in the guided migration of both cortical interneurons and excitatory neurons (Luccardini et al., 2013; Lai et al., 2015; Luccardini et al., 2015; László et al., 2020). Loss of N-cadherin function leads to slower migration, increased pausing, and significant loss of directionality of migrating cortical interneurons (Luccardini et al., 2013; Luccardini et al., 2015), similar to what we found 
previously (Myers et al., 2020; Smith et al., 2020). Cortical interneurons require N-cadherin for correct actomyosin contraction necessary for nucleokinesis and centrosomal placement during migration (Luccardini et al., 2013). We have recently shown that JNK inhibition also leads to disruptions of centrosome localization in migrating cortical interneurons (Smith et al., 2020). Additionally, conditional removal of $\mathrm{N}$-cadherin from cortical interneurons delays their entry into the cortical rudiment at embryonic day 14 , similar to what we saw in JNK conditional knockout animals (Myers et al., 2014; László et al., 2020; Myers et al., 2020). Interestingly, JNK activation increases $\mathrm{N}$-cadherin levels and cellular motility of pancreatic cancer cells (Shintani et al., 2006). N-cadherin expression was also shown to be regulated by JNK signaling in migrating myofibroblasts (De Wever et al., 2004). These suggest that JNK could have a critical role in regulating key cell adhesion molecules required for cortical interneuron migration.

Another important regulator of cortical interneuron migration is the gap junction protein connexin43 (Petrich et al., 2002; Elias et al., 2010). Overexpression of connexin43 promoted (and knockdown inhibited) the switch from tangential migration to radial migration in cortical interneurons by promoting adhesion between cortical interneurons and radial glial cells (Elias et al., 2010). Interestingly, studies in cardiomyocytes demonstrated that activation of JNK signaling downregulated the expression of connexin43 (Petrich et al., 2002). Therefore, it is possible that inhibiting JNK signaling in interneurons increases connexin43 expression, thus promoting adhesion and slowing cortical interneuron migration. This balance of JNK activity and connexin43 expression in cortical interneurons may ultimately regulate the timing of migratory stream exit by promoting the tangential to radial transition and cortical plate population.

While mechanisms controlling the expression and activity of cell adhesion molecules in migrating neurons remain to be explored, JNK signaling assist in the integration of extracellular signals, cytoskeletal proteins, and cytoplasmic machinery that are critically involved the guided migration of cortical interneurons. 


\section{Nanoscale topographical influences on cortical interneuron migratory behavior}

During migration, cortical interneurons must navigate a complex environment to engage in guided migration. Once inside of the cortical rudiment, interneurons alternate between tangential migration, maintaining two migratory streams in the marginal and subventricular zones, and radial migration, reorienting leading processes to travel between migratory streams and deposit in the cortical plate. These two modes of migration are controlled by the integration of extracellular guidance cues with intracellular signaling pathways and machinery, however, virtually nothing is known about how the physical landscape of the environment influences the guided migration of cortical interneurons. Leclech and colleagues recently described the use of micro-structured substrates and demonstrated that cortical interneurons are sensitive to the architecture of their environment (Leclech et al., 2019). Micropatterns regulated the migratory behavior of migrating interneurons by controlling cellular morphology, leading process branching dynamics, and microtubule stability (Leclech et al., 2019). While the microenvironment interneurons are on may affect their migratory behaviors, it is unknown whether these effects can be seen at the nanoscale.

Nanotopography has been used to study the migration of cancer cells in recent years (Nam et al., 2016; Ray et al., 2017; Tabdanov et al., 2018). Cells aligned to nanopatterns migrate at significantly faster speeds and further distances than cells on flat substrates (Ray et al., 2017). Alignment of microtubules and microtubule bundles parallel to the nanopattern grating are required for cellular alignment, and disruption of microtubule stability with nocodzole results in loss of cellular linearization with the nanopattern gratings (Tabdanov et al., 2018). Additionally, microtubules aligned in grooves of nanopatterns appear to control the cellular response to nanopatterns, with aligned microtubules leading to more elongated cells, which may contribute to increased speed of migration (Ray et al., 2017; Tabdanov et al., 2018). Thus, microtubule 
stability and alignment to nanotopography may underly the increased speed of migration in cortical interneurons migrating on nanopatterns.

Here, we are the first to show that a nanoscale environment orients interneurons to a single migratory direction and regulates the localization of the microtubule interacting protein doublecortin (Dcx). Dcx stabilizes microtubules and is regulated by phosphorylation of kinases, one of which being JNK (Gleeson et al., 1999; Gdalyahu et al., 2004). In humans, mutations to Dcx result in X-linked lissencephaly and Double Cortex Syndrome associated with the arrest of migrating cortical neurons (Raymond et al., 1995; Gleeson et al., 1998). Cortical interneurons devoid of Dcx display similar defects to migration and nucleokinesis that we see in our models of pharmacological and genetic removal of JNK signaling (Kappeler et al., 2006; Smith et al., 2020; Myers et al., 2020). JNK phosphorylation of Dcx (pDcx) regulates neurite growth and branching in neurons and pDcx normally localizes to growth cones (Kappeler et al., 2006; Koizumi et al., 2006; Jin et al., 2010; Lysko et al., 2014), but JNK inhibition displaces pDcx localization away from the growth gone tips (Gdalyahu et al., 2004). It is possible that JNK signaling influences the subcellular localization of Dcx, and subsequently, regulation of microtubules that ultimately controls the trajectory of interneuron migration. Our data suggest that the architecture of the environment can influence interneuron migration and may do so by regulating the subcellular distribution of Dcx. Future studies will need to determine whether JNK signaling contributes to the distribution of Dcx in the leading process and the alignment of cortical interneurons to nanopatterns.

\section{CONCLUSIONS}

Overall, this study provides new findings highlighting the importance of JNK signaling in interneuron migration through nucleokinesis in multiple environments. Interneurons migrating in streams of ex vivo slices, in an in vitro cortical cell co-culture assay, and in isolation of cortical 
cells in a 3D Matrigel matrix require JNK signaling for proper nucleokinesis dynamics. Here, we have also described a novel tool to explore cortical interneurons by controlling their migration through nanotopographical gratings. Our study reveals for the first time that a change in the nanoscale geometry of the environment can direct interneuron migration in vitro. When migrating in vivo, cortical interneurons are exposed to different cytoarchitectural arrangements along their migratory routes, but the effects of these changes has remained relatively unknown. Our results suggest that the architecture of the environment can influence interneuron migration, and that JNK signaling may contribute to directed migration of interneurons in the developing cortex.

\section{MATERIALS AND METHODS}

\section{Animals}

Animals were housed and cared for by the Office of Laboratory Animal Resources at West Virginia University. Timed-pregnant dams (day of vaginal plug = embryonic day 0.5 ) were euthanized by rapid cervical dislocation at embryonic day 14.5 (E14.5) and mouse embryos were immediately harvested for tissue culture. CF-1 (Charles River) were crossed to hemizygous DIx5/6-Cre-IRES-EGFP (DIx5/6-CIE; Stenman et al., 2003) males maintained on a C57BL/6J background to achieve timed pregnancies at E14.5.

\section{Organotypic slice cultures}

DIx5/6-CIE+ embryos were collected at E14.5 and dissected in ice-cold complete HBSS (cHBSS; Tucker et al., 2006). The embryonic brains were embedded in a solution of $3 \%$ low melting point agarose (Fisher Scientific BP165-25) in cHBSS, and sectioned coronally into 300 $\mu \mathrm{m}$ slices on a Leica VT1000 S vibratome, then transferred to poly-L-lysine/laminin-coated transwell membrane inserts in six-well plates (BD Falcon; Polleux and Ghosh, 2002). Wells were filled with $1.8 \mathrm{ml}$ of slice culture media containing either vehicle control dimethyl sulfoxide 
(DMSO, Sigma D2438) or $20 \mu M$ pan-JNK inhibitor SP600125 (Enzo Life Sciences BML-EI3050010) as described previously (Myers et al., 2014). Slices were imaged live for $12 \mathrm{~h}$ and analyzed for nucleokinesis dynamics.

\section{D Matrigel assay}

D/x5/6-C/E+ embryos were collected at E14.5. Medial ganglionic eminence (MGE) tissue was micro-dissected in ice-cold cHBSS, then cut into explants and stored in cHBSS. Matrigel (Corning \#356237) was combined 1:1 with serum-free media (Polleux and Ghosh, 2002), and $150 \mu \mathrm{l}$ of the Matrigel mixture was added to each well of an 8-well chamber coverslip slide (Thermo Fisher \#155411) while on ice. Two or three MGE explants were placed in each well near the coverslip. The chamber slide was then transferred to a tissue culture incubator at $37^{\circ} \mathrm{C}$ with $5 \% \mathrm{CO} 2$ for $30 \mathrm{~min}$ for the Matrigel mixture to solidify as a 3D matrix with the embedded explants. Warm serum-free media was added to each well and the explants were cultured for 24 h. After $24 \mathrm{~h}$, serum-free media containing either control (DMSO) or $20 \mu \mathrm{M} \mathrm{SP600125} \mathrm{was}$ added to each well then imaged live for $12 \mathrm{~h}$.

\section{Nanotopography fabrication}

Flat and nanopatterned polydimethylsiloxane (PDMS) or polystyrene (PS) substrates were performed as in (Song et al., 2016; Wang et al., 2016). In short, a master mold on a PS plate was generated by electron beam lithography $(E B L)$. The nanopattern was produced on a thin film of poly(methylmethacrylate) (PMMA) spin-coated on a silicon substrate by using a focused electron beam of $20 \mathrm{~nm}$ in diameter. The PMMA nanopattern was then deposited with a thin nickel layer, then lifted off. After the lift-off process, a reversed nickel pattern left on the silicon substrate functioned as a mask for the reaction ion etching process, which determined the height of nanotopography. The PDMS nanotopography replica was made by casting and curing the mixture of PDMS resin and curing agent (Sylgard 184kit, Dow Corning, MI, USA) in a 
10:1.05 w/w ratio on the EBL mold for $4 \mathrm{~h}$ at $70^{\circ} \mathrm{C}$. The PDMS nanotopography was expanded to a large area of nanopatterned substrate by applying a stitch technique (Song et al., 2016). After curing at $80^{\circ} \mathrm{C}$ for $2 \mathrm{~h}$, a large nanopatterned surface was created with $500 \mathrm{~nm}$ width between grooves and 500nm height grooves. The stitched mold was then imprinted into a PS substrate, which served as a master mold to replicate working PDMS (Song et al., 2016) or PS (Wang et al., 2016) nanotopography.

\section{UV Sterilization and Coating of Nanopattern}

Treat samples with $70 \%$ ethanol for $30 \mathrm{~min}$ in a tissue culture hood. The $70 \%$ ethanol was then aspirated completely. UV light was turned on for $30 \mathrm{~min}$. After UV treatment, samples were washed with sterile filtered 1 X PBS three times. After washing, coating was added. For collagen, a collagen solution $(50,100,250$, or $500 \mathrm{ug} / \mathrm{mL}$ or $1 \mathrm{mg} / \mathrm{mL})$ was added to each well covering the patterns and polymerized at room temperature for $1 \mathrm{~h}$. The collagen solution was then aspirated and wells were washed with 1X PBS three times. For Matrigel coating, a thin layer of Matrigel (diluted 1:10 or 1:50 with serum-free media) was added to each well while on ice. Matrigel was allowed to incubate for $1 \mathrm{~h}$ on ice, then was aspirated and rinsed once with $1 \mathrm{X}$ PBS. For poly-L-lysine (PLL) coating, PLL was diluted in sterile water (500nM or 1000nM) and added to each well. The solution was incubated overnight at $37^{\circ} \mathrm{C}$ in a tissue culture incubator with $5 \% \mathrm{CO}_{2}$. The wells were rinsed 2 times with $1 \mathrm{X}$ PBS. After all wells were rinsed, regardless of coating procedure, $500 \mu \mathrm{L}$ of serum-free media were added to each well.

\section{Nanopattern explant assay}

Flat or nanopatterned PDMS or PS were placed on the bottom of 8-well chamber coverslip slides (Thermo Fisher 155411). The wells were coated as described in "coating" section above. E14.5 DIx5/6-CIE+ and DIx5/6-CIE- embryos were sorted by GFP fluorescence and dissected in ice-cold cHBSS. MGEs were dissected from DIx5/6-CIE+ brains then cut into small explants and 
plated on flat or nanopatterned PDMS or PS. Each well contained 5-8 explants. Cultures were grown for 24 hours before live-imaging then imaged live for $12-15 \mathrm{~h}$ with control media. After imaging, the cultures were fixed and stained for analysis of cytoskeletal changes.

\section{Live-imaging}

After 24 hours of culture, samples were transferred to a Zeiss 710 Confocal Microscope with stable environmental controls maintained at $37^{\circ} \mathrm{C}$ with $5 \%$ humidified $\mathrm{CO}_{2}$. Multi-position timelapse z-series were acquired at 10-minute intervals over a 12-hour period with a Zeiss $20 \mathrm{X}$ Plan-Apo (Matrigel assay) or LD Plan-Neofluar 20×/0.4 Korr objective (Slice culture and nanopattern assays).

\section{Analysis of live-imaging}

4D live imaging movies were analyzed using Imaris 9.5.1 (Bitplane) software. Movies were evaluated during the first $12 \mathrm{~h}$ of recording. Cortical interneurons were tracked using the Spots feature of Imaris to measure migratory speed, distance, displacement, and track straightness data. Individual interneurons were tracked for a minimum of $2 \mathrm{~h}$. The track was discontinued if a cell remained stationary for 60 contiguous minutes, or if the tracked cell could no longer be unambiguously identified. Tracks from each movie were averaged together for dynamic analyses. Displacement was normalized to the minimum track length of $2 \mathrm{~h}$. Nucleokinesis distances were analyzed manually using Imaris Measurements feature to measure the distance between the soma front pre and post-nuclear translocation event.

\section{Fixation and Staining}

Cultures were rinsed three times with warm 1X phosphate-buffered saline (1X PBS; 136.9mmol $\mathrm{NaCl}, 2.683 \mathrm{mmol} \mathrm{KCl}, 4.290 \mathrm{mmol} \mathrm{Na}_{2} \mathrm{HPO}_{4} 7 \mathrm{H}_{2} \mathrm{O}, 1.470 \mathrm{mmol} \mathrm{K \textrm {K } _ { 2 }} \mathrm{PO}_{4}$ ) and fixed with $4 \%$ paraformaldehyde for $1 \mathrm{~h}$ at room temperature. Cultures were then rinsed five times with $1 \mathrm{X}$ 
PBS and blocked for $2 \mathrm{~h}$ in permeability solution (Myers et al., 2014) with 5\% normal goat serum and $0.01 \%$ Triton X-100 (Sigma T8787). Primary antibodies including Chicken anti-GFP (1:1500, Abcam), Guinea Pig anti-Doublecortin (1:1000, Abcam), and Rabbit anti-pSer334 Doublecortin (1:2000, Cell Signaling Technology) were diluted in permeability solution, applied to the wells, and incubated overnight at $4^{\circ} \mathrm{C}$. Wells were thoroughly rinsed with $1 \mathrm{X}$ PBS and incubated with secondary antibodies Alexa 488 conjugated goat anti-chicken (1:4000, Invitrogen), Alexa 546 or 633 conjugated goat anti-guinea pig (1:2000, Invitrogen), and Alex 546 conjugated goat anti-rabbit (1:2000, Invitrogen) diluted in permeability solution at room temperature for $2 \mathrm{~h}$. Hoechst (Thermo Scientific 62249, $1 \mu \mathrm{g} / \mathrm{ml}$ ) was used for a nuclear counterstain. Wells were rinsed in $1 \mathrm{X}$ PBS, then an aqueous mounting medium containing an anti-fade reagent was added and stored at $4^{\circ} \mathrm{C}$.

\section{Imaging of fixed samples}

Immunofluorescently-labeled samples were imaged on a Zeiss 710 confocal microscope with a 20x Plan-Apo objective lens or a 40X C-apochromat 1.2W M27 objective (Zeiss). Confocal micrographs were uniformly adjusted for levels, brightness, and contrast in Adobe Photoshop.

\section{Statistical Analysis}

Data were analyzed and graphs were produced using or estimation coding software (Ho et al., 2019). Data are presented as Gardner-Altman estimation plots with a total of 5000 bootstrap samples taken, and the $95 \%$ confidence interval bias-corrected. Statistical details can be found in Table 3.1. 


\section{ACKNOWLEDGEMENTS}

The authors would like to thank Dr. Amanda Ammer and Dr. Karen Martin for their microscopy support. Live-imaging experiments were performed in the West Virginia University (WVU) Imaging Facilities, supported by the WVU Cancer Institute, the WVU Health Science Center Office of Research and Graduate Education, and NIH grants P20RR016440, P30GM103488, P20GM121322, U54GM104942, P30GM103503, and P20GM103434.

\section{COMPETING INTERESTS}

No competing interests declared.

\section{AUTHOR CONTRIBUTIONS}

Conceptualization: S.E.S., Y.Y. and E.S.T.; Methodology: S.E.S., K.W., Y.Y., A.K.M, and E.S.T.; Formal analysis: S.E.S.; Investigation: S.E.S, K.W.; Writing: S.E.S., and E.S.T.; Visualization: S.E.S. and A.K.M; Supervision: Y.Y., and E.S.T.; Funding Acquisition: Y.Y, and E.S.T.

\section{FUNDING}

This work was supported by the National Institutes of Health grant R01NS082262 to EST and the West Virginia University Neurotechnology and Neuroscience Grant to EST and YY. 


\section{REFERENCES}

Anderson SA, Eisenstat DD, Shi L, Rubenstein JL (1997) Interneuron migration from basal forebrain to neocortex: dependence on DIx genes. Science 278:474-476.

Baudoin JP, Viou L, Launay PS, Luccardini C, Espeso Gil S, Kiyasova V, Irinopoulou T, Alvarez C, Rio JP, Boudier T, Lechaire JP, Kessaris N, Spassky N, Métin C (2012) Tangentially migrating neurons assemble a primary cilium that promotes their reorientation to the cortical plate. Neuron 76:1108-1122.

Bellion A, Baudoin JP, Alvarez C, Bornens M, Métin C (2005) Nucleokinesis in tangentially migrating neurons comprises two alternating phases: forward migration of the Golgi/centrosome associated with centrosome splitting and myosin contraction at the rear. J Neurosci 25:5691-5699.

Bennett BL, Sasaki DT, Murray BW, O'Leary EC, Sakata ST, Xu W, Leisten JC, Motiwala A, Pierce S, Satoh Y, Bhagwat SS, Manning AM, Anderson DW (2001) SP600125, an anthrapyrazolone inhibitor of Jun N-terminal kinase. Proc Natl Acad Sci U S A 98:1368113686.

Chang L, Karin M (2001) Mammalian MAP kinase signalling cascades. Nature 410:37-40.

Davis RJ (2000) Signal transduction by the JNK group of MAP kinases. Cell 103:239-252.

De Wever O, Westbroek W, Verloes A, Bloemen N, Bracke M, Gespach C, Bruyneel E, Mareel $\mathrm{M}(2004)$ Critical role of $\mathrm{N}$-cadherin in myofibroblast invasion and migration in vitro stimulated by colon-cancer-cell-derived TGF-beta or wounding. J Cell Sci 117:46914703.

Elias LA, Turmaine M, Parnavelas JG, Kriegstein AR (2010) Connexin 43 mediates the tangential to radial migratory switch in ventrally derived cortical interneurons. J Neurosci 30:7072-7077.

Gdalyahu A, Ghosh I, Levy T, Sapir T, Sapoznik S, Fishler Y, Azoulai D, Reiner O (2004) DCX, a new mediator of the JNK pathway. EMBO J 23:823-832.

Gleeson JG, Lin PT, Flanagan LA, Walsh CA (1999) Doublecortin is a microtubule-associated protein and is expressed widely by migrating neurons. Neuron 23:257-271.

Gleeson JG, Allen KM, Fox JW, Lamperti ED, Berkovic S, Scheffer I, Cooper EC, Dobyns WB, Minnerath SR, Ross ME, Walsh CA (1998) Doublecortin, a brain-specific gene mutated in human X-linked lissencephaly and double cortex syndrome, encodes a putative signaling protein. Cell 92:63-72.

Godin JD, Thomas N, Laguesse S, Malinouskaya L, Close P, Malaise O, Purnelle A, Raineteau O, Campbell K, Fero M, Moonen G, Malgrange B, Chariot A, Metin C, Besson A, Nguyen $\mathrm{L}(2012) \mathrm{p} 27$ (Kip1) is a microtubule-associated protein that promotes microtubule polymerization during neuron migration. Dev Cell 23:729-744.

Hildebrandt F, Benzing T, Katsanis N (2011) Ciliopathies. N Engl J Med 364:1533-1543.

Hirai S, Cui DF, Miyata T, Ogawa M, Kiyonari H, Suda Y, Aizawa S, Banba Y, Ohno S (2006) The c-Jun N-terminal kinase activator dual leucine zipper kinase regulates axon growth and neuronal migration in the developing cerebral cortex. J Neurosci 26:11992-12002.

Ho J, Tumkaya T, Aryal S, Choi H, Claridge-Chang A (2019) Moving beyond P values: data analysis with estimation graphics. Nat Methods 16:565-566.

Jin J, Suzuki H, Hirai S, Mikoshiba K, Ohshima T (2010) JNK phosphorylates Ser332 of doublecortin and regulates its function in neurite extension and neuronal migration. Dev Neurobiol 70:929-942.

Kappeler C, Saillour Y, Baudoin JP, Tuy FP, Alvarez C, Houbron C, Gaspar P, Hamard G, Chelly J, Métin C, Francis F (2006) Branching and nucleokinesis defects in migrating interneurons derived from doublecortin knockout mice. Hum Mol Genet 15:1387-1400. 
Kato M, Dobyns WB (2005) X-linked lissencephaly with abnormal genitalia as a tangential migration disorder causing intractable epilepsy: proposal for a new term, "interneuronopathy". J Child Neurol 20:392-397.

Koizumi H, Tanaka T, Gleeson JG (2006) Doublecortin-like kinase functions with doublecortin to mediate fiber tract decussation and neuronal migration. Neuron 49:55-66.

Kunde SA, Rademacher N, Tzschach A, Wiedersberg E, Ullmann R, Kalscheuer VM, Shoichet SA (2013) Characterisation of de novo MAPK10/JNK3 truncation mutations associated with cognitive disorders in two unrelated patients. Hum Genet 132:461-471.

Lai M, Guo Y, Ma J, Yu H, Zhao D, Fan W, Ju X, Sheikh MA, Malik YS, Xiong W, Guo W, Zhu X (2015) Myosin $X$ regulates neuronal radial migration through interacting with $\mathrm{N}$-cadherin. Front Cell Neurosci 9:326.

Lavdas AA, Grigoriou M, Pachnis V, Parnavelas JG (1999) The medial ganglionic eminence gives rise to a population of early neurons in the developing cerebral cortex. $\mathrm{J}$ Neurosci 19:7881-7888.

Leclech C, Renner M, Villard C, Métin C (2019) Topographical cues control the morphology and dynamics of migrating cortical interneurons. Biomaterials 214:119194.

Luccardini C, Leclech C, Viou L, Rio JP, Métin C (2015) Cortical interneurons migrating on a pure substrate of $\mathrm{N}$-cadherin exhibit fast synchronous centrosomal and nuclear movements and reduced ciliogenesis. Front Cell Neurosci 9:286.

Luccardini C, Hennekinne L, Viou L, Yanagida M, Murakami F, Kessaris N, Ma X, Adelstein RS, Mège RM, Métin C (2013) N-cadherin sustains motility and polarity of future cortical interneurons during tangential migration. J Neurosci 33:18149-18160.

Lysko DE, Putt M, Golden JA (2014) SDF1 reduces interneuron leading process branching through dual regulation of actin and microtubules. J Neurosci 34:4941-4962.

László ZI, Bercsényi K, Mayer M, Lefkovics K, Szabó G, Katona I, Lele Z (2020) N-cadherin (Cdh2) Maintains Migration and Postmitotic Survival of Cortical Interneuron Precursors in a Cell-Type-Specific Manner. Cereb Cortex 30:1318-1329.

McGuire JL, Depasquale EA, Funk AJ, O'Donnovan SM, Hasselfeld K, Marwaha S, Hammond $\mathrm{JH}$, Hartounian V, Meador-Woodruff JH, Meller J, McCullumsmith RE (2017) Abnormalities of signal transduction networks in chronic schizophrenia. NPJ Schizophr 3:30.

Meechan DW, Tucker ES, Maynard TM, LaMantia AS (2012) Cxcr4 regulation of interneuron migration is disrupted in 22q11.2 deletion syndrome. Proc Natl Acad Sci U S A 109:18601-18606.

Miyoshi G, Hjerling-Leffler J, Karayannis T, Sousa VH, Butt SJ, Battiste J, Johnson JE, Machold RP, Fishell G (2010) Genetic fate mapping reveals that the caudal ganglionic eminence produces a large and diverse population of superficial cortical interneurons. J Neurosci 30:1582-1594.

Morris NR, Efimov VP, Xiang X (1998) Nuclear migration, nucleokinesis and lissencephaly. Trends Cell Biol 8:467-470.

Moya F, Valdeolmillos M (2004) Polarized increase of calcium and nucleokinesis in tangentially migrating neurons. Cereb Cortex 14:610-618.

Myers AK, Meechan DW, Adney DR, Tucker ES (2014) Cortical interneurons require Jnk1 to enter and navigate the developing cerebral cortex. J Neurosci 34:7787-7801.

Myers AK, Cunningham JG, Smith SE, Snow JP, Smoot CA, Tucker ES (2020) JNK signaling is required for proper tangential migration and laminar allocation of cortical interneurons. Development 147:Doi: 10.1242/dev.180646.

Nam KH, Kim P, Wood DK, Kwon S, Provenzano PP, Kim DH (2016) Multiscale Cues Drive Collective Cell Migration. Sci Rep 6:29749.

Nery S, Fishell G, Corbin JG (2002) The caudal ganglionic eminence is a source of distinct cortical and subcortical cell populations. Nat Neurosci 5:1279-1287. 
Petrich BG, Gong X, Lerner DL, Wang X, Brown JH, Saffitz JE, Wang Y (2002) c-Jun N-terminal kinase activation mediates downregulation of connexin43 in cardiomyocytes. Circ Res 91:640-647.

Polleux F, Ghosh A (2002) The slice overlay assay: a versatile tool to study the influence of extracellular signals on neuronal development. Sci STKE 2002:p19.

Ray A, Lee O, Win Z, Edwards RM, Alford PW, Kim DH, Provenzano PP (2017) Anisotropic forces from spatially constrained focal adhesions mediate contact guidance directed cell migration. Nat Commun 8:14923.

Raymond AA, Fish DR, Sisodiya SM, Alsanjari N, Stevens JM, Shorvon SD (1995) Abnormalities of gyration, heterotopias, tuberous sclerosis, focal cortical dysplasia, microdysgenesis, dysembryoplastic neuroepithelial tumour and dysgenesis of the archicortex in epilepsy. Clinical, EEG and neuroimaging features in 100 adult patients. Brain 118 ( Pt 3):629-660.

Shintani Y, Wheelock MJ, Johnson KR (2006) Phosphoinositide-3 kinase-Rac1-c-Jun NH2terminal kinase signaling mediates collagen I-induced cell scattering and up-regulation of $\mathrm{N}$-cadherin expression in mouse mammary epithelial cells. Mol Biol Cell 17:2963-2975.

Silva CG, Peyre E, Adhikari MH, Tielens S, Tanco S, Van Damme P, Magno L, Krusy N, Agirman G, Magiera MM, Kessaris N, Malgrange B, Andrieux A, Janke C, Nguyen L (2018) Cell-Intrinsic Control of Interneuron Migration Drives Cortical Morphogenesis. Cell 172:1063-1078.e1019.

Smith SE, Coker NK, Tucker ES (2020) JNK Signaling Regulates Cellular Mechanics of Cortical Interneuron Migration. eNeuro 7.

Solecki DJ (2012) Sticky situations: recent advances in control of cell adhesion during neuronal migration. Curr Opin Neurobiol 22:791-798.

Song L, Wang K, Li Y, Yang Y (2016) Nanotopography promoted neuronal differentiation of human induced pluripotent stem cells. Colloids Surf B Biointerfaces 148:49-58.

Stenman J, Toresson H, Campbell K (2003) Identification of two distinct progenitor populations in the lateral ganglionic eminence: implications for striatal and olfactory bulb neurogenesis. J Neurosci 23:167-174.

Su P, Lai TKY, Lee FHF, Abela AR, Fletcher PJ, Liu F (2019) Disruption of SynGAP-dopamine D1 receptor complexes alters actin and microtubule dynamics and impairs GABAergic interneuron migration. Sci Signal 12.

Tabdanov ED, Puram V, Zhovmer A, Provenzano PP (2018) Microtubule-Actomyosin Mechanical Cooperation during Contact Guidance Sensing. Cell Rep 25:328-338.e325.

Tsai LH, Gleeson JG (2005) Nucleokinesis in neuronal migration. Neuron 46:383-388.

Tucker ES, Polleux F, LaMantia AS (2006) Position and time specify the migration of a pioneering population of olfactory bulb interneurons. Dev Biol 297:387-401.

Volk DW, Chitrapu A, Edelson JR, Lewis DA (2015) Chemokine receptors and cortical interneuron dysfunction in schizophrenia. Schizophr Res 167:12-17.

Wang K, Leong KW, Yang Y (2016) Expanding Nanopatterned Substrates Using Stitch Technique for Nanotopographical Modulation of Cell Behavior. J Vis Exp.

Wang X, Nadarajah B, Robinson AC, McColl BW, Jin JW, Dajas-Bailador F, Boot-Handford RP, Tournier C (2007) Targeted deletion of the mitogen-activated protein kinase kinase 4 gene in the nervous system causes severe brain developmental defects and premature death. Mol Cell Biol 27:7935-7946.

Westerlund N, Zdrojewska J, Padzik A, Komulainen E, Björkblom B, Rannikko E, Tararuk T, Garcia-Frigola C, Sandholm J, Nguyen L, Kallunki T, Courtney MJ, Coffey ET (2011) Phosphorylation of SCG10/stathmin-2 determines multipolar stage exit and neuronal migration rate. Nat Neurosci 14:305-313. 
Wichterle H, Garcia-Verdugo JM, Herrera DG, Alvarez-Buylla A (1999) Young neurons from medial ganglionic eminence disperse in adult and embryonic brain. Nat Neurosci 2:461466.

Wichterle H, Turnbull DH, Nery S, Fishell G, Alvarez-Buylla A (2001) In utero fate mapping reveals distinct migratory pathways and fates of neurons born in the mammalian basal forebrain. Development 128:3759-3771.

Xu Q, Cobos I, De La Cruz E, Rubenstein JL, Anderson SA (2004) Origins of cortical interneuron subtypes. J Neurosci 24:2612-2622.

Yamasaki T, Kawasaki H, Arakawa S, Shimizu K, Shimizu S, Reiner O, Okano H, Nishina S, Azuma N, Penninger JM, Katada T, Nishina H (2011) Stress-activated protein kinase MKK7 regulates axon elongation in the developing cerebral cortex. J Neurosci 31:1687216883.

Zhang F, Yu J, Yang T, Xu D, Chi Z, Xia Y, Xu Z (2016) A Novel c-Jun N-terminal Kinase (JNK) Signaling Complex Involved in Neuronal Migration during Brain Development. J Biol Chem 291:11466-11475. 


\section{TABLE LEGEND}

Table 1: Summary of Nucleokinesis Analyses. The type of measurement, experiment, condition, average, standard error of the mean, and statistic measurement are included for each analysis.

\begin{tabular}{|c|c|c|c|c|}
\hline \multicolumn{2}{|c|}{ Nucleokinesis Distance } & Average & SEM & Student's t-test \\
\hline \multirow[t]{2}{*}{ Slice } & Control & 16.48 & 0.46 & 0.0046 \\
\hline & SP600125 & 8.36 & 0.71 & \\
\hline \multirow[t]{2}{*}{ Matrigel } & Control & 11.18 & 0.46 & 0.0047 \\
\hline & SP600125 & 10.83 & 0.88 & \\
\hline \multirow[t]{2}{*}{ Nanotopography } & Nanopattern & 19.24 & 1.13 & 0.0013 \\
\hline & Flat & 13.00 & 0.85 & \\
\hline \multicolumn{2}{|l|}{ Frequency } & Average & SEM & Student's t-test \\
\hline \multirow[t]{2}{*}{ Slice } & Control & 2.82 & 0.17 & 0.0022 \\
\hline & SP600125 & 1.51 & 0.08 & \\
\hline \multirow[t]{2}{*}{ Matrigel } & Control & 2.26 & 0.21 & 0.0064 \\
\hline & SP600125 & 1.49 & 0.05 & \\
\hline \multirow[t]{2}{*}{ Nanotopography } & Nanopattern & 2.88 & 0.16 & 0.24 \\
\hline & Flat & 2.53 & 0.24 & \\
\hline \multicolumn{2}{|l|}{ Pause Duration } & Average & SEM & Student's t-test \\
\hline \multirow[t]{2}{*}{ Slice } & Control & 27.85 & 1.72 & 0.0057 \\
\hline & SP600125 & 42.79 & 2.17 & \\
\hline \multirow[t]{2}{*}{ Matrigel } & Control & 36.42 & 1.59 & 0.00088 \\
\hline & SP600125 & 45.17 & 0.60 & \\
\hline \multirow[t]{2}{*}{ Nanotopography } & Nanopattern & 30.21 & 2.09 & 0.19 \\
\hline & Flat & 34.71 & 2.39 & \\
\hline
\end{tabular}




\section{FIGURES}

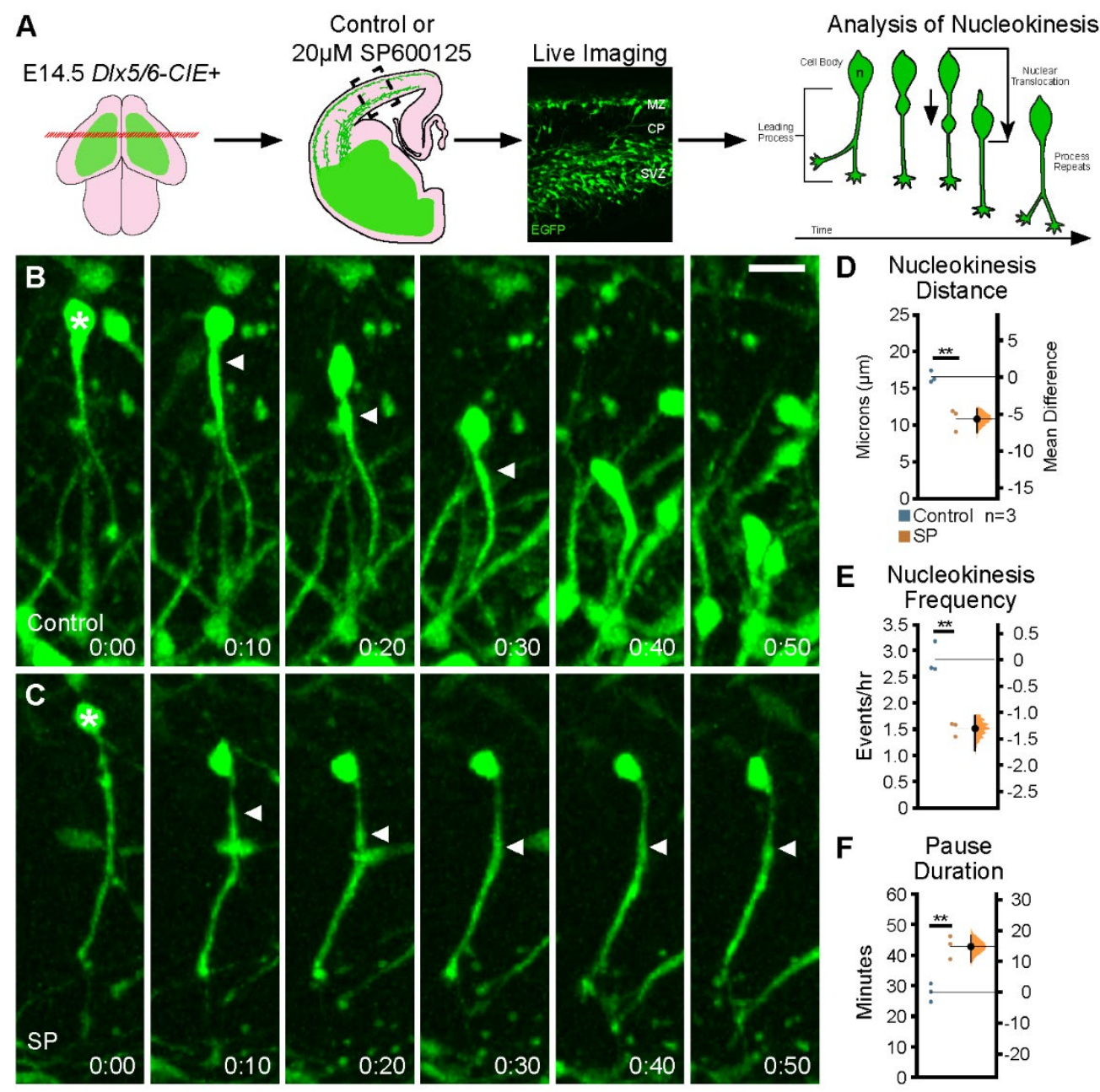

Figure 3.1: JNK activity is required for nucleokinesis of cortical interneurons migrating in ex vivo slices. A. Cartoon schematic of ex vivo slice culture of E14.5 D/x5/6-CIE coronal slices treated with control or 20uM SP600125. B. Control cortical interneuron undergoing normal nucleokinesis. C. Interneuron from SP600125-treated slice showing delayed nucleokinesis. Time is in minutes. Scale bar is $15 \mu \mathrm{m}$. D-F. Cortical interneurons from slices treated with JNK inhibitor have significantly shorter nucleokinesis distances (D), decreased frequency of nucleokinesis $(E)$, and increased pause duration $(F)$ compared to controls. In each condition, 15 cells well analyzed from $n=3$ movies over 3 experimental days. Data are presented as Gardner- 
Altman estimation plots. The values of groups are plotted on the left axes with the mean difference between groups plotted on the right axes as a bootstrap resampling distribution. The mean difference is depicted as a black dot with the $95 \%$ confidence interval indicated by the vertical error bars. ${ }^{* *} p<0.01$, Student's $t$-test. 

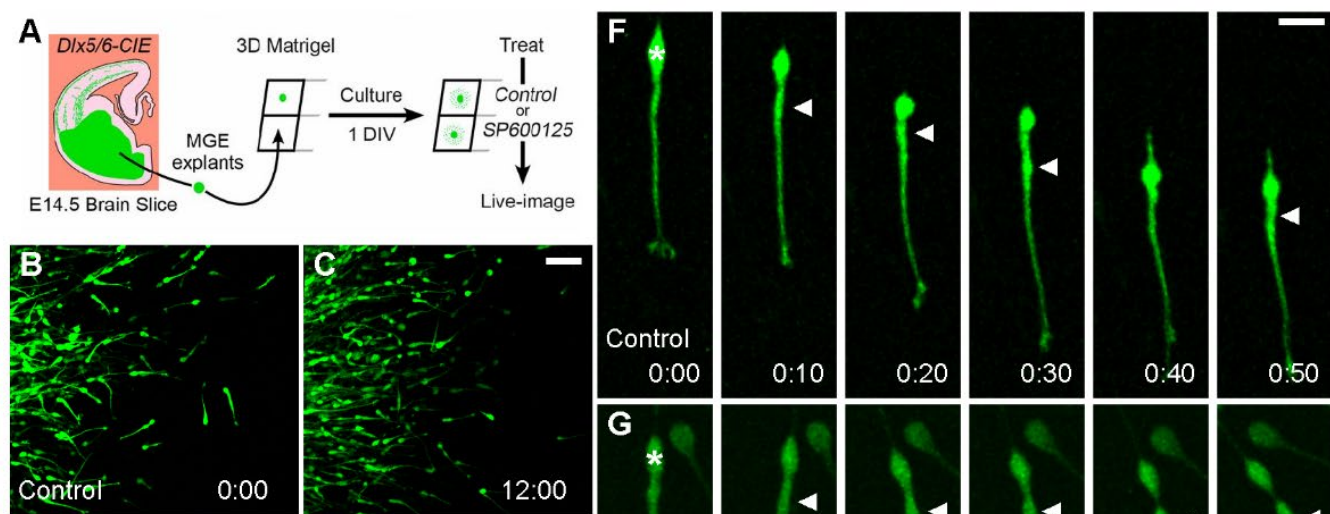

H Nucleokinesis

G
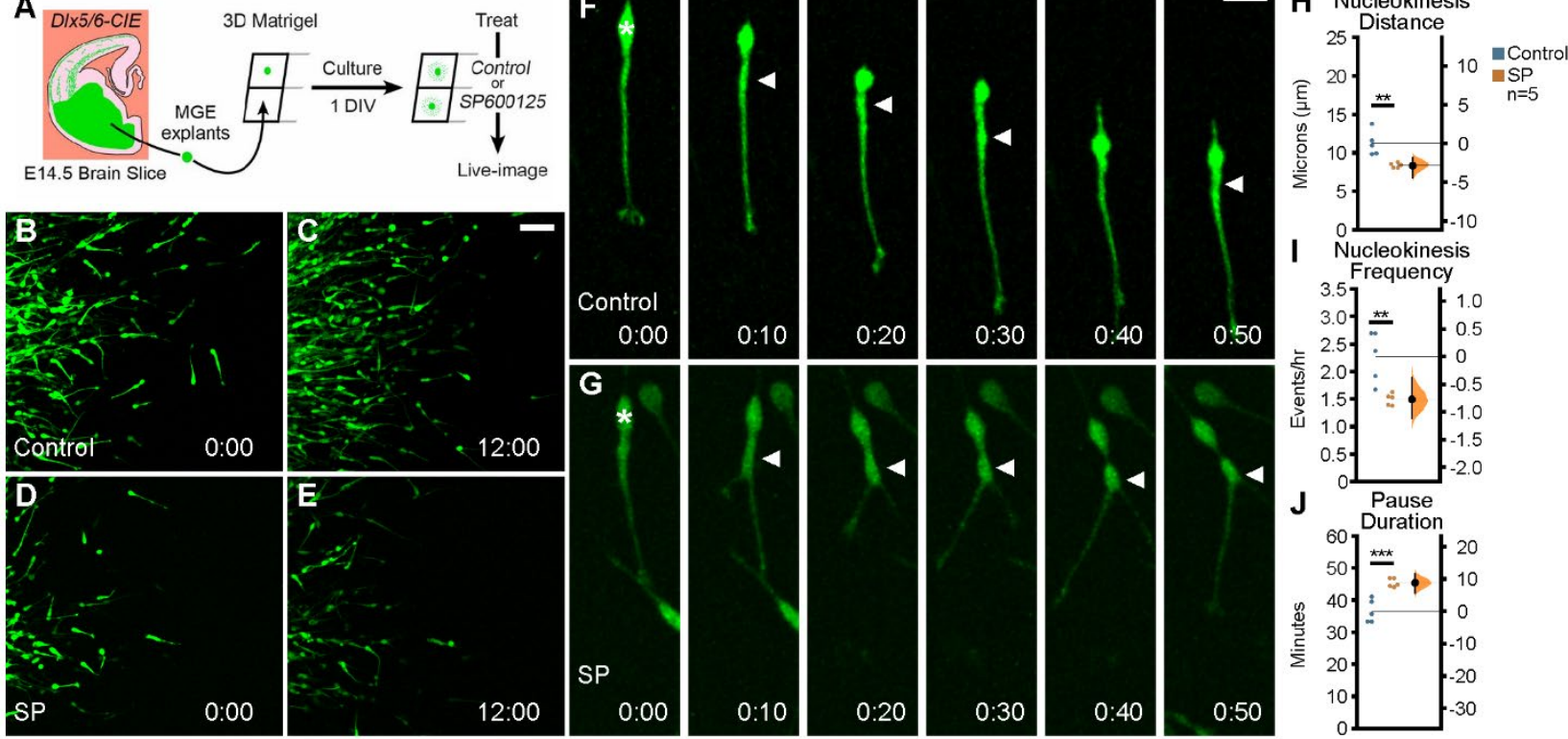

Figure 3.2: Pharmacological inhibition of JNK signaling perturbs nucleokinesis dynamics of cortical interneurons migrating in absence of other cortical neurons. A. Schematic illustration of 3D Matrigel assay where E14.5 DIx5/6-CIE MGE explants were cultured for 24h then treated with control or 20uM SP600125. B-E. Movie frames from E14.5 D/x5/6-CIE explants imaged live in control (B-C) or $20 \mu \mathrm{M}$ SP600125 (D-E) conditions for 12 hours. Scale bar is $50 \mu \mathrm{m}$. F. Control interneuron undergoing two rounds of nucleokinesis. G. SP600125treated interneuron unable to complete a single round of nucleokinesis within the same time frame as the control. Time is in minutes. Scale bar is $15 \mu \mathrm{m} . \mathrm{H}-\mathrm{J}$. Interneurons grown in absence of other cortical cells treated with JNK inhibitor have significantly shorter translocation distances $(\mathrm{H})$, decreased frequency of nucleokinesis $(\mathrm{I})$, and increased pause duration $(\mathrm{J})$ compared to control interneurons. A total of 25 cells were analyzed in each condition from $n=5$ movies over 3 experimental days. Data are presented as Gardner-Altman estimation plots. ${ }^{* * *} p<0.001$, ${ }^{* *} \mathrm{p}<0.01$, Student's $t$-test. 
A

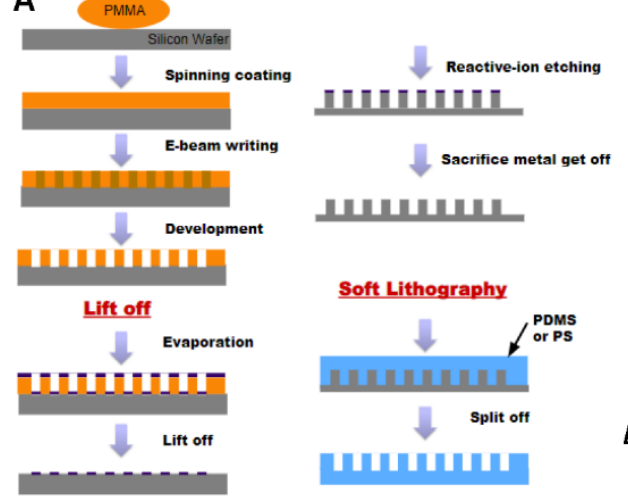

B
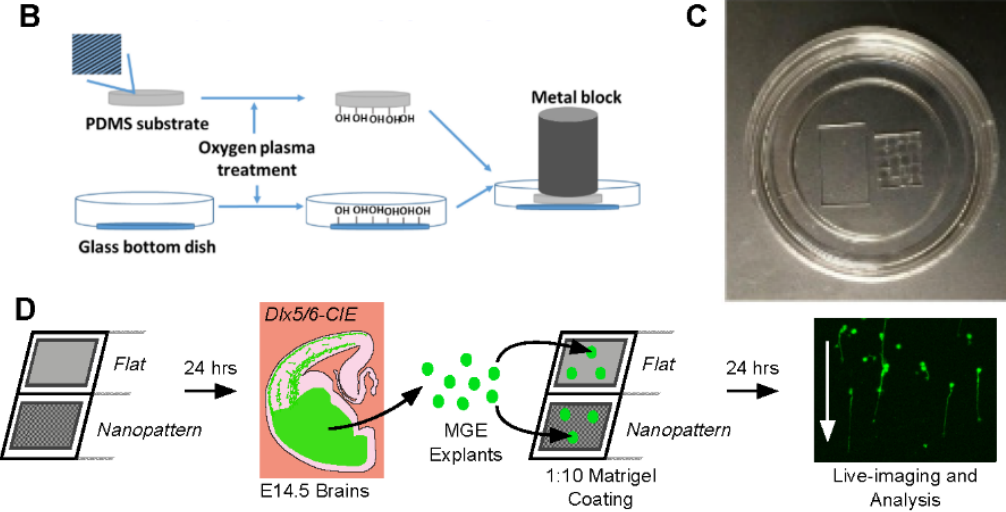

Figure 3.3: Fabrication of nanopattern topography to analyze cortical interneuron

migration. A-C. Schematic diagram of nanopattern fabrication to produce grooved topography $500 \mathrm{~nm}$ high and 500nm wide (A), substrate adherence to cover glass $(B)$, and example of flat and nanopatterned topography (C). D. Schematic of initial experimental design to determine experimental coating and culturing protocol using E14.5 DIx5/6-CIE MGE explants cultured on flat and nanopattern topography and assessed cellular health. 

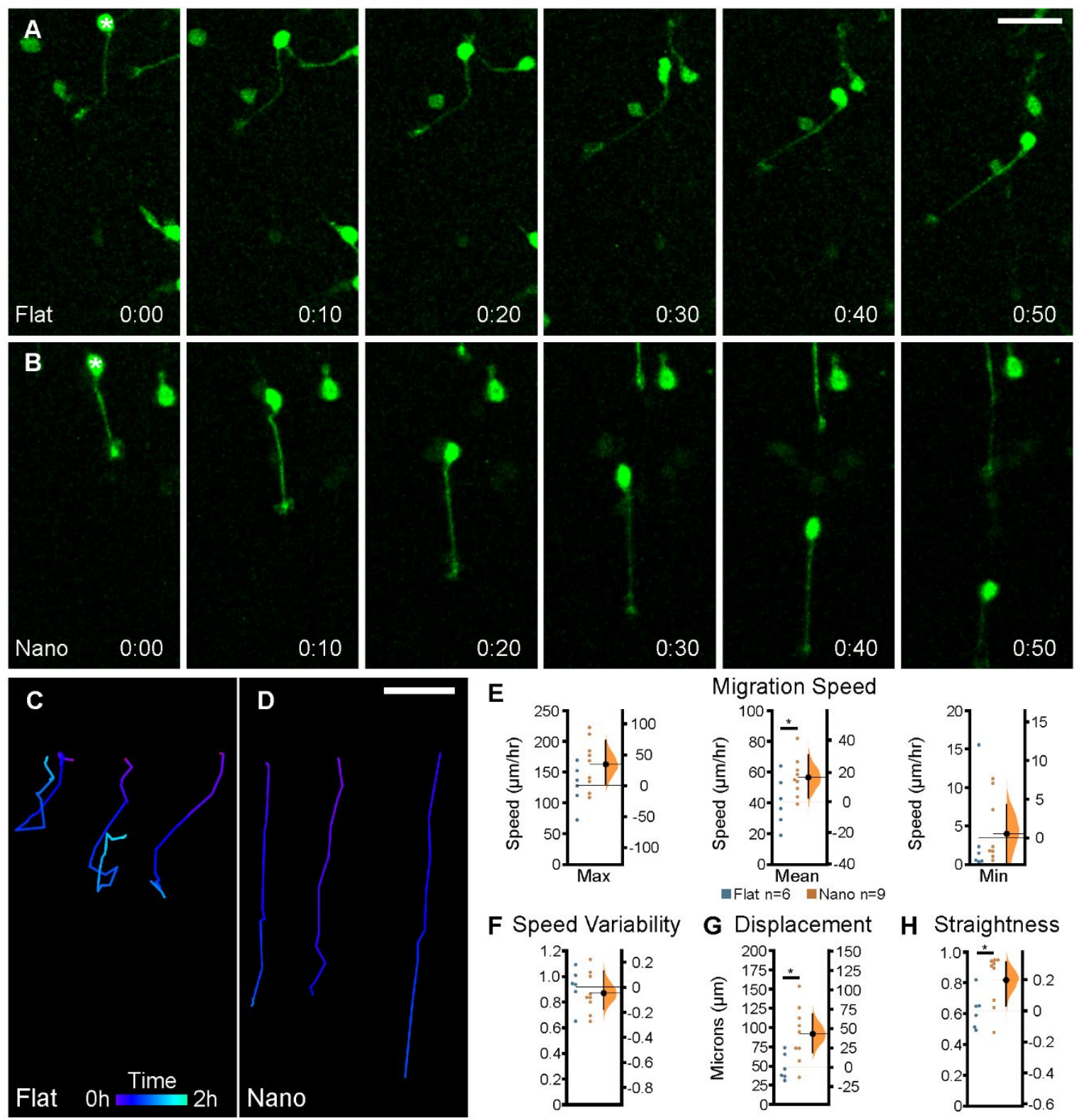

Migration Speed
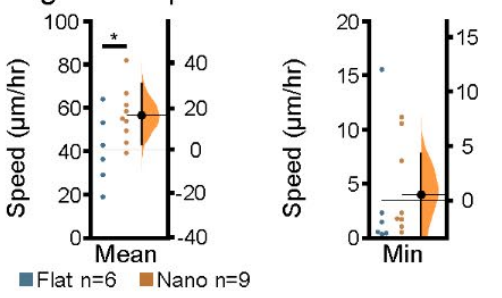

F Speed Variability

G Displacement

H Straightness
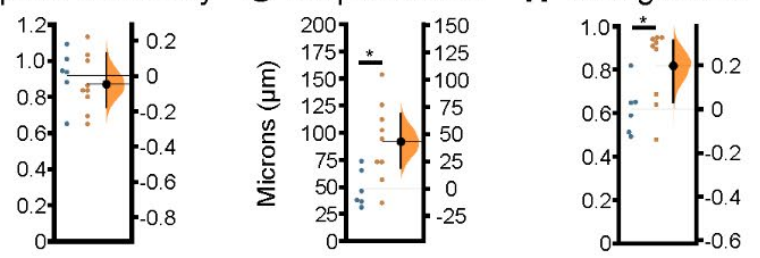

Figure 3.4: Nanopattern topography controls cortical interneuron migration.

A. Interneuron migrating on flat substrate displays curved migratory trajectory B. Interneuron migrating on nanopattern displays straight trajectory. Asterisk denotes cell body of interneuron. C. Three tracks of interneurons migrating on flat topography. D. Three tracks of interneurons migrating on nanopattern topography. Scale bar is $50 \mu \mathrm{m}$. E-H. Interneurons migrating on nanopattern have significantly faster mean migratory speeds $(E)$, larger normalized displacements $(F)$, and straighter migratory trajectories $(G)$, with no change in track speed 
variability $(H) . n=6$ movies containing 25 cells from 3 experimental days for flat migration. $n=9$ movies containing 25 cells from 3 experimental days for interneurons migrating on nanopatterns. Data are presented as Gardner-Altman estimation plots. ${ }^{*} p<0.05$, Student's $t$-test. 

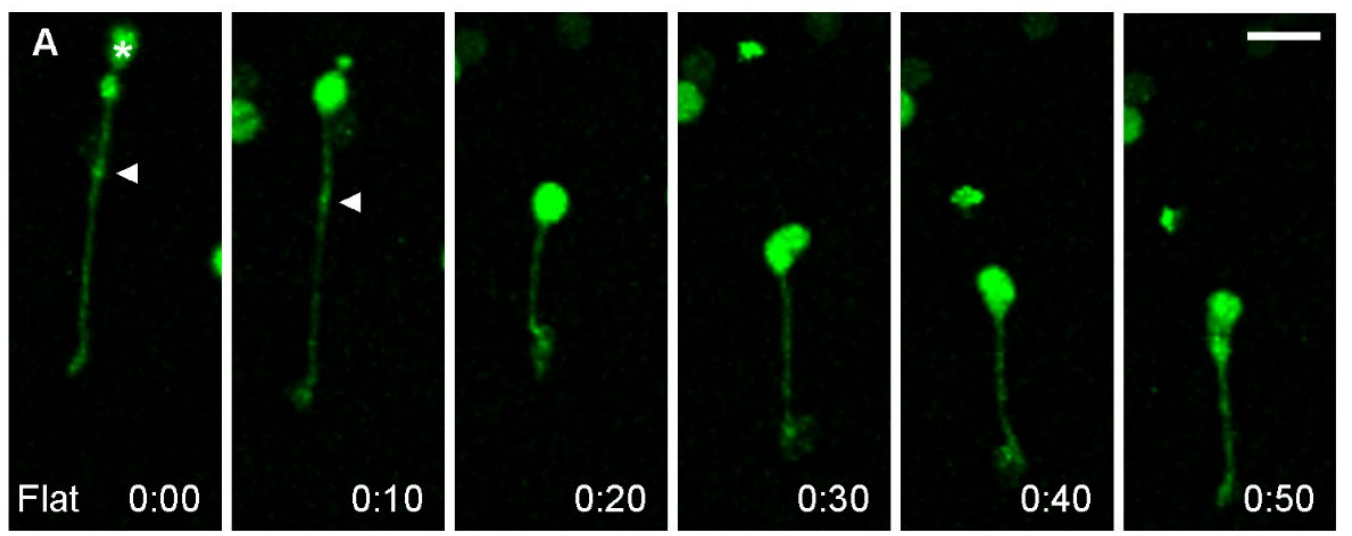

C Nucleokinesis
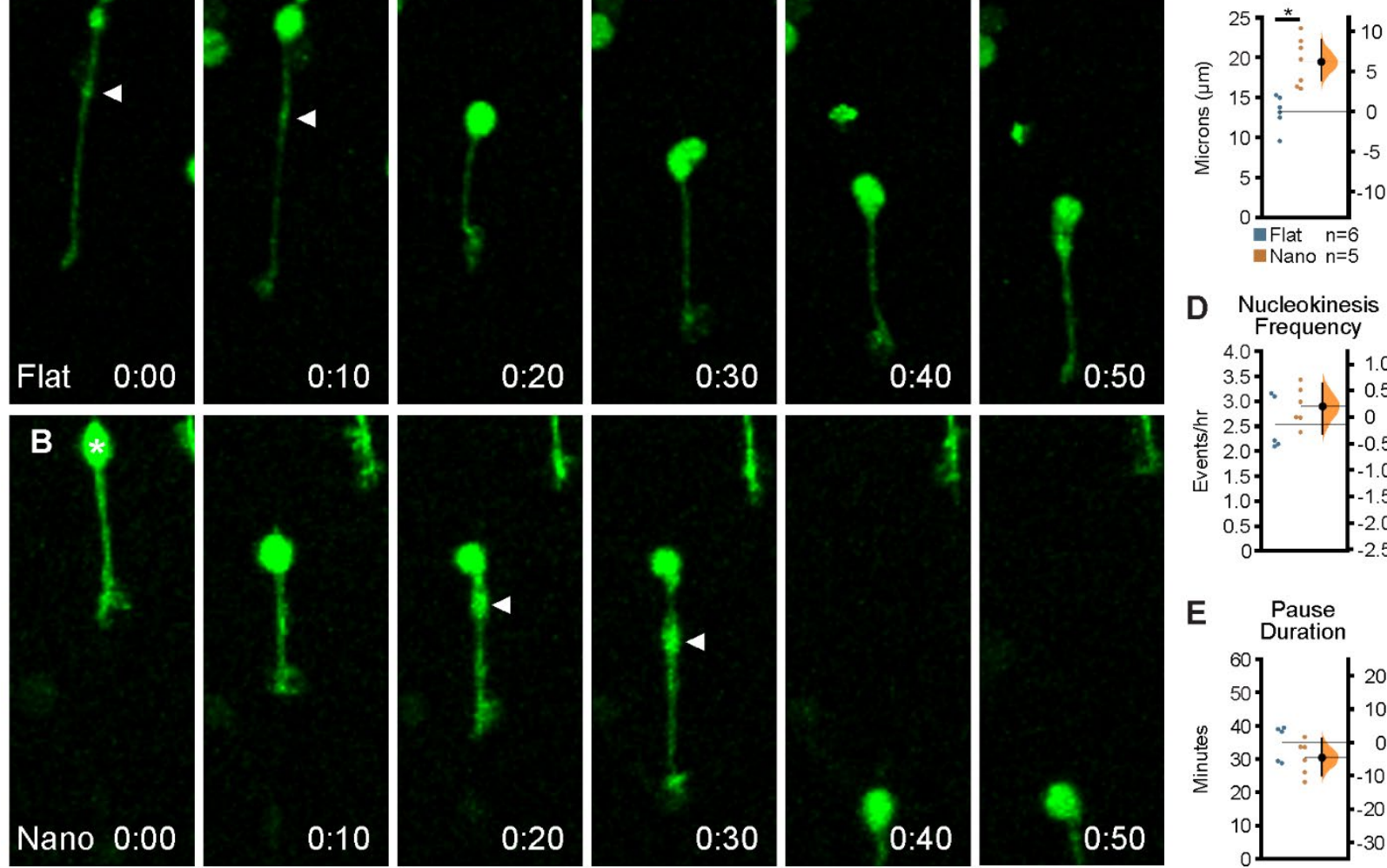

D Nucleokinesis
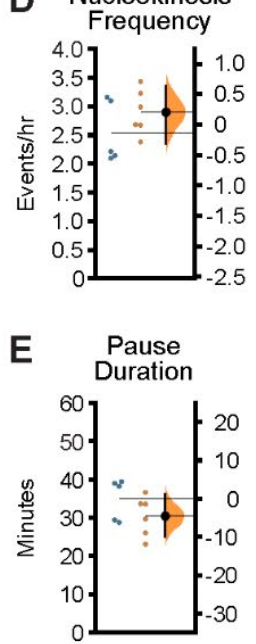

Figure 3.5: Nucleokinesis dynamics of interneurons migrating on nanopatterns.

A. Interneuron migrating on flat topography undergoing a round of nucleokinesis. B. Interneuron migrating on nanopattern undergoes multiple rounds of nucleokinesis in the same time frame.

Closed arrowhead represents swelling in leading processes. Asterisk represents cell body of interneuron undergoing nucleokinesis. Time is in minutes. Scale is $15 \mu \mathrm{m}$. C-E. Interneurons migrating on nanopattern topography travel significantly further distances during nucleokinesis (C), while maintaining a similar rate of nucleokinesis (D) and pauses between events (E) when compared to cells migrating on a flat topography. For flat migration, a total of $n=6$ movies containing 25 cells from 3 experimental days were analyzed. For nanopatterned migration, $n=7$ movies were analyzed containing 23 cells from 3 experimental days. Data are presented as Gardner-Altman estimation plots. ${ }^{* *} p<0.01$, Student's $t$-test 

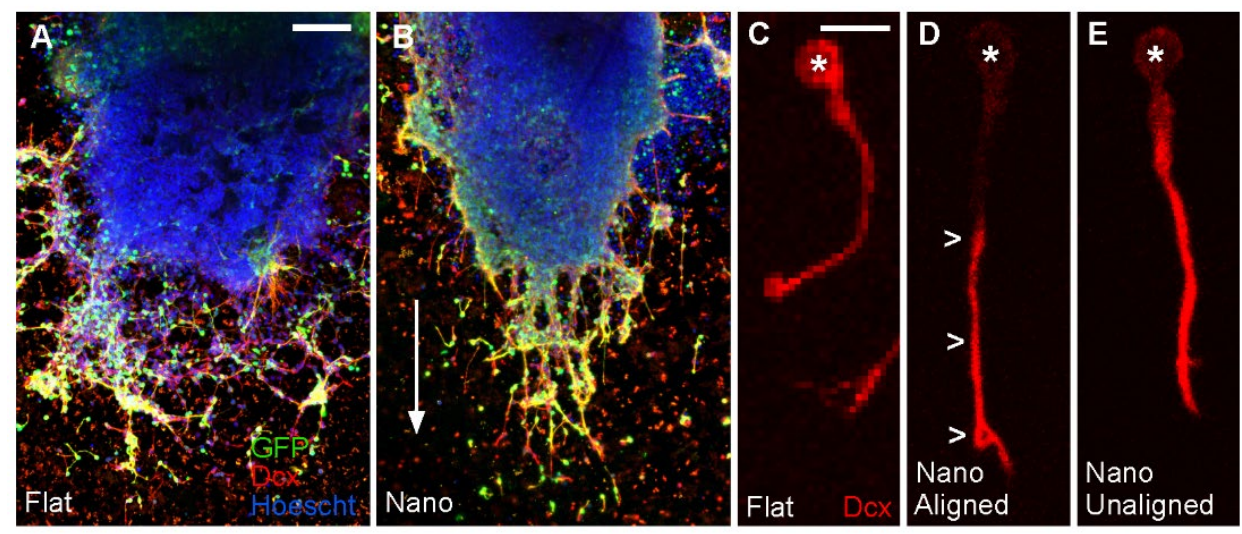

Figure 3.6: Altered subcellular distribution of doublecortin in the leading process of interneurons aligned to nanopatterns. A-B. MGE explants grown on flat (A) or nanopattern (B) topography stained for Doublecortin (Dcx). Arrow signifies the direction of pattern is vertical. Scale is $100 \mu \mathrm{m}$. C. A single interneuron on flat topography with uniform levels of Dcx along the leading process. D. Interneuron aligned to nanopattern shows increased intensity specific to the distal regions of the leading process. Open arrowheads point to increased levels of Dcx. E. Interneuron unaligned to the nanopattern shows uniform levels of Dcx along the leading process. Scale is $10 \mu \mathrm{m}$. 

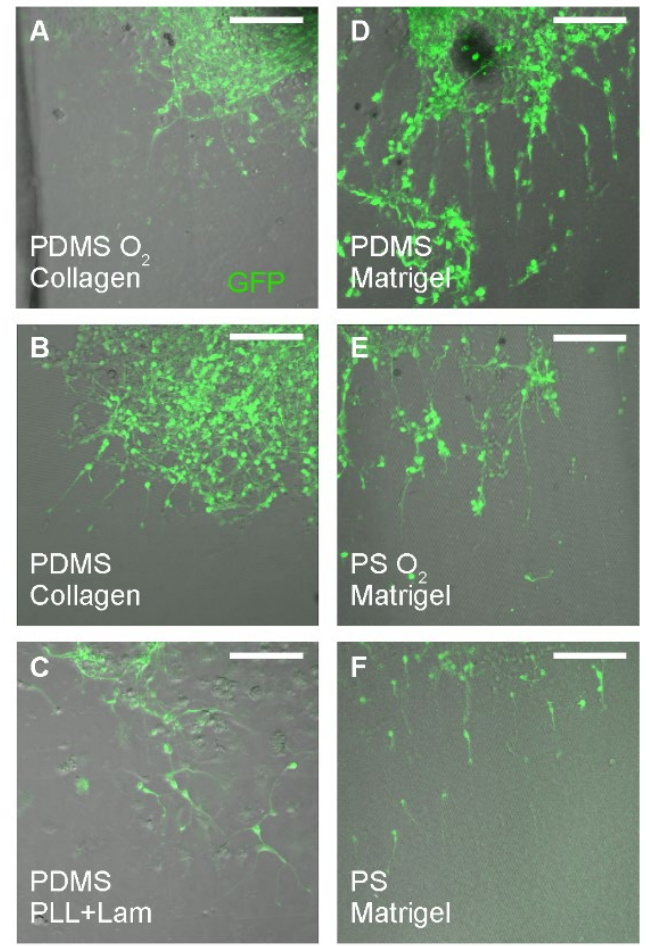

Supplemental Figure 3.1: Nanopattern coating and treatment strategies. A. Interneurons cultured on polydimethylsiloxane (PDMS) nanopatterns with 500nm grooves exposed to $30 \mathrm{~s}$ of oxygen plasma treatment and coated with $250 \mu \mathrm{M}$ collagen show poor outgrowth and alignment to grooves. B. Interneurons grown on PDMS nanopatterns with 500nm grooves and coated with $250 \mu \mathrm{M}$ of collagen show adhesion and outgrowth but poor alignment to grooves. C. Interneurons grown on 500nm nanopatterns made from PDMS with 500 nM poly-L-lysine (PLL) and laminin (Lam) coating have poor outgrowth and alignment. D. When grown on 500nm PDMS nanopatterns coated with a thin layer of Matrigel at 1:10 dilution with serum-free media (see methods), interneurons adhere and align to grooves but do not migrate far and quickly form clusters. E. Interneurons migrating on polystyrene (PS) treated with $30 \mathrm{~s}$ of oxygen plasma and coated with 1:10 Matrigel align and migrate along grooves but form clusters. F. Nanopatterns made from PS and coated with 1:10 Matrigel concentration show optimal alignment and outgrowth with interneurons freely migrating away from clusters. Scale bars are $100 \mu \mathrm{m}$. 
Chapter 4: Summary and Future Directions 


\section{SUMMARY}

In this dissertation, I have uncovered a novel role for the c-Jun $\mathrm{NH}_{2}$-terminal Kinase (JNK) signaling pathway in the migration of cortical interneurons. Prior to this work, the role of JNK signaling in the cell biological processes involved in cortical interneuron migration including nucleokinesis, leading process branching, and centrosome-cilia complex positioning, along with the requirement for JNK in navigating different topographical environments were unknown. I used a combination of pharmacological and genetic conditional triple knockout (cTKO) in vitro co-culture and ex vivo slice culture experiments to address these questions. In Chapter 2, I explored the requirement for JNK signaling in the saltatory process of nucleokinesis, dynamic branching of the leading process, and subcellular positioning of the centrosome-cilia complex in live migrating cortical interneurons using pharmacological inhibition and a cTKO mouse model. In Chapter 3, I discovered that JNK signaling controls cortical interneuron migration through the coordinated movement of the cell body during nucleokinesis regardless substrate environment and that cortical interneurons decipher nanotopographical cues to regulate migration. Together, this work provides new insight into the roles for JNK signaling in the cellular mechanisms required for the migration of cortical interneurons.

In Chapter 2, a combination of pharmacological and genetic approaches were used to examine the role of JNK signaling in cortical interneuron migration in an in vitro medial ganglionic eminence explant (MGE) cortical cell co-culture assay. Loss of JNK function using the pan-JNK inhibitor SP600125 caused cortical interneurons to severely slow their migration leading to shorter displacement distances. Additionally, JNK inhibition resulted in more variable migratory speeds compared to controls, suggesting that JNK signaling coordinates the movement of interneurons during nucleokinesis. Indeed, loss of JNK function significantly altered the kinetics of nucleokinesis with decreased amplitude, less frequent translocation events, and longer lasting cytoplasmic swellings in the leading process. Interestingly, a subset of JNK-inhibited 
cells migrating at similar speeds still exhibited significant defects in their migratory properties with decreased maximum speeds, reduced average and large nuclear translocation distances, and shorter cytoplasmic swelling extension. While cTKO interneurons migrated at similar speeds to wild-type controls, they had shorter displacement distances, more variable migratory speeds, and decreased straightness of migratory trajectories. Analysis of nucleokinesis kinetics in cTKO cells revealed significant reductions in nucleokinesis distance, but surprisingly, cTKO cells completed nucleokinesis at faster rates and had short-lived swellings compared to controls. With both pharmacological and genetic loss of JNK function, interneurons had less frequent growth cone splits and short lived interstitial side branches. Finally, we uncovered a novel role for JNK in controlling the subcellular distribution of the centrosome-cilia complex. Both centrosomes and primary cilia were mislocalized to the trailing process of migrating cortical interneurons under JNK-inhibition. Additionally, JNK inhibition had no effect on the length of the primary cilium, suggesting that JNK does not control the formation or stability of the primary cilium. In this chapter, we were able to demonstrate that migrating cortical interneurons require intact JNK signaling for regulating individual cell migration through leading process branching, nucleokinesis, and the localization of the centrosome-cilia complex.

In Chapter 3, we revealed that migrating cortical interneurons have a cell-intrinsic requirement for JNK signaling in nucleokinesis regardless of cellular environment. Upon JNK inhibition, cortical interneurons travel shorter distances and have decreased rates of nucleokinesis in ex vivo slice cultures, in vitro 3D matrixes, and in vitro co-cultures. These results suggest that JNK signaling plays similar roles in cortical interneuron migration with or without extracellular guidance cues. We also describe a novel tool to explore cortical interneuron migration using nanopattern topography. We discovered that cortical interneurons decipher nanoscale topographical cues in their physical environment to orient their direction and speed of migration. Cells migrating on nanopattern material had greater amplitude with similar frequency of 
nucleokinesis events compared to cells migrating on flat substrate. This suggests that nanopattern gratings control the directionality of cortical interneurons, enabling them to migrate longer distances over the same period of time. Finally, staining for the subcellular distribution of doublecortin, a protein involved in microtubule stability, revealed a leading process specific localization of doublecortin in cells aligned to the nanopattern gratings while cells unaligned or on flat substrate had a more diffuse localization throughout the cell.

We provide substantial evidence that JNK signaling plays an integral role in the coordinated movement of cortical interneurons through nucleokinesis, leading process branching, and centrosome-cilia positioning. While the exact molecular mechanisms involved in controlling the guided migration of cortical interneurons remains to be elucidated, future experiments should be directed towards exploring the requirement of JNK signaling across embryonic development (Figure 1A), JNK's role in ciliary signaling (Figure 1B), and in cytoskeletal dynamics (Figure 1C). Together, these experiments would provide a more complete understanding for the role of JNK signaling in interneuron migration.

\section{Figure 4.1:}

A Regulation of JNK expression and
activity is required for stream migration
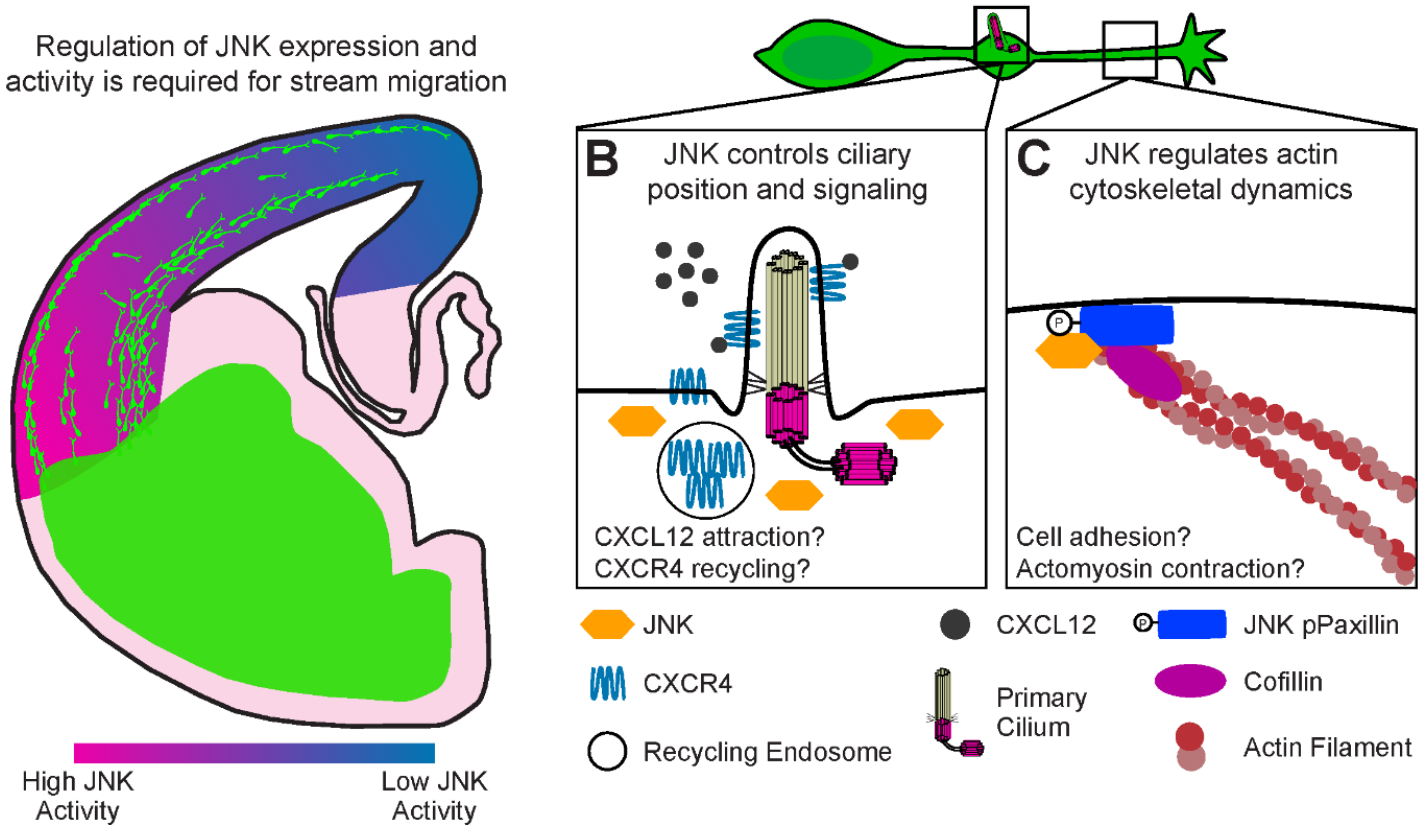


\section{DISCUSSION AND FUTURE DIRECTIONS}

\section{JNK signaling in Migrating Cortical Interneurons Across Embryonic Development}

Control of the precise timing of cortical interneuron migratory stream entry and exit is paramount for the development of cortical circuitry. While progress has been made on elucidating the extracellular guidance mechanisms controlling interneuron migration, little is known about the intracellular signaling events necessary for coordinating the response and movement of interneurons during stream migration. Our laboratory has demonstrated that the JNK signaling pathway is required for the formation and maintenance of cortical interneuron migratory streams in vivo, as well as the coordination of nucleokinesis and leading process branching during migration in vitro (Myers et al., 2014; Myers et al., 2020; Smith et al., 2020). In addition, by using a conditional triple knockout mouse model, we have shown that cortical interneurons have a cell-intrinsic requirement for JNK signaling during migration (Myers et al., 2020; Smith et al., 2020). While the highest transcript levels of all three JNK genes are found in the neocortex (Coffey, 2014), the protein expression and activity levels of each isoform in cortical interneurons during migration remains unknown. Therefore, investigating the temporal requirement of JNK signaling in cortical interneurons will create a more complete understanding of cortical development.

- Biosensors based on Förster resonance energy transfer (FRET) are relatively new tools that can be used to measure the spatiotemporal dynamics of intracellular signaling molecules in living cells. The JNK biosensor JNKAR1EV effectively reports JNK activity in live time-lapse imaged cells (Komatsu et al., 2011). Ex vivo slices with interneurons expressing JNKAR1EV (Figure A1) could be used to measure the activity of JNK signaling during migration, and imaged live with a multi-photon microscope for higher spatial and temporal resolution of JNK activity during nucleokinesis, leading process 
branching and stream migration (Figure A2). It will be important to quantify the activity of JNK signaling across development from interneuron entry into the cortex (about embryonic day 12.5) until radial migration and cortical plate invasion (about embryonic day 18.5).

- Combining fluorescence activate cell sorting (FACS) with quantitative polymerase chain reaction (qPCR) will provide more specific understanding for the individual roles of each Jnk isoform across interneuron migration. Cortex with fluorescently labeled interneurons (D/x5/6-CIE expressing) could be dissected, dissociated and FACS sorted for GFP to enrich for interneurons that can be used for qPCR. Samples could be taken and analyzed across interneuron migration in the cortex. Combining qPCR with western blot analysis of JNK isoforms in sorted cells will provide additional insight into the expression of JNK genes and proteins in interneurons during stream formation, migration, and exit.

- A photoactivatable JNK inhibitor could be used for precise spatial and temporal control of JNK inactivation in cortical interneurons to understand the role of JNK signaling during different stages of stream migration. The photoactivatable pLuc-LOV2WTJaWT-JBD construct (Hollos et al., 2020) uses the JNK binding domain of the JNK Interacting Protein 1 (JIP1) bound to the LOV2 domain of phototropin1 from Avena sativa to reversibly inhibit JNK signaling with light stimulation (Figure A3). Ex vivo slice cultures could be used to assess the effect of JNK inhibition on interneurons migrating at different stages of stream migration such as formation during initial entry, maintenance during tangential migration, and exit when cells turn radially to populate the cortical plate. This tool would also enable us to manipulate JNK signaling in cells migrating in different streams such as the marginal or subventricular zone stream allowing us to determine if cortical interneurons using different migratory routes have the same requirements for JNK signaling during migration. 


\section{Control of Ciliary Position and Signaling}

The analysis of interneurons devoid of JNK signaling revealed a novel role for JNK in the dynamic positioning of the primary cilium. JNK inhibition led to severe mislocalization of the primary cilium into the trailing process, regardless of the presence of a cytoplasmic swelling in the leading process, which was previously thought to be formed as the cilium moves forward prior to nucleokinesis. It is unknown whether the subcellular positioning of the primary cilium is required for proper ciliary signaling needed for sensing and responding to extracellular cues necessary for the guided migration of cortical interneurons.

C-X-C chemokine receptor 4 (CXCR4) is a receptor known to be required for the guidance of interneurons into the cortex and the formation of migratory streams (Tiveron et al., 2006; Stumm et al., 2007; Lysko et al., 2011; Wang et al., 2011; Abe et al., 2014). Cortical interneurons disperse from migratory streams and prematurely enter the cortical plate when CXCR4 is removed (Stumm et al., 2007; Lysko et al., 2011; Wang et al., 2011). Along with this, CXCR4 signaling was found to be disrupted in 22q11.2 deletion syndrome, a copy number variant syndrome thought to cause cortical circuit disorders (Meechan et al., 2009). CXCR4 is normally found diffusely in the primary cilium, but when the formation of the primary cilium is disrupted, it is localized to the base near the mother centriole (Higginbotham et al., 2012). Additionally, CXCR4-containing recycling endosomes cluster near the centrosome at the base of the primary cilium after addition of the CXCR4 ligand CXCL12 in Jurkat T cells, which are then recycled to the cell surface (Kumar et al., 2011). Clusters of CXCR4 also localize to the centrosome-ciliary complex in cortical interneurons treated with CXCL12 (Figure A4). Slice cultures of CXCL12RFP transgenic mice revealed that CXCL12 appears to preferentially localize to the primary cilium of migrating cortical interneurons (Abe et al., 2014). Interestingly, CXCL12 activates JNK 
signaling through CXCR4 to promote cellular migration in other cell types (Jones et al., 2007; Lue et al., 2011; Lu et al., 2019). Therefore, I hypothesize that JNK controls the positioning of the primary cilium which is then required for normal ciliary CXCR4 signaling involved in the guided migration of cortical interneurons.

Potential Experiments:

- Since CXCL12 treatment causes CXCR4 to cluster at the centrosome-ciliary region (Figure A4), it is possible that when the primary cilium is mislocalized to the trailing process, that CXCR4 clustering, and therefore recycling, may be diminished. Staining for CXCR4 in JNK-inhibited and CTKO interneurons treated with CXCL12 would provide insight into the role of JNK signaling in CXCR4 clustering.

- Flow cytometry of fixed cells can be performed with cTKO or JNK-inhibited interneurons to determine if CXCR4 receptor expression is disrupted with loss of JNK signaling (previously performed with Jnk1/2 conditional double knockout interneurons; Figure A5). The primary cilium of interneurons can also be isolated and analyzed with flow cytometry (Monaco et al., 2018) to determine if loss of JNK signaling disrupts cilia-specific localization of CXCR4. Treatment of JNK-inhibited or cTKO cells with CXCL12 would provide additional insight into the role of JNK signaling on CXCR4 localization and potential function.

- However, since the positioning of the primary cilium is highly dynamic, moving throughout the cell body and into the swelling depending on the stage of nucleokinesis, live-imaging analyses would need to be performed in order to develop a more comprehensive assessment for the role of JNK signaling in CXCR4 function and ciliary positioning. Interneurons co-expressing fluorescently labeled CXCR4 and Arl13b (primary cilia marker) could be used to assess the effect of JNK inhibition on CXCR4 and ciliary localization during cortical interneuron migration. Perfusion of CXCL12-565 
into culture media with SP600125 would determine if JNK inhibition disrupts CXCR4 ability to bind to CXCL12, internalize, and be recycled when localized to the trailing process of cortical interneurons. Additionally, these experiments could be performed in cTKO interneurons co-expressing fluorescently labeled CXCR4 and Arl13b.

- CXCR4 turnover is likely important for sustained signaling and guidance of cortical interneurons. Therefore, measuring the rate of CXCR4 recycling from endosomes back onto the cell membrane could further our understanding of JNK's role in CXCR4 signaling and interneuron migration. To answer this question, cortical interneurons could be electroporated with a fluorescently-tagged CXCR4 and Arl13b construct, then treated with CXCL12 and JNK-inhibitor (or in cTKO interneurons) and imaged live with lattice light sheet microscopy at millisecond intervals to capture the internalization of CXCR4 from the cell membrane, and recycling of CXCR4 back to the cell membrane.

- Since the primary cilium is thought to act as an antenna, sensing and responding to guidance signals in the extracellular environment, it is possible that disrupted ciliary placement prevents chemoattraction to CXCL12. To answer this question, a transwell assay could be performed (Figure A6). Dissociated interneurons would be placed on the top chambers of transwell inserts and media treated with CXCL12 alone, CXCL12 + JNK inhibitor, or JNK inhibitor alone. Once the cells are allowed to migrate through the transwell membrane for 24 hours, the inserts would be fixed, stained, imaged, and cells would be counted. This would determine if JNK inhibition blocks the chemoattraction of CXCL12 for migrating cortical interneurons. 


\section{JNK Signaling in Cytoskeletal Dynamics}

Migrating cortical interneurons require the dynamic remodeling of microtubule and actin cytoskeletal proteins for migration (Peyre et al., 2015). The nucleus is surrounded by a microtubule cage tethered to the centrosome which is connected to the microtubules of the leading process thought to generating the "forward" forces required for nuclear translocation (Tanaka et al., 2004; Higginbotham and Gleeson, 2007; Umeshima et al., 2007). Actin condenses in a cup-like shape at the rear of the cell body which then contracts, squeezing and propelling the nucleus forward towards the leading process (Bellion et al., 2005; Martini and Valdeolmillos, 2010). Migrating interneurons treated with nocodazole, a microtubule destabilizer, still complete nucleokinesis events and have actin condensation at the rear of the cell preceding nucleokinesis (Bellion et al., 2005; Martini and Valdeolmillos, 2010). Inhibition of actomyosin contraction with the non-muscle myosin ATPase inhibitor blebbistatin abolishes actin condensation at the rear of the cell and blocks nuclear movement (Martini and Valdeolmillos, 2010). Disrupting F-actin formation with latrunculin A results in rounder cell bodies consistent with the loss of actomyosin contraction that squeezes and elongates the nucleus prior to translocation (Martini and Valdeolmillos, 2010). Additionally, myosin II motors and F-actin dynamics were found to drive the coordinated movement and positioning of the centrosome during glia-guided migration (Solecki et al., 2009), suggesting a role for actin in not only the movement of the nucleus but also key organelles necessary for neuronal migration.

The leading process is highly dynamic, extending and retracting branches to sense and respond to cues in the environment necessary for the guided migration of cortical interneurons. Leading process branching is initiated through a membrane protrusion formed by F-actin meshwork containing actin-related proteins $2 / 3$ that stabilize branch points, and other proteins involved at the interface between the cell membrane and actin cytoskeleton such as cortactin and paxillin (Turner, 2000; Spillane et al., 2011; Lysko et al., 2014). Treatment of neurons with blebbistatin 
results in a failure of actin flow into the growth cone and also prohibits microtubule flow (Burnette et al., 2008). This change in the distribution of actin may lead to defects in growth cone splitting. Interestingly, recently identified molecular mediators of nucleokinesis and leading process branching also regulate actin dynamics to control interneuron migration.

In this dissertation, we have shown that JNK signaling controls multiple aspects of cortical interneuron migration including nucleokinesis, leading process branching, and positioning of the centrosome-cilia complex. Similar to other models with disrupted nucleokinesis and centrosome positioning, JNK inhibition leads to disrupted actin dynamics around the cell body (Figure A7). Indeed, defects in actin polymerization or actomyosin contractility may underly the severe disruptions in nucleokinesis that we have found. Thus, assessing the role of JNK signaling in regulating actin dynamics during cortical interneuron migration will provide great insight to the field.

- In vitro explant co-culture assays could be utilized to assess the role of JNK signaling in actin dynamics. Using a fluorescent LifeAct or Utrophin construct that labels F-actin in interneurons would allow for real time visualization of actin dynamics during cortical interneuron migration. Cultures could be treated with SP600125 (or perhaps a cellpermeable peptide inhibitor) and live-imaged to assess the effect of JNK inhibition on actin dynamics and contraction in the cell body, swelling, and growth cones of the leading process. Preliminary data suggest loss of JNK function disrupts actin dynamics. JNK inhibition leads to abnormal branches protruding from the cell body, and less organized growth cones over time (Figure A7). More quantitative measurements should be used to further explore these changes including measurement of actomyosin intensity distributed across the growth cone, growth cone surface area before splitting, and cell body actomyosin intensity and distribution. These measurements would provide 
clear evidence for the role of JNK signaling in the subcellular distribution of actomyosin forces in migrating interneurons.

- To develop a more complete understanding for the role of JNK signaling in actin dynamics, we must assess the localization of actin regulators involved in cellular migration such as non-muscle myosin IIB, cortactin, and paxillin. Co-cultures in control and SP600125-treated conditions stained for non-muscle myosin IIB were inconclusive (Figure A8) and should be reproduced in 3D Matrigel matrix explant cultures that isolate staining to only interneurons. Interneurons grown in Matrigel under control or JNKinhibited conditions show remarkably different cortactin staining during similar stages of nucleokinesis (Figure A9), suggesting that JNK signaling may be involved in actin connection to the cell membrane. Interestingly, another protein involved in actin dynamics, paxillin, is a known target of JNK (Huang et al., 2003; Kimura et al., 2008) and interacts directly with cortactin during migration (Bowden et al., 1999). Thus, the changes in cortactin localization may be a direct cause of the removal of JNKphosphorylated paxillin. Western blotting for non-muscle myosin IIB, cortactin, paxillin, and JNK-phosphorylated paxillin in cultured interneurons treated with JNK inhibitor would provide additional quantitative evidence.

- Actin accumulates around the centrosome, and actin contraction is required for the positioning of the centrosome during glial-guided migration (Solecki et al., 2009). It is possible that JNK signaling is involved in maintaining the structural integrity of actin necessary to contract and properly position the centrosome prior to nucleokinesis. Coexpression of LifeAct and a centrosome/primary cilium constructs (Centrin2 or Arl13b) in interneurons will further our understanding in the role of JNK regulated actin dynamics in the positioning of subcellular organelles. Comparing these data with other fluorescently labeled constructs such as myosin light chain kinase, myosin IIB, and even paxillin co-expressed with Centrin2 or Arl13b would provide further mechanistic insight 
into the role of JNK signaling in the coordinated movement of the centrosome-ciliary complex.

- Chromophore assisted light inactivation specifically inactivates target proteins by generating reactive oxygen species around the protein of interest (Jarvela and Linstedt, 2014). The photosensitizer KillerRed can be fused to a protein of interest (JNK) and upon illumination, specifically inactivate the target by generating reactive oxygen species (Bulina et al., 2006). Co-electroporation of a KillerRed-JNK fusion construct with Centrin2 and LifeAct will allow for the targeted depletion of JNK signaling around the centrosome-cilia complex and subsequent visualization of the effects of loss of centrosomal JNK on both the position of the organelle and any changes to the actin cytoskeleton.

\section{JNK signaling in interneuron migration: instructive or permissive?}

While the exact mechanisms behind JNK's control of interneuron migration remain to be elucidated, we have provided evidence that cortical interneurons require JNK signaling for normal migration. While cortical interneurons completely devoid of JNK signaling are still capable of performing leading process branching, completing nucleokinesis (Smith et al., 2020), and navigating the developing cortex (Myers et al., 2014; Myers et al., 2020), their migration is severely disrupted and they are unable to perform nucleokinesis and leading process branching normally or successfully form organized streams. Therefore, it is possible that JNK may not instruct interneuron migration, but rather act as a permissive signaling mechanism within cortical interneurons to fine-tune their migration and allow them to sense cues at the right time and place to make appropriate guidance decisions. Experimentally determining whether JNK signaling is instructive or permissive during interneuron migration is important to further our knowledge of JNK during cortical development. 
- An in vitro microfluidic assay could be utilized to determine the instructive versus permissive function of JNK signaling during cortical interneuron migration. Cortical interneurons could be electroporated with different constructs and cultured in channels and presented with a chemoattractive cue such as CXCL12 to direct their migration. There are three constructs that could be used to help elucidate permissive vs instructive role of JNK signaling during interneuron migration; a JNK biosensor, a photoactivatable constitutively active JNK, and a photoactivatable dominant negative inhibitor. The JNK biosensor would be used to determine the effect of CXCL12 chemoattraction on JNK activity within the cell. If there is a change in the distribution of active JNK within the interneurons toward the gradient of CXCL12, it could suggest that JNK is capable of playing an instructive role in interneuron migration.

- Next, a photoactivatable construct that upon light stimulation would release a MAPKK7JNK fusion protein to act as constitutively active JNK could be used. The attraction and migratory dynamics of interneurons expressing an activated JNK constructed in the microfluidic assay could be analyzed. If significantly more interneurons expressing this construct migrated towards the gradient of CXCL12 and migrated faster towards these signals, it would suggest that JNK has instructive roles in interneuron migration. Whereas if there was no effect, it would suggest that JNK is a permissive signal and increased activity does not necessarily lead to increased attraction or migratory speed.

- Finally, a photoactivatable dominant negative inhibitor of JNK could be used. After illuminated, if significantly less interneurons expressing this construct migrated towards the gradient of CXCL12, it would again suggest that JNK has instructive roles in interneuron migration. We already know that removal of JNK signaling slows migration and disrupts the kinetic properties of nucleokinesis and leading process branching, but if cells expressing this construct slowed it would further suggest that JNK acts as permissive signal that enables normal migration. 


\section{FINAL THOUGHTS}

The cerebral cortex plays key roles in a diverse range of tasks including perception, volitional movement, cognition, language, memory, and consciousness and is perhaps the most intricately designed region of the human brain to have evolved over the millennia. This highly organized brain structure is formed over the course of embryonic development and early postnatal life. During embryonic development, cortical excitatory projection neurons and inhibitory interneurons must migrate from their birthplaces into their proper layers within the cortical plate to establish the circuitry that enables the cerebral cortex to function properly. Since cortical interneurons are outnumbered by excitatory neurons, disruptions to the migration of cortical interneurons can lead to lasting alterations in cortical circuitry, resulting in neurodevelopmental disease. Therefore, it is imperative that we examine the mechanisms involved in the guided migration of cortical interneurons.

While many extracellular signaling molecules guiding the migration of cortical interneurons have been identified, the role of intracellular signaling pathways in the coordinated movement of cortical interneurons remain to be identified. In this dissertation, I have explored the role of the c-Jun $\mathrm{NH}_{2}$-terminal kinase ( $\mathrm{JNK}$ ) intracellular signaling pathway in the cell biological mechanisms required for cortical interneuron migration. In Chapter 2, I discovered a role for JNK signaling in the kinetics of nucleokinesis, leading process branching dynamics, and the positioning of the centrosome-cilia complex. In Chapter 3, I determined that JNK signaling controls nucleokinesis similarly regardless of cellular environment and developed a novel nanopattern method for studying the guided migration of cortical interneurons. Future efforts should be aimed towards exploring the biochemical mechanisms involved in JNK regulation of interneuron migration at the cellular and subcellular level. 


\section{REFERENCES}

Abe P, Mueller W, Schütz D, MacKay F, Thelen M, Zhang P, Stumm R (2014) CXCR7 prevents excessive CXCL12-mediated downregulation of CXCR4 in migrating cortical interneurons. Development 141:1857-1863.

Bellion A, Baudoin JP, Alvarez C, Bornens M, Métin C (2005) Nucleokinesis in tangentially migrating neurons comprises two alternating phases: forward migration of the Golgi/centrosome associated with centrosome splitting and myosin contraction at the rear. J Neurosci 25:5691-5699.

Bowden ET, Barth M, Thomas D, Glazer RI, Mueller SC (1999) An invasion-related complex of cortactin, paxillin and PKCmu associates with invadopodia at sites of extracellular matrix degradation. Oncogene 18:4440-4449.

Bulina ME, Chudakov DM, Britanova OV, Yanushevich YG, Staroverov DB, Chepurnykh TV, Merzlyak EM, Shkrob MA, Lukyanov S, Lukyanov KA (2006) A genetically encoded photosensitizer. Nat Biotechnol 24:95-99.

Burnette DT, Ji L, Schaefer AW, Medeiros NA, Danuser G, Forscher P (2008) Myosin II activity facilitates microtubule bundling in the neuronal growth cone neck. Dev Cell 15:163-169.

Coffey ET (2014) Nuclear and cytosolic JNK signalling in neurons. Nat Rev Neurosci 15:285299.

Higginbotham H, Eom TY, Mariani LE, Bachleda A, Hirt J, Gukassyan V, Cusack CL, Lai C, Caspary T, Anton ES (2012) Arl13b in primary cilia regulates the migration and placement of interneurons in the developing cerebral cortex. Dev Cell 23:925-938.

Higginbotham HR, Gleeson JG (2007) The centrosome in neuronal development. Trends Neurosci 30:276-283.

Hollos P, John JM, Lehtonen JV, Coffey ET (2020) Optogenetic Control of Spine-Head JNK Reveals a Role in Dendritic Spine Regression. eNeuro 7.

Huang C, Rajfur Z, Borchers C, Schaller MD, Jacobson K (2003) JNK phosphorylates paxillin and regulates cell migration. Nature 424:219-223.

Jarvela TS, Linstedt AD (2014) The application of KillerRed for acute protein inactivation in living cells. Curr Protoc Cytom 69:12.35.11-12.35.10.

Jones J, Marian D, Weich E, Engl T, Wedel S, Relja B, Jonas D, Blaheta RA (2007) CXCR4 chemokine receptor engagement modifies integrin dependent adhesion of renal carcinoma cells. Exp Cell Res 313:4051-4065.

Kimura K, Teranishi S, Yamauchi J, Nishida T (2008) Role of JNK-dependent serine phosphorylation of paxillin in migration of corneal epithelial cells during wound closure. Invest Ophthalmol Vis Sci 49:125-132.

Komatsu N, Aoki K, Yamada M, Yukinaga H, Fujita Y, Kamioka Y, Matsuda M (2011) Development of an optimized backbone of FRET biosensors for kinases and GTPases. Mol Biol Cell 22:4647-4656.

Kumar A, Kremer KN, Dominguez D, Tadi M, Hedin KE (2011) Ga13 and Rho mediate endosomal trafficking of CXCR4 into Rab11+ vesicles upon stromal cell-derived factor-1 stimulation. J Immunol 186:951-958.

Lu Y, Xing J, Yin X, Zhu X, Yang A, Luo J, Gou J, Dong S, Xu J, Hou T (2019) Bone MarrowDerived CD44. Stem Cells Int 2019:1513526.

Lue H, Dewor M, Leng L, Bucala R, Bernhagen J (2011) Activation of the JNK signalling pathway by macrophage migration inhibitory factor (MIF) and dependence on CXCR4 and CD74. Cell Signal 23:135-144.

Lysko DE, Putt M, Golden JA (2011) SDF1 regulates leading process branching and speed of migrating interneurons. J Neurosci 31:1739-1745. 
Lysko DE, Putt M, Golden JA (2014) SDF1 reduces interneuron leading process branching through dual regulation of actin and microtubules. J Neurosci 34:4941-4962.

Martini FJ, Valdeolmillos M (2010) Actomyosin contraction at the cell rear drives nuclear translocation in migrating cortical interneurons. J Neurosci 30:8660-8670.

Meechan DW, Tucker ES, Maynard TM, LaMantia AS (2009) Diminished dosage of 22q11 genes disrupts neurogenesis and cortical development in a mouse model of 22q11 deletion/DiGeorge syndrome. Proc Natl Acad Sci U S A 106:16434-16445.

Monaco S, Baur K, Hellwig A, Hölzl-Wenig G, Mandl C, Ciccolini F (2018) A Flow CytometryBased Approach for the Isolation and Characterization of Neural Stem Cell Primary Cilia. Front Cell Neurosci 12:519.

Myers AK, Meechan DW, Adney DR, Tucker ES (2014) Cortical interneurons require Jnk1 to enter and navigate the developing cerebral cortex. J Neurosci 34:7787-7801.

Myers AK, Cunningham JG, Smith SE, Snow JP, Smoot CA, Tucker ES (2020) JNK signaling is required for proper tangential migration and laminar allocation of cortical interneurons. Development 147:Doi: 10.1242/dev.180646.

Peyre E, Silva CG, Nguyen L (2015) Crosstalk between intracellular and extracellular signals regulating interneuron production, migration and integration into the cortex. Front Cell Neurosci 9:129.

Smith SE, Coker NK, Tucker ES (2020) JNK Signaling Regulates Cellular Mechanics of Cortical Interneuron Migration. eNeuro 7.

Solecki DJ, Trivedi N, Govek EE, Kerekes RA, Gleason SS, Hatten ME (2009) Myosin II motors and F-actin dynamics drive the coordinated movement of the centrosome and soma during CNS glial-guided neuronal migration. Neuron 63:63-80.

Spillane M, Ketschek A, Jones SL, Korobova F, Marsick B, Lanier L, Svitkina T, Gallo G (2011) The actin nucleating Arp2/3 complex contributes to the formation of axonal filopodia and branches through the regulation of actin patch precursors to filopodia. Dev Neurobiol 71:747-758.

Stumm R, Kolodziej A, Schulz S, Kohtz JD, Höllt V (2007) Patterns of SDF-1alpha and SDF1gamma mRNAs, migration pathways, and phenotypes of CXCR4-expressing neurons in the developing rat telencephalon. J Comp Neurol 502:382-399.

Tanaka T, Serneo FF, Higgins C, Gambello MJ, Wynshaw-Boris A, Gleeson JG (2004) Lis1 and doublecortin function with dynein to mediate coupling of the nucleus to the centrosome in neuronal migration. J Cell Biol 165:709-721.

Tiveron MC, Rossel M, Moepps B, Zhang YL, Seidenfaden R, Favor J, König N, Cremer H (2006) Molecular interaction between projection neuron precursors and invading interneurons via stromal-derived factor 1 (CXCL12)/CXCR4 signaling in the cortical subventricular zone/intermediate zone. J Neurosci 26:13273-13278.

Turner CE (2000) Paxillin and focal adhesion signalling. Nat Cell Biol 2:E231-236.

Umeshima H, Hirano T, Kengaku M (2007) Microtubule-based nuclear movement occurs independently of centrosome positioning in migrating neurons. Proc Natl Acad Sci U S A 104:16182-16187.

Wang Y, Li G, Stanco A, Long JE, Crawford D, Potter GB, Pleasure SJ, Behrens T, Rubenstein JL (2011) CXCR4 and CXCR7 have distinct functions in regulating interneuron migration. Neuron 69:61-76. 
Appendix 

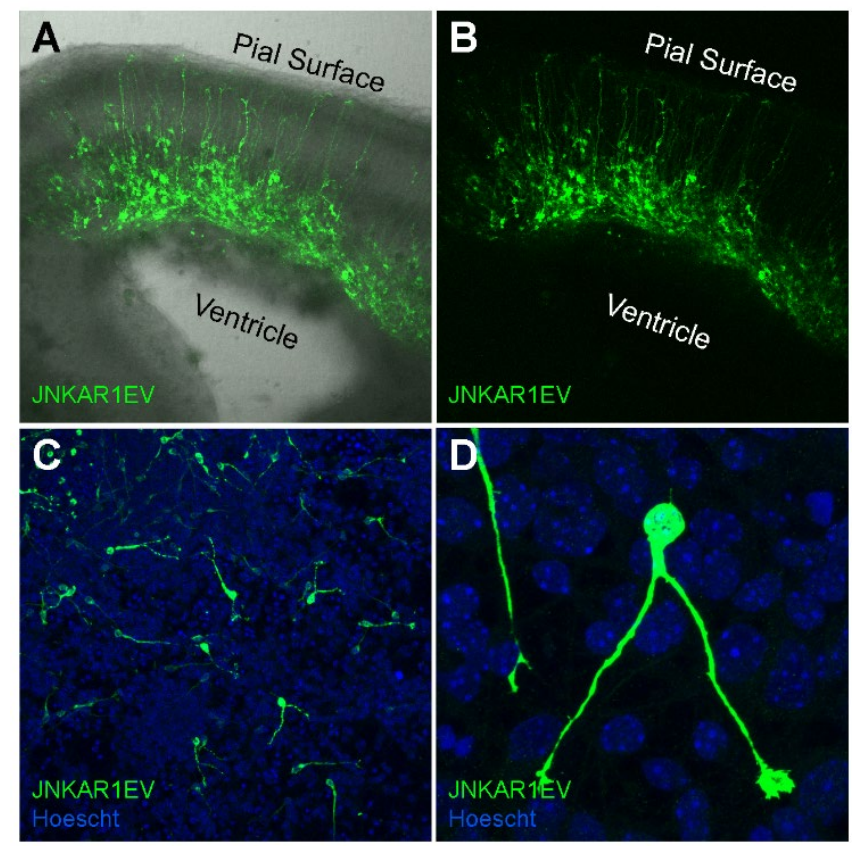

Figure A1. Electroporation of JNKAR1EV biosensor labels cortical excitatory projection neurons and inhibitory interneurons. A. Ex vivo slice with biosensor injected into the ventricle and electroporated into the ventricular zone. B. Expressing of biosensor in radially projecting neurons live. C. MGE explant cortical cell co-culture fixed and stained for GFP to label interneurons expressing biosensor. D. High magnification of a single interneuron expressing biosensor shows normal morphology. 


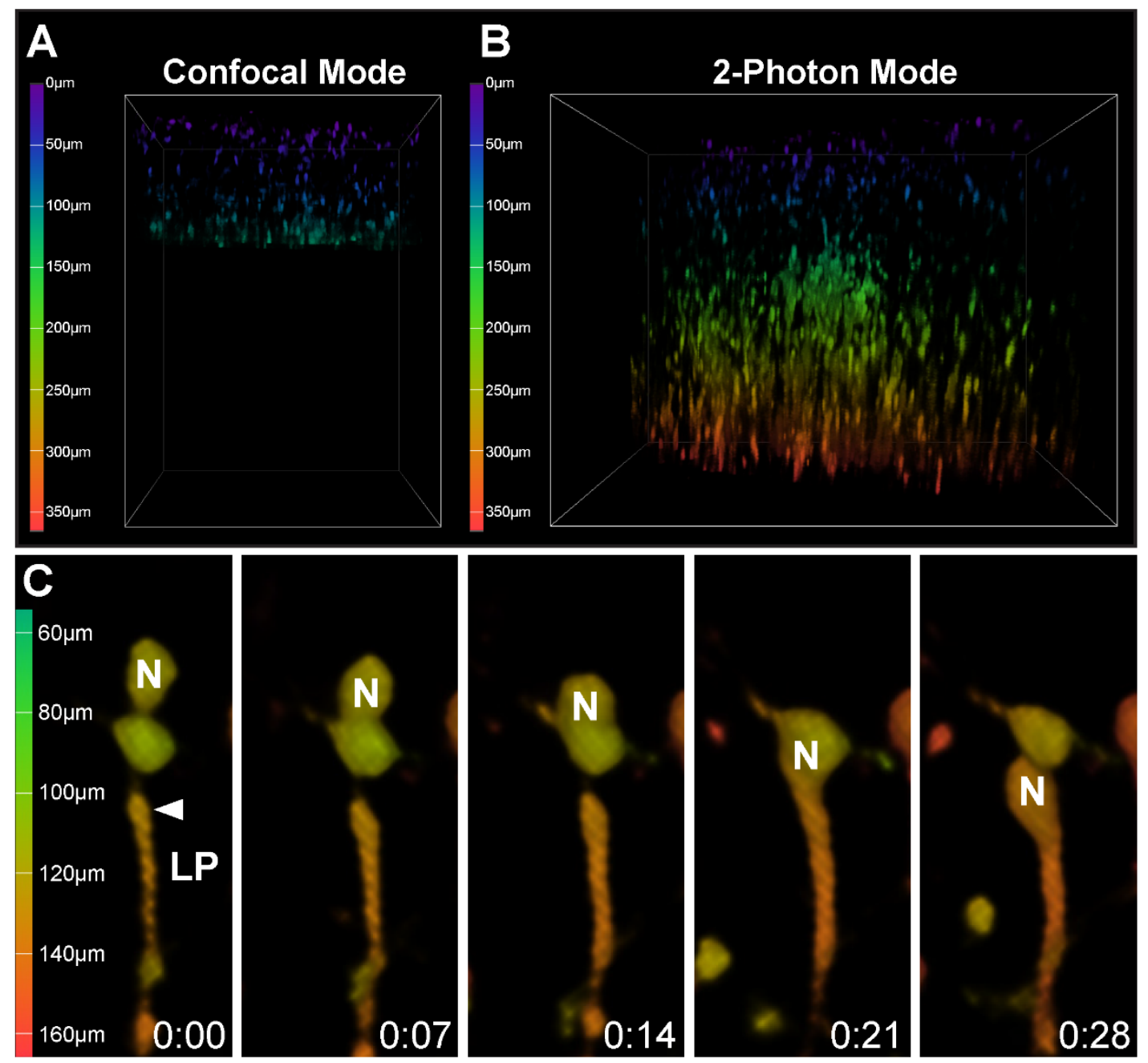

Figure A2. Cortical slice imaged live with 2-photon microscopy allows for higher spatial and temporal resolution than confocal microscopy. A. Ex vivo slice imaged lived with confocal microscope loses resolution at $100 \mu \mathrm{m}$ depth of tissue. B. 2-photon microscopy enables higher resolution at tissue depths unattainable by confocal microscope. C. A single interneuron can be seen undergoing nucleokinesis over $100 \mu \mathrm{m}$ deep using 2-photon microscopy. 


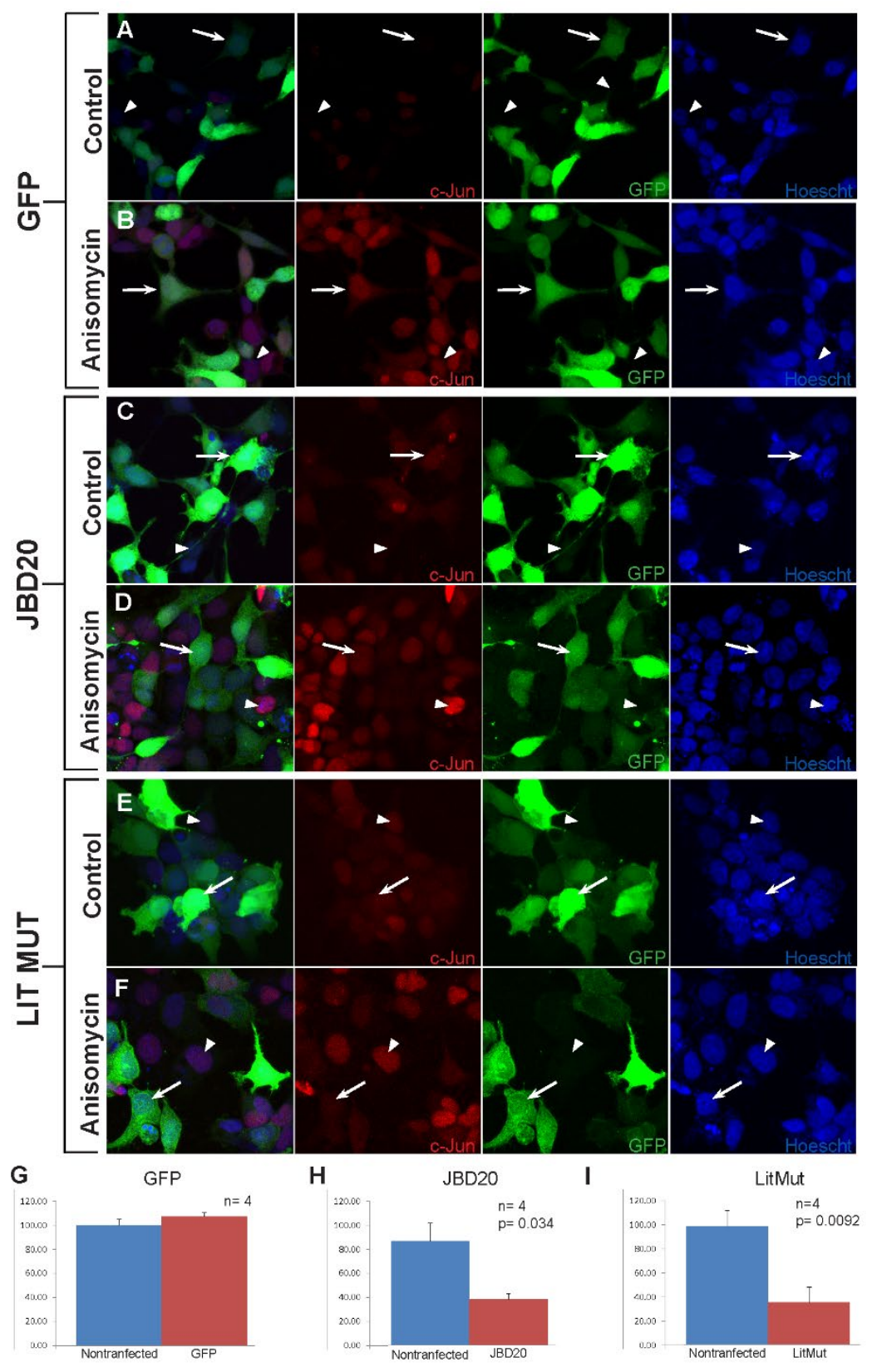

Figure A3. Constitutively active inhibitor complex (JBD20 and LitMut) blocks JNK phosphorylation of c-Jun. HEK293 cells were transfected with GFP construct (A,B), JBD20 $(C, D)$, or LitMut $(E, F)$ and grown in control $(A, C, E)$ or anisomycin stimulated conditions $(B, D, F)$. G-I. Quantification of p-cJun immunofluorescence. Fluorescence signal was measured in nuclei from individual cells in each well. The corrected nuclear fluorescence for transfected and nontransfected cells from each condition were determined. 

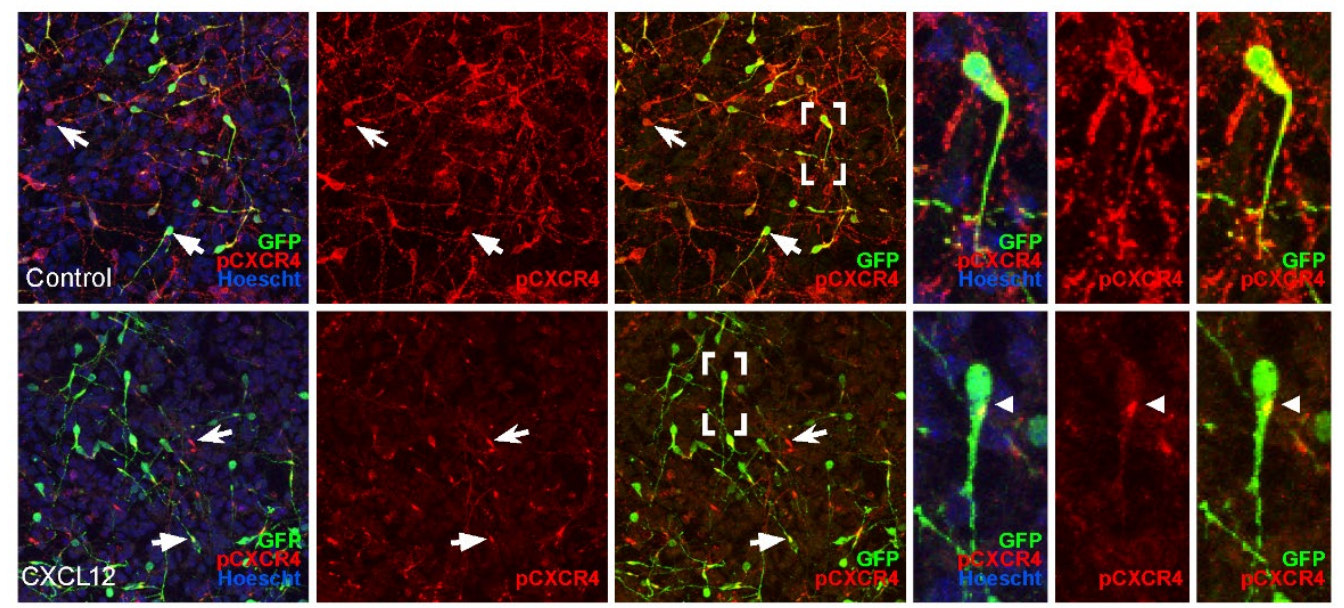

Figure A4. CXCR4 is activated in cortical interneurons upon CXCL12 treatment.

Control cultures show diffuse activated CXCR4 (phosphorylated-CXCR4; pCXCR4) throughout cell membrane (top panel). Upon 150nM CXCL12 treatment, pCXCR4 becomes internalized and forms punctate concentrations of receptor localized within the interneurons (bottom panel). 

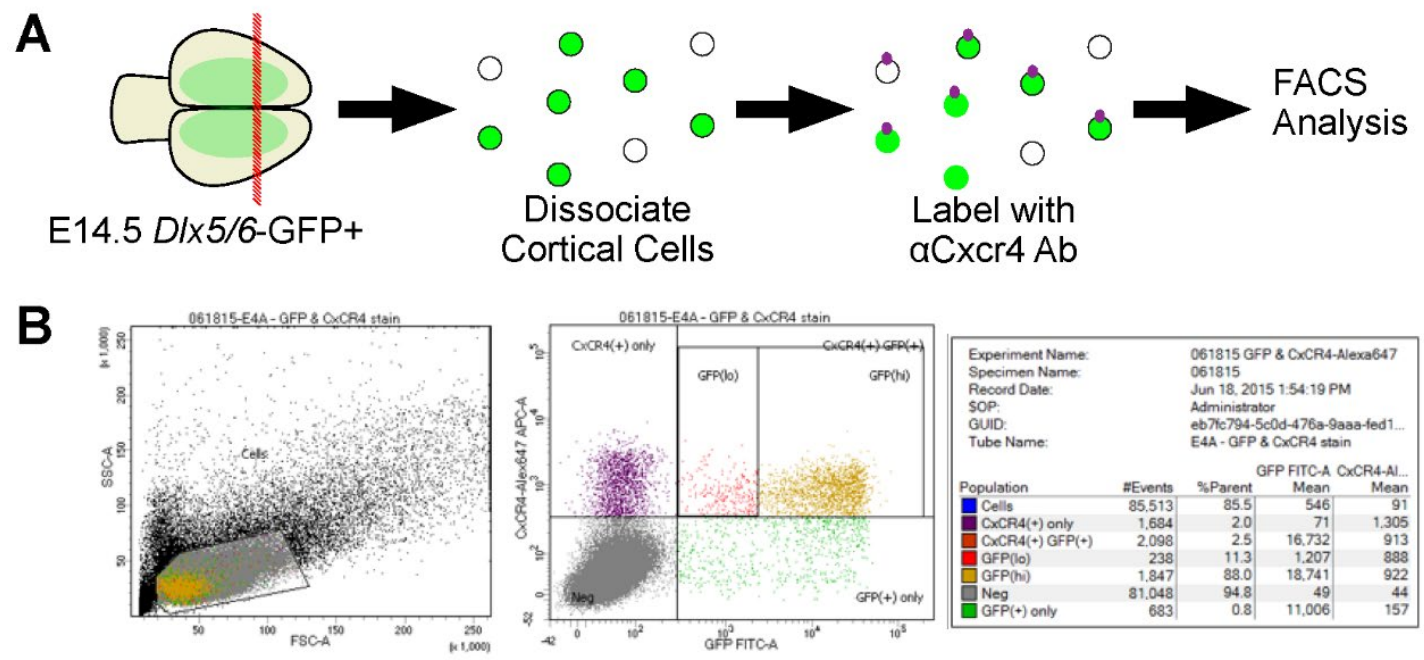

Figure A5. Flow cytometry analysis of Cxcr4 cell surface expression on cortical

interneurons. A. Schematic representation of the method used for FACS analysis of Cxcr4 on cortical interneurons. E14.5 DLX+ mouse cortices were micro-dissected and dissociated. Cells were incubated with anti-Cxcr4 antibody for 30 minutes to label Cxcr4 present on the cell surface, then fixed in $4 \%$ paraformaldehyde and analyzed with flow cytometry for abundance in the sample and for relative fluorescence intensity. B. Readout from a trial showing (left) the population of cells selected for analysis, (middle) the different populations of cells separated and measured and (right) the data obtained from this experiment. 

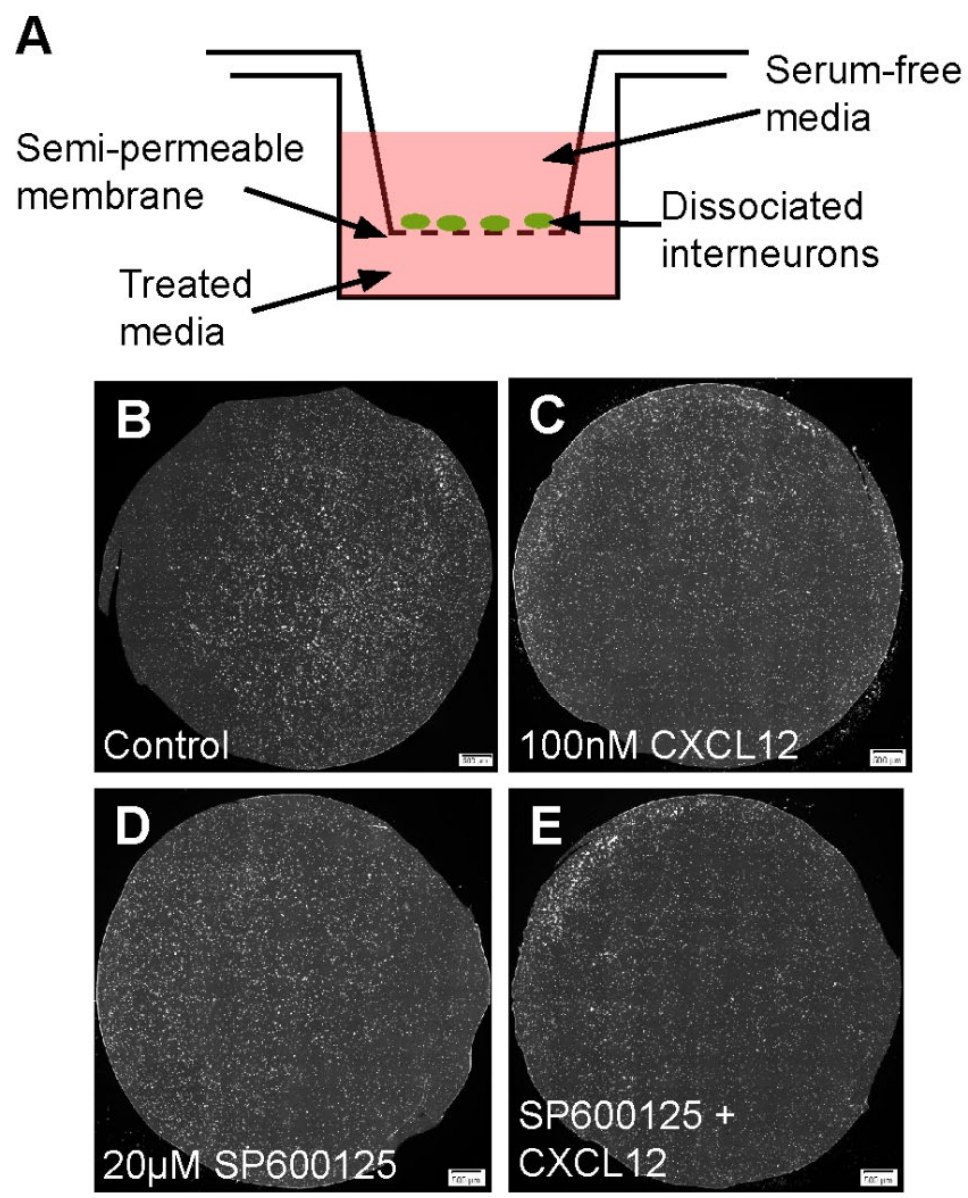

Figure A6. Transwell assay with dissociated interneurons from medial ganglionic

eminences. A. Schematic representation of the method used for transwell assay. E14.5 mouse MGEs were micro-dissected and dissociated. Cells were incubated for 24 hours on semipermeable membranes with serum-free media in top well and treated media on bottom well. BE. Representative wells of cells labeled with Hoescht nuclear counterstain in Control (B), 100nM

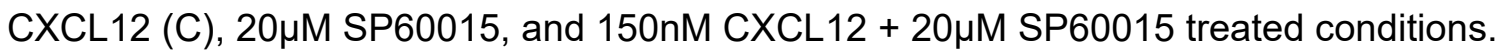




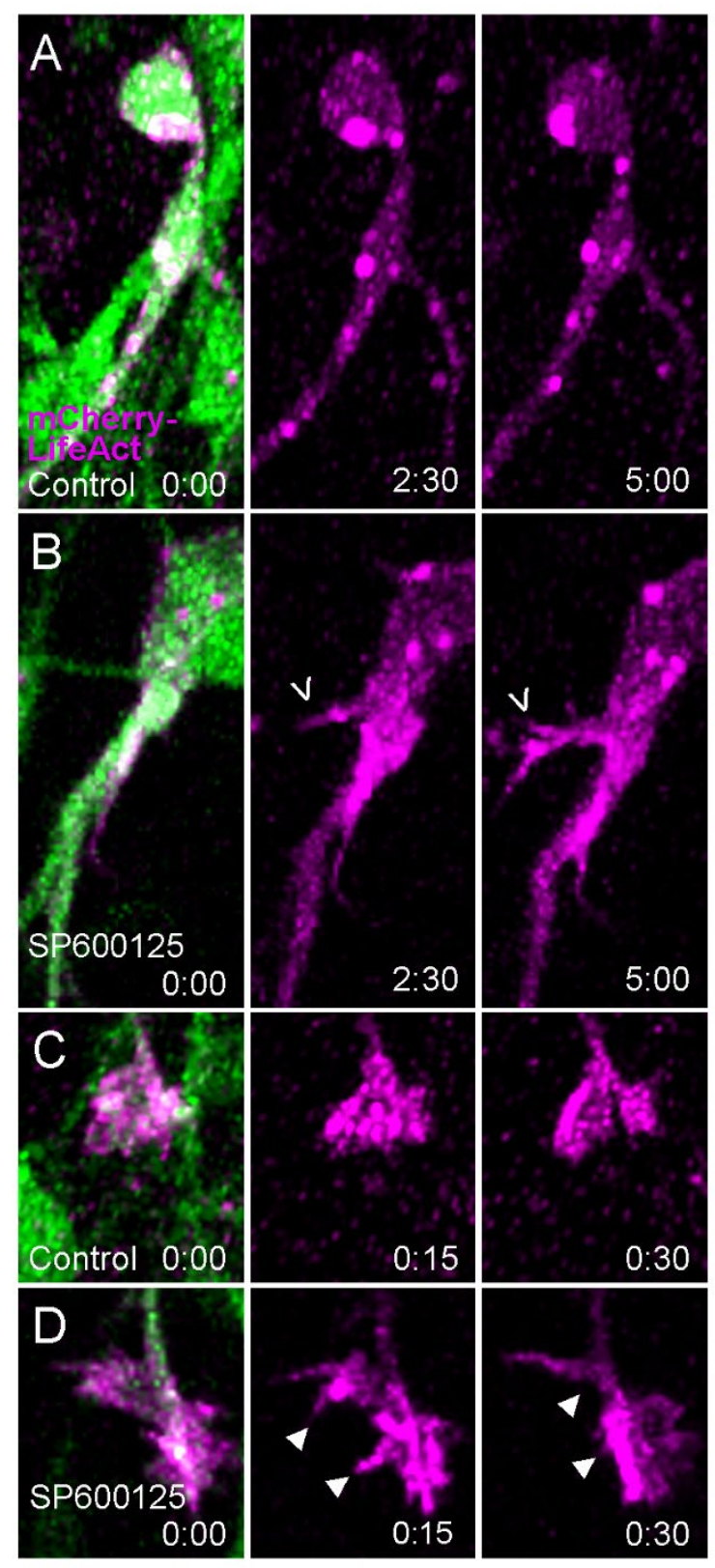

Figure A7. JNK inhibition disrupts actin dynamics in the cell bodies and growth cones of migrating cortical interneurons. A. Control cell expressing LiveAct with swelling ahead of cell body. B. JNK inhibited cell expressing LifeAct shows ectopic branches near their cell body compared to control. C. LifeAct allows for enhanced visualization of control growth cone dynamics. D. JNK-inhibited cell has disrupted growth cone dynamics. 

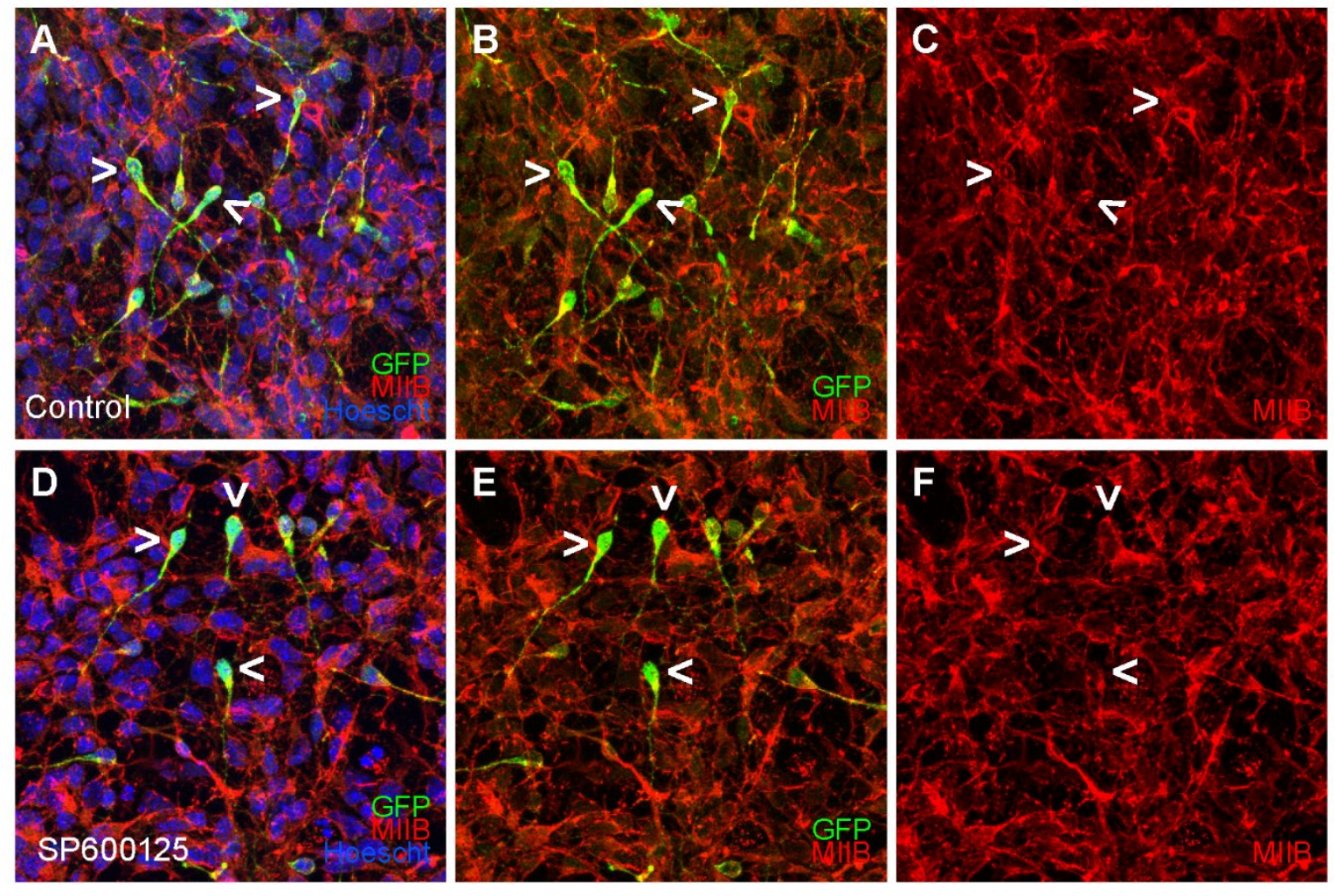

Figure A8. Myosin IIB labels soma and swelling of migrating cortical interneurons. A-C. Control cells stained with non-muscle myosin IIB have somal and swelling labeling during

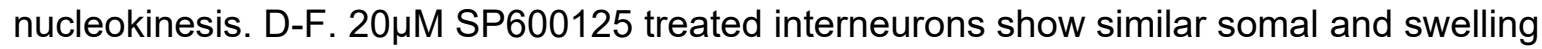
labeling as controls. Open arrowheads denote individual interneurons. 

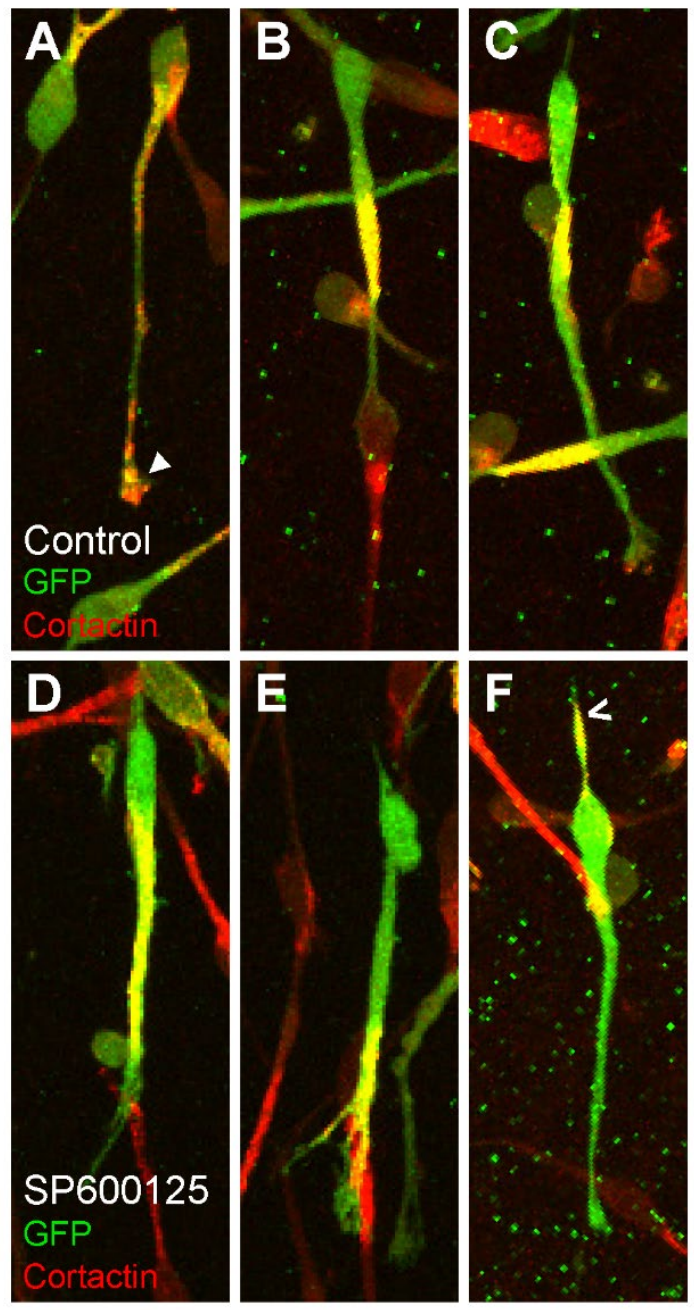

Figure A9. Migrating cortical interneurons require JNK signaling for proper localizaiton of cortactin. A-C. Control cells show localization of cortactin to the leading process and growth cone of a stationary interneuron $(A)$, to the cytoplasmic swelling of an interneuron initiating nucleokinesis (B), and during nuclear translocation (C). D-E. Interneurons treated with $20 \mu \mathrm{M}$ SP600125 for 4 hours have alters localization of cortactin. Cortactin labels the length of the leading process without entering the growth cone in a stationary interneuron (D), the distal portion of the lead process in an interneuron initiating nucleokinesis $(E)$, and the trailing process during nuclear translocation $(F)$. Closed arrowheads denote cortactin in the growth cones, open arrowhead labels cortactin in the trailing process. 

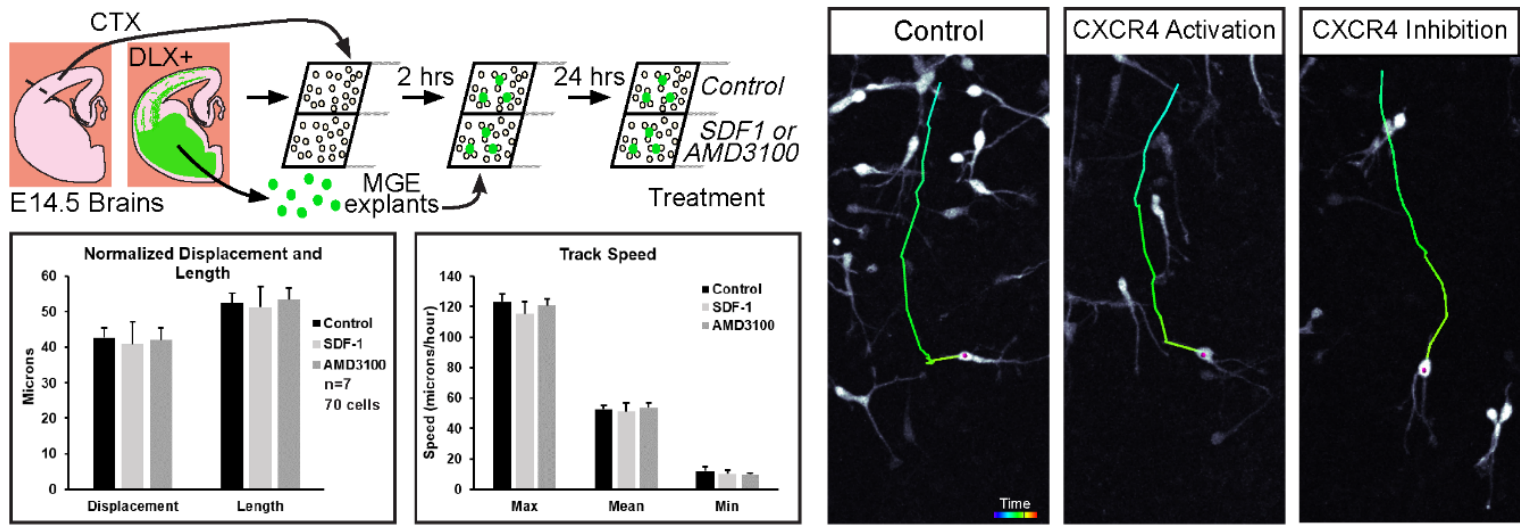

Figure A10. CXCR4 activation or inhibition does not affect overall migratory properties of cortical interneurons in vitro co-culture assay. Cortical interneurons were treated with CXCR4 ligand (CXCL12/SDF-1) or antagonist (AMD3100). Cortical interneurons treated with

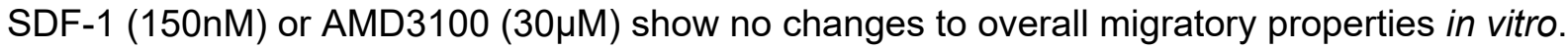



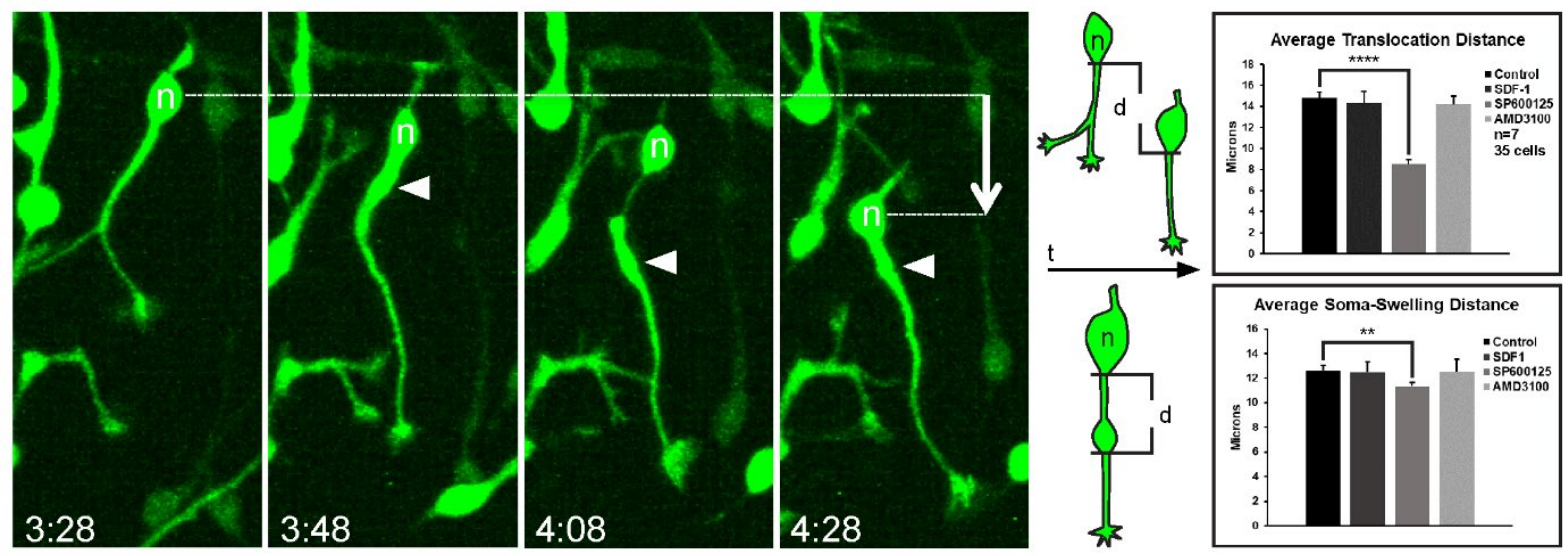

Figure A11. JNK- but not CXCR4-inhibition disrupts nucleokinesis in migrating cortical interneurons. Swellings (arrowheads) emerge in leading processes before cells bodies containing the nucleus $(\mathrm{n})$ translocate. Nuclear translocation and soma to swelling distance were affect under JNK-inhibition but not CXCR4-inhibition or stimulation. Statistical analyses were performed with two-tailed Student's t-tests: ${ }^{* * *} \mathrm{p}<0.0001,{ }^{* *} \mathrm{p}<0.01$. 


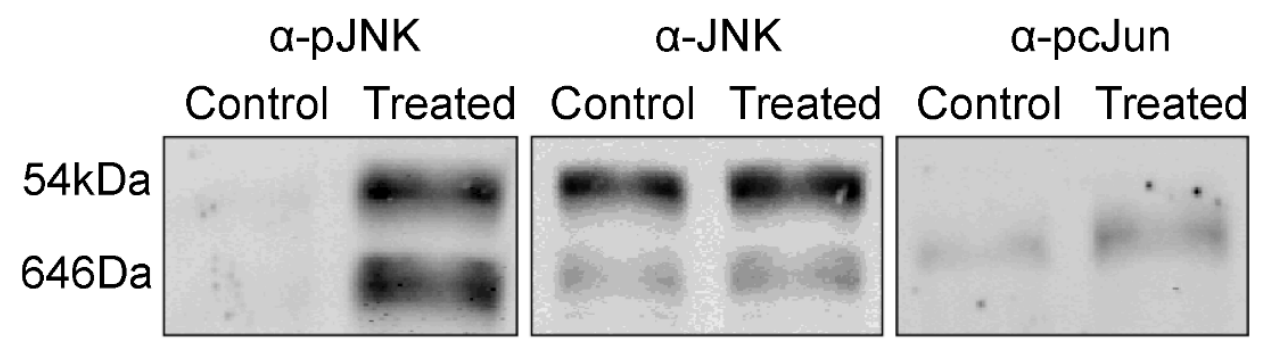

Figure A12. Western blot of activated JNK signaling in HEK293 cells.

Western blot of p-JNK (left), total JNK (middle) and JNK phosphorylated c-Jun (right) during control and anisomycin treatment (100nM) for 30 minutes in HEK293 cells. 


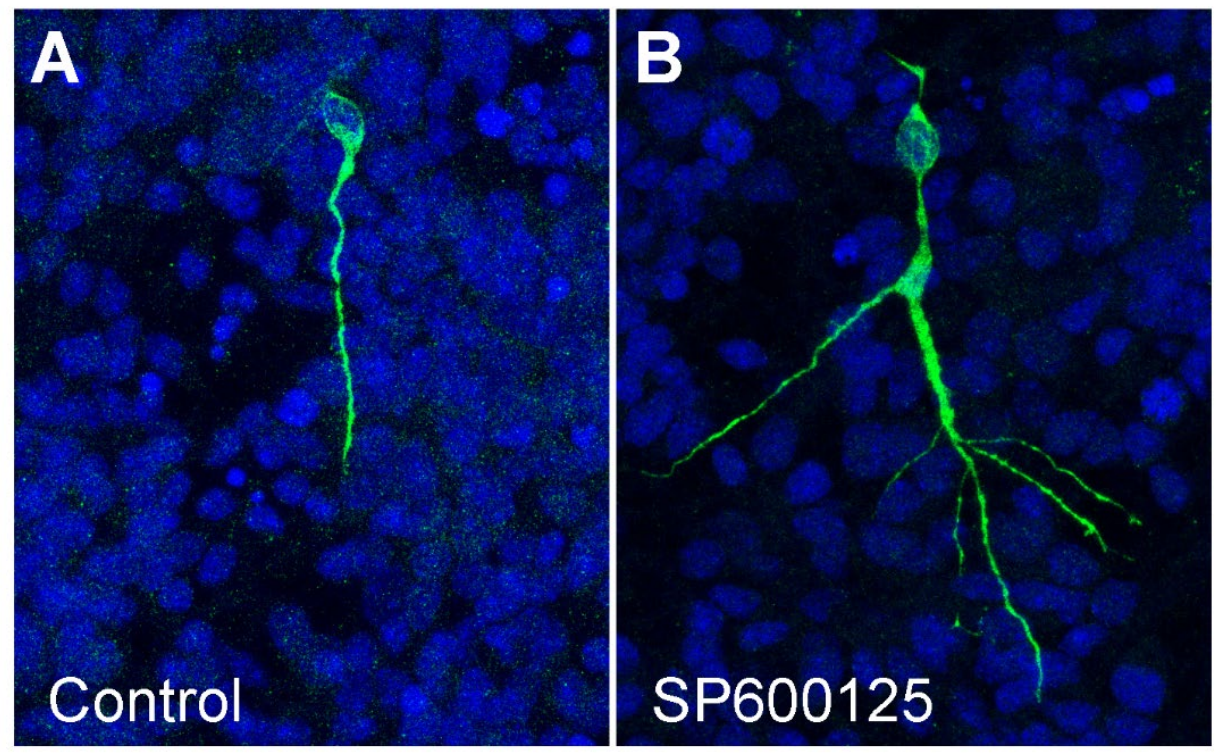

Figure A13. JNK-inhibited cortical interneurons expressing doublecortin construct have increased branching of the leading process. A. Control interneuron electroporated with GFP-

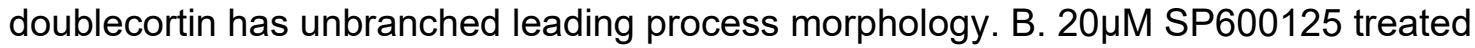
interneuron has increased branch morphology compared to control. 
A Nucleokinesis Distance

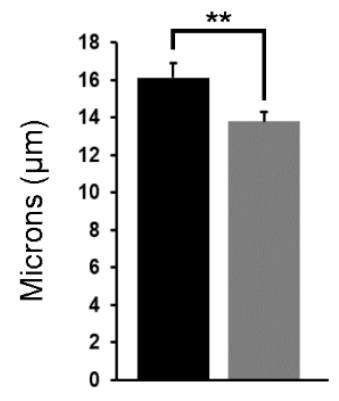

- $\mathrm{CDKO}$ - $\mathrm{CTKO} \mathrm{n}=5$
B Nucleokinesis Frequency

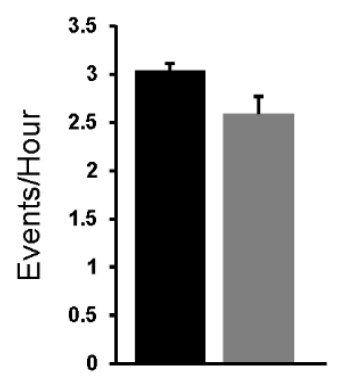

C Pause Duration

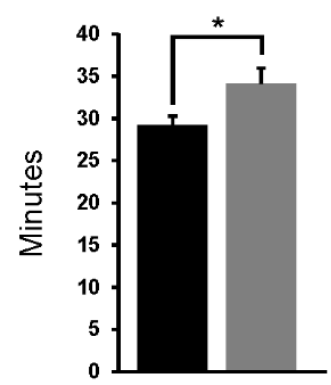

Figure A14. Cortical interneurons in conditional triple knockout (cTKO) slices have disrupted nucleokinesis. A. cTKO interneurons travel shorter nucleokinesis distances compared to conditional double knockout (cDKO) interneurons. B. cTKO and cDKO interneurons undergo nucleokinesis at similar rates. C. cTKO interneurons pause for a shorter duration between nucleokinesis events. $n=5$ movies from 3 experimental days containing 25 cells. Statistics were performed with Student's $t$-test, ${ }^{*} p<0.05,{ }^{* *} p<0.01$. 